\title{
DESARROLLO Y CARACTERIZACIÓN DEL MÉTODO DE DINAMOLISIS CAPILAR PARA EL ANÁLISIS DE SUELOS CONTAMINADOS \\ ESTUDIO DE LOS SUELOS DE LINARES
}

MONTSERRAT TRIO MASEDA, INGENIERA DE MINAS
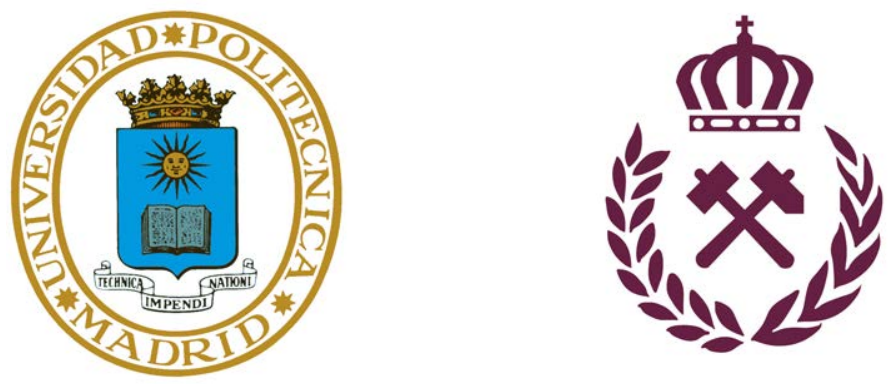

Escuela Técnica Superior de Ingenieros de Minas y Energía de Madrid Universidad Politécnica de Madrid

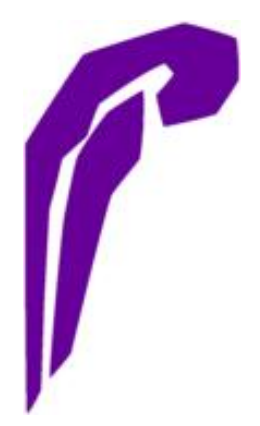

Freie Hochschule für Geisteswissenschaft

Goetheanum, Dornach Suiza

19 de Enero de 2016 
Montserrat Trio Maseda: Desarrollo y Caracterización del Método de Dinamolisis Capilar para el Análisis de Suelos Contaminados, Estudio de los suelos de Linares, () 19 de Enero de 2016

DIRECTORES:

Juan Francisco LLamas Borrajo

Virginia Sease, Ph. D.

LUGAR:

Madrid

FECHA:

19 de Enero de 2016 
We need to recognize that the divorce between thought and reality is a problem of central importance to all modern society.

Only by doing so we start to see what society needs.

\section{- Rudolf Steiner}

Dedicado a la memoria de Lili Kolisko.

$1889-1976$ 

Establishing policies for Soil protection and monitoring, requires the validation of effective analytical methods for determining soil quality and assess the state of contamination. The possibilities of Image Forming Methods (Bildschaffende Methode), and in particular the methods of Capillary Dynamolysis (Steigbild Methode) of L. Kolisko have been investigated in order to characterize soil quality from the point of view of its vitality. Based on the horizontal configuration known as Chroma-Test, proposed by E. Pfeiffer, the amendments to the original method that enable validation have been identified, and then verified through collaborative blind tests and through comparison with results provided by other experimental methods often used in agriculture to assess soil quality. As a case study the investigation at the former lead mining district of Linares, located in Jaen, Spain, is presented.

This research lays the groundwork for significant progress in the assessment of soils and their possible declaration as contaminated. The proposed Horizontal Capyllary Dynamolysis Method allows to identify in a simple and direct way the inhibiting effects on soil functions due to both local contamination and/or diffuse contamination.

\section{RESUMEN}

El establecimiento de políticas de vigilancia y protección del suelo exige la validación de métodos de análisis eficaces para determinar la calidad del suelo y hacer posible su evaluación en relación con su estado de contaminación. Para poder caracterizar el suelo desde el punto de vista de su vitalidad, se han investigado los Métodos de Formación de Imágenes (Bildschaffende Methode) y en particular los métodos de Dinamolisis Capilar (Steigbild Methode) desarrollados por L. Kolisko. Partiendo de la configuración horizontal conocida como Chroma-Test, propuesta por E. Pfeiffer, se han identificado las modificaciones del método original que hacen posible su validación. A continuación se han verificado realizando ensayos ciegos colaborativos y comparando los resultados con los obtenidos por otros métodos experimentales utilizados para evaluar la fertilidad del suelo. Como caso práctico se presenta una investigación en el antiguo distrito minero de plomo de Linares, situado en Jaén, España.

Esta investigación sienta las bases para un avance significativo en la evaluación de los suelos y su posible calificación como contaminados. El método Horizontal de Dinamolisis Capilar propuesto permite identificar de forma simple y directa los efectos inhibidores de las 
funciones del suelo debidas tanto a la contaminación puntual o local como a la contaminación difusa. 
La planificación de los desmuestres en Linares y la situación de las muestras sobre las imágenes de satélite que se presenta en el capítulo 6 han sido realizadas por Julián Martínez López basándose en sus trabajos previos de investigación geoquímica y su conocimiento de la zona. La toma de muestras se realizó con su colaboración.

Los análisis químicos incluidos en el capítulo to fueron realizados en los laboratorios ACME, Canadá.

La elección de los análisis físicos sencillos del capítulo 11 y la realización de los ensayos correspondientes se hicieron con la colaboración y supervisión de $\mathrm{M}^{\mathrm{a}}$ Soledad Garrido Valero.

Se han presentado las siguientes comunicaciones a congresos:

- Trio Maseda, Montserrat; LLamas Borrajo, Juan; Martínez López, Julian (2015): Caracterización de suelos contaminados mediante el método horizontal de Dinamolisis Capilar. In: X Congreso Ibérico de Geoquímica. Lisboa, 19-23 de octubre.

- Trio Maseda, Montserrat (2015): Contribution to the development of Pfeiffer's Chroma-Test for the characterization of contaminated soils. In : Evolving Science 2015. Shaping Goethean Science in Relation to Nature, to Society, to Anthroposophy. Dornach, Suiza, 30 September - 4 October. International Conference of the Science Section at the Goetheanum. 

Die Verwirklichung eines Geschehens vermöge einer außer dem Verwirklicher stehenden Gesetzmäßigkeit ist ein Akt der Unfreiheit, jene durch den Verwirklicher selbst ein solcher der Freiheit. Die Gesetze seines Handelns erkennen heißt sich seiner Freiheit bewusst sein. Der Erkenntnisprozess ist, nach unseren Ausführungen, der Entwicklungsprozess zur Freiheit.

"Wahrheit und Wissenschaft" Rudolf Steiner, 1892

El modo de trabajar sobre las cosas que se conocen dependerá siempre del modo en que se han buscado al principio muchas cosas que no se conocían.

"Cómo se hace una tesis" Umberto Eco, 1977

\section{AGRADECIMIENTOS}

Agradezco a Virginia Sease del Goetheanum, en Dornach Suiza, y a Juan LLamas de la Escuela Técnica Superior de Ingenieros de Minas y Energía (ETSIME), Universidad Politécnica de Madrid, España (UPM) su amplitud de espíritu para dirigir esta tesis desde sus respectivas concepciones.

Agradezco a Sophia Walsh y Oliver Conradt, ambos del Goetheanum, su apoyo para dar los primeros pasos y acompañar con entusiasmo cada pequeño avance y a Eduardo de Miguel de la ETSIME, UPM su dedicación durante el periodo de investigación tutelada.

Agradezco sinceramente a Julian Martínez de la Escuela Politécnica Superior de Linares, España (EPS) su inestimable ayuda y colaboración en la planificación y toma de muestras y por documentar su situación. A M ${ }^{a}$ Soledad Garrido, de la Asociación de Agricultura Biodinámica en España, por su colaboración para seleccionar y realizar los ensayos físicos sencillos.

A Ester Gruber de la Ita Wegman Klinik, Arlesheim, Suiza (IWK), Emilio García y Elena Sil, ambos de la ETSIME, UPM, por su colaboración en los ensayos ciegos.

Agradezco a los Srs Müller su donación de 10.000 CHF para financiar la parte aplicada de la investigación y a la empresa Citavi la donación de una licencia de su programa de gestión de bibliografía por valor de $150 €$.

Agradezco a Jordi Querol su valiosa mediación para entrar en contacto con la granja Andreashof en Überlingen, Alemania, y a los trabajadores de la granja por su cálida acogida. En especial quiero expresar mi agradecimiento a la Dra Cornelia Hahn, por su hospitalidad, y a Roland Ulrich y Bruno Rodríguez por introducirme al Chroma-test de E. Pfeiffer. 
A Julio Arrollo de la finca Río Pradillo, Cercedilla y a Leonor Delgado de Casa San Martín en Cañicosa, les agradezco su colaboración en la toma de muestras de suelos cultivados por el método de Agricultura Biodinámica.

En este trabajo han sido de gran valor las diferentes conversaciones mantenidas con expertos y las visitas a algunos laboratorios donde se utilizan actualmente los métodos generadores de imágenes. Han sido especialmente valiosas las indicaciones de Christine Picariello del Institut für Stroemungswissenschaften, en Herrischried, Alemania, Janet Barker que trabajó en el laboratorio de Dinamolisis Capilar de la IWK en Arlesheim, Suiza, las Doctoras Gudrung Merker y Sabine Sebastian que mantienen un laboratorio de Cristalizaciones Sensibles en Pforzheim, Alemania, la Dra. Birgit Seitz, del Labor für Empfindliche Kristallisation am Goetheanum y Johannes Kühl de la Sección de Ciencias Naturales del Goetheanum, en Dornach, Suiza.

Estoy especialmente agradecida a las personas que han contribuido al desarrollo de los programas de código abierto que he podido usar, con gran satisfacción, para elaborar la documentación. Particularmente a Andre Miede, autor de la plantilla Classicthesis y a Nicholas Mariette e Ivo Pletikosić por adaptarla a LYX.

Por último quiero expresar mi gratitud a mis padres Alfredo Trío y Filomena Maseda por su apoyo y a las numerosas personas que se han interesado por el proyecto o me han ayudado de formas variadas y cuyos nombres no figuran aquí. 
I INTRODUCCIÓN I

I CALIDAD DEL SUELO Y CARACTERIZACIÓN DE LA CONTAMINACIÓN 3

1.1 Situación actual 4

1.2 Métodos experimentales 4

1.3 El suelo como sistema o ¿el suelo como organismo? 6

2 Objetivos y ALCANCE DE LA INVEstigación 13

2.1 Objetivos específicos 13

2.2 Hipótesis de trabajo 13

2.3 Definiciones específicas para el método de Dinamolisis Capilar $\quad 15$

2.4 Estructura de la investigación $\quad 15$

II BASES DE PARTIDA I7

3 LAS FUERZAS FORMATIVAS Y SU INVESTIGACIÓN EXPERIMENTAL 19

3.1 "Bildungstrieb", F. F. Runge y origen de la Cromatografía 19

3.2 Métodos Generadores de Imágenes: Bildshaffende Methode 24

3.3 Dinamolisis Capilar de Lili Kolisko 27 3.3.1 Los métodos de Dinamolisis Capilar 29

3.4 Resumen 30

4 DesarRollo del Chroma-test de PFEIfFer 33

4.1 Procedimiento del Chroma-Test según Pfeiffer 34

4.1.1 Descripción 34

4.1.2 Interpretación 38

4.2 Contribuciones posteriores a Pfeiffer $4^{1}$

4.3 Resumen del desarrollo del Chroma-Test 44

4.3.1 Balzer y Graf 44

4.3.2 Giani 52

4.3.3 La estandarización del método Wala $\quad 58$

4.4 Resumen 59

III MATERIALES Y MÉtodos 61

5 LABoratorios Y EQUiPAMIENTO 63

5.1 Equipamiento y reactivos 63

5.2 Laboratorio de la granja Andreashof 66

5.2.1 Equipamiento 67

5.2.2 Métodos 67

5.3 Laboratorio de la ETSIME 67

5.3.1 Equipamiento 67 
5.3.2 Métodos 67

5.4 Laboratorio de plantas de la Ita Wegman Klinik, Arlesheim, Suiza 68

5.4.1 Equipamiento 68

5.4.2 Métodos 68

6 MUESTRAS 69

6.1 Toma y preparación de muestras 69

6.2 Descripción de las muestras 70

6.2.1 Muestras de agricultura Biodinámica $\quad 70$

6.2.2 Primera campaña de Linares 71

6.2.3 Segunda y tercera campañas de Linares $\quad 72$

6.3 Selección de muestras para análisis químicos $\quad 74$

6.4 Situación de las muestras 75

7 DOCUMENTACIÓN 87

7.1 Registro de datos 87

7.2 Escaneado y archivo de los dinamogramas 87

7.3 Elaboración de datos 89

7.3.1 Edición de figuras 89

7.3.2 Edición del texto y conversión a formato PDF 89

7.3.3 Bibliografía 89

8 MATERIALES Y MÉtodos PARA VALIDACIÓN 91

8.1 Diferencias entre los laboratorios colaboradores 9I

8.2 Muestras seleccionadas para los ensayos ciegos 91

8.3 Modificación del Chroma-Test 93

8.4 Interpretación de los dinamogramas 95

8.4.1 Morfología, zonas y rasgos 95

8.4.2 Zonas y razón simple 97

8.5 Ensayos físicos sencillos 101

8.5.1 Capacidad de Campo 101

8.5.2 Densidad aparente 102

8.5.3 Estabilidad del suelo. Slake test 103

8.5.4 Estabilidad de la micro-bioestructura del suelo 104

8.5.5 Humedad de Saturación 105

8.5.6 Textura 106

8.5.7 Coeficiente de Extensión Lineal, COLE 106

IV RESULTADOS 109

9 CONTRIBUCIÓN AL DESARROLLO DEL MÉTODO DE DINAMOLISIS CAPILAR III

9.1 Puesta a punto del método de ensayo $\quad 112$

9.1.1 Ensayos de control 112

9.1.2 Ensayos preliminares 113

9.2 Parámetros de influencia sobre el experimento 113

9.2.1 Limitaciones del desmuestre puntual 113

9.2.2 Sal metálica y su concentración 115 
9.2.3 Fabricante y marcaje de los filtros $\quad 120$

9.3 Resumen y discusión de los resultados 129

9.3.1 Control del experimento 129

9.3.2 Factores críticos 129

9.3.3 Estandarización del Método Horizontal de Dinamolisis Capilar 131

IO POTENCIAL PARA CARACTERIZAR LA CONTAMINACIÓN

10.1 Ensayos preliminares con varias sales metálicas 134

10.2 Valoración de la calidad de los suelos por medio de sus dinamogramas 145

10.3 Investigación de suelos de Linares 146

10.3.1 Zona muy afectada: $1^{a}$ campaña 146

10.3.2 Diferentes grados de afección por la minería: $2^{\mathrm{a}}$ Campaña 148

10.4 Posible contaminación agrícola: $3^{\text {a }}$ campaña $\quad 156$

10.4.1 Objetivos y descripción de las muestras de la $3^{\mathrm{a}}$ campaña 156

10.4.2 Resultados de la $2^{\mathrm{a}}$ y $3^{\mathrm{a}}$ campañas 158

10.5 Resumen 166

11 VALIDACIÓN 169

11.1 Ensayos ciegos colaborativos 170

11.1.1 Repetibilidad de cada ensayo y reproducción por operadores diferentes 170

11.1.2 Reproducción en días diferentes 176

11.1.3 Reproducción en laboratorios diferentes $\quad 178$

11.2 Ensayos físicos sencillos 180

11.2.1 Cuadrícula $12 \quad 180$

11.2.2 Cuadrícula $67 \quad 180$

11.2.3 Cuadrícula $91 \quad 180$

11.3 Resumen y discusión de los resultados 183

12 CONCLUSIONES 185

12.1 Resumen 185

12.2 Posibles usos 187

12.3 Recomendaciones para futuras investigaciones $\quad 187$

V APÉNDICES 191

BIBLIOGRAFÍA 193

A ESPECIFICACIONES DE LOS FILTROS 203

B ESPECIFICACIONES DE LOS REACTIVOS 209

C NOTAS SOBRE LAS ARCILLAS 225 
Figura $1 \quad$ Ecología de ecosistemas 10

Figura 2 Instalación de Goppelsroeder

Figura 3

Bildungstrieb der Stoffe. Runge,1855 22

Figura 4

Ejemplos de resultados con varios Métodos de Formación de Imágenes 25

Figura 5 Preparación de los filtros y disposición del ensayo 35

Figura $6 \quad$ Ejemplos de suelos (Pfeiffer, 1959) 40

Figura 7 Chroma-Standards de suelos según Voitl y Guggenberger 42

Figura $8 \quad$ Ensayos de Bangert (1994) 49

Figura 9 Reproducción del ensayo por Bangert en días diferentes 50

Figura to Variación de la concentración de $\mathrm{NaOH}$ y de $\mathrm{AgNO}_{3}$ para distintas cantidades de ácido ferúlico, 51

Figura 11 Cromatogramas de distintos tipos de suelos según Hassold 53

Figura 12 Influencia de la iluminación 54

Figura 13 Mapa de situación de las instituciones colaboradoras 64

Figura 14 Cámara aclimatada de Andreashof 66

Figura 15 Mapas de localización de las muestras y de las cuadrículas 75

Figura 16 Mapa de situación de las muestras de Linares 76

Figura 17

Figura 18

Primera Campaña: Linares I 77

Figura 19

Muestras Cuadrícula $12 \quad 78$

Muestras Cuadrícula $22 \quad 79$

Figura 20

Muestras Cuadrícula $59 \quad 80$

Figura 21

Muestras Cuadrícula 61 81

Figura 22

Muestras Cuadrícula $67 \quad 82$

Figura 23

Muestras Cuadrícula $69 \quad 83$

Figura 24

Muestras Cuadrícula $91 \quad 84$

Figura 25

Muestras Cuadrícula $93 \quad 85$

Figura 26

Muestras Cuadrícula $110 \quad 86$

Figura 27

Nomenclatura asociada al Chroma-Test $\quad 96$

Figura 28

Partición en zonas 99

Figura 29 Segmentos en relación áurea superpuestos a flores 100

Figura $30 \quad$ Ensayos físicos sencillos 102 
$\begin{array}{lll}\text { Figura } 31 \quad \text { Estimación cualitativa de la Textura } & 107\end{array}$

Figura 32 Efecto de concentraciones variables de nitrato de plata para filtros Whatman 4 y Anoia 1249 marcados a diferentes distancias del centro. $\quad 116$

Figura 33 Efecto, sobre muestras de varios suelos, de las concentraciones variables de sales de $\mathrm{Au}$ y de $\mathrm{Pb} \quad 118$

Figura 34 Efecto de concentraciones variables de sales de $\mathrm{Hg}, \mathrm{Cu}, \mathrm{Fe}, \mathrm{Sn}, \mathrm{Pb}$ y $\mathrm{Au} \quad 119$

Figura $35 \quad$ Posición de las marcas sobre los filtros y repetibilidad de los dinamogramas con filtros Whatman 4 y con filtros Anoia $1249 \quad 121$

Figura 36 Influencia de la posición de las marcas sobre los filtros. Muestra Cam. huerto 122

Figura 37 Influencia del marcaje. Muestra Blanco 123

Figura 38 Ampliación de la zona exterior $\quad 126$

Figura 39 Ampliación de la zona exterior $\quad 127$

Figura 40 Figura 41 Figura 42 Figura 43 Dinamogramas $1^{\text {a }}$ campaña. Tres sales 135 Dinamogramas $2^{\text {a }}$ campaña. Tres sales ${ }_{13} 8$ Dinamogramas $2^{\mathrm{a}}$ campaña. Tres sales 139 Dinamogramas de suelos de agricultura Biodinámica. Tres sales 141

Figura $44 \quad$ Resumen del potencial del Chroma-Test para diferenciar suelos y compost de diferentes calidades. $\quad 143$

Figura 45 $1^{\mathrm{a}}$ campaña de Linares. $\quad 147$

Figura 46 Desmuestre en base a geoquímica 148 $2^{a}$ Campaña de Linares. Método de Pfeiffer original y modificado 150

Figura 48 Comparación de análisis químicos con dinamogramas 155

Figura 49 $3^{\text {a }}$ campaña de Linares 159 Mineralurgia. Análisis y dinamograma 160 Balsas de lodos. Los dinamogramas no muestran rasgos radiales. $\quad 161$

Figura 52 Contaminación por la minería $\quad 163$

Figura 53 Figura 54 Figura 55 Figura 56 Suelos no afectados por la minería 165 Repetibilidad. Lote $\mathrm{n}^{\circ} 3$ ETSIME/ES 171 Repetibilidad. Lote $n^{\circ} 5$ ETSIME/EGG 172 Repetibilidad. Lote $\mathrm{n}^{\circ} 7$ ETSIME/MTM 173 Reproducción por tres operadores diferentes Reproducción en tres días diferentes $\quad 177$ Reproducción en tres laboratorios 179 Figura 60 Dinamogramas de diferentes suelos graníticos Figura 61 Guía para selección y características típicas de los filtros Whatman Grado 4. 205 
Figura 62

Figura 63

Figura 64

Figura 65

Figura 66

Figura 67

Figura 68

Figura 69
Ficha técnica del filtro ANOIA 1249207

Especificaciones del hidróxido sódico utilizado 211

Especificaciones de la sal de plata utilizada 213

Especificaciones de la sal de oro utilizada 215

Especificaciones de la sal de cobre utilizada 217

Especificaciones de la sal de mercurio utiliza-

da 219

Especificaciones de la sal de estaño utilizada 221

Especificaciones de la sal de plomo utilizada 223

ÍNDICE DE TABLAS

Tabla 1

Tabla 2

Tabla 3

Tabla 4

Tabla 5

Tabla 6

Tabla 7

Tabla 8

Tabla 9

Tabla 10

Tabla 11

Tabla 12

Tabla 13

Tabla 14

Tabla 15

Tabla 16

Tabla 17

Tabla 18

Tabla 19

Tabla 20

Tabla 21

Tabla 22

Tabla 23

Tabla 24

Tabla 25
Métodos experimentales de Dinamolisis Capilar 29

Dinamolisis Capilar y Cromatografía en Papel $\quad 30$ Modificaciones de Balzer y Graf 44

Objetivos de la investigación de Bangert $\quad 47$ Ensayos de Bangert $\quad 48$

Modificaciones de los procedimientos operativos del Chroma-Test 56

Modificaciones de los procedimientos operativos del Chroma-Test 57

Sales metálicas utilizadas en la ETSIME 66

Toma y preparación de muestras $\quad 70$

Muestras de agricultura Biodinámica $\quad 70$

Muestras Linares I. Primera campaña $\quad 71$

Muestras Segunda Campaña: Linares II $\quad 72$

Muestras Tercera Campaña: Linares III 73

Muestras para análisis químico 74

Registro de datos de campo y de laboratorio en hoja de cálculo $\quad 88$

Materiales y métodos en los ensayos ciegos $\quad 92$

Claves de identificación de las muestras usa-

das en los ensayos ciegos de validación $\quad 94$

Rasgos morfológicos característicos 97

Capacidad de Campo. Valores orientativos 101

Repetición del desmuestre 114

Calidades indicadas por los dinamogramas $\quad 145$

Clusters geoquímica y calidad por dinamogra-

mas 151

Análisis químicos $\quad 153$

Planificación de la tercera campaña de desmuestre 157

Resultados de los ensayos físicos 181 


\section{ACRÓNIMOS}

UPM Universidad Politécnica de Madrid, España

ETSIME Escuela Técnica Superior de Ingenieros de Minas y Energía

EPS Escuela Politécnica Superior de Linares, España

IWK Ita Wegman Klinik, Arlesheim, Suiza 



\section{Parte I}

\section{INTRODUCCIÓN}

En la Parte I de introducción se justifica el paradigma de la investigación, que tiene por objeto ampliar las posibilidades experimentales y las bases conceptuales y metodológicas en que se basa actualmente la investigación sobre suelos contaminados.

En el capítulo I se plantea la necesidad de tener en cuenta la naturaleza orgánica del suelo y su propia vitalidad para poder caracterizar el efecto de la contaminación sobre el propio suelo. Se propone la adopción de nociones y métodos adicionales basados en la Antroposofía de Rudolf Steiner y se indica su relación con los métodos convencionales de análisis.

En el capítulo 2 se plantean los objetivos, hipótesis y estructura general del trabajo de investigación. 

Cuando se quiere abordar el problema de caracterizar la contaminación de los suelos hoy en día, se adopta como base de partida el punto de vista que concibe el suelo como un sistema formado por sustancias minerales -sólidas, líquidas o gaseosas- y materia orgánica. El suelo se concibe como una mezcla de sustancias inertes y de materia orgánica procedente de los restos de organismos que en él habitan. Esta forma de abordar el problema es adecuada para caracterizar el suelo por medio de las técnicas de análisis, y especialmente del análisis químico.

Cuando se trata de caracterizar la fertilidad del suelo o los servicios ecosistémicos que proporciona, se recurre a índices para evaluar la capacidad del suelo para funcionar, en los que los análisis químicos pierden su protagonismo.

En el suelo se producen diversas sustancias orgánicas y se vincula al reino vegetal, constituyendo una transición entre lo mineral inerte y la biosfera. La comprensión de estas relaciones del suelo requiere planteamientos que abarquen no sólo los componentes del suelo, sino también los procesos generadores del propio suelo que van más allá de lo meramente terrestre, como son el ciclo de las estaciones y otras influencias externas. Rudolf Steiner, en su aproximación pionera a los problemas de la agricultura en 1924, concibe el suelo como parte del reino vegetal y proporciona un marco de conocimiento para comprender el suelo como un sistema dinámico vivo (Steiner, 1924). Sus planteamientos permiten vincular la calidad del suelo a su vitalidad y abordar el problema de la contaminación como una pérdida de vitalidad del propio suelo. Para evaluar la vitalidad del suelo hemos recurrido a los métodos de formación de imágenes, practicamente desconocidos fuera de pequeños círculos antroposóficos y escasamente desarrollados excepto en el ámbito de la calidad de alimentos.

En este trabajo se ha investigado el potencial del Método de Dinamolisis Capilar (Kolisko and Kolisko, 1939) y su variante horizontal, el Chroma-Test de Pfeiffer (1959) para evaluar el estado de los suelos. Ha sido necesario en primer lugar identificar las modificaciones del método original que permitan su estandarización y validación. El método modificado ofrece resultados prometedores como indicador de los efectos directos de la contaminación, ya sea local o difusa, sobre la vitalidad del propio suelo y abre nuevas posibilidades para caracterizar el estado de los suelos y los efectos de la contaminación. 


\section{I SITUACIÓN ACTUAL}

En Europa se distingue entre contaminación local o puntual del suelo, que resulta de actividades industriales o de la gestión de residuos, como es el caso de las minas y establecimientos de beneficio abandonados, y contaminación difusa del suelo, que afecta a grandes áreas, por ejemplo, con la aplicación de pesticidas. Es difícil cuantificar la extensión real de contaminación local de suelo ya que muchos países europeos carecen de inventarios exhaustivos y no existe legislación europea que obligue a los Estados miembros a identificar los lugares contaminados. Los contaminantes más comunes son metales pesados y aceites minerales. Los datos sobre contaminación difusa en Europa son incluso más limitados que los de contaminación local ya que no hay requisitos armonizados para recabar información. Un factor significante en la contaminación difusa es la aplicación excesiva de agroquímicos, como pesticidas y fertilizantes minerales (Jones et al., 2012, pp. 31-32).

Los informes sobre la gestión de sitios contaminados en Europa se refieren casi exclusivamente a la contaminación local (Liedekerke et al., 2014), (Panagos et al., 2013). En España existe legislación específica para este tipo de contaminación, que tiene por objeto identificar los posibles focos, inventariando las actividades productoras de contaminantes, y establecer límites de contenidos admisibles según uso del suelo para elaborar inventarios de suelos contaminados y proceder a la descontaminación (España. Ministerio de la Presidencia, 2005).

No hay estadísticas específicas sobre contaminación difusa del suelo, pero se infiere su alcance por las estadísticas de contaminación de las aguas. Según el informe de la Agencia Europea del Medio Ambiente SOER 2015, la contaminación procedente de fuentes difusas afecta a la mayoría de las masas de agua superficiales. La agricultura es una fuente particularmente importante de contaminación difusa: la escorrentía de fertilizantes provoca el enriquecimiento en nutrientes de las aguas. Los pesticidas agrícolas están asimismo muy presentes en las masas superficiales y subterráneas (AEMA, 2015, p. 64). En España la mayor parte del esfuerzo para estudios y monitorización se refiere a las concentraciones de nitratos en las aguas en las áreas donde se exceden los límites admisibles, aunque es preocupante también la situación de los pesticidas y otros agroquímicos (Custodio et al., 2014).

\subsection{MÉTODOS EXPERIMENTALES}

Entre los métodos utilizados para caracterizar los suelos se encuentran los de análisis químico en general. En la actualidad estos son los métodos más valorados para la descripción de riesgos asociados a los metales $u$ otras sustancias contaminantes en suelos. Los valores de fondo, los valores de referencia y los valores límite se refieren a 
contenidos sustanciales basados en los datos obtenidos por medio del análisis químico.

Otros métodos indican alguna actividad y miden la variación en el tiempo de parámetros físicos, químicos o biológicos que sirven de indicadores. Entre los químicos, el único indicador universal de la calidad del suelo aceptado es la variación de contenido en Carbono Orgánico del Suelo:

Soil Organic Carbon (SOC) is a measure of the total amount of organic carbon (C) in soil, independently of its origin or decomposition. Interest in SOC is common among soil scientists and related practitioners because of the importance for principle physical, chemical and biological soil ecological functions and because SOC is a universal indicator of soil quality. Consequently, as variations in SOC levels can have serious implications on many environmental processes such as soil fertility, erosion and greenhouse gas fluxes, the need to estimate SOC changes has become central to several pan-European and global environmental policies. (Stolbovoy et al., 2007, p. 7)

En el ámbito de la Agricultura se han desarrollado diversos métodos para caracterizar determinadas funciones o cualidades de los suelos. La presencia de sustancias húmicas suele asociarse directamente con la fertilidad y la actividad biológica del suelo. Una propiedad del suelo que se relaciona directamente con estas cualidades es su estructura. Los parámetros que las describen se utilizan para predecir la fertilidad del suelo y para estudiar la problemática de la erosión. En la presente investigación se han realizado algunos ensayos físicos sencillos (descritos en la sección 8.5) que se vienen usando como indicadores de la calidad del suelo por el valor de la información que proporcionan y la facilidad para realizarlos.

Para caracterizar la contaminación del suelo se utilizan también los test de toxicidad que se realizan con semillas y diversos organismos simples, y cuando están disponibles se usan también los datos médicos clínicos. El Real Decreto 9/2005, de 14 de enero, por el que se establece la relación de actividades potencialmente contaminantes del suelo y los criterios y estándares para la declaración de suelos contaminados, hace mención en su Anexo III, epígrafe 2. a) a los ensayos de toxicidad OCDE 208 (Ensayo de emergencia y crecimiento de semillas en plantas terrestres $^{1}$ ), OCDE 207 (Ensayo de toxicidad aguda en lombriz de tierra). En el apartado b) menciona los ensayos OCDE 201 (Ensayo de inhibición del crecimiento en algas), OCDE 202 (Ensayo de inhibición de la movilidad en Daphnia magna), OCDE 203 (Ensayo de toxicidad aguda en peces.)

1 Ensayos de germinación de semillas 
Los métodos generadores de imágenes (Bildschaffende MetHODE), uno de los cuales es, como hemos indicado, el método de Dinamolisis Capilar investigado se basan en fenómenos simples, de capilaridad y de cristalización, que se ven directamente modificados por el influjo del suelo ensayado. Pueden complementar los datos del análisis químico y sustituir ventajosamente en muchos casos a los métodos fisiológicos que estudian la actividad de algún organismo vivo y son una forma indirecta de evaluar los efectos del suelo contaminado.

En el ámbito de la Agricultura Biodinámica, el Chroma-Test de Pfeiffer, original o con diversas modificaciones, fue concebido para caracterizar la fertilidad de suelos y composts. La relación entre las sustancias húmicas y el Chroma-Test fue estudiada en primer lugar por el propio Pfeiffer (1959). La relación entre el contenido de sustancias húmicas y el Chroma-Test de Pfeiffer ha sido investigada por Blank (1991), Kanzler (1991), Bangert (1994) y Hassold-Piezunka (2003). Las investigaciones de Haßold Piezunka han dado resultados concluyentes, tras un amplio estudio de muestras de composts industriales de restos orgánicos por medio de ensayos convencionales y espectroscópicos, que corroboran que el Chroma-Test refleja las sustancias húmicas solubles en medio alcalino.

\subsection{EL SUELO COMO SISTEMA O ¿EL SUELO COMO ORGANISMO?}

Al considerar las funciones del suelo se desvelan una serie de características únicas de especial importancia para la elaboración de políticas:

- Es el resultado de complejas interacciones entre el clima, la geología, la vegetación, la actividad biológica, el tiempo y la utilización del terreno. La proporción en la que se encuentran sus componentes - principalmente partículas de arena, limo y arcilla, materia orgánica, agua y aire así como la manera en la que dichos componentes forman una estructura estable entre ellos definen el tipo de suelo. Además, el suelo contiene un número variable de capas sucesivas, que a su vez reúnen una gran variedad de propiedades físicas, químicas y biológicas diferentes. Por eso, es un medio muy variado. En Europa, se han identificado más de 320 tipos de suelo principales, con propiedades químicas y físicas notablemente diferentes incluso a nivel local. Dicha diversidad requiere una perspectiva local en el desarrollo de políticas de protección de suelos.

- El suelo es un recurso prácticamente no renovable con una cinética de degradación relativamente rápida y, por el contrario, tasas de formación y regeneración extremadamente lentas. La superficie de suelo per capita para la 
producción de alimentos es limitada. Si el suelo se degra$\mathrm{da}$, su capacidad total para realizar sus funciones se ve reducida. Por lo tanto, la prevención, la cautela y una gestión sostenible del suelo han de ser el pilar central de las políticas de protección de suelos.

- El suelo tiene una gran capacidad de almacenaje y amortiguación debida en gran parte a su contenido en materia orgánica. Dicha capacidad no se refiere sólo al agua, los minerales y los gases, sino también a un gran número de sustancias químicas, como ciertos agentes contaminantes naturales y artificiales, que pueden acumularse en el suelo aunque, si se liberan, pueden tener pautas de distribución muy diferentes. Ciertos contaminantes pueden sobrepasar de forma desapercibida los umbrales de irreversibilidad de almacenaje y amortiguación. Es, por tanto, vital llevar a cabo políticas de prevención basadas en sistemas de vigilancia y alerta rápida para evitar el deterioro del medio ambiente así como riesgos para la salud pública.

- El suelo agrícola es un recurso inestimable y limitado, cuyo valor se debe a la labor desarrollada por el hombre durante décadas e incluso siglos. La degradación irreversible de este recurso supone no sólo destruir el bien más preciado de los agricultores sino hipotecar las oportunidades agrícolas de generaciones futuras. Por este motivo, las políticas de protección de suelos han de prestar especial atención al uso sostenible y a la gestión de los suelos agrícolas con el fin de garantizar su fertilidad y valor agronómico.

- El suelo es un medio vivo con una gran biodiversidad. Esta actividad biológica contribuye a determinar la estructura y fertilidad del suelo y resulta por lo tanto fundamental para que pueda realizar sus funciones, incluida la producción de alimentos. Actualmente, la información de la que se dispone acerca del impacto de las actividades humanas en el equilibrio del suelo es muy escasa. Por ello, es necesario obtener más datos, a la vez que se han de tomar medidas que garanticen la protección de la biodiversidad del suelo a título preventivo.

- Al contrario que el aire y el agua, el suelo es un componente del terreno que está generalmente sujeto a derechos de propiedad. (Comisión Europea, 2002, p. 8)

Esta multiplicidad de funciones justifica la diversidad de enfoques con que se puede abordar el problema de caracterización del suelo. A continuación hemos seleccionado algunos antecedentes para mostrar la importancia que han tenido algunos planteamientos generales, que 
han sido eclipsados por la creciente especialización acontecida en las concepciones predominantes desde el último siglo, pero que han servido de base para ese conocimiento especializado. Con lo que sigue no queremos sino mostrar el esfuerzo de grandes investigadores por explicar la naturaleza de lo mineral y la relación de la Tierra con la vida y el resto del cosmos.

Francesco Redi (1626-1697) demostró con sus experimentos que la vida solo puede surgir de otra vida, que el origen de un ser vivo solamente se produce a partir de otro ser vivo.

although Vernadsky $(1863,1945)$ was acquainted with Oparin's work, he sees Earth as a planet on which life has always been present, it being a characteristic inherent to the essence of the planet itself [McMenamin MAS (1998) Annotations to Vernadsky, V. I. The Biosphere. Copernicus Springer-Verlag, New York, 199]. He is referring to Redi's principle of 1669: "All the living are born from the living" when he states that "living organisms have always sprung from living organisms during the whole of geological history". (Piqueras, 1998, p. 166)

Lamarck en su Hidrogéologie, publicada en 1802, enfatiza la similitud de los compuestos bióticos y abióticos y atribuye a todas las sustancias complejas un origen como restos de organismos vivos o de sus excreciones.

Lamarck assumes [Lamarck JB (1802) Hydrogéologie. Paris] that all complex substances that can be found in free state in nature are the remains of living organisms, or the products of their excretion. This continuing activity of organisms changes permanently the face of Earth's crust, and as Lamarck remarks, it is quite surprising that this strikingly obvious truth (la vérité frappante) has not yet been accepted by most naturalists. Like Werner and Humboldt, Lamarck tried to consider the nature as a whole, emphasizing the close interconnections of abiotic and biotic compounds. (Ghilarov, 1998)

La búsqueda de una ciencia integradora a partir de los fenómenos de la vida -no de la materia- reaparece de forma recurrente de la mano de eminentes investigadores

Thus the idea of Earth's crust that is not only embraced by life, but is under its strict control, can be considered as such sort of ideas that periodically emerge in the scientific community (Hydrogéologie by Lamarck, Biosphere by Vernadsky, and Gaia by Lovelock are just the examples of 
such emergence), encountering not only approval but also highly critical (or even skeptical) acceptance. (Ghilarov, 1998)

\section{La Biosfera y Gaia}

The questions posed by Lamarck in Hydrogéologie were perhaps too general for that time and therefore often appeared to be unanswerable. However, it is well known that some aspects of this concept of Earth's crust were highly appreciated by Lyell. The recognition of life as a major geological force occurred only in the 2oth century, and was closely connected with the idea of "Biosphere". Though the very term was coined by the famous Austrian geologist Suess in 1875, the whole concept was elaborated by Russian mineralogist and the founder of biogeochemistry Vladimir Vernadsky. According to Vernadsky the biosphere is a "special cover of Earth's crust embraced by life" and constantly modified by the living organisms, or, in Vernadsky's words, by "living matter," whose activity is the most powerful chemical force on the Earth. Vernadsky repeatedly emphasized that life is not a "superficial," or "accidental" phenomenon. Moreover, it is deeply connected with the structure of Earth's crust, participating in its mechanisms and performing extremely important functions. As Vernadsky remarks, "there is no great chemical equilibrium in Earth's crust without a considerable influence by biological processes". (Ghilarov, 1998, pp. 163-164)

Y sobre la relación de la vida con el cosmos.

Vernadsky escribe, "La idea de la vida como un fenómeno cósmico" se encuentra en registros científicos desde hace mucho tiempo. Hace siglos, al final del XVII, el científico holandés Christian Huyghens (1629-1695) en su último trabajo, Cosmotheoros, que fué publicado postumamente, formuló esta cuestión científica [...] en este libro Huyghens estableció la generalización científica de que "la vida es un fenómeno cósmico, marcadamente diferenciado de la materia no viva". He denominado recientemente esta generalización "el principio de Huyghens" (Vernadsky, 2005).

A la corriente de pensamiento que hemos localizado en los albores de la ciencia moderna, desde Redi, hasta nuestros días, se ha añadido la que concibe los procesos inorgánicos como base de la vida. Al concebir el suelo como un agregado de sustancias inertes, solamente se tiene en consideración su naturaleza inorgánica y se estudia como un sistema al que se atribuye un funcionamiento mecánico. 


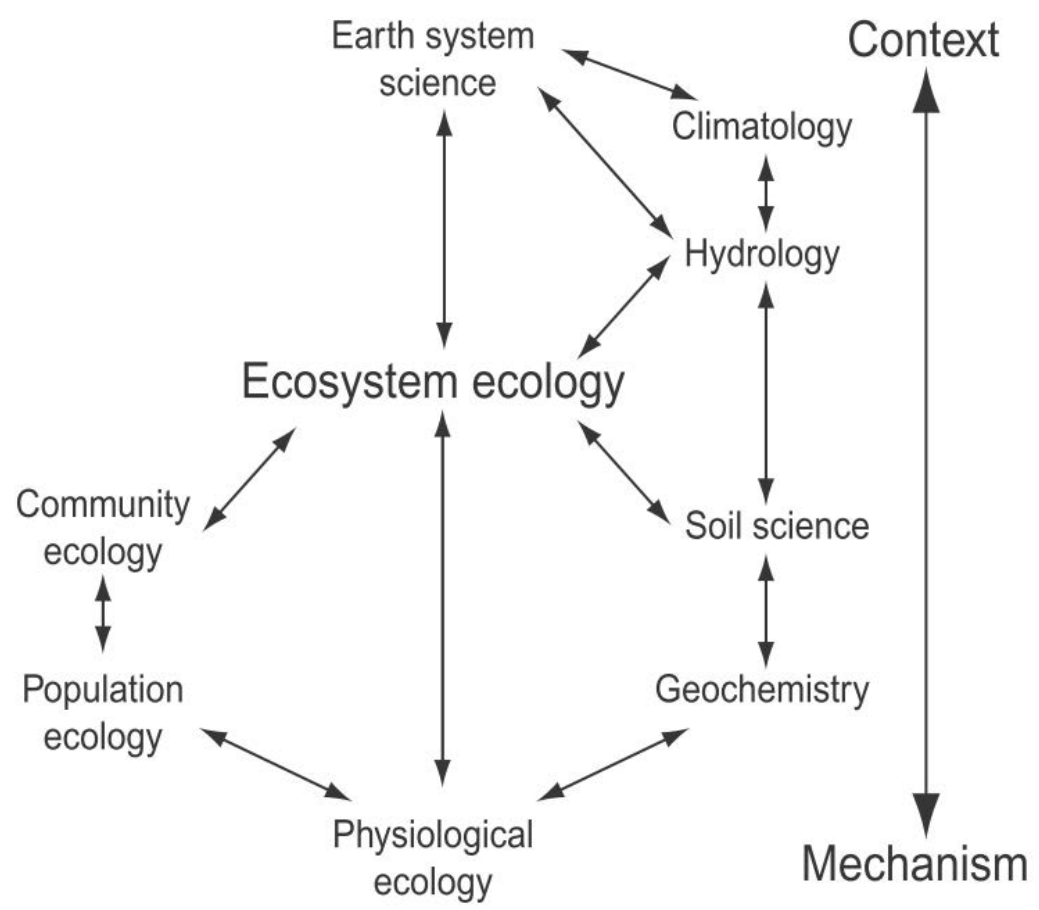

Figura 1: Relaciones entre la ecología de ecosistemas y otras disciplinas. La ecología de ecosistemas integra los principios de varias disciplinas biológicas y físicas y proporciona las bases mecanicistas para la earth system science, las Ciencias del Sistema Tierra. Figura y texto de Principles of Terrestrial Ecosystem Ecology (Chapin III et al., 2002).

En base a los métodos de la química se atribuye al humus una actividad de almacén y al suelo una conducta inorgánica. Se considera idéntico el nitrógeno inorgánico y el nitrógeno "viviente" de los aminoácidos del humus.

Hasta el siglo XX no estuvo del todo claro que las plantas no absorbían materia orgánica y que el carbono de estas procedía de la atmósfera, por fijación del anhídrido carbónico, mientras que los macro nutrientes (nitrógeno, fósforo, potasio) y los micro nutrientes (tales como el azufre, el hierro o el magnesio) eran absorbidos por las raíces desde el suelo en forma inorgánica. La materia orgánica, el humus, únicamente contribuía a la nutrición vegetal de forma indirecta, liberando al suelo estos elementos inorgánicos durante el proceso de su degradación, de su mineralización. Así, por ejemplo, el nitrógeno se absorbía en forma de nitrato o de amonio, y estas especies químicas inorgánicas, al entrar en contacto con las raíces, no guardaban memoria de su procedencia, fuera ésta la materia orgánica del suelo o una instalación de síntesis química. 
Esta conclusión abrió el camino a los abonos orgánicos de síntesis ... no es hasta después de la Segunda Guerra Mundial cuando se dispone en abundancia de abonos químicos baratos, junto a todo un repertorio de insecticidas, fungicidas, herbicidas, estimuladores de crecimiento y otros productos químicos de aplicación agrícola... Las plantas extraen del suelo (en forma inorgánica) sus nutrientes orgánicos. (García Olmedo, 2009).

Este modo de pensar químico y mecanicista, excluye categóricamente toda posibilidad de utilizar concepciones e hipótesis que no provengan de las concepciones e hipótesis de la propia Química y de sus métodos. Asumir una concepción del suelo como entidad viva, al lado de la doctrina puramente química, no supone ninguna contradicción ni negación del valor de la misma en su ámbito de validez, sino una ampliación, que puede ser fructífera para quien se enfrente a la realidad con ánimo de comprenderla. La concepción antroposófica del suelo proporciona los elementos necesarios para ampliar el conocimiento del suelo como medio vivo, y propone métodos de investigación apropiados para caracterizarlo como tal.

$\mathrm{Al}$ acercarnos a la naturaleza del suelo reconocemos los procesos elementales que colaboran en su formación. Tanto el proceso de descomposición de los restos orgánicos que se depositan en el suelo como los procesos de alteración de las rocas son procesos naturales. Por medio de ellos se transforma, por una parte la materia orgánica depositada en la superficie terrestre, y por otra las rocas, dando lugar a la formación de minerales secundarios, entre los que destacan especialmente las arcillas. Por medio de un tercer proceso armonizador, las lombrices y otros organismos hacen que los dos primeros procesos confluyan y se formen compuestos húmicos y humus estable (Cloos, 2003, p. 50). La consideración de los procesos primordiales que intervienen en la formación del suelo permiten colocarlo dentro de la vida de la tierra en el centro de la biosfera y adquirir una base conceptual para comprender sus funciones naturales.

Las primeras referencias acerca del conocimiento de la importancia de las lombrices de tierra datan de ... cuando Aristóteles las llamó el intestino de la tierra. En 1777 Gilbert White escribió "El gusano de tierra en apariencia ínfimo eslabón de la cadena de la naturaleza, dejaría si desapareciera, un lamentable vacío ..." ya que ellas cierran el ciclo de la vida. "Los gusanos de tierra parecen ser los grandes promotores de la vegetación ... La tierra sin ellos pronto parecería fría, desierta desprovista de fermentación y por consiguiente estéril". En 1888 después de muchos años de estudio Charles Darwin publicó su obra maestra La formación de la cubierta vegetal, a través de la ac- 
ción de las lombrices de tierra (www.humussol.com [Consulta: Dic-2014]) 
Proponemos abordar el problema de la contaminación como una pérdida de vitalidad del propio suelo. Para ello investigamos el potencial del método de Dinamolisis Capilar (Kolisko and Kolisko, 1939), partiendo de la configuración del Chroma-Test de Pfeiffer (1959).

\subsection{OBJETIVOS ESPECÍfICOS}

La investigación se presenta ordenada atendiendo a los tres objetivos principales contemplados:

1. Protocolizar el Método Horizontal de Dinamolisis Capilar en base a los planteamientos de Kolisko and Kolisko (1939) y partiendo del Chroma-Test de Pfeiffer (1959). La contribución de esta investigaciòn se presentan en el capítulo 9.

2. Caso práctico. Investigar el potencial del Método Horizontal de Dinamolisis Capilar para caracterizar la contaminación de los suelos aplicándolo a muestras de suelos del antiguo distrito minero de Linares seleccionadas en base a las investigaciones geoquímicas previas de la tesis doctoral de Julián Martínez López (Martínez et al., 2007; Martínez López et al., 2008). Los resultados se presentan en el capítulo 10 .

3. Verificar que el Método Horizontal de Dinamolisis Capilar es validable. Se presentan los resultados en el capítulo II.

\subsection{HIPÓTESIS DE TRABAJO}

Las nociones que asumimos como hipótesis de trabajo, a partir de los conocimientos que proporciona la Antroposofía, se enuncian a continuación:

1. En este trabajo se toma un punto de vista que considera la parte de la naturaleza del suelo que lo vincula al reino vegetal terrestre. En el suelo se producen de forma natural diversas sustancias orgánicas, entre ellas los compuestos húmicos, que contienen aminoácidos y dan testimonio de su parentesco con el reino vegetal.

2. Asumimos que para que se formen los compuestos húmicos a partir de la materia orgánica han de existir un tipo de fuerzas diferentes de las fuerzas presentes en los minerales, que denominaremos fuerzas formativas, término frecuentemente utilizado 
Al introducir la noción de "fuerzas formativas" podemos diferenciar las fuerzas que hacen posible que las sustancias del reino mineral, de otro modo sujetas a las leyes físicas, lleguen a integrarse en el reino vegetal.

Con la noción de un cuerpo de fuerzas formativas se tiene la posibilidad de comprender las relaciones constatadas en la práctica, entre la estructura, la materia orgánica y las funciones biológicas del suelo en ámbitos antroposóficos. Las leyes del reino mineral son diferentes de las leyes del reino vegetal. En este último además de actuar las fuerzas propias de los minerales, que son las habitualmente investigadas mediante los métodos analíticos convencionales, han de actuar las fuerzas formativas para que se formen las variadas sustancias proteicas del reino vegetal. Las fuerzas formativas vinculadas al suelo se contraponen a las fuerzas que tienden a mineralizarlo. Las fuerzas formativas modifican las sustancias y fuerzas del reino mineral, que podemos denominar fuerzas minerales o fuerzas físicas.

Con la noción de un cuerpo de fuerzas formativas se tiene la posibilidad de comprender las relaciones constatadas en la práctica, entre la estructura, el humus, y las funciones biológicas del suelo. Podemos pensar que en los experimentos de Dinamolisis Capilar las fuerzas formativas del suelo actúan produciendo formas características o patrones, al fijarse sobre el soporte de solidificación ofrecido por el papel de filtro. Estas mismas fuerzas formativas son responsables de la formación de grumos de estructura del suelo. En los grumos encontramos organizada la materia orgánica del suelo, formando moléculas orgánicas complejas, que son determinantes de la fertilidad del suelo, de su capacidad para retener agua y del riesgo de erosión.

3. Se puede estudiar la afinidad del suelo con el reino vegetal, por su capacidad para modificar la configuración de las sales metálicas con que se pone en contacto por medio del experimento de Dinamolisis Capilar. De este modo el método de Dinamolisis Capilar permite estudiar el equilibrio en el suelo entre las fuerzas fisicas tendentes a la mineralización y las fuerzas formativas tendentes a configurar la materia orgánica.

4. Es posible caracterizar las sustancias, en el sentido de la hipótesis precedente, por su relación con los siete metales $\mathrm{Au}, \mathrm{Ag}, \mathrm{Fe}, \mathrm{Sn}$, $\mathrm{Pb}, \mathrm{Hg}$ y $\mathrm{Cu}^{\mathrm{I}}$

5. En el método horizontal de Dinamolisis Capilar, las fuerzas formativas del suelo se expresan en los rasgos radiales, rítmicos, ondulantes y difuminados. Las fuerzas minerales hacen que se formen límites marcados en forma de anillos, que constituyen rasgos circulares bien diferenciados.

Partiendo de la experiencia, adoptamos los siguientes postulados:

1. La contaminación favorece la mineralización del suelo y afecta negativamente a las fuerzas formativas del mismo.

I En la concepción antroposófica, se atribuye a los procesos vinculados con estos metales una relevancia especial en los fenómenos vitales. Es frecuente encontrarlos en la bibliografía de la medicina y la agricultura. La literatura antroposófica se refiere a veces a este grupo como los siete metales principales. Ver Pelikan (1996) y Steiner and Wegman (1925) para una introducción al tema desde esta concepción. 
2. Es posible comparar, ordenar, jerarquizar y establecer escalas de calidad del suelo por los resultados de la Dinamolisis Capilar (en base a sus rasgos morfológicos), por medio de sustancias y suelos de referencia.

En la práctica se asumen convencionalmente, de forma más o menos explícita, postulados análogos a estos. El primero expresa que hay una relación directa entre la contaminación y el deterioro del suelo. Aquí queremos evaluarla por medio de sus fuerzas formativas. El segundo está implícito en los niveles genéricos de referencia, estándares, baselines, entre otros referentes asociados a los resultados de los análisis químicos utilizados habitualmente en la actualidad.

\subsection{DEFINICIONES ESPECíficAs PARA EL MÉTOdo DE DiNAMo- LISIS CAPILAR}

A continuación definimos una terminología específica, apropiada para el método de Dinamolisis Capilar

1. Llamamos Dinamograma al resultado de un experimento de Dinamolisis Capilar.

2. Llamamos Patrón de un suelo (o de un proceso en un suelo) a la imagen, que aparece en un dinamograma obtenido a partir de una muestra del suelo (sometido a dicho proceso). Lo utilizaremos para caracterizar la calidad del suelo (afectado por dicho proceso).

3. Denominaremos Signatura de un suelo o de un proceso al conjunto de los 7 patrones obtenidos con cada una de las sales de los metales $\mathrm{Au}, \mathrm{Ag}, \mathrm{Fe}, \mathrm{Sn}, \mathrm{Pb}, \mathrm{Hg}$ y $\mathrm{Cu}$ utilizadas inicialmente por L. Kolisko (ver nota 1 ).

4. La calidad, y el estado de contaminación de un suelo, se puede caracterizar por su Signatura, que muestra la relación entre las fuerzas formativas y las fuerzas minerales.

\subsection{ESTRUCTURA DE LA INVESTIGACIÓN}

Una primera familiarización con las posibilidades del método y su alcance se realizó mediante un periodo de aprendizaje del método Chroma-Test de Pfeiffer, durante el primer semestre del año 2011 en la granja Andreashof en Überlingen, Alemania. Se realizaron ensayos con distintos tipos de suelos y composts para tener una experiencia de los procesos naturales que se dan en los suelos y de su reflejo en el Chroma-Test. A continuación se completó el aprendizaje ensayando diversas plantas y sus partes principales, raíces, hojas y tallos, flores, con el mismo objetivo. El trabajo preliminar de laboratorio se completó en Madrid entre 2011 y 2012, en las instalaciones de la ETSIME. 
Todo ello ha servido para definir los objetivos y plantear las hipótesis de trabajo de la investigación.

La estructura del trabajo se puede esquematizar como sigue:

1. Ampliación del marco conceptual mediante las nociones y métodos experimentales de la Antroposofia.

a) Introducción al problema de investigación de los suelos contaminados, justificación, objetivos y alcance, conceptos e hipótesis de trabajo (capítulos 1 y 2)

b) Revisión de la literatura.

1) Concepciones y origen de los métodos experimentales relacionados con el investigado (capítulo 3 )

2) Estado del método investigado, (capítulo 4)

2. Estandarización y aplicación a un caso práctico: suelos de Linares y de Agricultura Biodinámica

a) Contribución a la estandarización del método Horizontal de Dinamolisis Capilar

1) Investigación de los parámetros de influencia partiendo del Chroma-Test (capítulo 9)

2) Validación con diversos instrumentos (capítulo I1)

b) Comprobación de la validez de las hipótesis de trabajo y del potencial del método (capítulo 10)

Cada parte del texto va precedida de una breve descripción de su contenido. En las partes que constan de más de un capítulo, cada capítulo comienza con una sección de introducción y finaliza con un resumen. Las nociones procedentes de la Antroposofía que han sido necesarias, ya se han introducido en forma de hipótesis de trabajo en la sección 2.2. 


\section{Parte II}

\section{BASES DE PARTIDA}

La Parte II recoge los principales antecedentes bibliográficos en cuanto a los métodos experimentales basados en la adsorción capilar, su contexto en la investigación de las fuerzas formativas y su ámbito de aplicación.

El capítulo 3 se dedica a los antecedentes relativos al método de Dinamolisis Capilar, y el capítulo 4 se refiere de forma más específica a la configuración horizontal establecida por Pfeiffer y conocida con el nombre de Chroma-Test, que hemos tomado como punto de partida en el trabajo experimental. 



\section{INTRODUCCIÓN}

Se ha investigado el método de Dinamolisis Capilar, uno de los denominados Métodos Generadores de Imágenes, en alemán Bildsachaffende Methoden, desarrollados a partir de la Antroposofía de Rudolf Steiner durante la primera mitad del siglo XX. La finalidad de los Métodos Generadores de Imágenes es poner de manifiesto las fuerzas formativas presentes en las sustancias. Estos métodos complementan los métodos de análisis químico, que estudian las sustancias desde el punto de vista de su composición.

En la sección 3.1 se recogen los principales aspectos del método de Dinamolisis Capilar en relación con su origen y parentesco con otros métodos de Cromatografía, enfatizando la diferencia de objetivos de las diversas técnicas basadas en el fenómeno de la adsorción capilar. También se indican las diferentes concepciones bajo las que se han desarrollado los métodos cromatográficos convencionales y los de Dinamolisis Capilar, aspecto este de suma importancia para poder valorar el método de forma objetiva.

En la sección 3.2 se introduce la bibliografía sobre los Métodos Generadores de Imágenes en general.

En la sección 3.3 se indican los principales antecedentes bibliográficos del análisis capilar de Lili Kolisko.

Como resumen del capítulo, en la sección 3.4, se comparan los principales antecedentes de la línea de investigación propuesta.

\section{1 “BildungSTRIEB", F. F. RUNGE Y ORIGEN DE LA CROMATO- GRAFÍA}

Para el acercamiento a los métodos generadores de imágenes es de gran importancia conocer las ideas y las intenciones con las que fueron investigados inicialmente. Podemos reconocer concepciones y aspiraciones diferentes en las técnicas cromatográficas desde el inicio de su utilización científica, en el siglo XIX.

El inicio de la cromatografía de partición sobre papel con fines separativos se atribuye al físico alemán Shönbein, hacia 1861. Su discípulo Goppelsroeder investigó el fenómeno y publicó una monografía sobre "Análisis Capilar" (figura 2), que también investigó Rheinboldt. El botánico de origen ruso M. Tswett, que conocía estos estudios, desarrolló cuarenta y cinco años más tarde, el método llamado "Análisis 


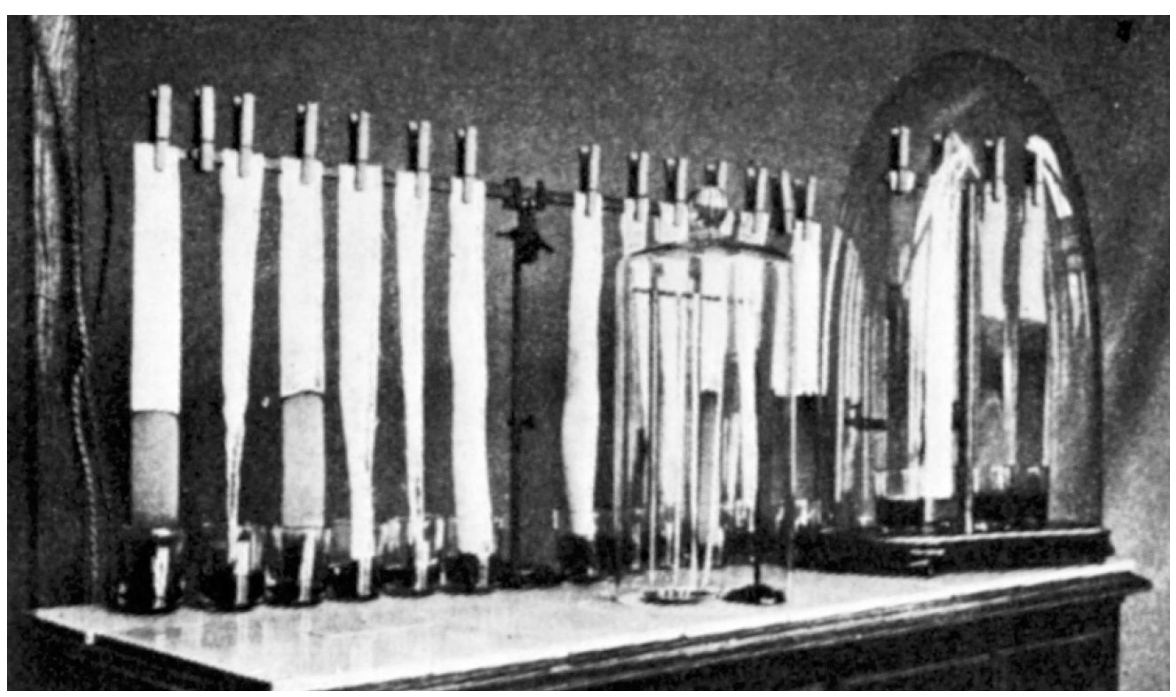

Figura 2: Instalación de Goppelsroeder (Williams, 2002, p. 922)

Cromatográfico de Adsorción", introdujo el uso de columnas de adsorción y se le atribuyó el uso por primera vez del término "cromatograma" (Mittelman, 1941). La creencia de que la palabra "cromatografía" fue acuñada por Tswett ha sido posteriormente refutada (Williams and Weil, 1952).

Los primeros desarrollos y aplicaciones se deben al químico Friedlieb Ferdinand Runge (1795-1867). A menudo su contribución a la cromatografía no ha sido considerada más que como un antecedente pre-científico escasamente valorado:

Runge's activities around the middle of the last century are sometimes mentioned as the precursors to paper chromatography. This is really not true; still, Runge's beautiful pictures look indeed like some kind of artistic paper chromatograms. Therefore, we should deal briefly with his activities. Friedlieb Ferdinand Runge was by training both a physician and a chemist, but most of his professional activities were in the field of chemistry, with a very early interest in the chemistry of dyes.... Runge's work on "chromatography" is a curious mixture of science, practical application, art, and tricks.... Even Weil and Williams (Williams and Weil, 1952), who try to present Runge as the real founder of "scientific paper chromatography," characterize his work in the following way:

Runge outdid himself-this must be stated-in trick chromatography, in which he let to merge the moving zones of one or more mixtures applied on the paper. In this way pictures were obtained which were different in design and color, 
and obviously Runge had the greatest delight in their surprising effect.

Runge was really a natural philosopher, and he considered his color pictures to be the revelation of some mysterious force....

Runge believed that the self-grown pictures shown by him are produced by a special force ... which has nothing to do with magnetism, electricity or galvanism. This force is not working from the outside, rather it is living in the original substances in the mixtures to be separated and it will become 'active' when the molecules of the components reorganize when meeting each other in the paper. Runge calls this mysterious force the "generative force." He considers it a prototype of the life energy which is active in plants and also animals.

Although often mentioned as the originator of paper chromatography, Runge should be considered mainly as an artist. It is a pleasure to view his pictures; however, his books represent "an essay on the philosophy of Nature" [quoted by Williams and Weil after Goppelsroeder] and not scientific paper chromatography. Naturally, Runge should be considered as an artist only as his activities connected to color and thus to "chromatography," and not in the context of the evolution of chemistry. He was one of the early German organic chemists, a pioneer in the investigation and utilization of coal tar to produce pigments and other chemical products and thus one of the founders of the famous German chemical industry. (Ettre, 1980, pp. 11-13)

No obstante, el reconocimiento y el interés por su obra han aumentado en los últimos años. La industria de pigmentos químicos le rindió el debido homenaje en 1935 (Kränzlein, 1935). También se empieza a reconocer su originalísima labor pionera en la cromatografía sobre papel, Bussemas and Ettre (2004), Schwenk (2005), Beneke (1999), y en el arte Runge (2014).

El método experimental de Runge consistía en dejar gotear un reactivo en el centro de un papel adsorbente esperando a que cada gota se difunda antes de aplicar la siguiente, y una vez seco el papel así preparado, hacer lo mismo con la sustancia a investigar. En su obra Zur Farbenchemie. Musterbilder für Freunde des Schönen und zum Gebrauch für Zeichner, Maler, Verzier und Zeugdrucker ${ }^{1}$ aparecida en 1850 en Berlín

1 Química de los colores. Ilustraciones de patrones para amigos de lo bello y para uso de dibujantes, pintores, decoradores e impresores 


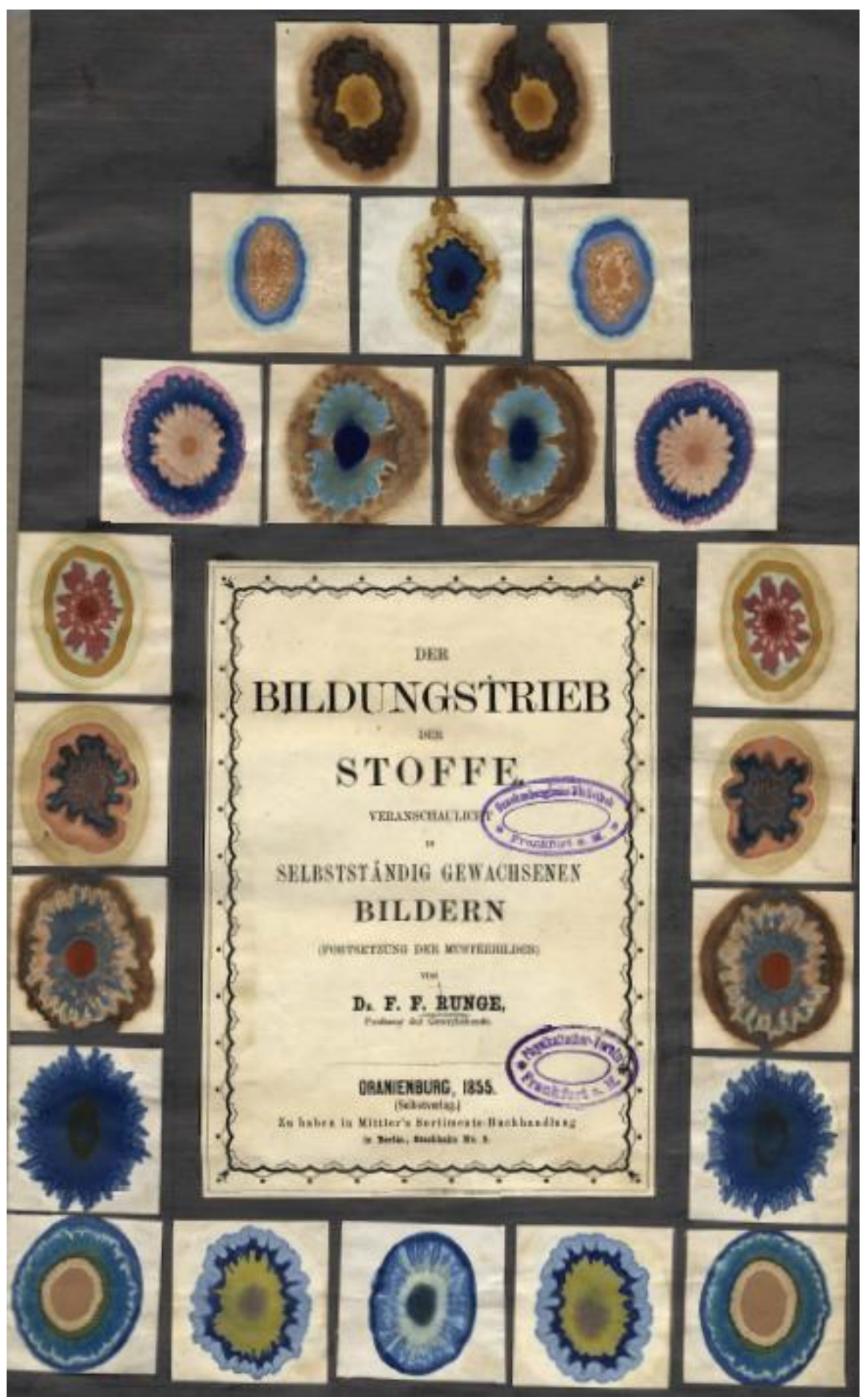

Figura 3: Bildungstrieb der Stoffe, Runge (1855). Ejemplar de la Universidad de Frankfurt 
... (Runge) presenta la forma primigenia de la cromatografía sobre papel. En el año 1855 apareció un segundo libro con el título Der Bildungstrieb der Stoffe, veranschaulicht in selbständig gewachsenen Bildern ${ }^{2} .$. con este trabajo Runge se movía siguiendo a Goethe ... lo que Blumenbach (1752-1840), Goethe y Runge designan con "Bildungstrieb" (fuerza formativa) hoy se denomina auto organización de la materia.... la intención de Runge en su Bildern, die sich selber mahlen ${ }^{3}$ es nada menos que la demostración fehaciente de la existencia de esta, en principio hipotética, fuerza formativa ... (Krätz, 1992, pp. 152-157).

La noción de Bildungstrieb, fuerza formativa ha sido objeto de diferentes interpretaciones. Las mismas observaciones son interpretadas de modo diferente según la concepción en que se encuadren. Una interpretación de la diferencia de planteamiento entre Kant y BlumenbachGoethe en relación con el término "Bildungstrieb" se encuentra en Kant and Blumenbach on the Bildungstrieb: A Historical Misunderstanding (Richards, 2000).

Rudolf Steiner aborda el problema epistemológico de fondo, indica que la carencia de conceptos y métodos adecuados para caracterizar los organismos vivos, y la aplicación de las mismas nociones y métodos que sirven para caracterizar lo inorgánico, es el principal obstáculo que limita el avance en el conocimiento de la naturaleza orgánica. Plantea esta problemática en su tesis doctoral, publicada con el título Verdad y Ciencia, Steiner (1892), en la que además de mostrar las limitaciones impuestas por la epistemología de Kant que llevan a rechazar o calificar como no científicos los planteamientos como el de Runge, propone formas de superarlas.

La experiencia y el razonamiento sin prejuicios no pueden dejar de reconocer, tanto en el ámbito científico como en el técnico, el valor de las ideas que Runge aplicó con tanto éxito.

We should mention here that despite of the unusual (we might say, unscientific) explanations, the Bildungstrieb was well received by Runge's peers: he received for it the special medal of the World Exhibition held in 1855 in Paris, and the book also was honored by the World Industrial Exhibition held in 1862 in London. Thus, the scientific world knew about Runge's work and considered it worth for recognition. (Bussemas and Ettre, 2004)

Hoy en día la cromatografía se usa exclusivamente, si exceptuamos los métodos de Dinamolisis Capilar, para separar sustancias.

2 La fuerza formativa de las sustancias, hecha visible en imágenes creadas por si mismas

3 Imágenes que se pintan a si mismas 
F. F. Runge, one of the first industrial chemists, discovered and isolated the plant alkaloids quinine, atropine, catechol, and caffeine. From coal tar oil he was able to isolate phenol, aniline, quinoline, and thymol. He was far ahead of his time, having proposed large-scale production of coal tar dyes, wax candles, and synthetic fertilizer. Had he not been impeded but rather encouraged by the Prussian bureaucracy, he might today be considered the founder of pharmaceutical chemistry and coal tar dyes and fertilizer industries. From his publications, Runge can be considered the discoverer of capillary analysis, developed as an analytical tool 100 years later in the form of paper chromatography. (Schwenk, 2005)

El propio Runge indica como punto de partida de su investigación las dificultades para identificar los analitos presentes en una muestra mediante reacciones de separación. "En estos análisis normalmente se hacen las mezclas en tubos de ensayo, y hay que tener especial cuidado de que no se eche en exceso o en defecto de lo uno o de lo otro, porque podría suceder que algo muy importante se le oculte al observador, y no descubra o encuentre un componente, que se habría dado a conocer por su reactante indicador al modificar la relación cuantitativa." Para evitar esta inseguridad que incomodaba su trabajo, Runge prescinde de los tubos de ensayo y mezcla los reactivos gota a gota sobre papel adsorbente. Descubre así un nuevo mundo de configuraciones y mezclas de colores cuya existencia no había podido sospechar y que le resulta sorprendente. Pronto conoce las condiciones para obtener las imágenes más bellas y variadas, y también el modo de reproducirlas. Resalta la importancia de difundir este descubrimiento por su valor no sólo para la Química sino también para las Bellas Artes (Runge (1850), citado por Beneke (1999); Krätz (1992)).

\subsection{MÉTOdOS GENERADORES DE IMÁGENES: BILDSHAFFENDE ME- THODE}

Los Métodos Generadores de Imágenes han sido utilizados dentro de las actividades basadas en la Antroposofía, desde que se desarrollaron a principio del siglo XX hasta el momento actual, con el fin de investigar la vitalidad de diversas sustancias orgánicas. En el campo de la agricultura sirven para la caracterización de suelos o composts y para la determinación de la calidad de alimentos (figura 4). En el de la medicina para el diagnóstico por medio del estudio de la sangre, la orina y otros fluidos y extractos orgánicos, así como para la caracterización de las sustancias utilizadas en farmacología. La intención original para la que se concibieron los métodos generadores de imágenes fue el estudio de las fuerzas formativas (Wachsmuth, 1951). La investigación básica fue desarrollada especialmente por sus 

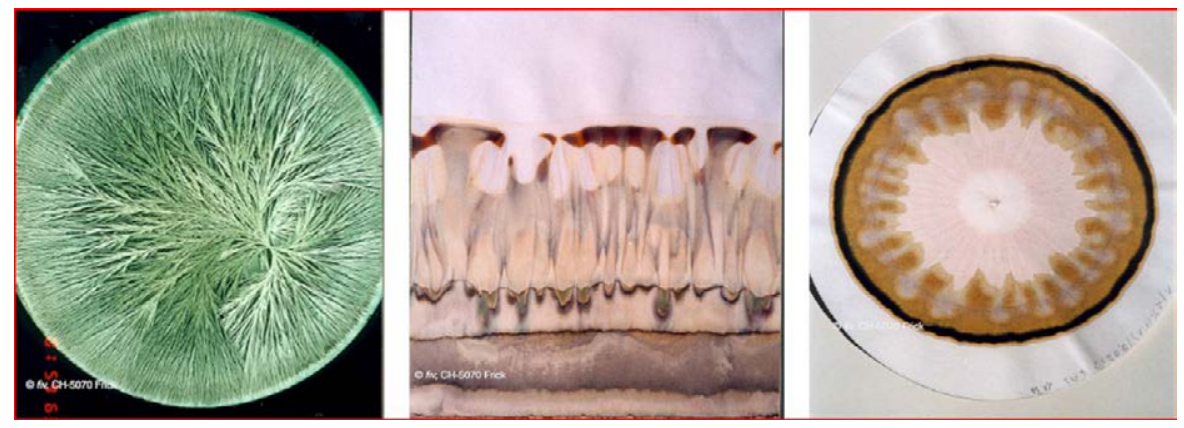

(a) Leche Demeter cruda. Demeter es el marchamo internacional de los productos de Agricultura Biodinámica.
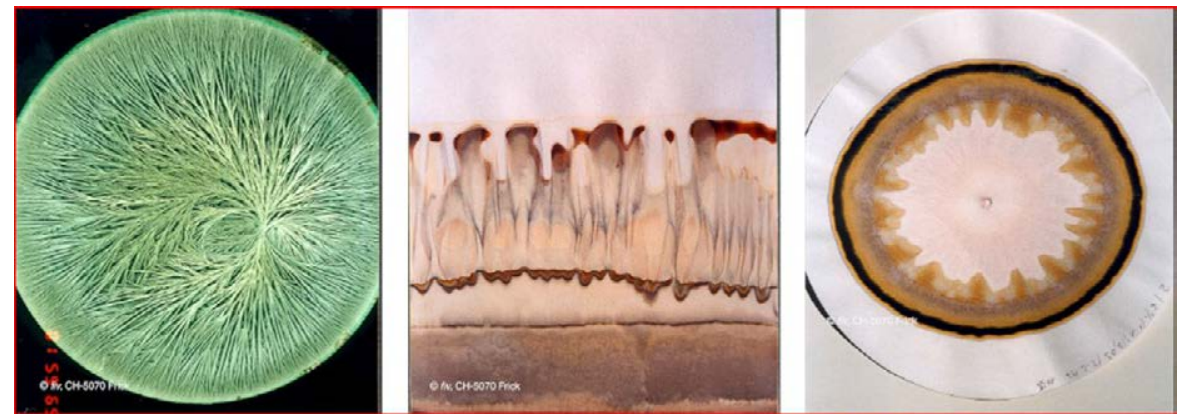

(b) Leche Bio pasteurizada
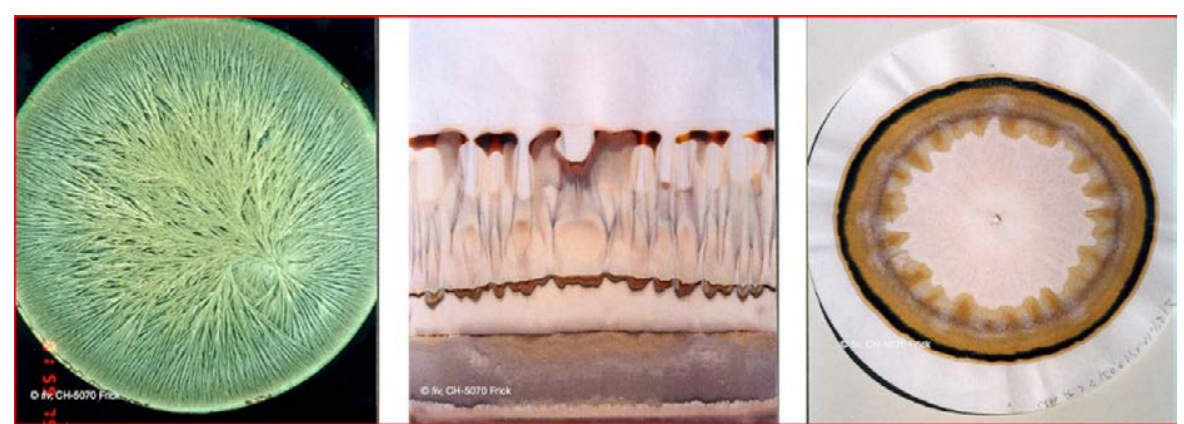

(c) Leche convencional pasteurizada

Figura 4: Ejemplos de resultados con varios Métodos de Formación de Imágenes para diferentes tipos de leche:

Izquierda: Cristalizaciones Sensibles.

Centro: Método Wala.

Derecha: Chroma-Test

Imagen procedente de $w w w$.fiv.ch. 
Los métodos generadores de imágenes se concibieron para poner de manifiesto las fuerzas formativas descubridores. Lili Kolisko resume los resultados principales de sus investigaciones con la Dinamolisis Capilar en Agriculture of Tomorrow Kolisko and Kolisko (1939). Pfeiffer implementa también el método de las Cristalizaciones Sensibles de Cloruro de Cobre Pfeiffer (1931), Selawry (1992), que Alla Selawry desarrolla notablemente Selawry (1957).

El principal método horizontal de Dinamolisis Capilar fue dado a conocer por Pfeiffer en Chromatography Applied to Quality Testing Pfeiffer (1959), que él denominó simplemente "cromatografía de filtro redondo", o cromatografía sin más. Posteriormente se han ido extendiendo las denominaciones Chroma-Boden-Test y Chroma-Test para referirse a su método. Otros investigadores han ido enriqueciendo con sus resultados el conocimiento de las sustancias y de los procesos biológicos mediante estos nuevos métodos. Desde el principio han despertado el interés de universidades e instituciones de investigación, también en los campos de las Ciencias de la Tierra, como muestra la introducción de A. Newhouse sobre los fundamentos cristalográficos de las cristalizaciones sensibles de Cloruro de Cobre (Selawry, 1957) y la reseña de la citada publicación publicada por el Departamento de Geología y Geofísica de la Universidad de Yale en The American Journal of Science. Yale University por Krynine (1957).

Ursula Graf (antes Balzer-Graf) ha impulsado de forma notable el desarrollo de los métodos generadores de imágenes y se ha especializado en investigar la calidad de los alimentos, Balzer (1987); Balzer and Balzer-Graf (1989); Balzer-Graf and Balzer (1991); Balzer-Graf et al. (1998). Recientemente y en la actualidad se realizan investigaciones sobre la calidad de los alimentos y el tipo de cultivo, Huber et al. (2010), Kahl and Zalecka (2009), Kahl et al. (2009), Fritz et al. (2011, 2013) y Mäder et al. (2007) o para demostrar los efectos de las diluciones homeopáticas Baumgartner et al. (2012). También se investigan los métodos computerizados de análisis de las imágenes para el método de Cristalizaciones Sensibles, Andersen et al. (1999), Szulc et al. (2010), Kokornaczyk et al. (2012), Unluturk et al. (2013) y Doesburg et al. (2015) y para el método Wala de Dinamolisis Capilar Unluturk et al. (2011).

Existen publicaciones con carácter divulgativo como son las de Tesson and Fernandez-Bravo (2000) sobre el método de cristalizaciones sensibles, Barker (2009) sobre el método Wala de Dinamolisis Capilar y Voitl and Guggenberger (1986) sobre el Chroma-Test.

Otro importante método generador de imágenes es el Tropfbildmethode, de Theodor Schwenk, desarrollado en el Institut für Strömungswissenschaften en Herrischried Alemania, que se usa en la evaluación de efectos sobre el agua.

Los métodos generadores de imágenes se han utilizado con éxito en la medicina y en la industria farmacéutica, pero su uso apenas ha 
trascendido más allá de pequeños círculos muy especializados dentro de la Antroposofía.

Los métodos de formación de imágenes relevantes para esta investigación, son los siguientes:

- el método de dinamolisis capilar, concebido por Kolisko and Kolisko (1939), que hemos elegido porque ofrece un modo de estudiar el papel primordial que Rudolf Steiner otorga a los metales en los procesos vitales.

- el CHROMA-TEST, desarrollado por Pfeiffer para caracterizar la actividad biológica de suelos y composts (Pfeiffer, 1959). Consideramos este método como una variante horizontal del método de Dinamolisis Capilar. Lo hemos elegido por existir ya investigaciones previas, aplicadas a suelos con fines agrícolas, que también tienen por objeto caracterizar la calidad del suelo.

Los métodos de Dinamolisis Capilar tienen la particularidad de utilizar como reactivo sales metálicas. La variante horizontal conocida como Chroma-Test que nos interesa especialmente, es muy cercana al método originalmente usado un siglo antes por Runge.

\subsection{DINAMOLISIS CAPILAR DE LILI KOLISKO}

Lili Kolisko resalta la importancia del fenómeno de la capilaridad en la naturaleza y el interés que ha suscitado

El fenómeno de la capilaridad es conocido desde antiguo y ha sido estudiado en el siglo XIX por muchos investigadores famosos como Laplace (1805), Th. Young (1805), Gay Lussac (1808), Gauss (1830), Quinke (1858), Mendelejeff (1860), Roentgen (1878). La capilaridad es el fenómeno de impregnación por un fluido de cualquier medio poroso como una esponja, azúcar o la cera ascendiendo por la mecha en una vela encendida. Este fenómeno está presente en toda la naturaleza. El suelo toma agua por capilaridad, la savia de las plantas y árboles asciende por capilaridad, y en los animales y seres humanos la sangre circula por conductos capilares. Cada sustancia tiene su propio límite de ascenso. El agua asciende por un papel de filtro hasta una cierta altura, el alcohol hasta otra diferente. (Kolisko and Kolisko, 1939)

El método experimental de Lili Kolisko utiliza el fenómeno de adsorción y distribución (o partición) como base. Lo que diferencia su método es en primer lugar la finalidad. Además introduce la posibilidad de que la sustancia a estudiar interactúe con una sal metálica que se ha dejado ascender por el papel y secar, antes o después de 
dejar ascender la muestra que se investiga. Con ello se ponen de manifiesto formas y colores que son el objeto de investigación. Se hacen así visibles los efectos de las fuerzas que hemos denominado fuerzas formativas. En el reino vegetal, vemos que cada planta se presenta en la naturaleza con formas características para cada especie. Las imágenes proporcionadas por los métodos generadores de imágenes son una huella producida por las mismas fuerzas que configuran la apariencia externa y la estructura interna de la planta, y por ello pueden ser usadas para caracterizarla. El método original de Dinamolisis Capilar lo presentan Kolisko and Kolisko (1939) en la Parte II, capítulo XVIII. Capillary Dynamolysys y en los siguientes capítulos, en los que expone ejemplos de uso, p. 154-204, efectos de estiércol, composts y fertilizantes químicos sobre los suelos a partir de la p. 186 y efectos de las concentraciones traza a partir de la p. 162. En la tercera parte, a partir de la página 286 , muestra otros resultados de algunos de sus experimentos con composts y suelos.

Este método nos capacita para juzgar muy rápido el valor de cualquier estiércol o fertilizante. (Kolisko and Kolisko, 1939, p. 295).

La mayor parte de la experiencia de L. Kolisko no está publicada, debido en gran medida a las limitaciones técnicas de su tiempo para reproducir las imágenes, y especialmente, las imágenes en color. En la publicación principal mencionada arriba solo presenta algunos ejemplos en los que utilizó preferentemente el cloruro de oro como reactivo.

En los archivos de la ITA WEgMAN KLINIK, en Arlesheim, Suiza, visitados en compañía de Janet Barker, autora de (Barker, 2009), en junio de 2012, existen ensayos realizados entre 1929 y 1938 por Rudolf Hauschka (1889-1969) que dan testimonio del uso de siete sales metálicas en los experimentos de Dinamolisis Capilar para investigar determinadas plantas medicinales. Están archivados bajo el epígrafe "Steigbild Metallen". Parecen haber sido la base para el desarrollo del método Wala ya que Hauschka es el fundador de este laboratorio farmacéutico y trabajó en la Ita Wegman Klinik antes de fundarlo. En el mismo archivo existe otra carpeta denominada "Kallkhof Mappe" que recoge una serie de ensayos de Dinamolisis Capilar realizados en Alsacia durante la Segunda Guerra Mundial. La importancia de estos experimentos desde el punto de vista de esta investigación es que se mantienen en el marco conceptual proporcionado por Rudolf Steiner, pues utilizan las sales de los siete metales que propuso Lili Kolisko siguiendo sus indicaciones (Kolisko and Kolisko, 1939). Los métodos actualmente utilizados sólo se sirven de sales de Ag y de Fe. Por ello los ensayos mencionados constituyen un importante antecedente. Desgraciadamente no están suficientemente documentados, por lo que su valor es solo testimonial de la línea de investigación que queremos retomar. 


\subsubsection{Los métodos de Dinamolisis Capilar}

En la Dinamolisis Capilar se usa una tira de papel de filtro (de unos $45 \mathrm{~cm}$ de largo) en la que se deja ascender el fluido a estudiar. Una vez seco se deja ascender una sal metálica. Es posible invertir el orden, impregnando el papel primero con la sal y después con la muestra. También es posible usar más de una sal, dando lugar a distintas variaciones del método. En lugar de usar papel de filtro rectangular y colocarlo verticalmente, es posible utilizar papel de filtro circular y disponer el experimento horizontalmente, dando lugar a las dos configuraciones básicas, la configuración vertical y la configuración horizontal. El método de Pfeiffer conocido como Chroma-Test, se puede considerar como una variante de la configuración horizontal del método de Dinamolisis Capilar.

Lili Kolisko diseñó numerosas configuraciones para implementar sus experimentos basados en el fenómeno de Dinamolisis Capilar. Según el campo de aplicación o el objetivo del experimento variaba los elementos de su configuración con gran flexibilidad.

En la actualidad encontramos en uso y protocolizadas dos configuraciones del método de Dinamolisis Capilar:

A. Chroma-Test de Pfeiffer

B. Método Wala.

Ambos usan la misma sal de plata como reactivo y el de Wala usa además una sal de hierro. El número de fases de difusión y su orden son diferentes. El uso de filtros redondos, dispuestos horizontalmente, o de filtros rectangulares colocados verticalmente durante el ensayo, es característico de cada método. La tabla I resume las características individuales de cada método, considerando las sales usadas, las fases de difusión y la posición del filtro de papel.

Tabla 1: Métodos experimentales de Dinamolisis Capilar

\begin{tabular}{lcc}
\hline \multicolumn{1}{c}{ Método: } & Chroma-test & MÉtodo wala \\
\hline \hline $\begin{array}{l}\text { Sal(es) } \\
\text { usadas: }\end{array}$ & $\mathrm{AgNO}_{3}$ & $\mathrm{AgNO}_{3}$ y $\mathrm{FeSO}_{4}-7 \mathrm{H}_{2} \mathrm{O}$ \\
\hline \hline $\begin{array}{l}\text { Fases de } \\
\text { difusión y } \\
\text { orden: }\end{array}$ & Fase 1: $\mathrm{AgNO}_{3}$ & Fase 1: Extracto \\
\cline { 2 - 3 } & Fase 2: Extracto & Fase 2: $\mathrm{AgNO}_{3}$ \\
\hline \hline $\begin{array}{l}\text { Disposición } \\
\text { del filtro: }\end{array}$ & horizontal & Fase 3: FeSO \\
\hline
\end{tabular}




\subsection{RESUMEN}

Hemos visto en la sección 3.I en la página 19 que la intención original del químico Friedlieb Ferdinand Runge, precursor de la técnica investigada, no se dirigió a separar las sustancias, sino que abordó el aspecto de la dinámica vinculada a las fuerzas formativas presentes en ellas, abriendo nuevas posibilidades de investigación a la química que han permanecido prácticamente inexploradas. En Lili Kolisko vemos un nuevo impulso asociado a las ideas de Rudolf Steiner, para servirse de esta técnica en la agricultura y la medicina antroposóficas.

En la tabla 2 se recogen los principales elementos diferenciados de las técnicas de Cromatografía y de Dinamolisis Capilar.

Tabla 2: Dinamolisis Capilar y Cromatografía en Papel

\begin{tabular}{|c|c|c|}
\hline & CROMATOGRAFÍA & DINAMOLISIS CAPILAR \\
\hline Fenómeno de base & \multicolumn{2}{|c|}{ Adsorción capilar } \\
\hline Objeto de ensayo & Sustancias & Fuerzas Formativas \\
\hline Objetivo del ensayo & $\begin{array}{l}\text { Separación de } \\
\text { sustancias }\end{array}$ & $\begin{array}{c}\text { Efectos de las } \\
\text { Fuerzas Formativas }\end{array}$ \\
\hline $\begin{array}{l}\text { Resultado del } \\
\text { ensayo }\end{array}$ & CROMATOGRAMA & DINAMOGRAMA \\
\hline
\end{tabular}

El término cromatograma se utiliza para las técnicas que tienen como objetivo separar las sustancias. Creemos justificado diferenciar los Métodos de Dinamolisis Capilar de los métodos cromatográficos convencionales por tener una base conceptual y una finalidad diferente. Si bien tienen una base física común, los primeros se orientan a investigar las fuerzas formativas mientras que los segundos se dirigen hacia la separación e identificación de las sustancias.

Por ello para diferenciar los resultados de estos dos tipos de experimentos preferimos la denominación DINAMOGRAMA en lugar de cromatograma, ya que aunque se basen en el mismo fenómeno físico, como hemos podido ver, parten de concepciones y objetivos muy diferentes.

El hecho de usar determinadas sales metálicas como reactivos también confiere identidad propia al Método de Dinamolisis Capilar4.

En este texto se usa la denominación cromatograma en los antecedentes, respetando la nomenclatura que usó Pfeiffer. En cuanto a los resultados propios, se ha optado preferentemente por el nombre de

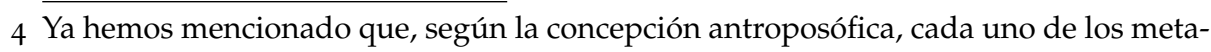
les llamados principales actúa de forma específica en los procesos vitales (ver nota 1 en la página 14). 
dinamograma, más acorde con la nomenclatura de L. Kolisko y con el objetivo del experimento. 



\section{INTRODUCCIÓN}

En este capítulo se describe el CHROMA-BODEN-TEST O CHROMATEST utilizado por Pfeiffer, se resumen los usos y se presentan las principales contribuciones a su desarrollo.

En la sección 3.3.I se introdujeron las características generales de los métodos De Dinamolisis CAPILAR de Lili Kolisko, entre los que podemos considerar el Chroma-Test como una variante horizontal.

El Chroma-Test de Pfeiffer se ha utilizado fundamentalmente en el ámbito de la Agricultura con dos finalidades principales. Por una parte se ha usado para caracterizar suelos y composts y por otra para caracterizar alimentos. Pfeiffer presenta su método originalmente como un método cromatográfico cualitativo para la determinación de factores biológicos. Y explica que lo utiliza desde 1953 para determinar diferencias en la formación de humus tanto en suelos como en composts. Diferencias, que no pueden ser determinadas por análisis químicos:

Hay suelos que teniendo contenidos casi idénticos de sustancias minerales muestran grandes diferencias en cuanto a su eficiencia biológica, producción y calidad de las cosechas. (Pfeiffer, 1959).

La causa de las diferencias la atribuye a la estructura del suelo y la condición del humus.

En la sección 4.I se presenta una traducción completa del método original de Pfeiffer, que también incluye sus indicaciones para la interpretación de las imágenes. Los procedimientos operativos que Pfeiffer toma en consideración son los siguientes procesos:

- preparación de los filtros

- extracción

- ensayo: difusión del extracto

- REVElado

- INTERPRETACIÓN

En la sección 8.4 se amplían las nociones para explicar e interpretar los resultados.

En la sección 4.2 se enumeran las principales contribuciones a la difusión del método de Pfeiffer y su utilización en el ámbito de los suelos. 
Los desarrollos y aplicaciones del Chroma-Test realizadas en la Universidad Carl-von-Ossietzky, en Oldenburg Alemania, junto con los antecedentes relevantes vinculados a los Balzer, quedan recogidos en la secciones 4.3. Algunos Métodos Generadores de Imágenes han podido ser validados para valorar la calidad de determinados alimentos y para poder diferenciar el método agrícola por el que se han cultivado: convencional, ecológico o biodinámico (Kahl and Zalecka, 2009), (Kahl et al., 2009) y (Fritz et al., 2011). En la subsección 4.3.3 se hace referencia a la estandarización del método de Wala, realizada por un equipo internacional en el que han participado la Universidad de Kassel en Witzenhausen Alemania, el Louis Bolk Institut de Holanda y la Biodynamic Research Association de Dinamarca.

\subsection{PROCEDIMIENTO DEL CHROMA-TEST SEGÚN PFEIFFER}

El procedimiento propuesto por Pfeiffer (1959) para uso por los agricultores, actualmente más conocido como Chroma-Test, se transcribe a continuación, traducido literalmente por la autora.

\subsubsection{Descripción del Chroma-Test de Pfeiffer}

1. Preparativos:

a) Utilizar filtros circulares de papel Whatman $n^{\circ} 1$ ó $n^{\circ} 4$ de $15 \mathrm{~cm}$ de diámetro. Hacer una perforación en el centro, de unos $2 \mathrm{~mm}$ de diámetro.

b) Preparar una mecha del mismo papel de filtro cortando un cuadrado de $2 \mathrm{~cm}$ de lado y enrollándolo apretado formando un cilindro. Colocar esta mecha en el orificio perforado en el centro del filtro, de modo que sobresalga por ambas caras del disco y que esté en contacto con el fondo de la cápsula de porcelana situada debajo de él (ver esquema de la figura $5 \mathrm{~d}$ ). Es importante que la mecha esté en contacto

Las medidas originales están en pulgadas. con toda la periferia del orificio central del disco de papel.

c) Hacer marcas con lápiz a $1^{1 / 2}$ y $2^{3 / 3}$ de pulgada ${ }^{1}$ de distancia al centro, para indicar hasta dónde debe avanzar o ser absorbida la disolución. Dependiendo de la dirección de la fibra en el filtro de papel, a veces la disolución se extiende más rápido en una dirección que en otra, por ello se ponen las marcas en dos direcciones aproximadamente perpendiculares (ver esquema de la figura $5 \mathrm{~d}$ ).

1) N.T: Aproximadamente 3,8 y $6 \mathrm{~cm}$. Ver la sección 9.3.2 sobre variabilidad imputable a carencias técnicas. 


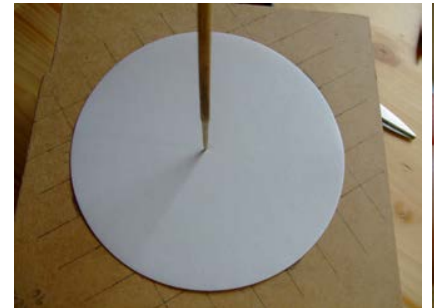

(a) Perforación

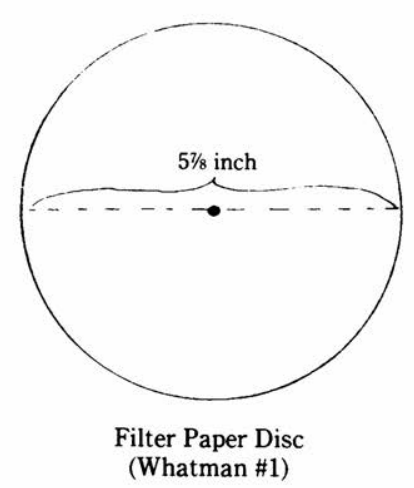

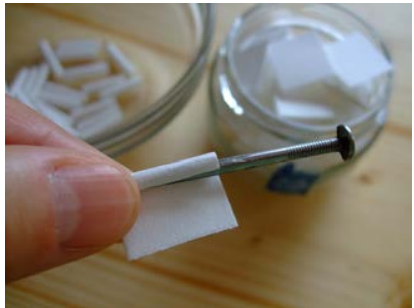

(b) Mecha

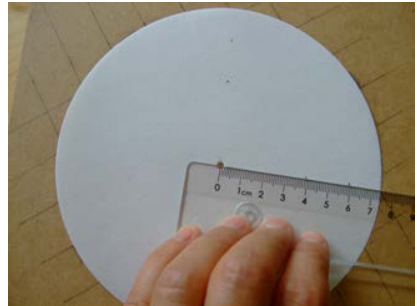

(c) Marcaje

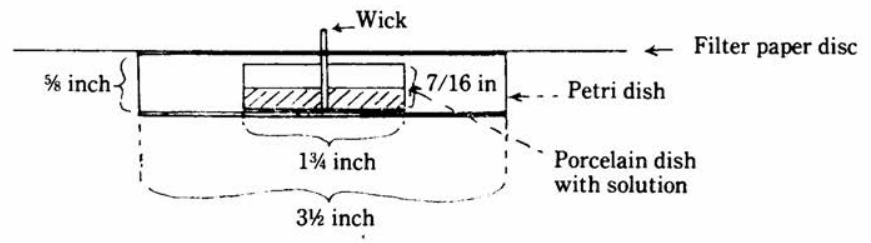

(d) Disposición del Chroma-Test de Pfeiffer (1959)

Figura 5: Preparación de los filtros y disposición del ensayo

d) Tener preparada una disolución al 0,5 \% de Nitrato de Plata, $\mathrm{AgNO}_{3}$, de pureza analítica, en agua destilada. La disolución se ha de conservar en una botella verde o marrón protegida de la luz solar directa (no usar tapón de corcho); puede prepararse una vez por semana. En cualquier caso no debe ser demasiado vieja y no debe tener ningún anillo oscuro ni depósitos.

e) Colocar centrado el disco de papel de filtro con la mecha sobre una placa de Petri de $9 \mathrm{~cm}$ de diámetro; la altura de la placa de Petri es de $1,5 \mathrm{~cm}$. Colocar sobre el centro de la placa de Petri una cápsula de porcelana de $4,5 \mathrm{~cm}$ de diámetro y $1 \mathrm{~cm}$ de profundidad (ver esquema de la figura $5 \mathrm{~d}$ ).

f) Verter 3 a $5 \mathrm{~cm}^{3}$ de la disolución al $0,5 \%$ de $\mathrm{AgNO}_{3}$ en la cápsula de porcelana; retirar el disco de papel antes de verter y volver a colocarlo a continuación. Esta cantidad 
de disolución puede ser usada para preparar tres discos de papel, uno tras otro ${ }^{2}$.

g) La disolución al 0,5\% de $\mathrm{AgNO}_{3}$ se difundirá, por capilaridad, sobre el disco, irradiando en todas direcciones. Cuando alcance la primera marca de lápiz a $1^{1 / 2}$ pulgada, en el esquema de la figura $5 d, a_{1}$ o $a_{2}$, retirar el disco inmediatamente de la placa de Petri y retirar la mecha sin demora, con mucho cuidado para no rasgarlo. A continuación colocar el disco sobre otra placa de Petri para que se seque. Protegerlo de la luz directa y del polvo (no es necesario que esté a oscuras). En cuanto esté seco, colocarlo a oscuras en una caja para conservarlo en una atmósfera seca. Los discos se pueden conservar unas 3-5 horas sin que el $\mathrm{AgNO}_{3}$ reaccione con el papel y produzca decoloraciones. No se debe usar ningún disco que muestre la más ligera decoloración. Por consiguiente, lo mejor es preparar los filtros inmediatamente antes de su uso. Por supuesto, los filtros han de ser manipulados con cuidado; el disco no debe tener ninguna huella táctil ni manchas; estas pueden ser causa de reacciones no deseadas ${ }^{3}$.

2. Procedimiento de ensayo:

Disponer las cápsulas de porcelana y las placas de Petri en una caja (ver párrafo 5. Apparatus). Verter el extracto húmico, o lo que se quiera ensayar, en la cápsula de porcelana. Utilizar $5 \mathrm{ml}$ del extracto a ensayar (ver $\mathrm{n}^{\circ}$ 6). Colocar sobre la disolución el filtro preparado, con una nueva mecha, sostenido por la placa de Petri, de modo que la mecha alcance el fondo de la cápsula de porcelana. Dejar que la disolución se extienda hasta que alcance la primera marca de lápiz a $6 \mathrm{~cm}\left(\mathrm{~b}_{1} \mathrm{o} \mathrm{b}_{2}\right.$ en la figura $\left.5 \mathrm{~d}\right)$. Esto llevará unos 20-60 minutos. No dejar que rebase la marca. Retirar el disco y la mecha y colocarlo de nuevo sobre una placa de Petri para que se seque ${ }^{4}$.

\section{Revelado:}

El revelado del patrón debe tener lugar con luz natural difusa (no luz solar directa).

Para que los resultados sean comparables, el revelado debe hacerse siempre con la misma intensidad luminosa. A no ser que se use luz artificial definida (por ejemplo fluorescentes), se necesita cierta capacidad para juzgar la intensidad de revelado, esto es, para saber cuando evaluar el patrón. Simplemente, no exponer a la luz directa del sol ${ }^{5}$.

\footnotetext{
2 Nota: Ver la sección 9.3.2 sobre variabilidad imputable a carencias técnicas.

3 Idem

4 Idem

5 Idem
} 


\section{Evaluación:}

Conservar los discos en un lugar oscuro (cualquier archivador) y seco. Colocar una hoja de papel entre cada disco para evitar que reaccionen entre si. Los dedos pueden dejar huellas en los discos.

\section{Apparatus:}

El ensayo se realiza dentro de una cámara con la parte superior de vidrio, subdividida en tres secciones móviles, para poder observar el proceso. El tamaño de la cámara es arbitrario. Nosotros usamos una de $91 \mathrm{~cm}$ de largo, $43 \mathrm{~cm}$ de ancho y $10 \mathrm{~cm}$ de alto. Se pueden procesar en ella doce discos. La cámara está pintada con pintura de aluminio ${ }^{6}$. Ha de limpiarse y airearse después de cada uso. No es aconsejable acumular demasiados discos en una cámara; se han de disponer varias cámaras si se quieren hacer más ensayos simultáneos. La atmósfera en la cámara debe ser húmeda, cercana a la saturación o punto de rocío. Por consiguiente, introducimos pocillos con agua destilada repartidos en el interior de la cámara ${ }^{7}$. Este agua se evaporará y mantendrá una humedad constante. La temperatura apenas influye pero debe mantenerse entre 18 y $30^{\circ} \mathrm{C}$.

Material de laboratorio necesario:

- Placas de Petri de $90 \mathrm{~mm}$ de diámetro, $15 \mathrm{~mm}$ de alto

- Cápsulas de porcelana, $40 \mathrm{~mm}$ diámetro, $12 \mathrm{~mm}$ de alto

- Papel de filtro, Whatman $\mathrm{n}^{\circ} 1$ o $\mathrm{n}^{\circ} 4$, circular, $15 \mathrm{~cm}$ de diámetro

- Tubos graduados o marcados a $5 \mathrm{~cm}^{3}$

\section{Estándares para la preparación y extracción de muestras}

En el Biochemical Research Laboratory se han probado muchos métodos de extracción y grados de concentración de las muestras. A continuación solo se informa de los procedimientos que han dado los mejores resultados y que pueden ser comparables con nuestros ensayos y usar nuestro método de interpretación. Hay que tener en cuenta que cualquier cambio en la extracción, o en la concentración, modifica el patrón observable, por lo que los cromatogramas obtenidos con procedimientos de preparación diferentes no pueden ser comparados. En cualquier otro caso,
En la figura 14 en la página 66 se muestra una cámara
El Biochemical Research Laboratory fue fundado por Pfeiffer en 1946 y se cerró en 1975

6 N.T: La pintura de aluminio (aluminium paint) es un material de revestimiento que consta de una base de resina cargada con partículas sólidas de aluminio. Se utiliza para pintar una variedad de materiales, incluyendo metales, madera y mampostería. Este tipo de pintura ofrece muchas ventajas sobre otros tipos de pinturas y recubrimientos. Es de larga duración y resistente, y es uno de los mejores tipos de pintura a utilizar en entornos con aceites, grasas y productos químicos. Este material es altamente resistente a la oxidación y la corrosión (información procedente de http:/ / www.wisegeek.com/what-is-aluminum-paint.htm).

7 N.T: Se utiliza agua caliente para mantener la humedad relativa en torno al $60 \%$ 
Pfeiffer describe además algunos métodos de extracción para varios tipos de alimentos se ha de estandarizar la interpretación. En algunos casos puede ser necesario variar las concentraciones y los tiempos de extracción.

Preparación de extractos de suelos y composts:

Introducir $5 \mathrm{~g}$ de compost o de suelo en un matraz Erlenmeyer de $125 \mathrm{~cm}^{3}$. Añadir $50 \mathrm{~cm}^{3}$ de una disolución al $1 \%$ de hidróxido de sodio (preparada con pelets de hidróxido de sodio). Mezclar bien, haciendo girar el matraz, dejarlo reposar 15 minutos, a continuación volver a mezclar. Transcurrida una hora, mezclar bien una vez más girando el matraz. Dejarlo reposar otras cinco horas más. Tras la sexta hora, verter el líquido cuidadosamente en un vaso de precipitados pequeño. Usar $5 \mathrm{~cm}^{3}$ de este extracto para cada cápsula de porcelana ${ }^{8}$.

\subsubsection{Evaluación de las imágenes según Pfeiffer}

indicaciones preliminares: para aprender a interpretar las imágenes, comenzar con sustancias bien definidas. Progresivamente se tendrá una colección de estándares

consideraciones a tener en cuenta para interpretar los cromatogramas:

NúMERo, anchura y color de las diferentes zonas, así como su formación regular o irregular y matices. En las imágenes reproducidas en la figura 6, se distinguen tres zonas principales: Una zona exterior y una zona media, debidas principalmente al material orgánico ensayado; una zona interior que indica la presencia o ausencia de mineralización. El ancho de las zonas corresponde con la cantidad de sustancias características.

ANILlos formados entre la zona media y la exterior y en el borde de la zona exterior.

COLOR de las zonas: un marrón claro o medio, homogéneamente distribuido, indica una buena formación de humus coloidal; puntos de acumulación marrón oscuros indican sustancias húmicas ácidas; radiaciones violeta indican aumento de la mineralización y disminución de la materia orgánica. En el caso de extractos de plantas, preparaciones de vitaminas y alimentos, se observan otros colores.

RADIACIÓN, número, color y configuración de las formaciones con aspecto de espina. Las radiaciones violeta de la zona central indican otra vez la tendencia mineralizante a la descomposición. Las distintas fases de fermentación (primera, descomposición; segunda, formación de humus; ter-

8 Nota: Ver la sección 9.3.2 sobre variabilidad imputable a carencias técnicas. 
cera, mineralización y gran avance de la descomposición) están claramente indicadas en los cromatogramas de suelos y composts.

INTERPRETACión de LAS imÁgenes de la Figura 6 Pfeiffer muestra algunos ejemplos. Aquí sólo reproducimos parte de la explicación de los dos primeros:

$\mathrm{N}^{\mathrm{o}}$ 1: Un extracto de suelo virgen negro de la región del río Misuri en el Estado de Misuri, ejemplo de suelo rico en humus estable (ver fig. 6, ejemplo número 1), una estructura ideal, friable y de máxima fertilidad. Destaca el tono marrón del borde, con manchas más oscuras, la regularidad de las puntas en la zona media y la armonía de los rasgos radiales. La zona interior es marrón oscuro, sin tonos violeta...

$\mathrm{N}^{\mathrm{o}}$ 2: Como contraste muestra un pesado suelo arcilloso (ver fig. 6, ejemplo número 2), indicando que se empasta y hace costra al secar, y que cuando está húmedo mancha y es pegajoso. Carece de aireación y presenta muchos problemas estructurales. Los análisis químicos son equívocos, ya que este suelo ocluido es más bien infértil. ... La ausencia de compuestos húmicos valiosos se muestra en la falta de forma y en la débil coloración marrón del borde y de la zona media del cromatograma. La zona interior es comparativamente grande y apenas contiene signos de humus. La radiación capilar tiene un tono violeta, indicando la mineralización de este suelo. Su color negro no refleja la presencia de humus estable sino que se debe a la reducción de materia orgánica cruda. Este suelo está bastante muerto.

\subsubsection{Contribuciones posteriores para la interpretación}

Desde el punto de vista de la interpretación de los resultados, Beckman (1993) y (1994), tras analizar los fundamentos teóricos de las técnicas cromatográficas, pone de manifiesto la necesidad de acudir a las nociones de la Antroposofía para poder establecer las bases de la interpretación. En la segunda obra citada presenta un resumen de las nociones utilizadas por diferentes autores para evaluar los resultados del Chroma-Test. En el caso de suelos se aceptan en general las indicaciones originales de Pfeiffer (1959) que fueron completadas en Der Chroma-Boden-Test por Voitl and Guggenberger (1986). Algunas de las indicaciones dadas a Beckman por Georg Wilhelm Schmidt para poder estudiar las fuerzas formativas de las plantas por medio del Chroma-Boden-Test, complementan las indicaciones de Pfeiffer para los suelos y composts:

Las fuerzas formativas se muestran en ritmos y ondulaciones. Las fuerzas minerales se muestran en la aparición de límites abruptos. La actuación de las fuerzas formativas se hará visible desdibujando las formas y construyendo 


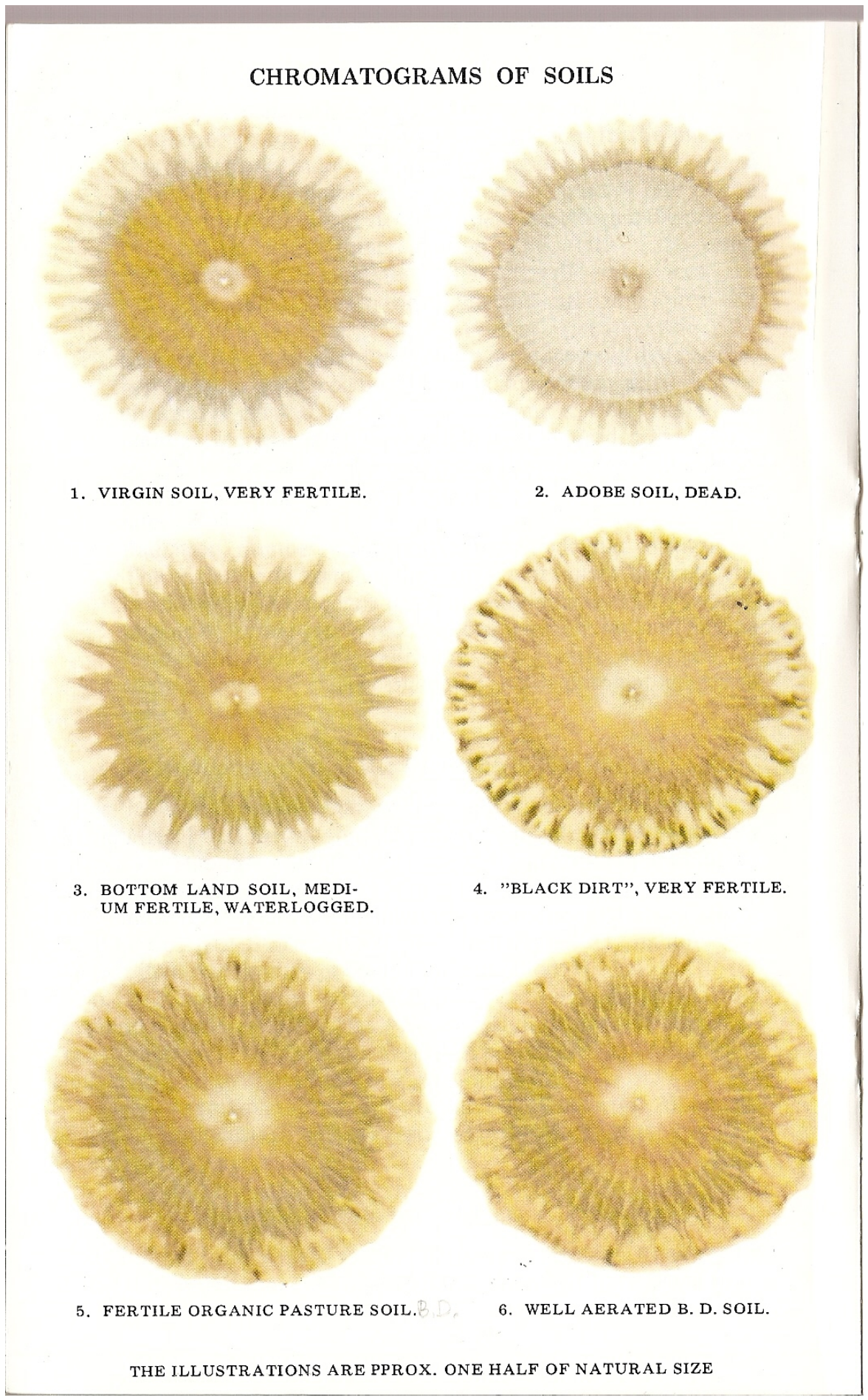

Figura 6: Ejemplos de suelos (Pfeiffer, 1959) 
transiciones. En el dinamograma aparecen límites abruptos en la forma por medio de formaciones anulares bien marcadas o por radiaciones con costillas angulosas. Según Schmidt estas formas indican las fuerzas minerales.

Una condición necesaria es que la muestra, lo físico, esté suficientemente diluido, para que lo formativo pueda actuar. Si la dilución es insuficiente sólo actúa lo físico. Por ello es necesario encontrar la dilución adecuada para cada sustancia investigada.

Cree que será posible encontrar las bases para poder conocer la actividad de las fuerzas formativas por medio del Chroma-Test. Para ello se han de ensayar plantas que crezcan en condiciones extremas. Se pueden elegir extremos asociados a la geografía como por ejemplo plantas que crecen en las montañas y en los llanos o laderas norte y sur de montañas; o situaciones extremas en el tiempo, como la siembra antes de la luna llena o de la luna nueva, o la siembra temprana y la tardía. (Beckman, 1994)

Bangert (1994) investiga hasta qué punto se puede justificar la formación de las imágenes por medio de la adsorción capilar.

Haßold-Piezunka (2003) mide los anchos de las zonas y caracteriza los colores usando una carta de colores Munsell estándar. Su investigación amplía y, en lineas generales, corrobora lo expuesto por Pfeiffer para composts sobre las relaciones entre las distintas sustancias húmicas y las zonas y coloraciones de los cromatogramas.

\subsection{CONTRIBUCIONES POSTERIORES A PFEIFFER}

A continuación indicamos las principales iniciativas para la investigación y difusión del Chroma-Test.

SABARTH Y KOEPF Sabarth y Koepf continuaron las investigaciones de suelos y otras sustancias en el Biodynamic Research Laboratory en Spring Valley, New York, fundado por Pfeiffer. Ver Sabarth (1962), Sabarth (1968) y Koepf (1964).

voitl y GUgGenberger Der Chroma-Boden-Test de Voitl and Guggenberger (1986), escrito a partir de los archivos de Pfeiffer, supone una contribución sustancial en cuanto a la nomenclatura y la interpretación de los resultados, que completa lo que ya había sido publicado en vida por Pfeiffer, recogiendo criterios morfológicos más precisos (ver sección 8.4. I en la página 95) y una "Carta de Chroma Standards", de la que en la figura 7 se reproducen la parte correspondiente a la clasificación de los suelos en tres categorías con fines agrícolas. 


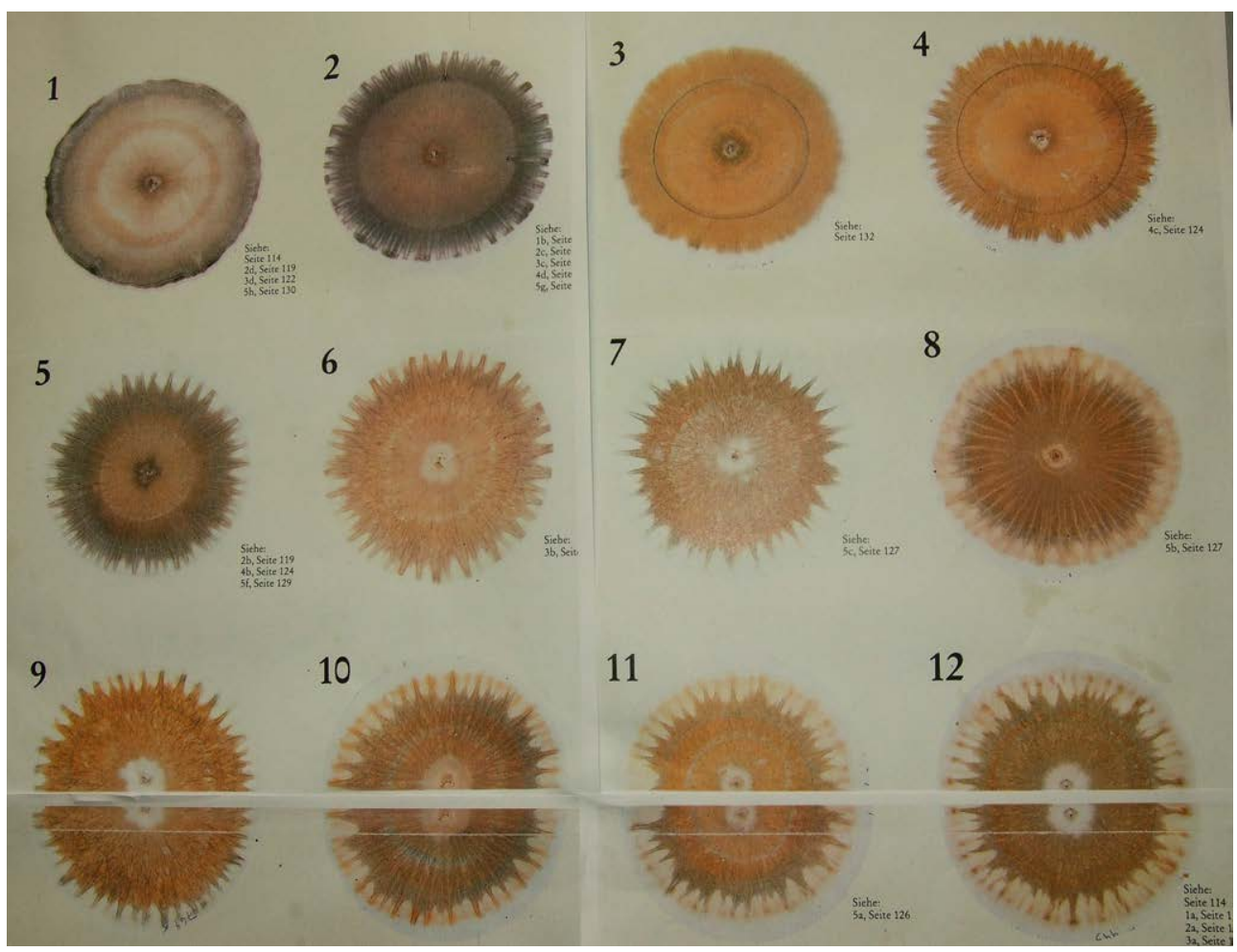

Figura 7: Chroma-Standards de suelos según Voitl y Guggenberger (1986).

BALZER Y GRAF De gran importancia para todos los métodos Generadores de Imágenes son las contribuciones de Fritz Balzer y Ursula Graf (antes Balzer-Graf). Sus experiencias con el Chroma-Test, iniciadas en 1980, dieron las pautas para el ulterior desarrollo de este método. Su contribución se recoge en la sección 4.3.

ZUKUNFTS-INSTITUT En el Zukunfts-Institut se investigó el método Chroma-Test entre 1986 y 1994 (Bechmann, 2011). El Chroma-Test se utilizó en primer lugar para investigar suelos de bosque, posteriormente se adaptó para investigar alimentos (Beckman et al., 1993). Se valoró por su gran utilidad para seguir el proceso de maduración del compost (Beckman and Stölzer, 1994). Como paso previo para estandarizar la interpretación de los cromatogramas mereció especial atención la metodología para interpretar los cromatogramas y el potencial del Chroma-Test como método de medición (Beckman, 1994).

investigaciones aCADÉmicas El Chroma-Test fue objeto de varios proyectos de fin de carrera en diversas universidades de habla alemana en relación con usos del suelo en Agricultura: Niederlechner (1987), Tondl (1989), Saalfeld (1989) y los de Bangert y de la Universidad de Oldenburg bajo la dirección de L. Giani que mencionamos a continuación. 
BANGERT Bangert (1994) revisa detalladamente las contribuciones al desarrollo del método, y hace alusión a las dificultades de valorar la literatura previa por disponer en general a lo sumo de copias en blanco y negro de los resultados y a la dificultad de interpretarlos en base a sus rasgos morfológicos, por la diversidad de criterios en la elección de los mismos usados por los diferentes autores. Precisa que la falta de definición del objeto de investigación dificulta la comprensión y evaluación correcta de los resultados del método. Los términos "valor biológico", "ácidos húmicos" se ponen en relación con los rasgos característicos de los dinamogramas sólo en base a resultados empíricos, sin proporcionar nociones que permitan comprender las relaciones entre "ácidos húmicos" y los rasgos morfológicos del dinamograma. Su investigación se dirige a investigar los fundamentos teóricos del Chroma-Test, su relación con la cromatografía de papel circular, los parámetros de influencia sobre los procedimientos definidos por Pfeiffer y sus modificaciones, y las posibilidades de aplicación del método, en especial para caracterizar el humus. En la sección 4.3 se recoge su contribución al desarrollo del Chroma-Test.

GIANI En la Universität Oldenburg, Alemania se ha investigado el Chroma-Test, según reflejan los proyectos de fin de carrera de Blank (1991) y Kanzler (1991) y la tesis doctoral de Hassold-Piezunka (2003), dirigidos todos por L. Giani. Una síntesis del desarrollo del método y de su estado de caracterización hasta 1994 está recogida en Zu Kenntnisstand und Methodenentwickelungen des Chroma-Boden-Tests de Nikola Haßold (1994). La utilidad del Chroma-Test para valorar la madurez y calidad de composts industriales de desechos orgánicos ha sido investigadas por Haßold (2003), que cita además varios antecedentes en este ámbito de aplicación: Hertelendy (1974), Brinton (1983), Inoko (1979), Jiménez and García (1989). En la sección 4.3 se recoge su contribución al desarrollo del Chroma-Test. 


\subsection{RESUMEN DEL DESARROLLO DEL CHROMA-TEST}

En las subsecciones que siguen se analizan las contribuciones de los dos grupos de investigación principales, vinculados al laboratorio de suelos del Dr. Balzer (subsección 4.3.1), y a la Universidad de Oldenburg (subsección 4.3.2). También se reseña la estandarización del método Wala (subsección 4.3.3)

\subsubsection{Balzer y Graf}

\subsubsection{Fritz Balzer y Ursula Graf}

Ursula Graf (antes Balzer-Graf) y Fritz Balzer inician sus experiencias con el Chroma-Test en 1980. Según Hassold (1994), encuentran correcta la descripción y el reparto de zonas en los cromatogramas descrito por Voitl y Guggenberger (ver sección 8.4.I), pero consideran necesario modificar el método para poder asegurar que los resultados se puedan reproducir. Sus modificaciones se resumen en la tabla 3.

Tabla 3: Modificaciones sugeridas por Balzer y Graf, según Hassold (1994)

MODIFICACIONES DE BALZER

Fijar las condiciones ambientales del experimento dentro de límites estrechos (temperatura, humedad relativa, iluminación)

Uso de volúmenes fijos (Pfeiffer sólo usa las marcas en el filtro para controlar la difusión del reactivo y del analito)

Ensayos con cantidades fijas de cada fracción de humus, además del ensayo con $5 \mathrm{~g}$ de suelo

Acortamiento del tiempo de extracción de 6 horas a temperatura ambiente, hasta 3,5 horas a $28^{\circ}$ Celsius

Centrifugación del extracto en lugar de decantación

Uso de campanas individuales en vez de una cámara aclimatada 


\subsubsection{Bangert}

Bangert (1994) adopta como base de su investigación las modificaciones de Balzer. Sumariza los siguientes antecedentes:

1. Preparación de los filtros

a) Tipo de filtro:

Balzer y Balzer-Graf encuentran experimentalmente que los filtros Whatman 1 y Schleicher \& Schuell 2043 A son equivalentes.

b) Influjo de la iluminación durante y tras la sensibilización de los filtros con $\mathrm{AgNO}_{3}$ :

Hertelendy realiza el proceso de sensibilización y secado de los filtros a oscuras.

Blank y Kanzler usan una lámpara amarilla-verdosa de laboratorio fotográfico, con una densidad luminosa de o,61 lux

c) Cantidad inicial de disolución de $\mathrm{AgNO}_{3}$ :

Balzer y Balzer-Graf reducen el volumen disponible para cada ensayo a o,5 ml. Debido a la creciente escasez de disolución, la velocidad de difusión se va reduciendo al acercarse a la marca a $4 \mathrm{~cm}$, eliminando el riesgo de sobrepasarla.

d) Secado de los filtros:

Balzer y Balzer-Graf establecen experimentalmente en $3 \mathrm{~h}$ el tiempo de secado de los filtros sensibilizados, en condiciones del $60 \%$ de $\mathrm{Hrel}$ y $20^{\circ} \mathrm{C}$.

\section{Extracción}

a) Relación entre cantidad de muestra y cantidad de disolución de $\mathrm{NaOH}$ :

Pfeiffer establece $5 \mathrm{~g}$ de suelo para $50 \mathrm{ml}$ de disolución de $\mathrm{NaOH}$ (1:10)

Balzer y Balzer-Graf ensayan además cantidades estándar de Humus: $200 \mathrm{mg}$, $100 \mathrm{mg}$ y $50 \mathrm{mg}$ de materia orgánica en $50 \mathrm{ml}$ de disolución de $\mathrm{NaOH}$

b) Tiempo de extracción:

Pfeiffer establece 6 horas a una temperatura entre 18 y $24^{\circ} \mathrm{C}$ Balzer y Balzer-Graf reducen el tiempo de extracción a $3^{1 / 2}$ horas, a $28^{\circ} \mathrm{C}$, lo que permite completar el ensayo en una jornada de 8 horas. Comprueban que los resultados son equivalentes.

c) Conservación del extracto:

Blank y Kanzler advierten cambios en 16 horas, por lo que recomiendan limitar el tiempo de conservación del extracto. 
d) Atmósfera durante la extracción:

Blank y Kanzler informan de diferencias halladas entre extractos realizados en envases cerrados y abiertos tras 16 horas de conservación. A $40^{\circ} \mathrm{C}$ aumentan las diferencias.

e) Decantación / Centrifugación:

Por razones de simplicidad, Pfeiffer renunció a la centrifugación considerando suficiente la decantación.

Saalfeld, Blank, Kanzler, Balzer y Graf optan por centrifugar.

3. Ensayo: Difusión del extracto

a) Cantidad inicial de extracto:

Balzer y Balzer-Graf reducen el volumen disponible para cada ensayo a 1,3 ml. Debido a la creciente escasez de disolución, la velocidad de difusión se va reduciendo al acercarse a la marca a $6 \mathrm{~cm}$, eliminando el riesgo de sobrepasarla.

b) Influencia de la iluminación:

Pfeiffer no informa de las condiciones de iluminación del laboratorio.

Hertelendy realiza el proceso sin luz.

Blank y Kanzler usan una lámpara amarilla-verdosa de laboratorio fotográfico, con una densidad luminosa de tan solo o,61 lux.

c) Condiciones de temperatura y humedad relativa:

Tanto Hertelendy como Balzer y Balzer-Graf utilizan campanas individuales para evitar las variaciones de temperatura y humedad relativa en la cámara producidas por las aperturas, que son normalmente necesarias porque los extractos de muestras diferentes se difunden a diferente velocidad. A partir de una humedad inicial del $60 \%$, se constata un aumento de la humedad relativa en el interior de la campana, que depende de la muestra, de hasta el $100 \%$ dentro de la campana de $1,7 \mathrm{l}$, con 1,3 $\mathrm{ml}$ de extracto.

4. Revelado y conservación de los cromatogramas

a) Pfeiffer propone el revelado con luz difusa, indicando que es necesario desarrollar una apreciación del tiempo necesario por medio de la experiencia.

b) Blank y Kanzler revelan las imágenes en 5 días con una densidad de iluminación de 138 lux

c) Balzer y Balzer-Graf mantienen los cromatogramas secos en la oscuridad, y se revelan a oscuras

d) Saalfeld indica que los cromatogramas, iluminados y luego conservados a oscuras, se oscurecen más intensamente 
Las modificaciones de Balzer fueron adoptadas por Bangert e investigadas con los objetivos expuestos en la tabla 4 .

Los ensayos de Bangert con interés para la presente investigación se resumen en la tabla 5 .

En cuanto a la reproducción de los ensayos en días diferentes, Bangert sigue sin obtener resultados satisfactorios, como se puede ver en la figura 9.

Bangert investiga también el efecto de varias concentraciones de nitrato de plata y de hidróxido de sodio. Además investiga el efecto de la cantidad de materia orgánica de suelos y otras sustancias orgánicas. Como muestra de su amplia investigación reproducimos una imagen en la figura 10.

Tabla 4: Objetivos de la investigación de Bangert (1994)

OBJETIVOS DE LA INVESTIGACIÓN DE BANGERT

Problemas para reproducir los ensayos. Investigación de parámetros

Fundamentos teóricos de la formación de las imágenes

Posibilidades de aplicación 


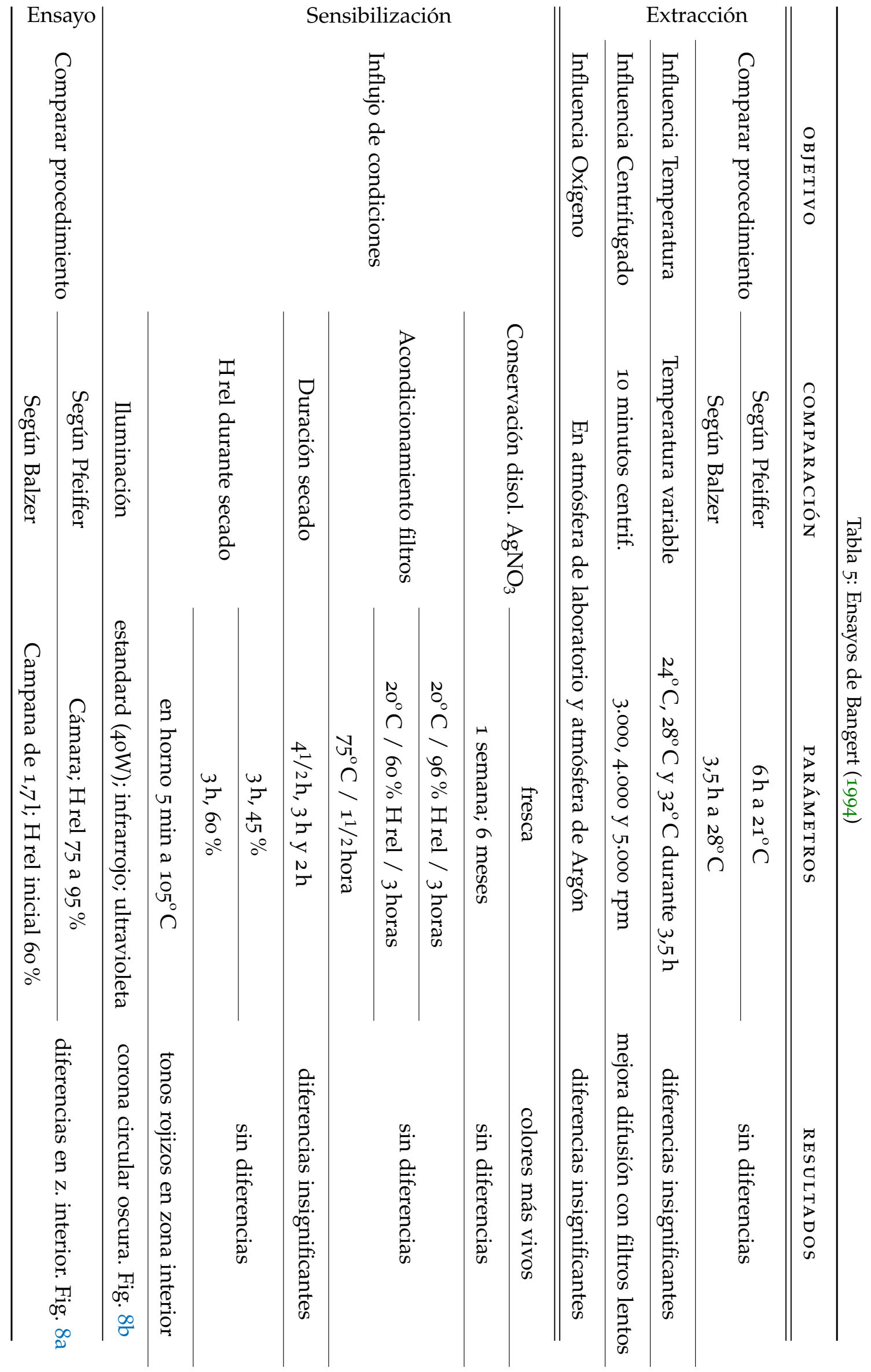




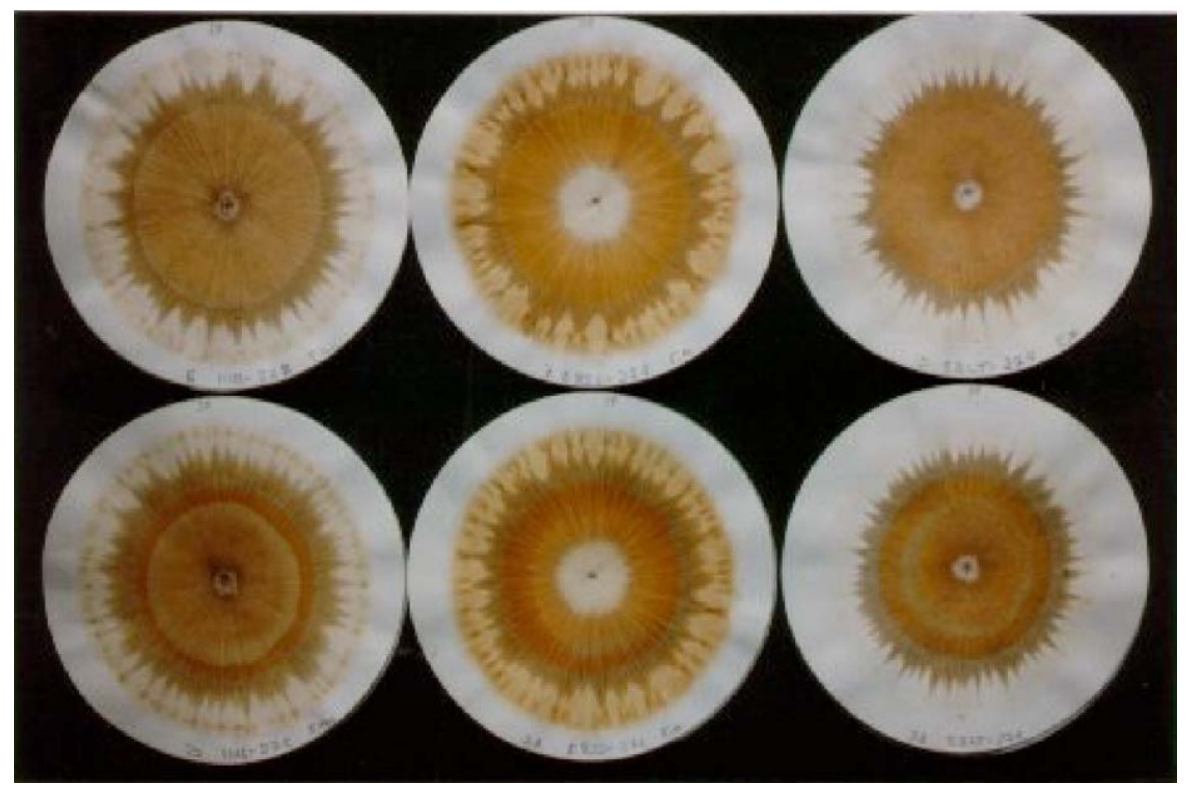

(a) Ensayo en campana y en cámara, según Bangert (1994)

Fila superior: método Balzer, con campana

Fila inferior: método Pfeiffer con cámara

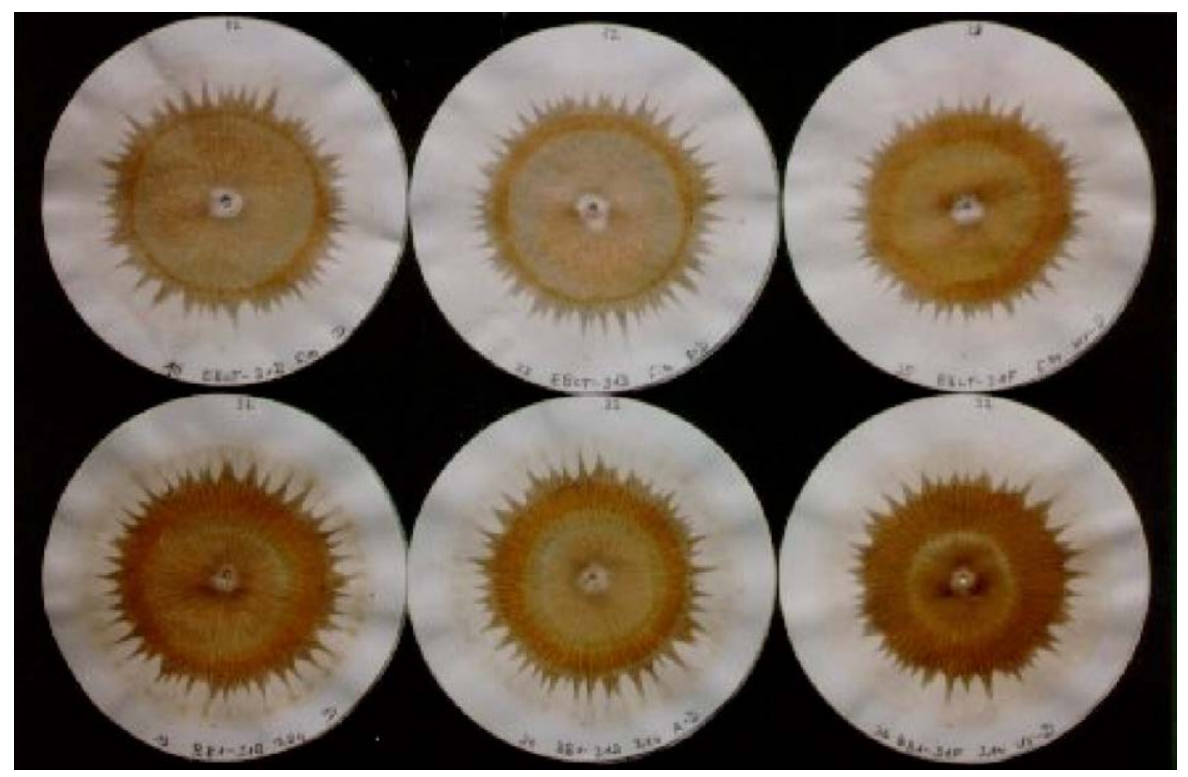

(b) Influjo de la iluminación durante la sensibilización de los filtros, según Bangert (1994). Cada fila corresponde a una muestra diferente.

Izquierda: lámpara estándar (40 W). Centro: lámpara infrarrojo. Derecha: lámpara ultravioleta

Figura 8: Ensayos de Bangert (1994) 

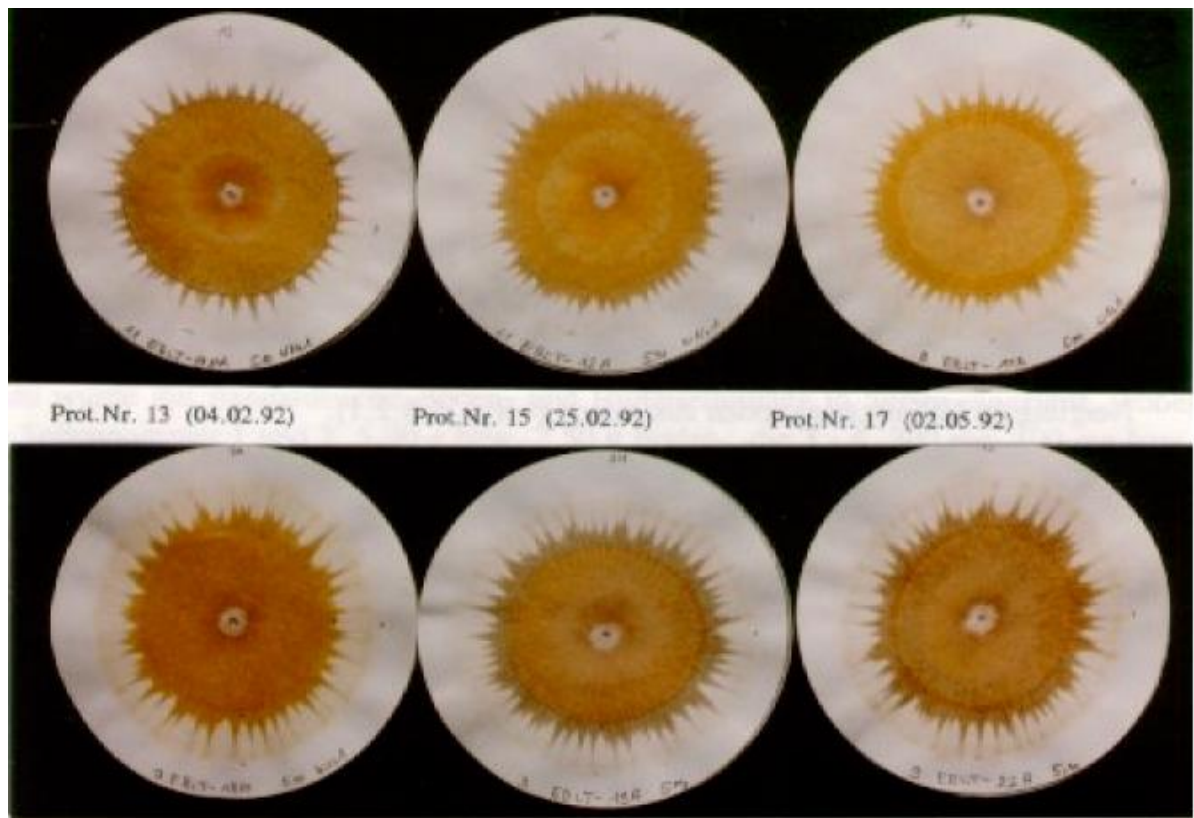

Prot.Ne. 20 (12.07.92)

Prot.Nr. $24(01.11 .92)$

Prot.Nr. 25 (04.11.92)

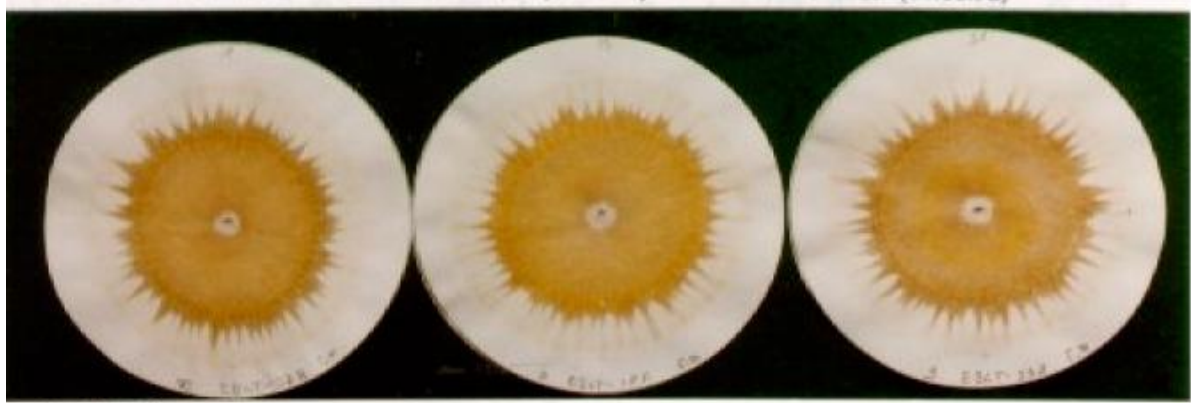

Prat.Nr. 28 (11.11.92)

Prot.N. $29(15.11,92)$

Prot.Nr.31 (10.01.93)

Figura 9: Reproducción del ensayo por Bangert en días diferentes (Bangert, 1994). Todas las imágenes corresponden a la misma muestra 

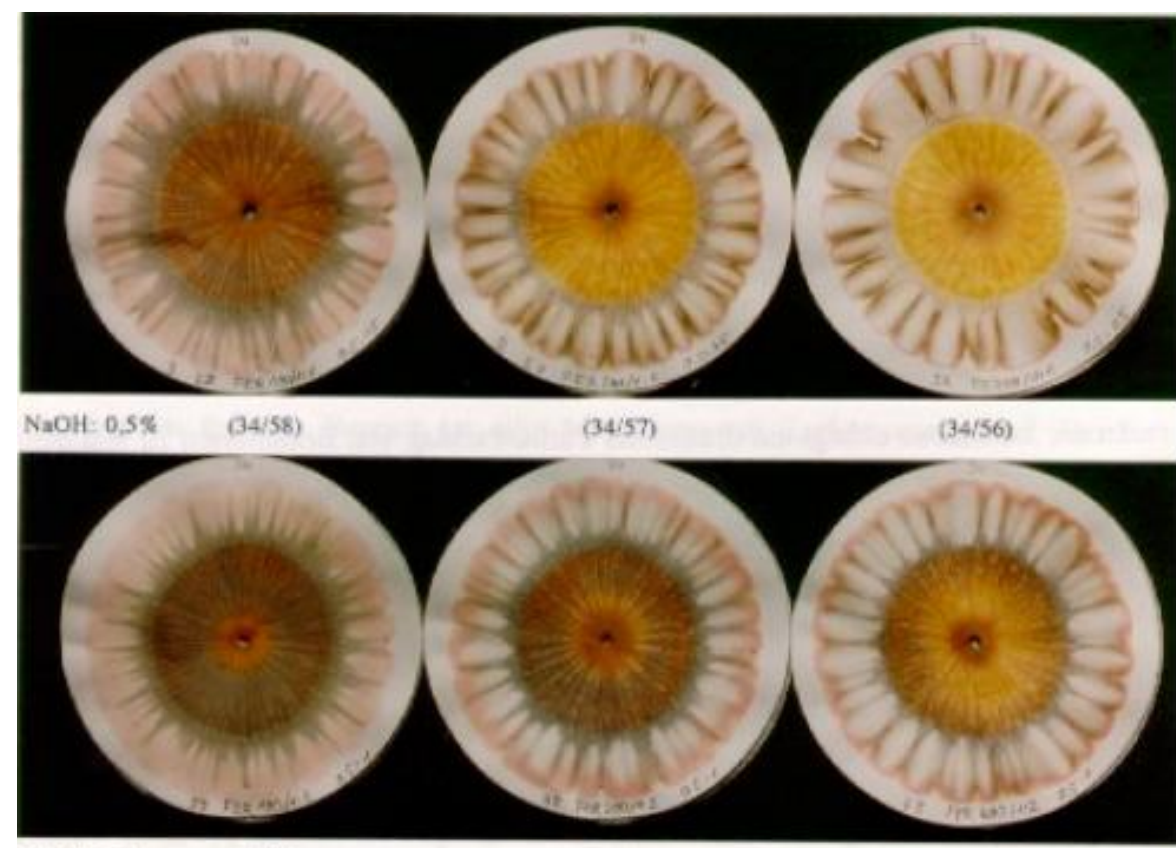

NaOH: $1 \% \quad(34 / 50) \quad(34 / 49) \quad(34 / 48)$
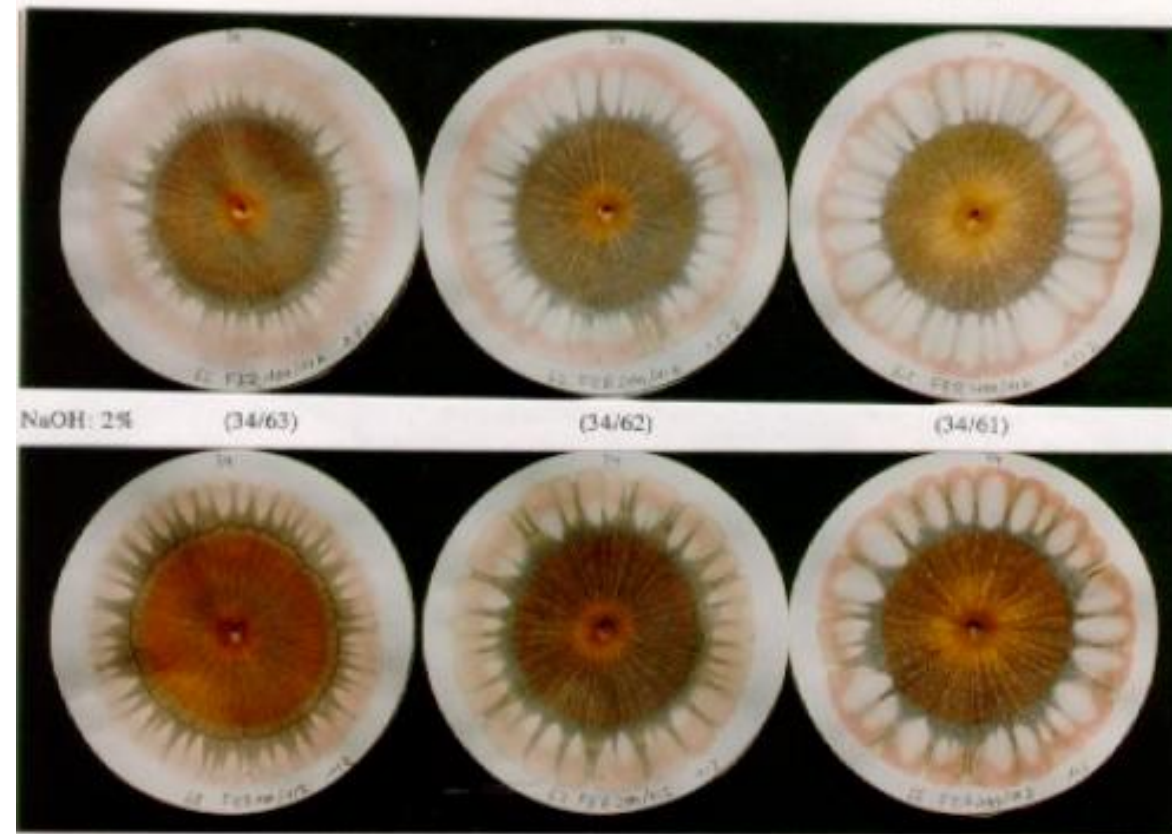

$\mathrm{N} 2 \mathrm{OH}: 2 \%$

(34/68)

(34/67)

$(34 / 66)$

Figura 10: Variación de la concentración de $\mathrm{NaOH}$ y de $\mathrm{AgNO}_{3}$ para distintas cantidades de ácido ferúlico (Bangert, 1994)

Izquierda: $100 \mathrm{mg}$. Centro: $200 \mathrm{mg}$. Derecha: $400 \mathrm{mg}$

$1^{\text {a }}$ fila: $\mathrm{AgNO}_{3}$ al $0,5 \%$ y NaOH al o, $\%$.

$2^{\text {a }}$ fila: $\mathrm{AgNO}_{3}$ al $0,5 \%$ y $\mathrm{NaOH}$ al $1 \%$

3 fila: $\mathrm{AgNO}_{3}$ al $0,5 \%$ y NaOH al $2 \%$

4 fila: $\mathrm{AgNO}_{3}$ al $1 \%$ y NaOH al $2 \%$ 


\subsubsection{Giani}

En la Universidad de Oldenburg, Alemania se ha investigado el Chroma-Test, según reflejan dos proyectos de fin de carrera, de Blank (1991) y Kanzler (1991) y la tesis doctoral de Hassold-Piezunka (2003), dirigidos todos por L. Giani.

\subsubsection{Blank y Kanzler}

Además de su estudio del ensayo y de diversos parámetros y condiciones, son de destacar sus investigaciones pioneras para caracterizar varios tipos de suelos elegidos con criterios edafológicos. En la figura 11 se muestran imágenes de varios tipos de suelo, que muestran características diferenciadas. 

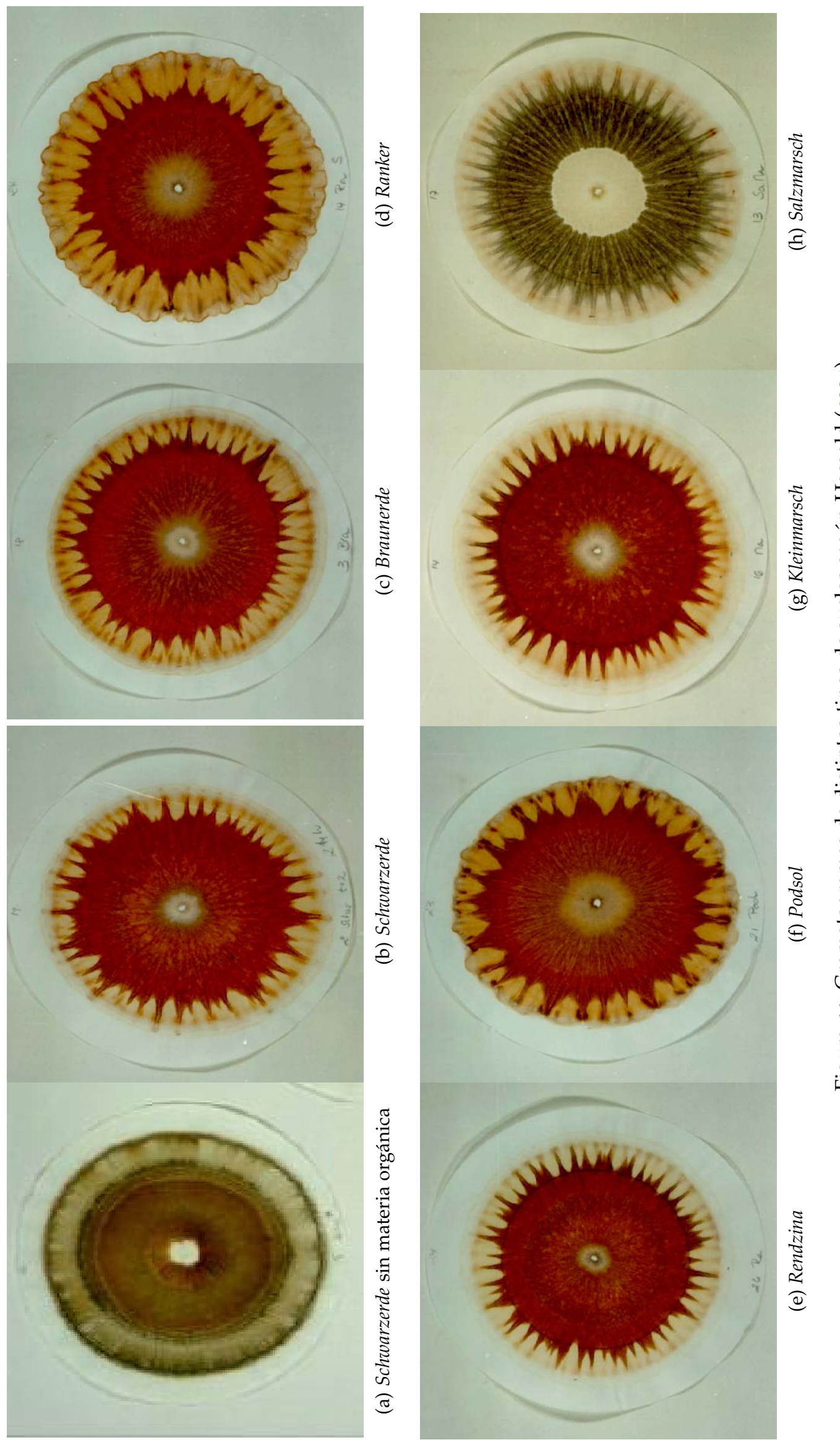


\subsubsection{Haßold-Piezunka}

Haßold, posteriormente Haßold-Piezunka, revisa en 1994 las investigaciones precedentes que estuvieron principalmente orientadas a estandarizar el método de Pfeiffer y resume el estado del desarrollo del Chroma-Test en Zu Kenntnisstand und Methodenentwickelungen des Chroma-Boden-Tests (Haßold, 1994).

En las tablas 6 y 7 se recogen las principales variaciones del método de Pfeiffer utilizadas en el ámbito de suelos y composts.

Haßold adapta algunos parámetros para analizar composts, como el uso de $2,5 \mathrm{~g}$ de la fracción menor de $10 \mathrm{~mm}$, y tras ensayos para evaluar la utilidad de centrifugar, opta por prescindir del centrifugado, por no mejorar sustancialmente la calidad de las imágenes resultantes.

En la figura 12 se recogen ensayos que muestran la influencia de la iluminación durante el proceso de exposición para el revelado de las imágenes, expuestos por Haßold (1994). La luz influye en la coloración y formas de las imágenes. Es necesario por tanto definir condiciones de iluminación homogéneas durante todas las etapas del proceso.

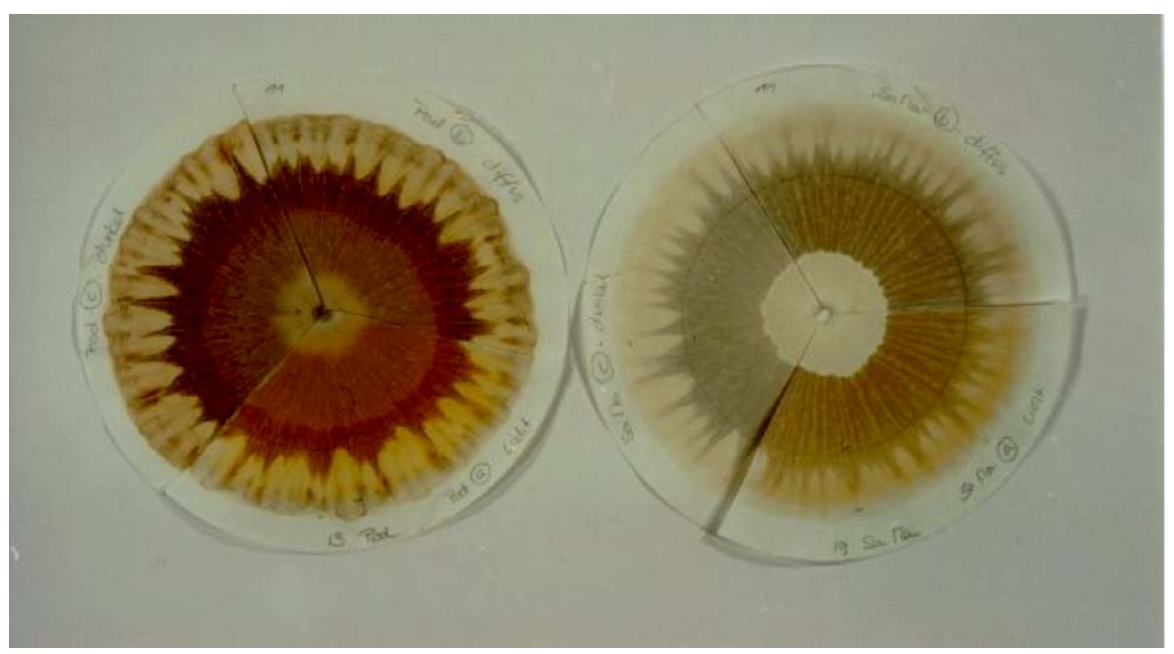

Figura 12: Estado tras 17 semanas en diferentes condiciones de iluminación. Izquierda: Podsol. Dcha: Salzmarsch. De Haßold (1994) Sector izquierdo: en oscuridad Sector derecho superior: bajo luz de día difusa Sector derecho inferior: bajo luz de día directa

Muchas de las investigaciones de las décadas de los ochenta y noventa fueron proyectos de fin de carrera y no tuvieron continuidad. La de Haßold-Piezunka (2003) es la primera y única tesis doctoral sobre el Chroma-Test y lleva el título Eignung des Chroma-Boden-Test zur Bestimmung von Kompostqualitaet und Rottegrad ${ }^{9}$, y fue realizada en la Fakulltät für Mathematik und Naturwissenschaften der Carl-

9 Aptitud del Chroma-Test para determinar la calidad y grado de madurez de composts 
von-Ossietzky Universität ${ }^{10}$. En este trabajo investiga varios composts industriales y compara los resultados obtenidos por diferentes métodos de análisis con los del Chroma-Test. Mide varios parámetros clásicos para caracterizar la calidad y grado de madurez del compost, como relación $\mathrm{C} / \mathrm{N}$, humedad, materia orgánica, $\mathrm{pH}$, capacidad de intercambio catiónico, test de auto calentamiento y nitrógeno mineral. Además caracteriza la materia orgánica mediante análisis del contenidos de sustancias húmicas e investiga, por medio del análisis espectroscópico FT-IR, estructuras moleculares específicas en las sustancias orgánicas. Por último realiza ensayos de emergencia ${ }^{11}$ y crecimiento de semillas en plantas terrestres. La correlación de los resultados analíticos con los diferentes elementos de los cromatogramas (tamaño y color de las zonas y estructuras) dio como resultado que el color de la zona exterior y las formaciones de tipo nube que aparecen en ella son especialmente buenos indicadores de la calidad del proceso de compostaje y del compost final. Otros rasgos como el color de la zona interior o las estructuras radiales confirman el buen compostaje en los cromatogramas que muestran una zona exterior de color claro. Concluye que el Chroma-Test posibilita una valoración rápida de la calidad del proceso de compostaje y de los riesgos de utilización de los composts finales y que el Chroma-Test es una imagen de las sustancias húmicas solubles en medio alcalino.

10 Facultad de Matemáticas y Ciencias Naturales de la Universidad Carl-von-Ossietzky (Oldenburg-Alemania)

11 Ensayos de germinación de semillas. 
Tabla 6: Modificaciones de los procedimientos operativos del Chroma-Test (a partir de Haßold (1994) y (2003))

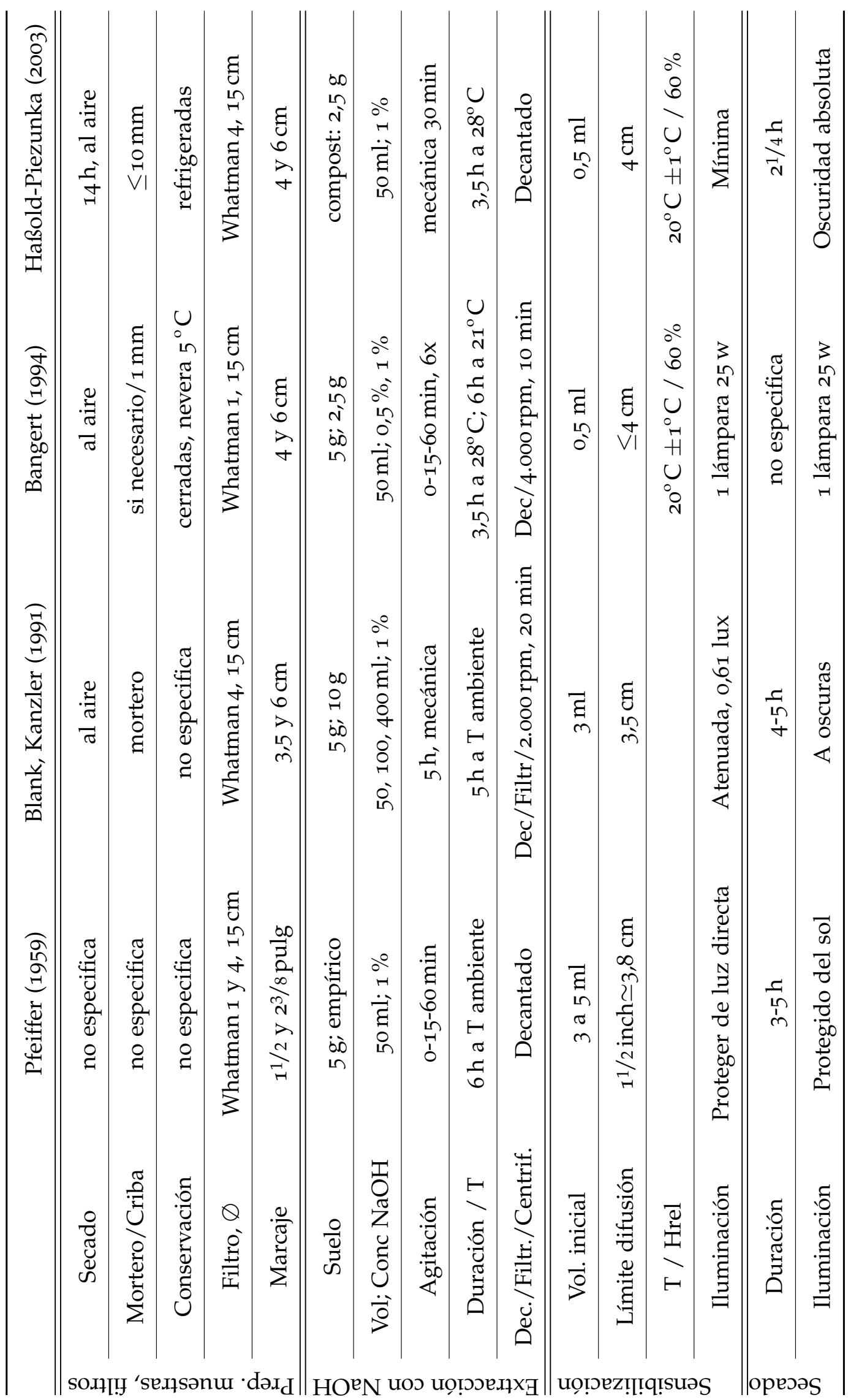


Tabla 7: Modificaciones de los procedimientos operativos del Chroma-Test (a partir de Haßold (1994) y (2003)

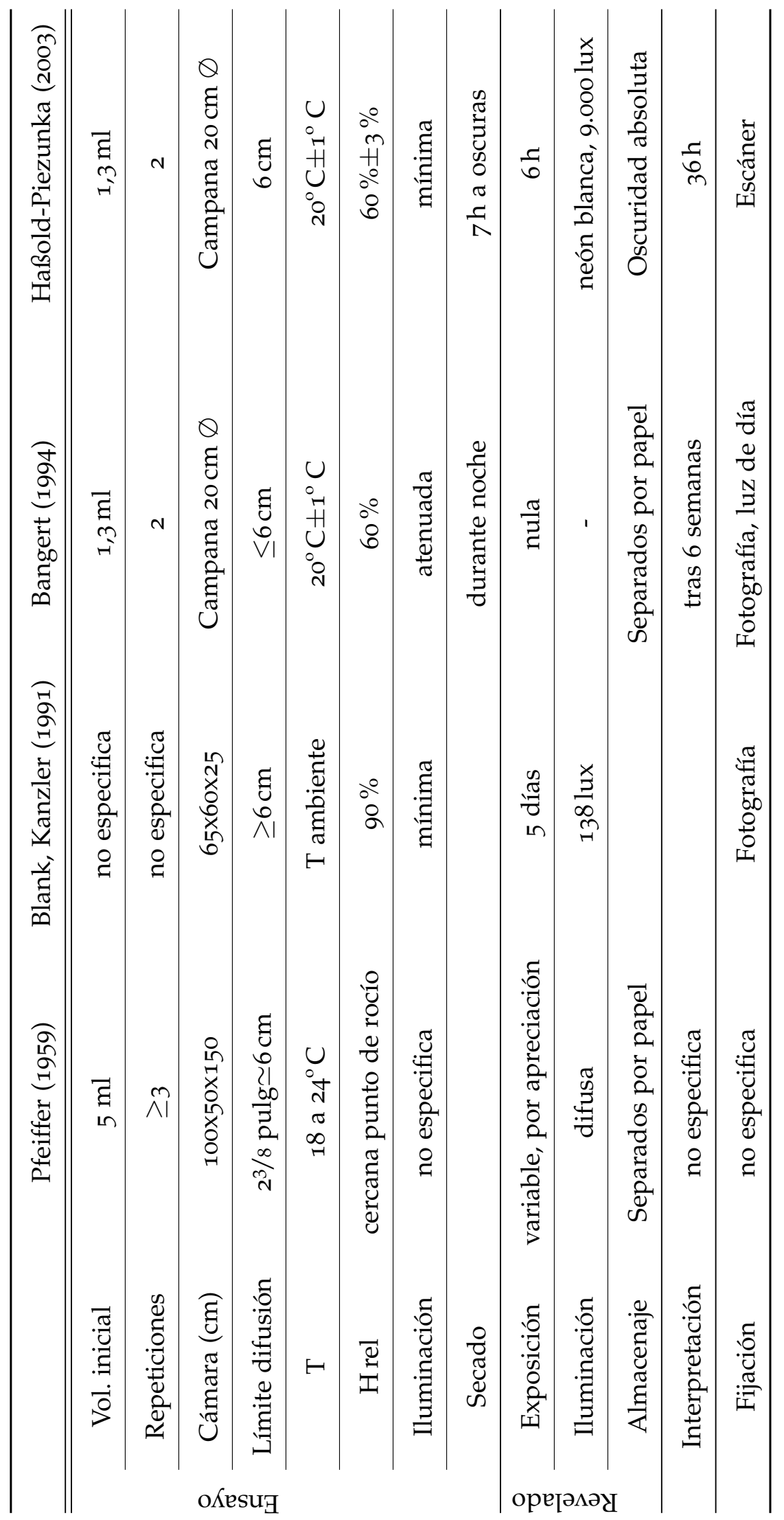




\subsubsection{La estandarización del método Wala}

\subsubsection{Zalecka}

El método de Wala es una variante del método de Dinamolisis Capilar, en muchos aspectos similar al de Pfeiffer, como se muestra en la sección 3.3.1. En la actualidad la investigación más importante de este método ha tenido por finalidad su adaptación a la normativa internacional para poder estandarizarlo y usarlo como instrumento para calificar la calidad de los alimentos. A este fin se dedicó la tesis doctoral de Zalecka (2006) en la Universidad de Kassel, en Alemania.

La experiencia vinculada al desarrollo y validación del método Wala ha sido fundamental para orientar la investigación. La metodología seguida y muchas de las conclusiones obtenidas para su validación son generalizables y aplicables a la variante horizontal de método de Dinamolisis Capilar aquí investigada. Particularmente valioso es el estudio de los factores que influyen en el experimento realizado por Zalecka (2006; 2010).

With the Steigbild technique patterns are produced on thin-layer chromatographic paper and evaluated as a fingerprint of the sample as a whole. To be applied in routine analysis the method has to be standardized according to international standard norms. The operating procedures were documented and a method for the visual evaluation was standardized. Then several factors of influence were tested and the reproducibility was investigated. The method is able to differentiate patterns from samples from different farming treatments and processing steps. Farm pairs of organic and conventional farm management can be distinguished as statistical significant and classified according to the farming system for carrot and wheat samples. This represents a significant step forward beyond the state of the art. (Kahl and Zalecka, 2009) 


\subsection{RESUMEN}

El Chroma-Test de Pfeiffer en su forma original (descrita en la sección 4.1), no asegura resultados reproducibles. Varios investigadores han trabajado en el desarrollo del método y han introducido diversas modificaciones (resumidas en las tablas 3 en la página 44, 6 en la página 56, y 7 en la página 57) que parecen haberles procurado resultados satisfactorios. Pero la efectividad individual de cada medida adoptada no está documentada y algunas de ellas complican considerablemente el procedimiento de ensayo y la preparación de las muestras. Por ello en esta investigación ha sido necesario partir de nuevo de la configuración original del Chroma-Test descrita por Pfeiffer e investigar los parámetros de influencia, para determinar qué modificaciones son realmente necesarias y poder prescindir de las superfluas (capítulo 9 en la página III).

Otro aspecto que presenta dificultades es la interpretación de los resultados cuando sólo se considera la naturaleza física y química del suelo. Por ello, en esta investigación hemos considerado necesario introducir las nociones sobre las fuerzas formativas que permiten ampliar el marco conceptual y adquirir representaciones más amplias de la naturaleza del suelo y de la utilidad de los Métodos de Formación de Imágenes para caracterizarla (ver las hipótesis de trabajo en la sección 2.2 en la página 13 y los antecedentes en el capítulo 3 en la página 19). 



\section{Parte III}

\section{MATERIALES Y MÉTODOS}

En el capítulo 5 se describen las características relevantes de los laboratorios que han tomado parte en la investigación.

En el capítulo 6 se describen las muestras investigadas. En el capítulo 7 se describe el modo de documentar la investigación;

En el capítulo 8 se sintetizan los materiales y métodos utilizados en la validación del método Horizontal de Dinamolisis Capilar. 

En esta investigación han colaborado las siguientes instituciones:

DIRECCIÓN :

- Universidad Politécnica de Madrid, Escuela Técnica Superior de Ingenieros de Minas y Energía de Madrid (ETSIME), España

- Freie Hochschule für Geisteswissenschaft am Goetheanum, Dornach, Suiza

TOMA DE MUESTRAS:

- Escuela Politécnica de Linares (EPS Linares), España

- Universidad Politécnica de Madrid, ETSIME

ENSAYOS FÍSICOS SENCILLOS:

- Marisol Garrido, experta en Agricultura Ecológica y responsable de la Oficina de Certificación Demeter- España, marchamo de calidad de la Agricultura Biodinámica.

ENSAYOS COLABORATIVOS:

- Universidad Politécnica de Madrid, ETSIME, España

- Granja Andreashof, Uberlingen, Alemania

- Ita Wegman Klinik, Arlesheim, Suiza

\subsection{EQUIPAMIENTO Y REACTIVOS}

El equipamiento necesario para realizar los ensayos de Dinamolisis Capilar es muy simple. Aparte del equipamiento habitual para la

- Preparación de las muestras (secado y criba a 2 mm),

- Disolución de los reactivos y

- Limpieza de los materiales,

se requiere el siguiente equipamiento

- Cámara aclimatada para poder mantener una elevada humedad relativa 


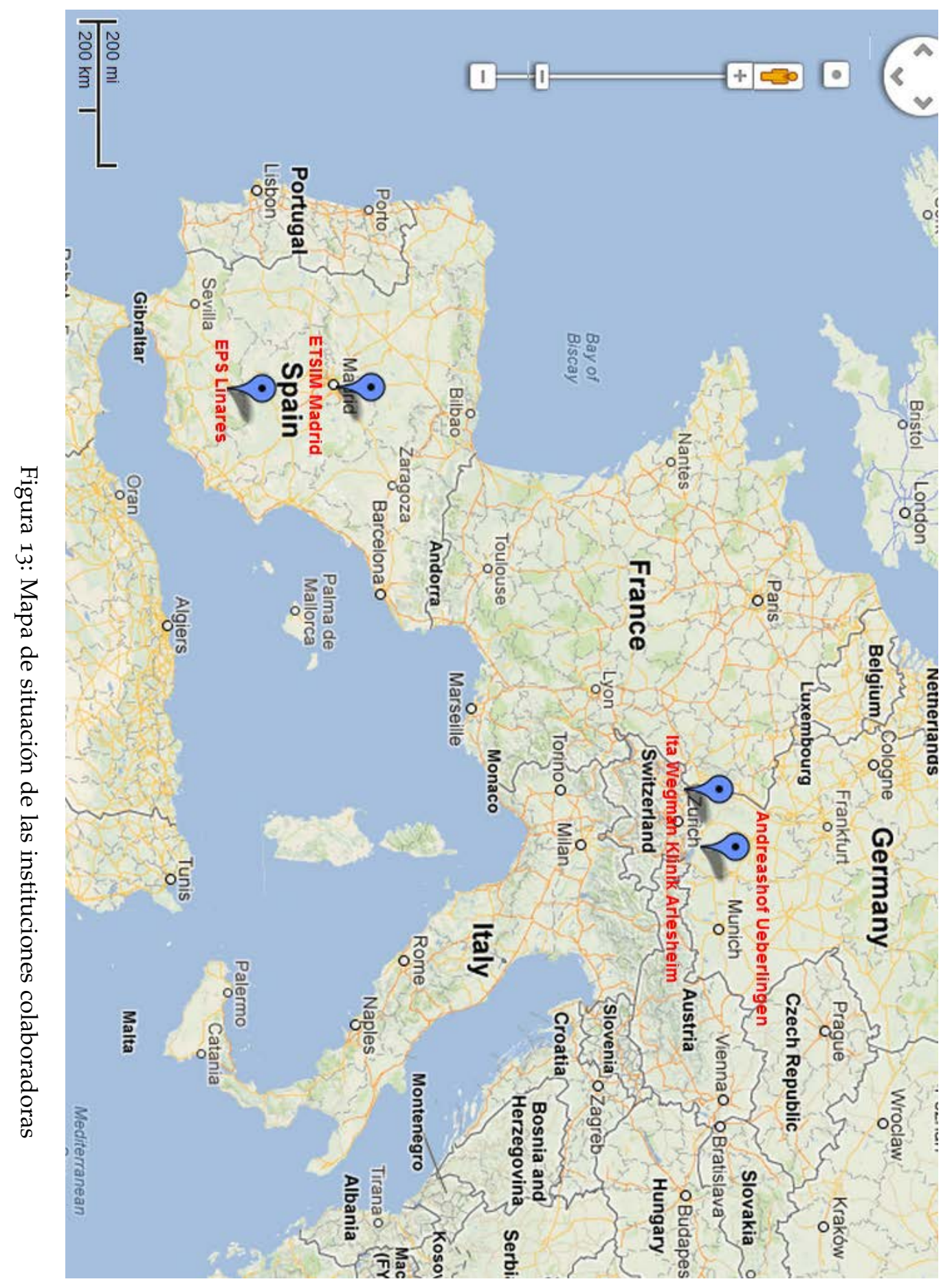


- Escáner y sistema de almacenamiento digital para "fijar" los dinamogramas. Ver detalles en la sección 7.2 en la página 87 .

y se han utilizado los siguientes materiales

- Matraces Erlenmeyer de $125 \mathrm{ml}$.

- Vasos de precipitados de $50 \mathrm{ml}$

- Vidrios de reloj de unos $5 \mathrm{~cm}$ de diámetro.

- Petris de $12 \mathrm{~cm}$ de diámetro, en los que quepan bien los vidrios de reloj. Pueden ser de plástico.

- Filtros Whatman 4 y ANOIA 1249 circulares de $15 \mathrm{~cm}$ de diámetro. Las especificaciones de los filtros se encuentran en el apéndice A en la página 203.

- Pipetas automáticas de tipo Eppendorf.

- Fundas de plástico para conservar las imágenes originales.

- Archivo de las imágenes a oscuras

REACTIVOS UTILIZADOS:

1. Agua destilada

2. $\mathrm{NaOH}$ en pelets o lentejas p.a.

3. Las sales metálicas utilizadas se recogen en la tabla 8 .

Las especificaciones de los reactivos se encuentran en el apéndice B en la página 209 . 
Tabla 8: Sales metálicas utilizadas en la ETSIME

\begin{tabular}{cccc}
\hline Fórmula & Denominación & Laboratorio & Referencia \\
\hline \hline $\mathrm{AgNO}_{3}$ & Silver Nitrate & $\begin{array}{c}\text { Sigma } \\
\text { Aldrich }\end{array}$ & 209139-25G \\
\hline $\mathrm{HAuCl}_{4}-{ }_{3} \mathrm{H}_{2} \mathrm{O}$ & $\begin{array}{c}\text { Gold (III) Chloride } \\
\text { trihydrate }\end{array}$ & $\begin{array}{c}\text { Sigma } \\
\text { Aldrich }\end{array}$ & 520918-1G \\
\hline $\mathrm{CuSO}_{4}-{ }_{5} \mathrm{H}_{2} \mathrm{O}$ & $\begin{array}{c}\text { Copper (II) Sulfate } \\
\text { pentahydrate }\end{array}$ & Merck & 1.02790.0250 \\
\hline $\mathrm{FeSO}_{4}-7 \mathrm{H}_{2} \mathrm{O}$ & $\begin{array}{c}\text { Iron (II) Sulfate } \\
\text { heptahydrate }\end{array}$ & Merck & 1.03965 .0100 \\
\hline $\mathrm{HgCl}_{2}$ & $\begin{array}{c}\text { Mercury (II) } \\
\text { Chloride }\end{array}$ & Merck & 1.04419 .0050 \\
\hline $\mathrm{SnCl}_{2}-2 \mathrm{H}_{2} \mathrm{O}$ & $\begin{array}{c}\text { Tin (II) Chloride } \\
\text { dihydrate }\end{array}$ & Merck & 1.07815 .0100 \\
\hline${\mathrm{Pb}\left(\mathrm{NO}_{3}\right)_{2}}_{4}^{\text {Lead (II) Nitrate }}$ & Merck & 1.07398 .0100 \\
\hline
\end{tabular}

\subsection{LABORATORIO DE LA GRANJA ANDREASHOF EN ÜBERLIN-} GEN, ALEMANIA

Durante el periodo de aprendizaje del Chroma-Test en 2011 se realizaron ensayos en la granja Andreashof con diversos tipos de suelos y composts. También se realizaron ensayos con plantas.

El equipamiento del laboratorio es muy simple, muy fiel al descrito por Pfeiffer (1959).
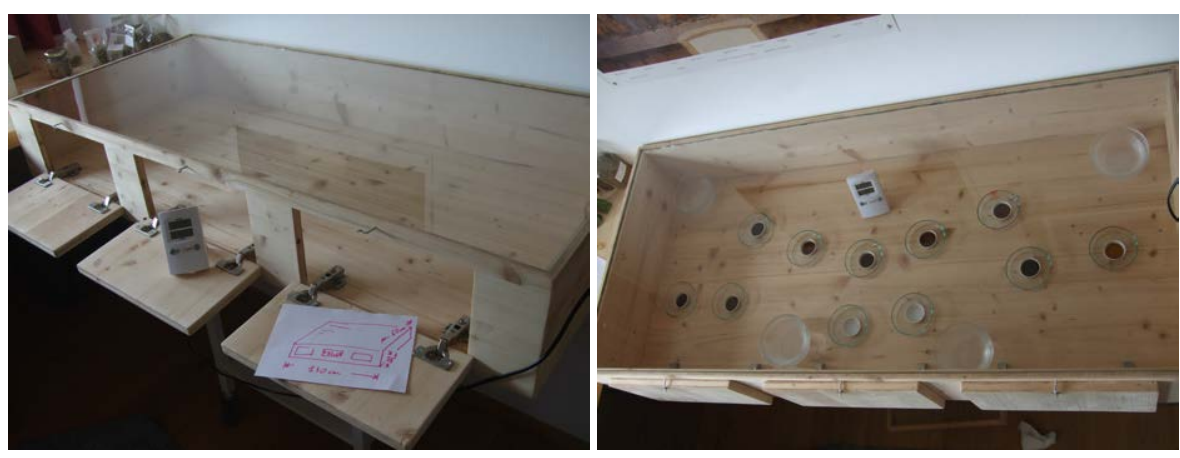

Figura 14: Cámara aclimatada de Andreashof 


\subsubsection{Equipamiento}

- Para el secado de las muestras dispone de estufas calentadas mediante un circuito de agua, especialmente diseñadas para el secado de plantas.

- Cámara aclimatada: En Andreashof se utiliza una caja de madera de $130 \mathrm{~cm}$ de ancho, $60 \mathrm{~cm}$ de profundidad y $20 \mathrm{~cm}$ de altura, con cubierta de vidrio y acceso frontal, que se puede ver en la figura 14. La humedad se mantiene por medio de recipientes con agua caliente.

\subsubsection{Métodos}

Se utiliza el método original de Pfeiffer (1959), descrito en la sección 4.1 en la página 34 .

\subsection{LABORATORIO DE LA ESCUELA TÉCNICA SUPERIOR DE INGE- NIEROS DE MINAS Y ENERGÍA DE MADRID, ESPAÑA}

Durante 2011 y 2012 se realizaron ensayos principalmente de suelos, y en menor medida, de composts. En los ensayos ciegos colaboraron Elena Sil y Emilio García como operadores.

\subsubsection{Equipamiento}

- Para el secado de las muestras dispone de una estufa eléctrica.

- Como cámara aclimatada se adaptó una vitrina de gases, aislando sus paredes con paneles de corcho blanco. Para mantener la humedad relativa en torno al 6o \% se utilizó un humificador de ultrasonidos de la marca ORBEGOzo.

- Dispone de sistema de destilación de agua y de sistema de desionización de agua MILLI Q

\subsubsection{Métodos}

Durante 2012 se realizaron ensayos siguiendo primero el método original de Pfeiffer (1959), descrito en la sección 4.1 en la página 34. Posteriormente se fueron adoptando las modificaciones indicadas en cada caso. Para los ensayos ciegos se adoptaron las modificaciones indicadas en la sección 8.3 en la página 93 . 
5.4 LABORATORIO DE PLANTAS DE LA ITA WEGMAN KLINIK, ARLESHEIM, SUIZA

Se trata de un pequeño laboratorio en el que actualmente se realizan ensayos de preparados de plantas por el método de Dinamolisis Capilar de Wala. Ha colaborado en los ensayos ciegos.

\subsubsection{Equipamiento}

Para mantener en todo el laboratorio la humedad relativa en torno al $60 \%$ se utiliza un humificador.

\subsubsection{Métodos}

Se ha utilizado el método de Pfeiffer (1959) con las modificaciones para los ensayos ciegos indicadas en la sección 8.3 en la página 93. 


\subsection{TOMA Y PREPARACIÓN DE MUESTRAS}

- La toma de muestras se ha realizado de forma selectiva y puntual sobre los $20 \mathrm{~cm}$ más superficiales del suelo, con ayuda de azada o de pala.

- El secado se ha realizado en estufa a menos de $50^{\circ} \mathrm{C}$, excepto en la tercera campaña de Linares, que se hizo al aire ${ }^{1}$, sobre papel secante.

- Se desmenuzan los agregados a mano, ayudándose con un rulo de madera.

- Se homogeneiza y cuartea hasta tener la cantidad deseada. Para el Chroma-Test se precisan 5 g. Para poder realizar todos los ensayos físicos seleccionados se recomienda tomar muestras de unos $500 \mathrm{~g}$.

- Se criba. La fracción utilizada es la menor de 1 mm, excepto en la tercera campaña de Linares, que se cribó a $2 \mathrm{~mm}$.

- Las muestras se han conservado en viales de vidrio o en bolsas de plástico.

En la tabla que sigue se resumen los datos relevantes en cuanto a la toma y la preparación de las muestras utilizadas para los ensayos de Dinamolisis Capilar.

Para la primera campaña se utilizó el procedimiento descrito por Voitl and Guggenberger (1986) que se atribuye a Pfeiffer. Indica que se muelan las muestras en mortero de porcelana. Tras los ensayos preliminares se decidió no moler las muestras, por no haber detectado ninguna ventaja y para posibilitar así la simplificación del proceso de preparación. También se comprobó la escasa influencia del cribado.

El Chroma-Test sólo requiere $5 \mathrm{~g}$ de muestra. Para realizar los ensayos de estabilidad del suelo descritos en la sección 8.5 se reservaron 3 ó 4 terrones de más de $1 \mathrm{~cm}^{3}$. Para el resto de ensayos físicos sencillos se tomaron muestras de aproximadamente $500 \mathrm{~g}$.

1 Siguiendo el método oficial de análisis de suelos del Ministerio de Agricultura (1976). 
Tabla 9: Toma y preparación de muestras

\begin{tabular}{|c|c|c|c|c|}
\hline & TOMA & PREPARACIÓN & SECADO & CRIBA \\
\hline $\begin{array}{l}1^{\text {a }} \text { Campaña } \\
\text { Linares }\end{array}$ & $30 / 03 / 2011$ & $31 / 03 / 2011$ & Estufa $<50^{\circ} \mathrm{C}$ & $<1 \mathrm{~mm}$ \\
\hline $\begin{array}{l}2^{\mathrm{a}} \text { Campaña } \\
\text { Linares }\end{array}$ & $04 / 05 / 2011$ & $4-6 / 5 / 2011$ & Estufa $<50^{\circ} \mathrm{C}$ & $<1 \mathrm{~mm}$ \\
\hline Biodinámicos & $12 / 09 / 2011$ & $15 / 09 / 2011$ & Estufa $<50^{\circ} \mathrm{C}$ & $<1 \mathrm{~mm}$ \\
\hline $\begin{array}{c}3^{\text {a }} \text { Campaña } \\
\text { Linares }\end{array}$ & $07 / 05 / 2012$ & $18 / 05 / 2012$ & $\mathrm{Al}$ aire 9 días & $<2 \mathrm{~mm}$ \\
\hline
\end{tabular}

\subsection{DESCRIPCión DE LAS MUESTRAS}

\subsubsection{Muestras de agricultura Biodinámica}

Con el fin de disponer de referentes de suelos sanos y de composts, se tomaron muestras en dos granjas que utilizan el método de Agricultura Biodinámica. La finca Rio Pradillo se encuentra en Camorritos, Cercedilla, Madrid. La huerta de la Casa San Martín se encuentra en Cañicosa, Matabuena, Segovia.

Tabla 10: Muestras de agricultura Biodinámica

\begin{tabular}{|c|c|c|}
\hline IDENTIFICACIÓN & LUGAR & DESCRIPCIÓN \\
\hline Cam. huerto & $\begin{array}{c}\text { Finca Río Pradillo, } \\
\text { Camorritos }\end{array}$ & $\begin{array}{l}\text { Suelo sobre } \\
\text { granito }\end{array}$ \\
\hline Compost 1 año Cam & $\begin{array}{c}\text { Finca Río Pradillo, } \\
\text { Camorritos }\end{array}$ & $\begin{array}{c}\text { Estiércol de } \\
\text { vaca }\end{array}$ \\
\hline Cañ. huerto casa & $\begin{array}{c}\text { Casa San Martín, } \\
\text { Cañicosa }\end{array}$ & $\begin{array}{c}\text { Suelo sobre } \\
\text { granito }\end{array}$ \\
\hline Cañ. huerto-humus & $\begin{array}{c}\text { Casa San Martín, } \\
\text { Cañicosa }\end{array}$ & $\begin{array}{l}\text { Suelo sobre } \\
\text { granito }\end{array}$ \\
\hline
\end{tabular}




\subsubsection{Primera campaña de Linares}

Se trata de un pequeño itinerario transversal al filón de Arrayanes, cerca de la antigua Fundición La Cruz, en la zona más afectada por la actividad minero metalúrgica. Ver el mapa de situación de la figura 16 en la página 76 y las imágenes de satélite de las páginas siguientes, en las que se puede observar la localización exacta de las muestras. Todas las muestras se tomaron en olivar, excepto la $3 b$.

Tabla 11: Muestras Linares I. Primera campaña

\begin{tabular}{ccc}
\hline ID & LUGAR & DESCRIPCIÓN \\
\hline \hline I & F. La Cruz & $\begin{array}{c}\text { Olivar en Triásico. Sobre filón de } \\
\text { Arrayanes }\end{array}$ \\
\hline 2 & F. La Cruz & $\begin{array}{c}\text { Olivar en Triásico. Sobre filón de } \\
\text { Arrayanes }\end{array}$ \\
\hline 3 & F. La Cruz & Olivar en Triásico. Sobre filón de \\
& & Arrayanes \\
\hline 3 B & F. La Cruz & Balsa de lodos de flotación \\
\hline 4 & F. La Cruz & Olivar en Triásico. Sobre filón de \\
& & Arrayanes \\
\hline
\end{tabular}




\subsubsection{Segunda y tercera campañas de Linares}

Ver el mapa de situación, figura 16 en la página 76. En las imágenes de satélite de las páginas que siguen, se puede observar la localización exacta de las muestras, en rojo las de la segunda campaña y en verde las de la tercera.

En las tablas 12 y 13 se describen las muestras. El sustrato geológico de las muestras de la tercera campaña es el mismo que el de las correspondientes de la segunda campaña.

Los primeros dígitos del identificador de la muestra, bajo el encabezado [ID], se corresponden con el número de la cuadrícula usada por J. Martínez López (2007) que se reproduce en la figura $15 \mathrm{~b}$ en la página 75. Los dígitos tras el guión identifican las muestras de la tercera campaña tomadas en la correspondiente cuadrícula.

Tabla 12: Muestras Segunda Campaña: Linares II

\begin{tabular}{ccc}
\hline ID & LUGAR & DESCRIPCIÓN \\
\hline \hline 12 & La Garza & $\begin{array}{c}\text { Olivar en coluvión granítico. Empastado tras } \\
\text { lluvia. Lavadero Mina S. Ignacio }\end{array}$ \\
\hline 22 & Pozo Chabes & Monte bajo de retama. Sobre granito \\
\hline 59 & Mina Esmeralda & Dehesa sobre Triásico \\
\hline 61 & Cañada Incosa & Dehesa sobre granito \\
\hline 67 & Polvorín & Olivar en Triásico. Manejo ecológico \\
\hline 69 & Autovía & Olivar en Triásico. Terrazas. \\
\hline 91 & La Tortilla & Olivar en Triásico junto Torre de Perdigones \\
\hline 93 & Linares & Pradera. Sobre Triásico \\
\hline 110 & Linares & Olivar en Mioceno. Empastado tras lluvia. No \\
& & afectado por minería \\
\hline
\end{tabular}


Tabla 13: Muestras Tercera Campaña: Linares III

\begin{tabular}{ccc}
\hline ID & LUGAR & DESCRIPCIón \\
\hline \hline 12-1 & La Garza & Como 12, bajo lavadero Mina S. Ignacio \\
\hline $12-2$ & La Garza & Encinillas \\
\hline $61-1$ & Cañada Incosa & Como 61, al borde de la carretera \\
\hline $61-2$ & Cañada Incosa & Encinas \\
\hline $67-1$ & Polvorín & Como 67, olivar \\
\hline $67-2$ & Polvorín & Eucaliptos \\
\hline $69-1$ & Autovía & Como 69, en olivar \\
\hline $69-2$ & Autovía & Retama \\
\hline $91-1$ & La Tortilla & Olivar contiguo al de 91 \\
\hline $91-2$ & La Tortilla & Olivar contiguo al de 91 \\
\hline $91-3$ & La Tortilla & Como 91 \\
\hline $93-1$ & Linares & Como 93, prado \\
\hline $93-2$ & Linares & Como 93, prado \\
\hline $93-3$ & Linares & Como 93, prado \\
\hline
\end{tabular}




\subsection{SELECCIÓN DE MUESTRAS PARA ANÁlisis QUímicos}

Se realizaron análisis químicos de las muestras de la segunda campaña de Linares y de la muestra de suelo cultivado por el método biodinámico que aparecen en la tabla 14. Las dos primeras no están afectadas por ningún tipo de actividad minera. Las del grupo 2/3, están afectadas por la minería y las del grupo 1/3 están afectadas más severamente por la mineralurgia y/o metalurgia asociadas al antiguo beneficio del mineral de plomo.

Tabla 14: Muestras para análisis químico

\begin{tabular}{|c|c|c|c|}
\hline ID & GRUPO & LUGAR & DESCRIPCIÓN \\
\hline CAMORRITOS & & Cercedilla & Huerta sobre granito \\
\hline 69 & $3 / 3$ & Autovía & Olivar sobre Triásico \\
\hline 67 & \multirow{3}{*}{$2 / 3$} & Polvorín & Olivar sobre Triásico \\
\hline 93 & & Linares & Pradera sobre Triásico \\
\hline 61 & & Cañada Incosa & Dehesa sobre granito \\
\hline 91 & \multirow{2}{*}{$1 / 3$} & La Tortilla & Olivar sobre Triásico \\
\hline 12 & & La Garza & Olivar sobre granito \\
\hline
\end{tabular}




\subsection{SITUACIÓN DE LAS MUESTRAS}

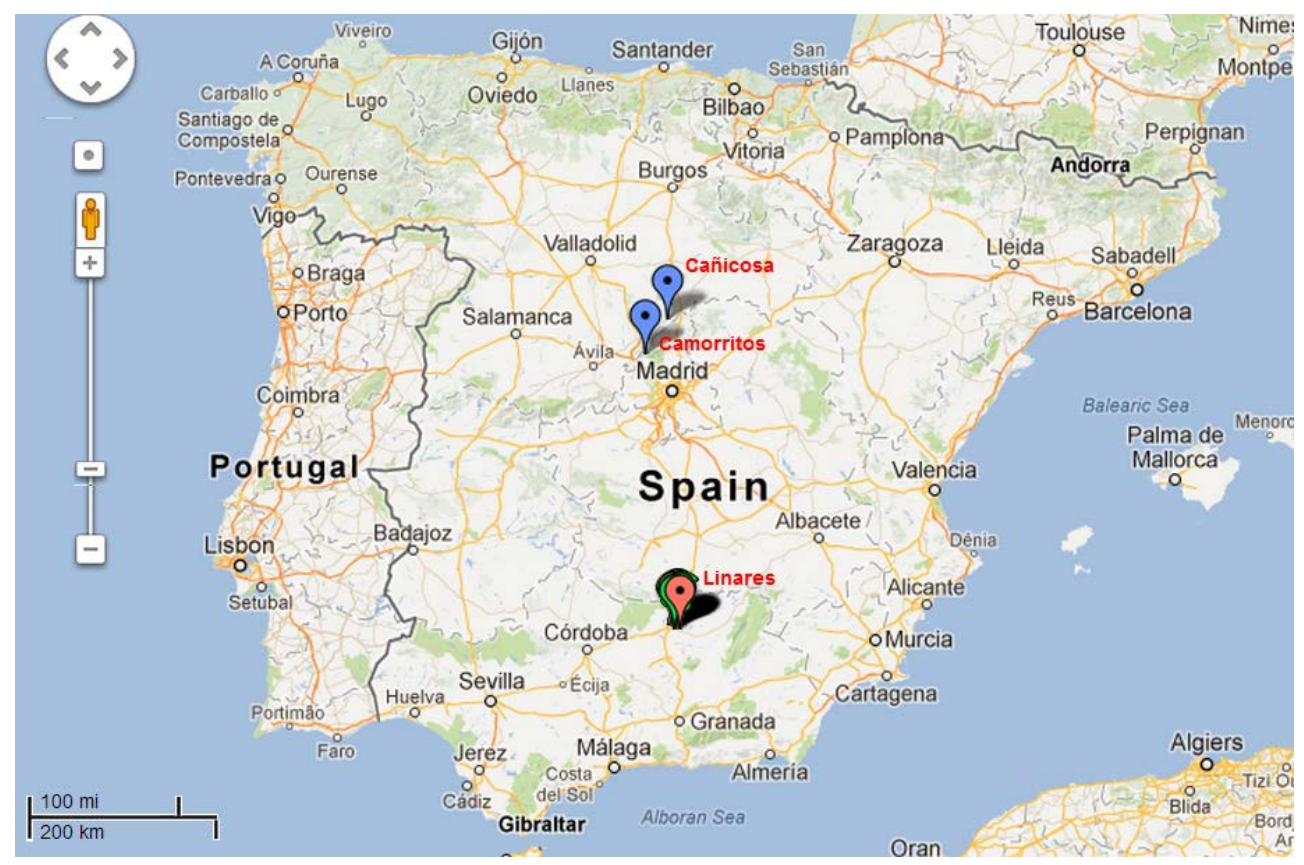

(a) Mapa de localización de muestras

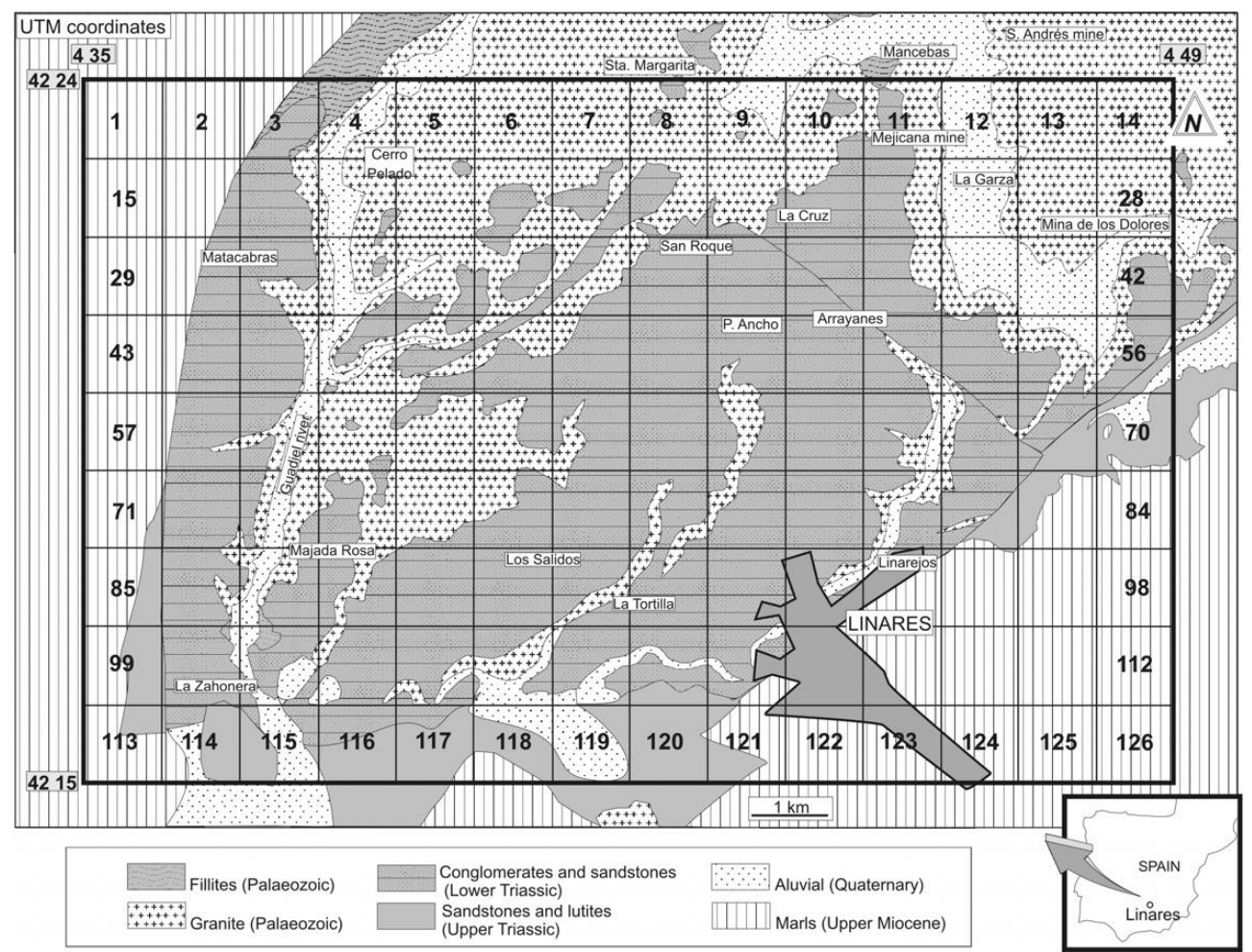

(b) Mapa de localización de las 126 cuadrículas de 1 km² utilizada por Martínez López et al. (2008)

Figura 15: Mapas de localización de las muestras y de las cuadrículas 


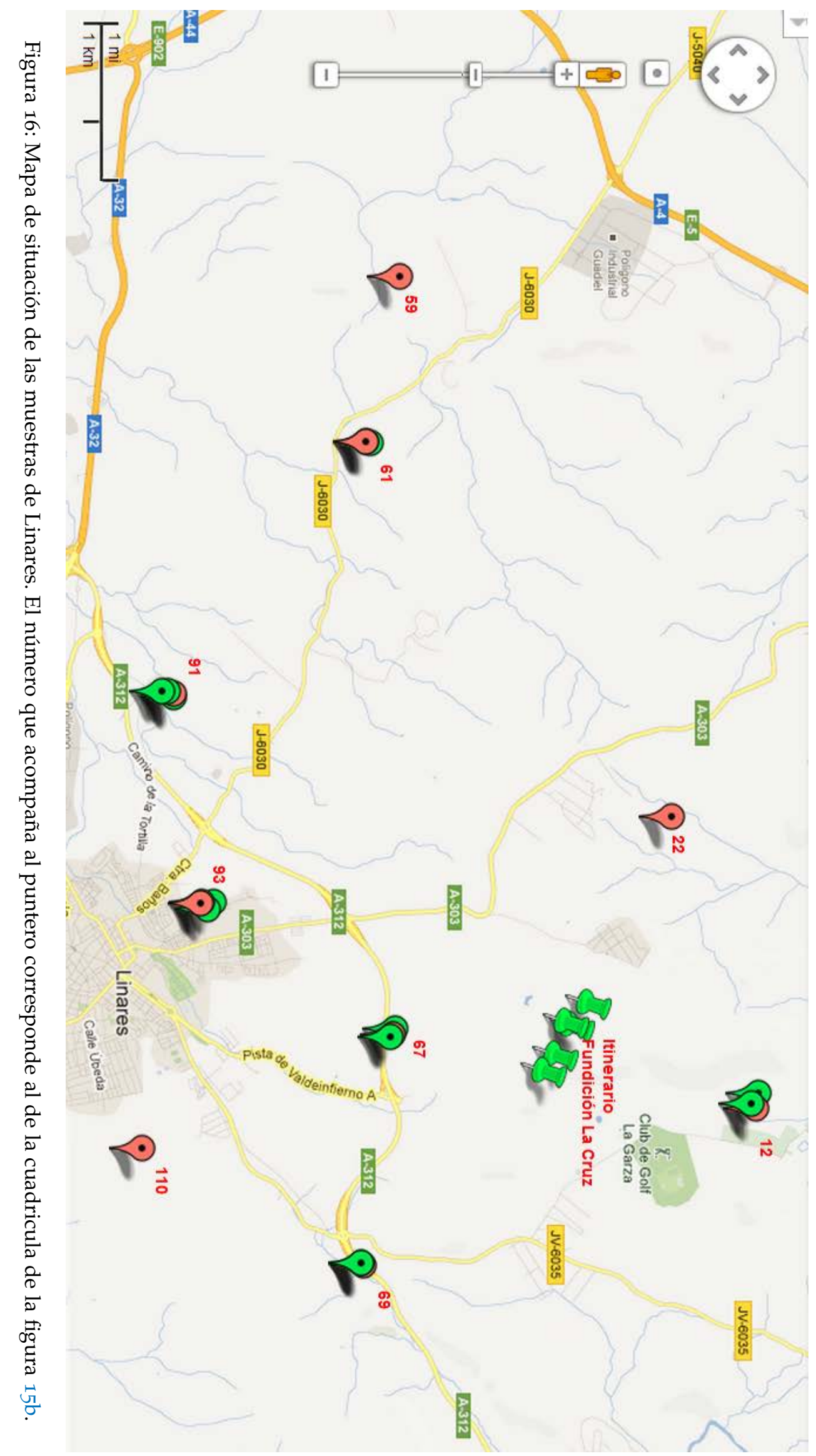



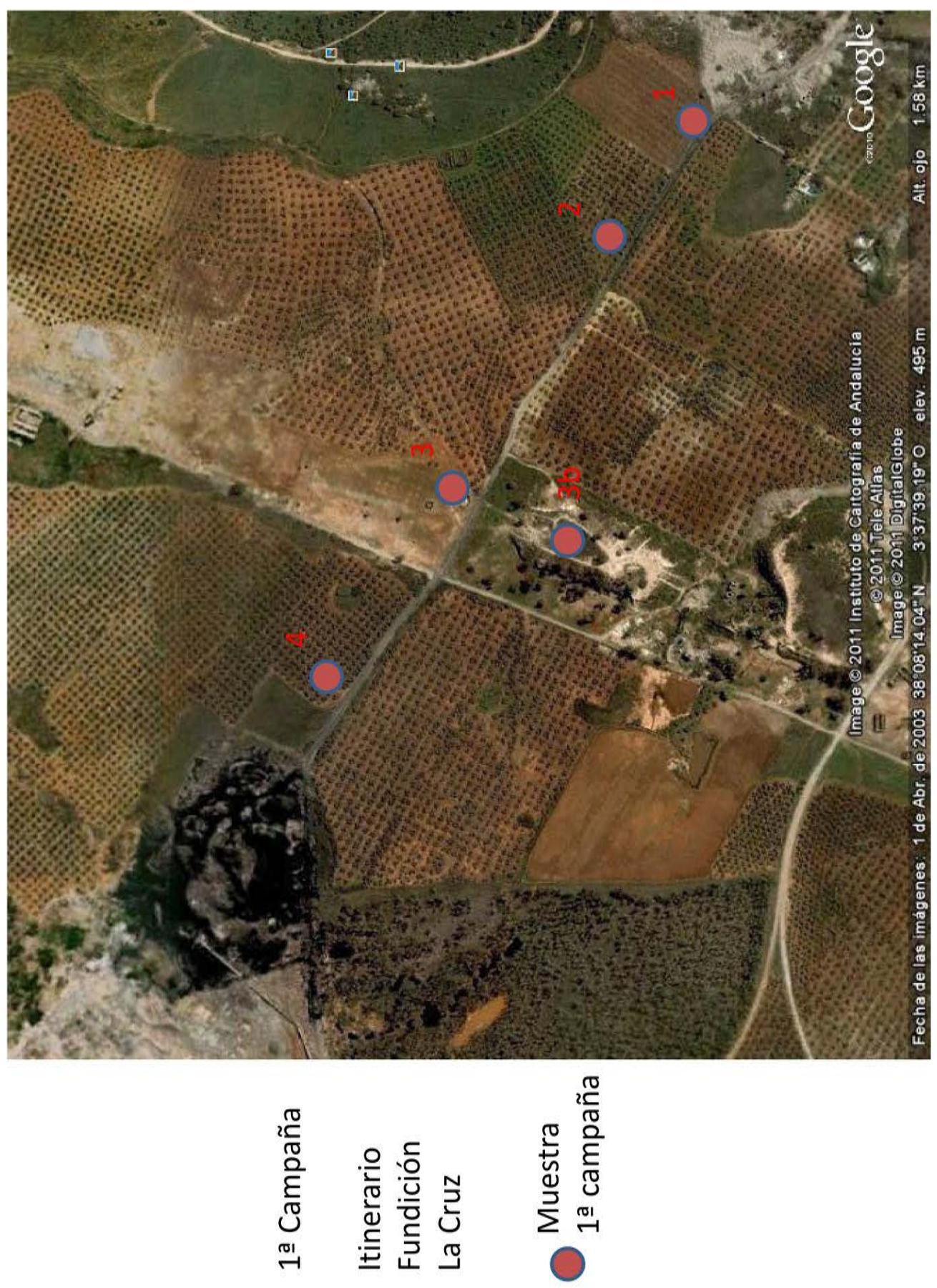

Figura 17: Primera Campaña: Linares I 

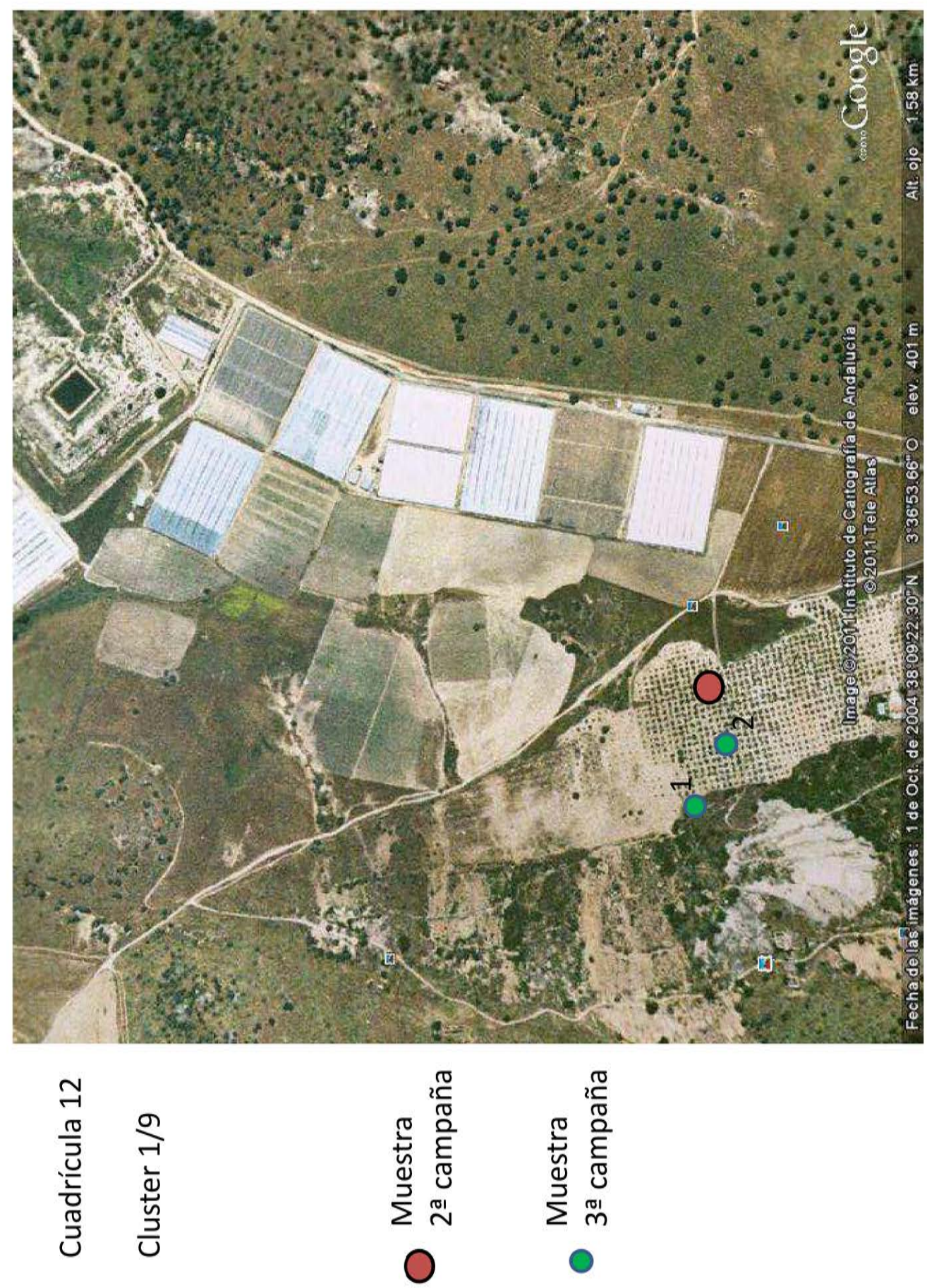

Figura 18: Muestras Cuadrícula 12 


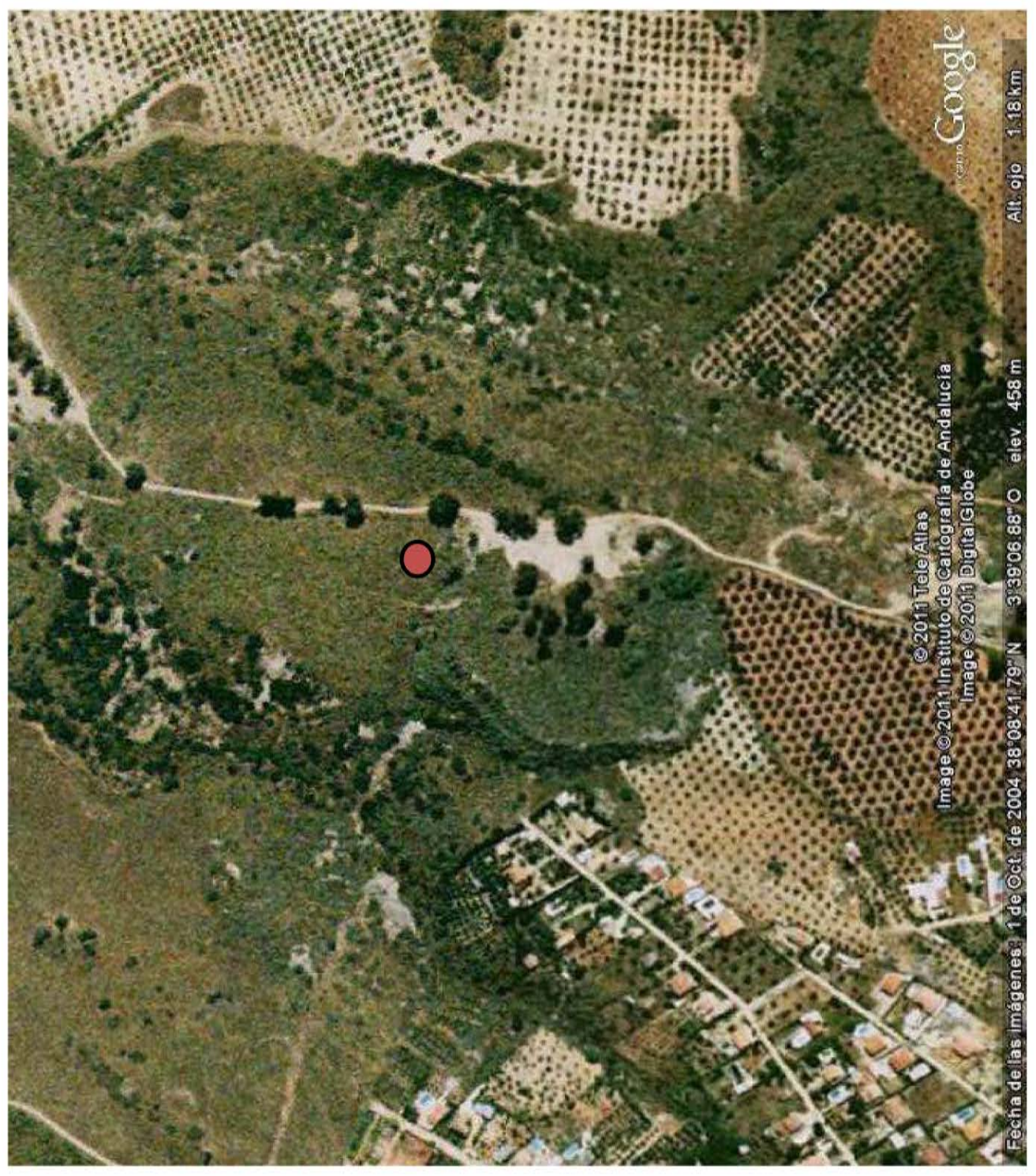

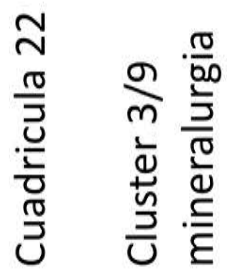

Figura 19: Muestras Cuadrícula 22 


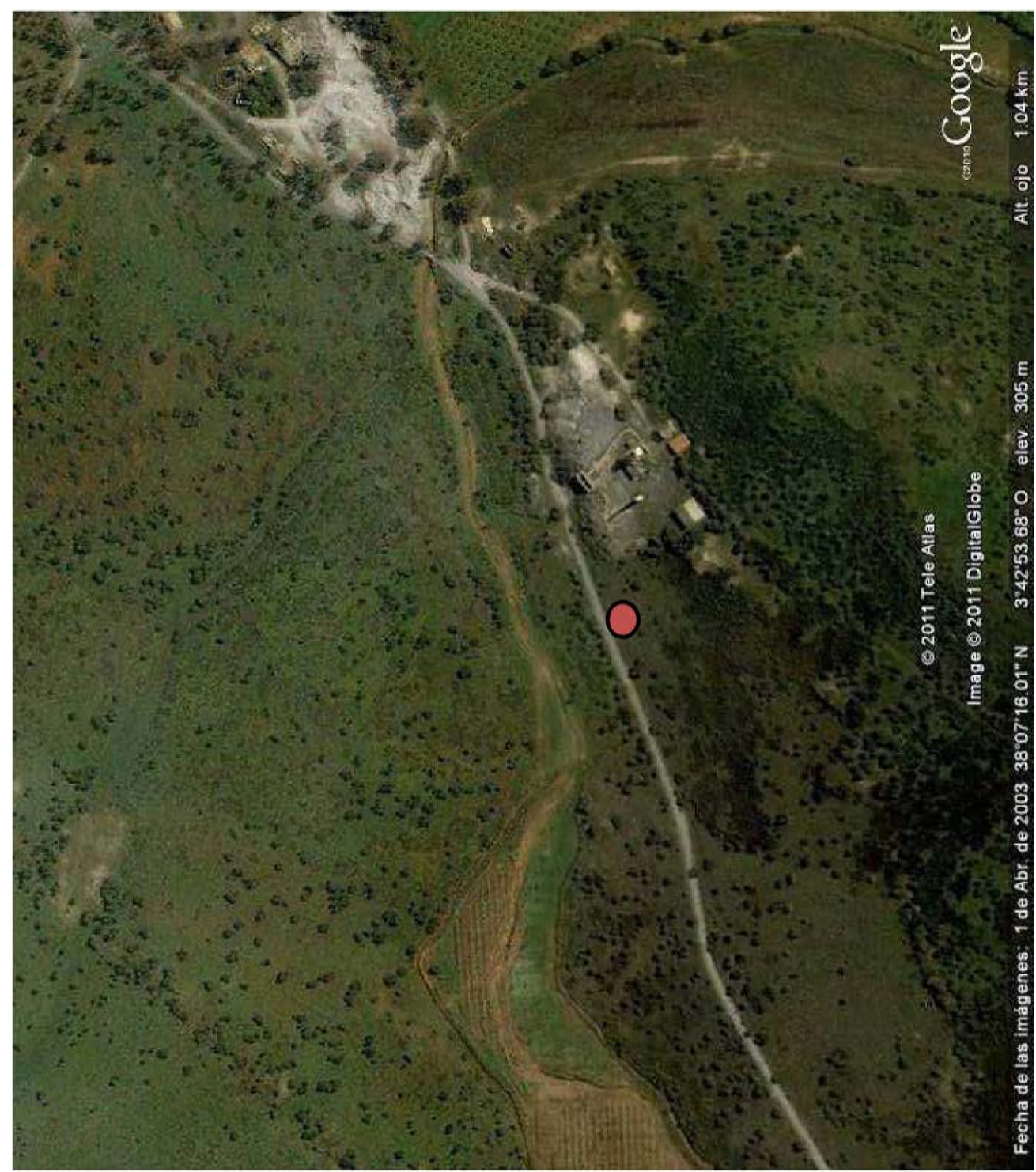

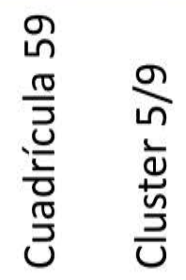

Figura 20: Muestras Cuadrícula 59 


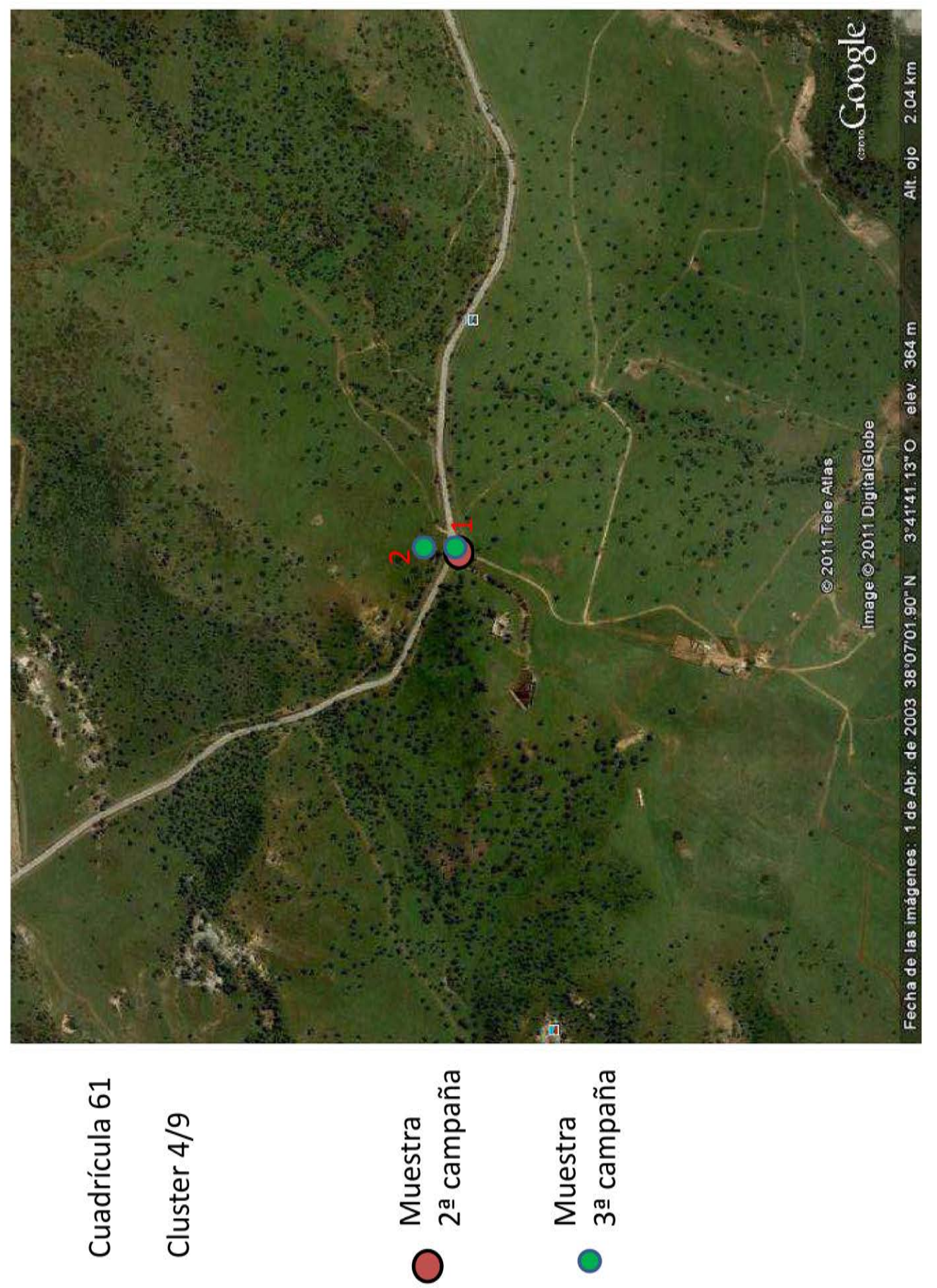

Figura 21: Muestras Cuadrícula 61 


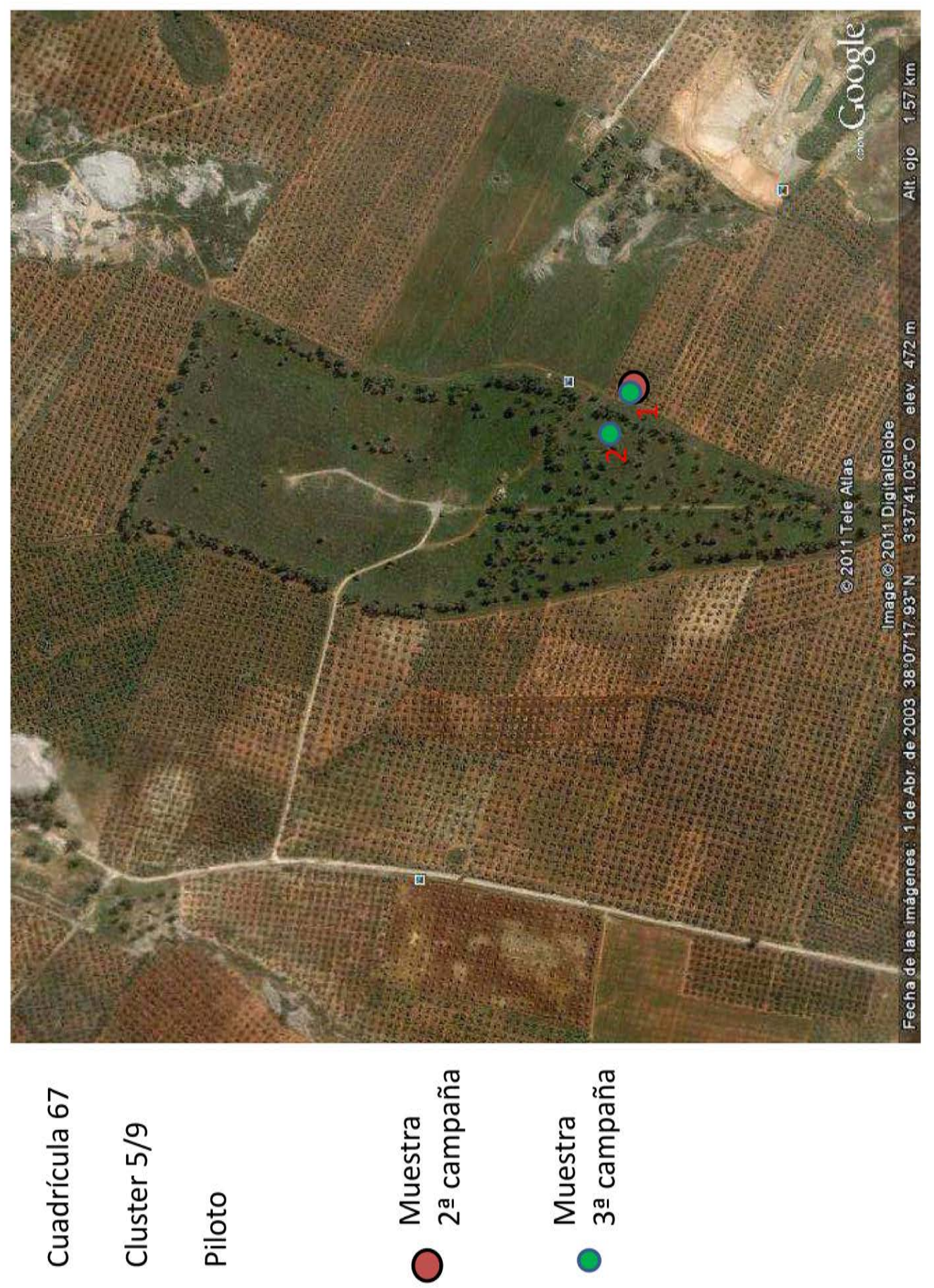

Figura 22: Muestras Cuadrícula 67 


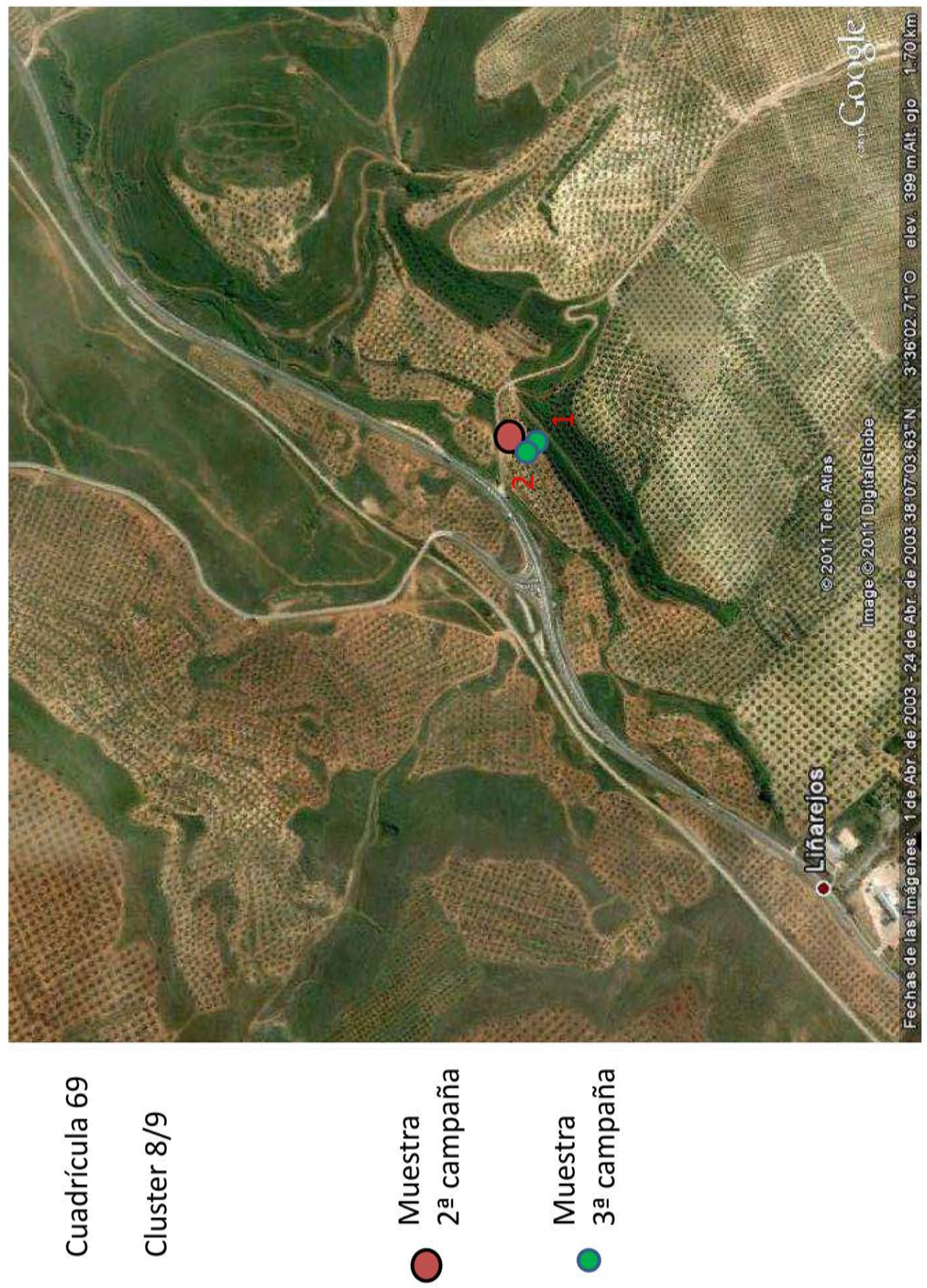

Figura 23: Muestras Cuadrícula 69 


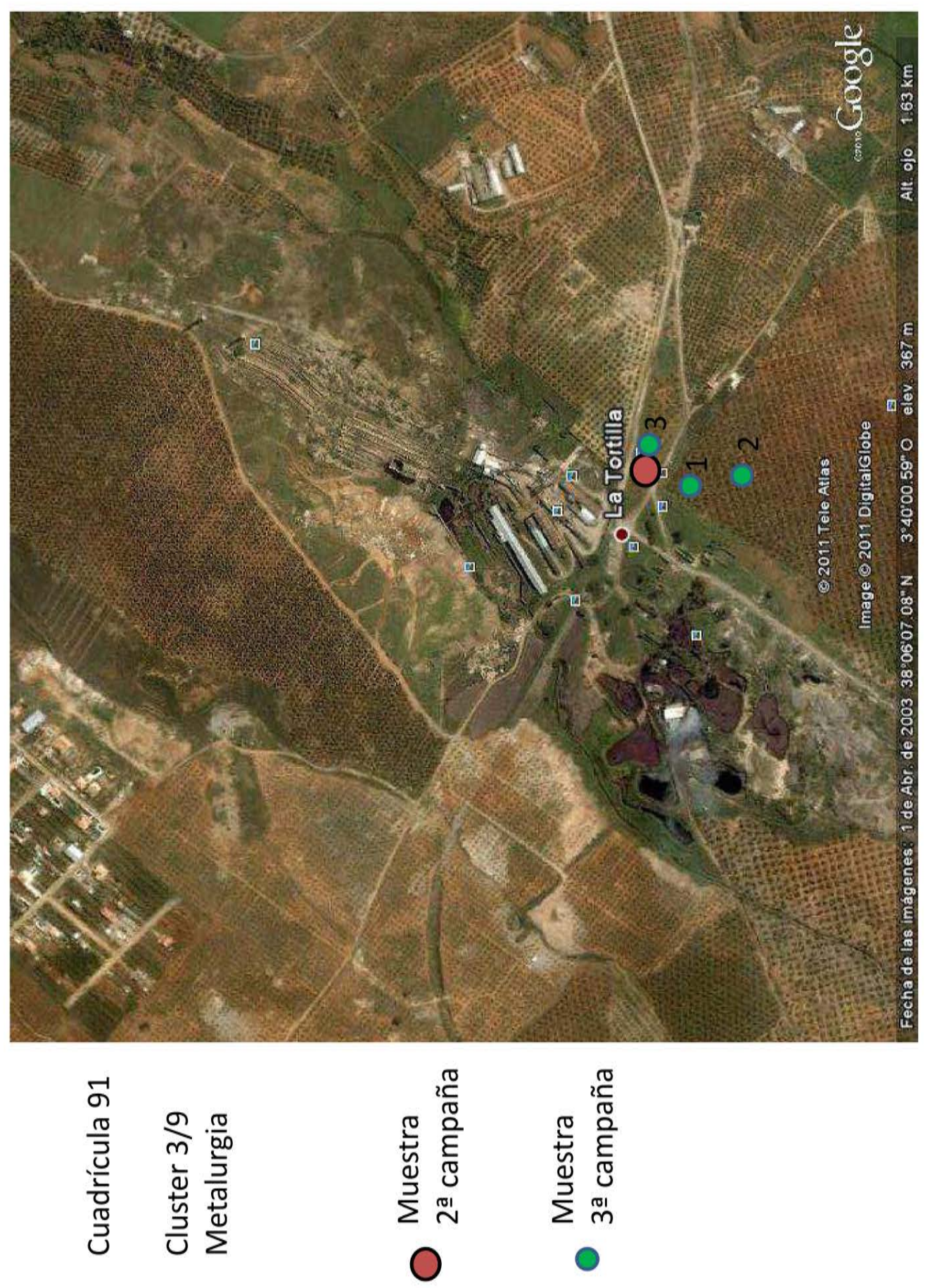

Figura 24: Muestras Cuadrícula 91 

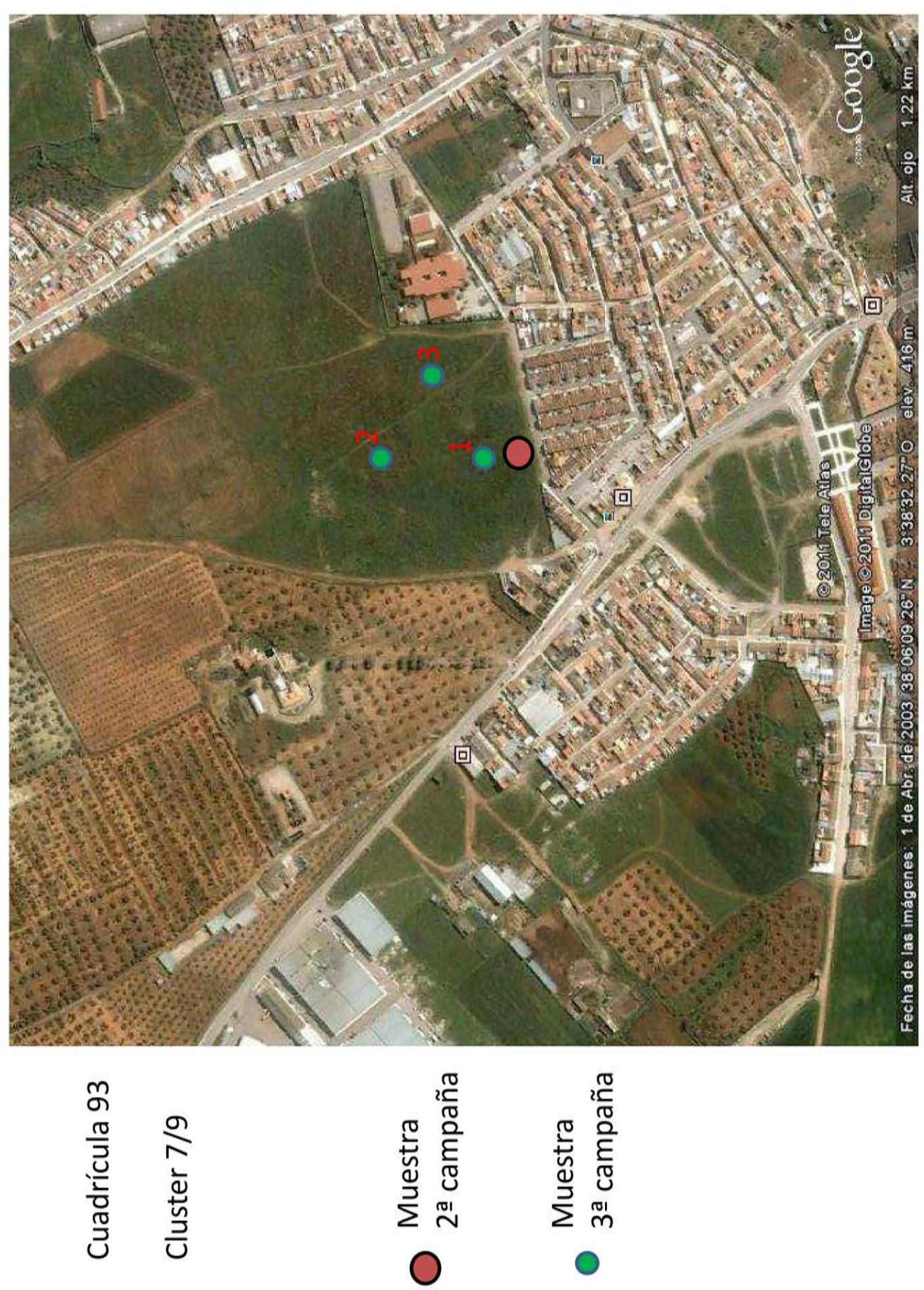

Figura 25: Muestras Cuadrícula 93 

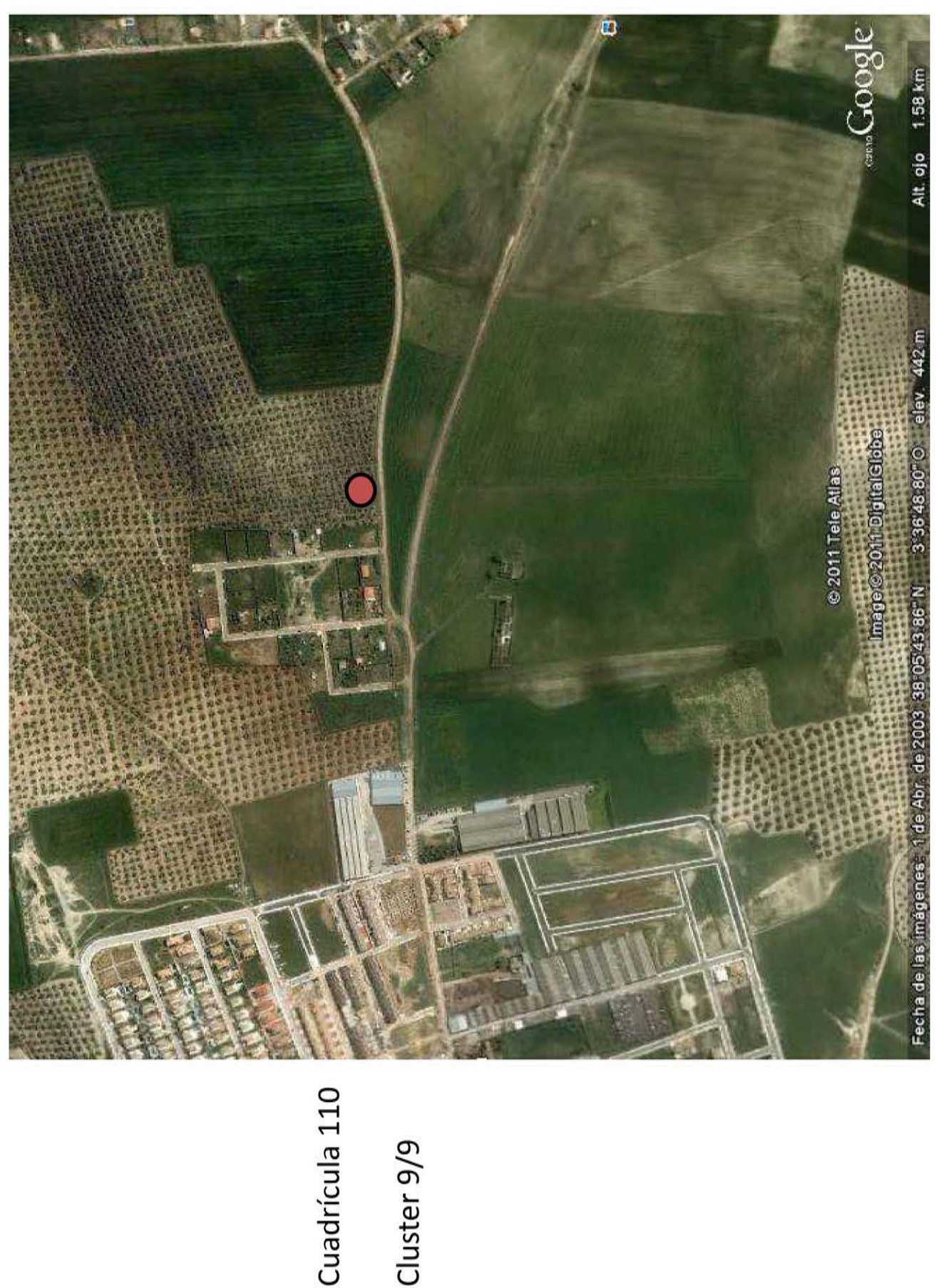

Figura 26: Muestras Cuadrícula 110 
En este capítulo se describen los procedimientos de registro de datos, elaboración y archivo utilizados.

\subsection{REGISTRO DE DATOS}

Los datos del cuaderno de campo y del cuaderno de laboratorio han sido transcritos a hojas de cálculo.

En el fichero de dinamogramas cada línea corresponde a un registro y contiene los campos y encabezados de la hoja de cálculo que se recogen en la tabla 15 .

\subsection{ESCANEADO Y ARCHIVO DE LOS DINAMOGRAMAS}

Para archivar los dinamogramas se han utilizado

- fundas protectoras de plástico, tamaño DIN A5, multitaladro de la marca Y.E.S.

- archivadores de cartón con caja, tamaño DIN A5, de la marca CENTAuRo

Archivo digital

- El escáner ha de configurarse con el perfil de calibración ICC correspondiente a la tarjeta de calibración elegida. Se ha optado por la tarjeta suministrada por la compañía Wolf Faust, con la referencia Ri 10714, conforme con los estándares IT8 e ISO 12641. En el ordenador del laboratorio de la ETSIME se ha obtenido el perfil ICC con el programa VUESCAN 9 PROFESSIONAL EDition, de la compañía Hamrick Software. El mismo programa permite calibrar los escáneres y las impresoras u otros dispositivos de salida con el mismo perfil, de modo que se puede asegurar la reproducibilidad de los colores en cualquier dispositivo. Este procedimiento se basa en el adoptado para validar las imágenes obtenidas a través de un método similar, descrito en Zalecka (2006).

- Los dinamogramas se han escaneado en formato TIFF raw, sin procesar, con el programa Vuescan 9 Professional de Hamrick Software. La resolución de escaneado utilizada fue de 300 dpi, con un factor de reducción del tamaño de salida de 2. 
Tabla 15: Registro de datos de campo y de laboratorio en hoja de cálculo

\begin{tabular}{|c|c|c|}
\hline & CAMPO & DESCRIPCIÓN \\
\hline \multirow{3}{*}{ 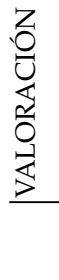 } & Defecto & Descripción del defecto técnico \\
\hline & Calidad & $\begin{array}{c}{[\mathrm{OK}]=\text { correcto }[\mathrm{DE}]=\text { con defecto }} \\
{[\mathrm{RE}]=\text { rechazado }[\mathrm{CN}]=\text { control, }[]=\text { no evaluado }}\end{array}$ \\
\hline & NumReg & Número de orden en la hoja de cálculo \\
\hline \multirow{3}{*}{ 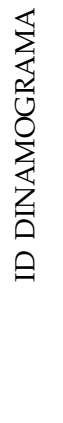 } & TIF, JPG & $\begin{array}{c}\text { Nombre del fichero digital asociado, formado } \\
\text { por la fecha invertida, día, mes, año, más el } \\
\text { identificador del dinamograma ID } \\
\text { [AAAAMMDDxx] }\end{array}$ \\
\hline & FECHA & Fecha del ensayo [DD/MM/AAAA] \\
\hline & ID & $\begin{array}{c}\text { Número del dinamograma, formado por dos o } \\
\text { tres dígitos }[\mathrm{xx}]\end{array}$ \\
\hline \multirow{3}{*}{ 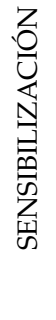 } & DIL. SAL & $\begin{array}{l}\text { Fecha de dilución de la sal metálica utilizada } \\
\qquad[\mathrm{DD} / \mathrm{MM} / \mathrm{AAAA}]\end{array}$ \\
\hline & CONC. $(\%)$ & $\begin{array}{l}\text { \% de concentración de la sal seguido por el } \\
\text { catión metálico de la sal }[0,25 \% \mathrm{Au}]\end{array}$ \\
\hline & OTROS & Campo libre \\
\hline \multirow{3}{*}{ 啗 } & FABRICANTE & $\begin{array}{l}\text { Fabricante y modelo de filtro utilizado } \\
\text { [Whatman 4] }\end{array}$ \\
\hline & Diametro & Diámetro en mm del filtro [XXX mm] \\
\hline & $\begin{array}{l}\text { MARCAS/ } \\
\text { VOLUMEN }\end{array}$ & $\begin{array}{l}\text { Distancia de las marcas al centro del filtro en } \\
\mathrm{cm} / \text { Volúmenes pipeteados en } \mathrm{ml}[3-6 \\
\mathrm{cm} / 0.1-0,7 \mathrm{ml}]\end{array}$ \\
\hline \multirow{2}{*}{ 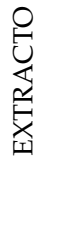 } & $\begin{array}{c}\text { ID } \\
\text { EXTRACTO }\end{array}$ & Identificación del extracto ensayado \\
\hline & $\begin{array}{l}\text { FECHA EX- } \\
\text { TRACCIÓN }\end{array}$ & Fecha de extracción [DD/MM/AAAA] \\
\hline \multirow{3}{*}{ 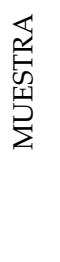 } & IDENTIFICACIÓN & Identificación de la muestra \\
\hline & $\begin{array}{l}\text { FECHA DES- } \\
\text { MUESTRE }\end{array}$ & $\begin{array}{l}\text { Fecha de la toma de la muestra } \\
\text { [DD/MM/AAAA] }\end{array}$ \\
\hline & LUGAR & Lugar en que se tomó la muestra \\
\hline \multicolumn{2}{|c|}{ OTROS } & Comentarios libres \\
\hline
\end{tabular}


El archivo digital permite "fijar" las imágenes, que se oscurecen con el tiempo, y además el procesado y análisis posterior con otros programas. Unido al reducido espacio de almacenamiento que requiere el archivo digital y a la facilidad para reproducirlo, representa una gran mejora respecto al archivo físico.

\section{7·3 ELABORACIÓN DE DATOS}

\section{7·3.1 Edición de figuras}

Los mapas de situación de instituciones y de muestras se han realizado con la aplicación de uso libre Google maps de Google.

Las figuras se han realizado con el programa INKSCAPE 0.48, un programa de edición de gráficos vectoriales de código abierto y de libre uso bajo licencia pública general GNU (ver http://inkscape.org/). Permite trabajar directamente con los ficheros TIFF de los dinamogramas y exportar los resultados a formato PNG con la resolución que se prefiera. En la mayoría de los casos se ha usado 300 dpi, para mantener una calidad de visualización adecuada.

\subsubsection{Edición del texto y conversión a formato PDF}

Para la edición del documento de tesis se ha utilizado el programa LYX Copyright (C) 1995 by Matthias Ettrich y la plantilla CLASSIC THESIs desarrollada por André Miede. Se trata también de software de libre uso y código abierto bajo licencia pública general GNU (ver http://www.lyx.org/)

\subsubsection{Bibliografía}

Para el manejo de la bibliografía y obtención de la base de datos Bibtex se ha utilizado el programa cit Avi 3 de Swiss Academic Software. 

En este capítulo exponemos las condiciones particulares en que se realizaron los ensayos que se describen en el capítulo 11 en la página 169, que tiene como objetivo comprobar la validez de las modificaciones del método original de Pfeiffer (1959) que se describen aquí.

En la sección 8.1 se recogen las diferencias en cuanto a materiales y método entre los laboratorios participantes en los ensayos ciegos colaborativos. La sección 8.2 se refiere a las muestras utilizadas en los mismos. Las modificaciones del método original de Pfeiffer, el Chroma-Test, se recogen en la sección 8.3. Los resultados de los ensayos de validación fueron interpretados según los criterios morfológicos de la sección 8.4.

Por último, en la sección 8.5 se describen los procedimientos de los ensayos físicos que hemos seleccionado para comparar sus resultados con los de la Dinamolisis Capilar.

\subsection{DIFERENCIAS ENTRE LOS LABORATORIOS COLABORADORES}

La tabla 16 recoge las diferencias relevantes entre los laboratorios colaboradores en cuanto a equipamiento, materiales y métodos. En la sección 5 en la página 63 se describieron los respectivos equipamientos.

\subsection{MUESTRAS SELECCIONADAS PARA LOS ENSAYOS CiEgOS}

Las muestras utilizadas proceden de la tercera campaña de Linares, de mayo del 2012. Ver el capítulo 6 para su descripción y localización.

PREPARACIÓN DE LAS MUESTRAS El secado de las muestras se realizó en Madrid, al aire durante nueve días. Se han cribado a $2 \mathrm{~mm}$ y se han preparado siguiendo las instrucciones establecidas por el Ministerio de Agricultura para los métodos oficiales de análisis de suelos:

Preparación De La Muestra. Suelos

1.1 Principio: La muestra natural de un suelo, cuando llega al laboratorio, debe ser acondicionada como fase previa para la realización de los distintos análisis. Este acondicionamiento incluye la separación de los posibles elementos 


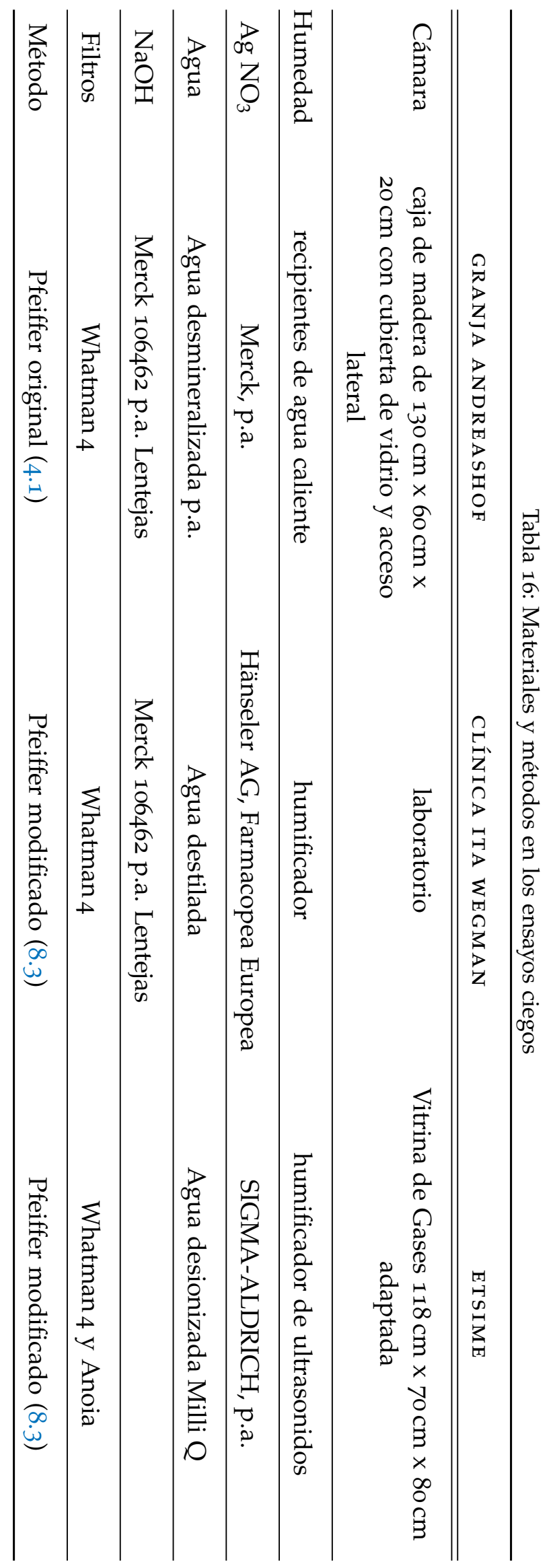


gruesos, la preparación de la muestra para análisis físicos y la preparación para ciertos análisis químicos.

1.2. Material y aparatos:

1.2.1. Bandejas numeradas para colocar la muestra.

1.2.2. Tamiz de $2 \mathrm{~mm}$. de luz.

1.2.3. Martillo de goma o madera, rodillo o molino especial para disgregar los terrones, con una separación entre muelas superior a $1 \mathrm{~cm}$.

\subsection{Procedimiento:}

Colocar la muestra en una bandeja y disgregar a mano, si es posible. los terrones existentes. Mantener las bandejas al aire libre hasta que se equilibre su humedad con la del laboratorio. Durante la desecación, disgregar a mano los terrones existentes. El desprendimiento de polvo es un indicio de haber logrado este equilibrio. Pesar la muestra. con la aproximación del gramo. Disgregar mecánicamente los terrenos mediante un martillo de goma o madera, rodillo o molino especial. Tamizar la totalidad de la muestra por un tamiz de 2 milímetros de luz. Recoger la porción que haya pasado por el tamiz en un recipiente. Esta fracción se denomina tierra fina seca al aire (TFSA). (Ministerio de Agricultura, 1976, pp. 6458-6459)

PREPARACIÓN DE LOS LOTES Se hicieron siete lotes, cada uno conteniendo bolsitas de unos $20 \mathrm{~g}$ de cada una de las siete muestras seleccionadas. Los identificadores de las muestras de cada lote se codificaron aleatoriamente, como se muestra en la tabla 17 .

Los lotes $\mathrm{n}^{\circ} 3, \mathrm{n}^{\circ} 5 \mathrm{y} \mathrm{n}^{\circ} 7$ se entregaron a tres operadores del laboratorio de la ETSIME. El lote $\mathrm{n}^{\circ} 1$ se envió al laboratorio de la Ita Wegman Klinik [IWK], en Arlesheim, Suiza. Y el lote ${ }^{\circ} 2$ se envió al laboratorio de la granja Andreashof [AH], en Ueberlingen, Alemania.

\subsection{MOdificACIÓN DEL CHROMA-TEST UTILIZAdA}

El método original de Pfeiffer (1959) (el Chroma-Test) se transcribe traducido al español en la Parte II, con las bases de partida, en la sección 4.I. Recordemos que es una variación horizontal del método de Dinamolisis Capilar de L. Kolisko y que lo hemos adoptado como punto de partida en nuestra investigación. La investigación inicial de los factores de influencia y del potencial del método (capítulos 9 y 10) se realizó con el Chroma-Test original y en su caso se indican los parámetros variados. A lo largo de la investigación hemos intentado mantener las condiciones lo más cercanas posibles al método original de Pfeiffer, modificando o añadiendo sólo aquello que conlleve claras ventajas de algún tipo. 
Tabla 17: Claves de identificación de las muestras usadas en los ensayos ciegos de validación

\begin{tabular}{ccccccccc}
\hline Lote & 12.1 & 12.2 & 67.1 & 67.2 & 91.1 & 91.2 & 91.3 & $\begin{array}{c}\text { Laboratorio } \\
\text { Operador }\end{array}$ \\
\hline \hline $\mathrm{n}^{\mathrm{o}} 1$ & 46 & 14 & 18 & 49 & 25 & 35 & 24 & IWK EG \\
\hline $\mathrm{n}^{\mathrm{o}} 2$ & 19 & 6 & 48 & 40 & 21 & 45 & 37 & AH BG \\
\hline $\mathrm{n}^{\mathrm{o}} 3$ & 5 & 4 & 22 & 20 & 10 & 43 & 42 & ETSIME ES \\
\hline $\mathrm{n}^{\mathrm{o}} 4$ & 44 & 39 & 36 & 30 & 41 & 8 & 23 & Sin asignar \\
\hline $\mathrm{n}^{\circ} 5$ & 28 & 34 & 15 & 17 & 3 & 9 & 31 & ETSIME EGG \\
\hline $\mathrm{n}^{\circ} 6$ & 2 & 27 & 33 & 47 & 16 & 32 & 13 & Sin asignar \\
\hline $\mathrm{n}^{\mathrm{o}} 7$ & 12 & 29 & 11 & 7 & 1 & 26 & 38 & $\begin{array}{c}\text { ETSIME } \\
\text { MTM }\end{array}$ \\
\hline
\end{tabular}

La información que sigue complementa el método original de Pfeiffer descrito en la sección 4.1. Para los ensayos ciegos se han adoptado las siguientes modificaciones:

- Se hacen 3 ensayos por muestra, más otros 3 blancos con el $\mathrm{NaOH}$ al 1 \% usado en la extracción. También es recomendable sensibilizar 2 filtros más, uno al principio y otro al final de la sensibilización. Estos dos últimos se secarán con los otros pero se conservarán siempre a oscuras sin exponerlos nunca a la luz.

$$
\text { Total filtros a sensibilizar }=\left(N^{\mathrm{o}} \text { de muestras }+1\right) * 3+2
$$

- Las marcas en el papel de filtro se ponen a $4 \mathrm{~cm}$ y $6 \mathrm{~cm}$ del centro.

- Las cantidades de disolución de Nitrato de Plata y de extractos de suelo se miden exactamente con la ayuda de una pipeta. Las cantidades utilizadas son $0,5 \mathrm{ml}$ y $1,2 \mathrm{ml}$ respectivamente. El pipeteo de volúmenes exactos fue introducido por Balzer porque permite un mejor control del experimento y evita desbordamientos más allá de las marcas (citado en Bangert 1994).

- Los filtros se dejan secar en la oscuridad tanto después de la difusión del nitrato de plata como después de la difusión del extracto $^{1}$.

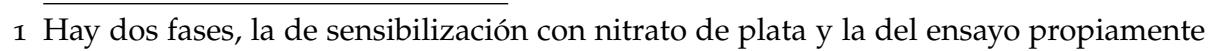
dicho, de difusión del extracto del suelo. Entre una y otra pueden transcurrir varias horas. Los filtros sensibilizados han de mantenerse en oscuridad absoluta para evitar 
- Después del secado en la oscuridad durante toda la noche, las imágenes secas se exponen a luz difusa del laboratorio alrededor de 6 horas.

- Pasados tres días se procede a escanear las imágenes. Los detalles para la calibración del escáner se encuentran el la sección 7.2.

En los ensayos preliminares se investigaron diversas condiciones de iluminación, ya que la luz juega un importante papel en la formación de las imágenes.

Las imágenes se han escaneado con un perfil de calibración ICC (ver 7.2), como método para "fijarlas", ya que se oscurecen con el transcurso del tiempo, y para facilitar su consulta y archivo.

\subsection{INTERPRETACIÓN DE LOS DINAMOGRAMAS}

El método de Dinamolisis Capilar proporciona imágenes que es necesario relacionar con la calidad del suelo. Hemos tenido que introducir la noción de fuerzas formativas, las fuerzas configuradoras de la materia orgánica del suelo, para poder plantear el problema de la calidad del suelo como su capacidad para oponerse, por medio de dichas fuerzas formativas, a la tendencia a mineralizarse. Con este planteamiento es necesario en primer lugar conocer cómo se expresa, por medio del ensayo de Dinamolisis Capilar, la dinámica de estos dos tipos de fuerzas: las fuerzas formativas vinculadas con la formación de la materia orgánica del suelo, afín al reino vegetal, y las fuerzas que hemos denominado minerales, porque tienden a mineralizar el suelo.

En las secciones que siguen se muestran las bases morfológicas utilizadas en la interpretación para caracterizar la expresión de las fuerzas formativas y de las fuerzas minerales en los dinamogramas.

\subsubsection{Morfología, zonas y rasgos}

La valoración de las imágenes obtenidas requiere, en primer lugar una caracterización morfológica. Esta se lleva a cabo normalmente siguiendo el método establecido por Pfeiffer (1959) (ver la subsección 4.1.2). A continuación describimos los elementos morfológicos identificables en los dinamogramas, que sirven para valorar la calidad de los suelos. En la figura 27 se muestra la nomenclatura usada por Pfeiffer (1959).

que aparezcan decoloraciones en forma de coronas dentro de la zona interior. En la segunda fase es necesaria la exposición a la luz, pero ha de ser estandarizada. En este caso, por terminar el ensayo normalmente al final de la jornada, se ha preferido mantener los filtros en la oscuridad y realizar la exposición a la luz durante el día siguiente. 


\section{Método de Pfeiffer:}

1-Sensibilización de los filtros con una dilución de $\mathrm{AgNO} 3$ al 0,5\% hasta una marca a $4 \mathrm{~cm}$ del centro.

2-Impregnación de los filtros sensibilizados con el extracto a estudiar, hasta otra marca a $6 \mathrm{~cm}$ del centro.

A partir de la zona media, característica de esta configuración experimental, Pfeiffer denominó el resto de las zonas diferenciables:

- Por fuera de la zona media puede aparecer una zona más clara que se denomina zona exterior. En este ejemplo es blanca con manchas ocre, coronando los picos o dientes de la zona media.

- Por dentro de la zona media está la zona interior. En este ejemplo se diferencia claramente por su color grisáceo. La textura radial se llama radiación.

- En el centro de la imagen se aprecia una pequeña zona más clara que se denomina zona central.
- Imagen obtenida por el método de Pfeiffer, en el que aparece la zona media característica de esta configuración particular de los experimentos de dinamolisis capilar

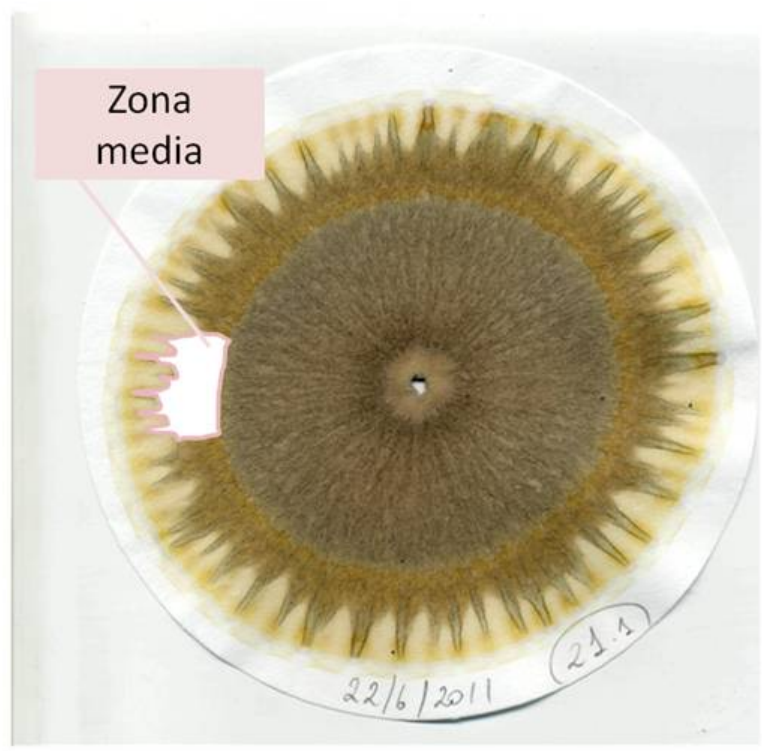

(a) Zona media en el Chroma-Test

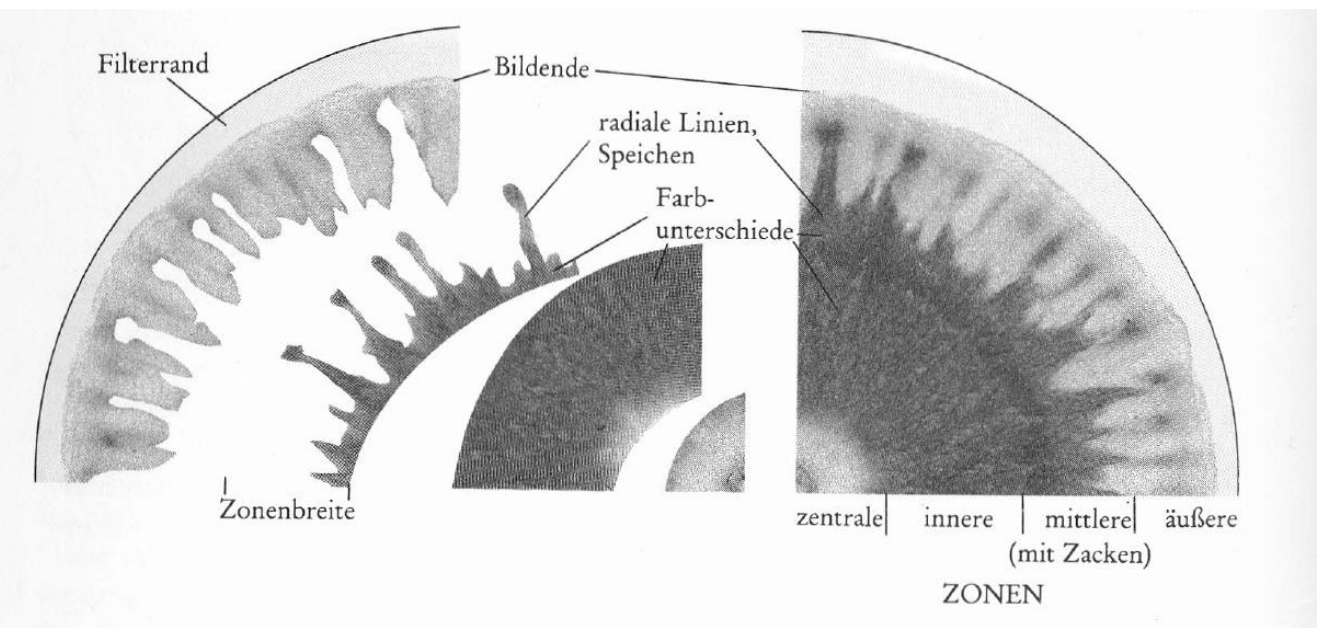

(b) Zonas y rasgos de los patrones. De Voitl and Guggenberger (1986)

Zonen [Zonas]: zentrale [central], innere [interior], mittlere (mit Zacken) [media (con picos)], äußere [exterior]

Figura 27: Nomenclatura asociada al Chroma-Test 
En la figura 27a se muestra la situación de la zona media, que va a servir para definir el resto de zonas diferenciables. A partir de la zoNA MEDiA, característica de esta configuración experimental, Pfeiffer diferenció las demás zonas. Por fuera de la zona media puede aparecer una zona más clara que se denomina zONA EXTERIOR. En este ejemplo es blanca con manchas ocre, coronando los picos o dientes de la zona media. Por dentro de la zona media se encuentra la zoNA INTERIOR. En este ejemplo se diferencia claramente por su color grisáceo. La textura radial se denomina RADiAción. En el centro de la imagen se aprecia una pequeña zona más clara que se denomina ZONA CENTRAL.

Los rasgos morfológicos característicos de cada zona se resumen en la tabla 18 .

\begin{tabular}{lcc}
\hline & Rasgos radiales & Rasgos circulares \\
\hline \hline Zona exterior & Nubes, Manchas, Flecos & Aureolas \\
\hline Zona media & Picos, Dientes & Límite con z. i. \\
\hline Zona interior & Radiación & Diferencias en coloración \\
\hline
\end{tabular}

Tabla 18: Rasgos morfológicos característicos

En este trabajo hemos prescindido de la zona central para realizar la interpretación.

En la figura 28 se pueden apreciar varios dinamogramas con diferentes rasgos.

Las relaciones entre los dinamogramas y la calidad del suelo se pueden resumir así:

LOS RASGOS RADIALES están relacionados con las fuerzas formativas del suelo y su tendencia a comportarse de forma más vegetal u orgánica.

LOS RASGOS CIRCULARES están relacionados con las fuerzas mineralizantes del suelo y con su tendencia a comportarse de modo inorgánico.

\subsubsection{Zonas y razón simple}

En la figura 28 se muestran los resultados de dos experimentos con el blanco y con tres muestras de diferente calidad. En la fila superior se muestran los resultados cuando simplemente se difunde el extracto, sin sensibilizar previamente el filtro con una sal metálica. En la hilera inferior se muestran los resultados del Chroma-Test, según el 
método original de Pfeiffer (1959) descrito en la sección 4.1. Si comparamos las imágenes de las dos filas de la figura 28 podemos ver que la zonación se produce incluso sin sensibilizar el filtro de papel con la sal metálica, como se aprecia en la fila superior, y que el fenómeno de partición en zonas se pone claramente de manifiesto en las muestras de suelo de Cam. huerto. En la imagen superior, esta separación de zonas se ha producido de forma espontanea. Estas imágenes se han obtenido con la simple difusión del extracto, sin sensibilización previa del filtro. En la figura se pone de manifiesto la partición en dos zonas delimitadas claramente por un anillo más oscuro en la muestra de Cam. huerto. En la fila superior vemos que en la imagen del blan$\mathrm{co}$, correspondiente a la solución de $\mathrm{NaOH}$ utilizada como medio de extracción, no aparece ninguna coloración ni zona diferenciable; la siguiente imagen de la muestra 61.1 sólo muestra la zona "manchada" por el extracto tras difundirse por el filtro de papel. La de la muestra 61.2 mancha más el papel, insinúa una diferencia de zonas, y muestra rasgos radiales en el borde de la zona exterior. En la de Cam. huerto se puede observar claramente la diferenciación en tres zonas, la interior separada por el anillo más oscuro, una zona media y otra zona exterior con "flecos".

En la fila inferior la zonación se muestra en todos los casos y se refuerza por la presencia del nitrato de plata.

El ratio de los radios de la zona interior y exterior es muy cercano al número $\Phi$, que expresa la relación áurea. La relación o proporción áurea es muy frecuente en la naturaleza, la arquitectura y el arte y se le suele atribuir una impresión armoniosa. La relación áurea entre dos segmentos $\mathrm{A}$ y $\mathrm{B}$ cumple la condición de que $\mathrm{A}+\mathrm{B}$ es a $\mathrm{A}$ como A es a B:

$$
\frac{A}{B}=\frac{A+B}{A}=\Phi
$$

La única solución positiva de la ecuación es

$$
\Phi=1+5 \sqrt{2}=1,6180 \ldots
$$

En el Chroma-Test este ratio aparece entre las marcas sobre los filtros cuando se disponen a 3,7 y $6 \mathrm{~cm}$ de distancia al centro.

La literatura en torno al número $\Phi$ es sumamente extensa. Encontramos una recapitulación histórica de los pensamientos que la proporción áurea ha suscitado en los más diversos campos de la ciencia el arte y la religión en Livio (2006). En cuanto a la literatura de orientación antroposófica citamos la obra póstuma de W. Buehler (1996) y los artículos de J. Schultz (1968). Rudolf Steiner contestó a una pregunta respecto a la razón simple, indicando de forma sucinta la universalidad de las leyes que rigen los procesos formativos en la naturaleza.

La sección áurea, ya que se basa en el efecto de lo que hay en el espacio, se apoya en una ley oculta de la que 


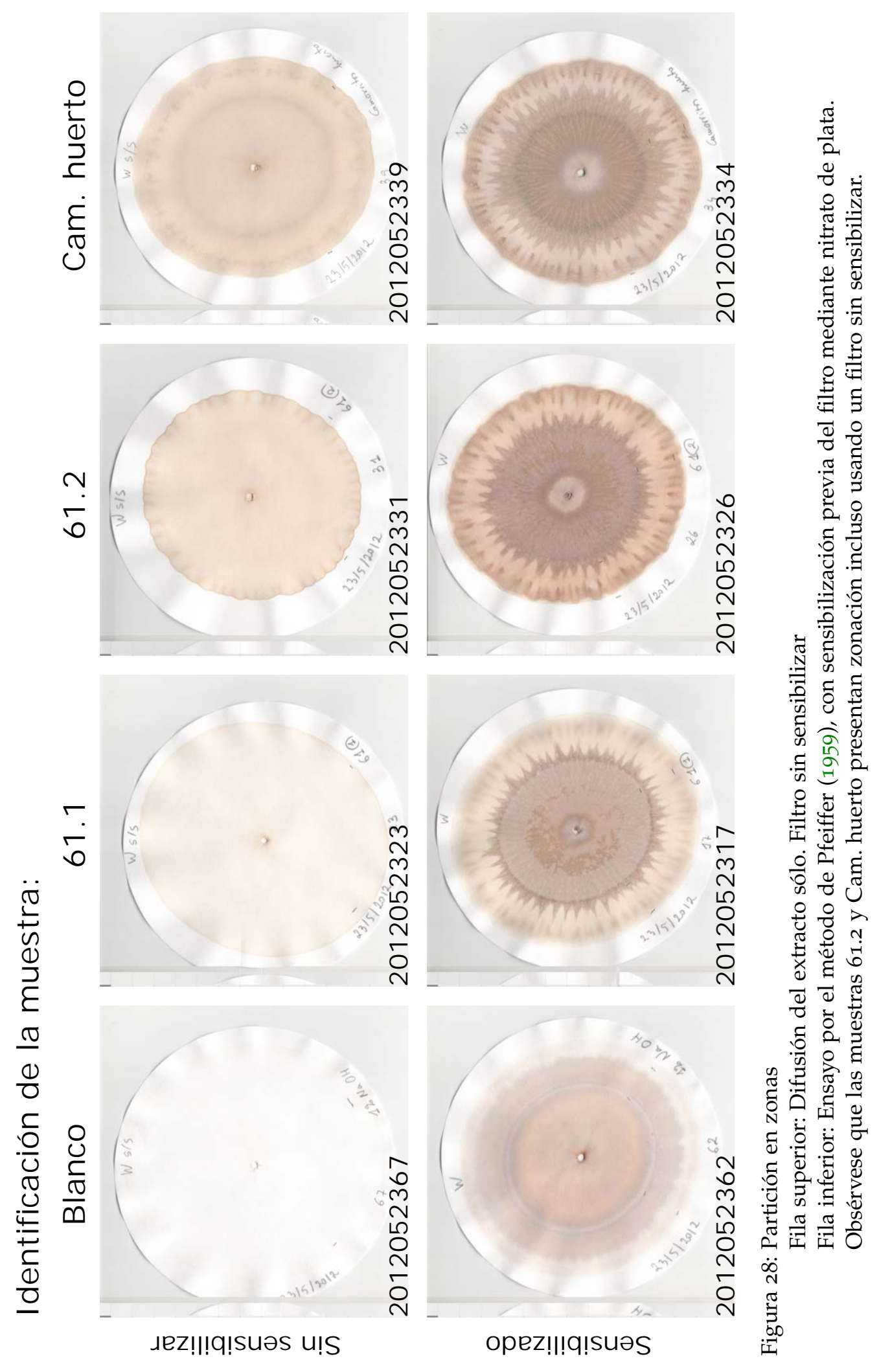


Goethe dijo que lo más oculto es lo más evidente y viceversa, que es la ley que más íntimamente está relacionada con nuestra constitución humana: la ley de la repetición y de la repetición variada. En la literatura budista, por ejemplo, siempre se repite lo mismo, solo que con alguna variación. No se deben omitir, ya que no sólo el contenido es lo que importa. En la sección áurea no se trata sólo de una mera repetición, sino de un reencuentro dentro de la misma cosa, puesto que en realidad sólo consta de tres componentes. Ese encontrarse dentro de una repetición repetición en sí no configurada - es la razón por la cual la sección áurea nos resulta tan simpática. (R. Steiner, Berlín 13 de febrero de 1913)
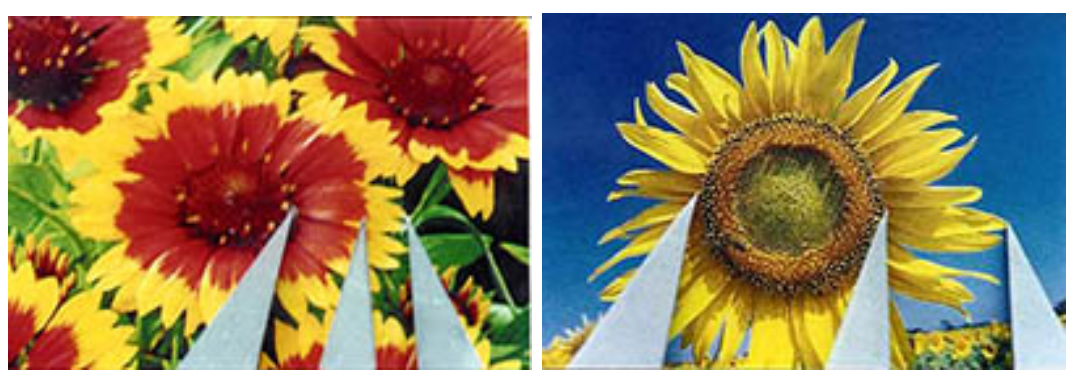

Figura 29: Segmentos en relación áurea superpuestos a flores (www.goldenmeangauge.co.uk) 


\subsection{ENSAYOS Físicos SENCILLOS}

Con el fin de conocer las características de los suelos investigados se han realizado algunos ensayos sencillos, que no requieren equipamiento especial y que son muy útiles en la práctica. Los ensayos se han seleccionado en base a la experiencia de $\mathrm{M}^{\mathrm{a}}$ Soledad Garrido ${ }^{2} \mathrm{y}$ se han realizado con su colaboración.

\subsubsection{Capacidad de Campo}

La capacidad de campo de un suelo se define como la cantidad de agua que puede retener éste a drenaje libre. Su valor tiene relación con la textura y la estructura del suelo. El resultado se da en porcentaje, es decir, es la cantidad de agua que pueden retener $100 \mathrm{~g}$ de suelo. Esta medida es muy útil para calcular la dosis de riego de los cultivos, y además, en general, da una idea muy real de las características hídricas del suelo ${ }^{3}$. En la tabla 19 se da una orientación para evaluar los niveles de capacidad de campo (Garrido Valero, 1993, pp. 37-38).

Tabla 19: Capacidad de Campo. Valores orientativos

\begin{tabular}{cc}
\hline CAPACIDAD DE CAMPO $(\%)$ & VALORACIÓN \\
\hline \hline$<7$ & Muy baja \\
\hline $7-12$ & Baja \\
\hline $12-20$ & Media baja \\
\hline $20-30$ & Media \\
\hline$>30$ & Elevada \\
\hline
\end{tabular}

Se ha realizado el ensayo utilizando la fracción $<2 \mathrm{~mm}$ del suelo seco.

1. En una probeta de plástico de $100 \mathrm{~cm}^{3}$ se vierten $100 \mathrm{~g}$ de suelo 4 y se anota el volumen ocupado, $\mathrm{H}$ en $\mathrm{cm}^{3}$.

2. A continuación se vierten con cuidado $10 \mathrm{ml}$ de agua y se deja hasta el día siguiente.

3. Se mide entonces el volumen que ha quedado seco, h, por debajo de la zona superior humedecida, también en $\mathrm{cm}^{3}$.

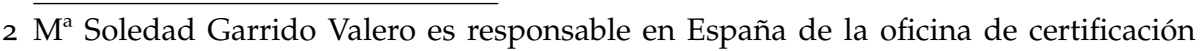
de Demeter, marca internacional de calidad de la Agricultura Biodinámica.

3 Y de manera indirecta se puede relacionar con el potencial para la actividad biológica del suelo (Garrido Valero 2014. Comunicación personal).

4 Tomado de la fracción de TFSA (tierra fina seca al aire). Ver la sección 8.2 en la página 91 sobre preparación de las muestras para ensayos físicos por los métodos oficiales del Ministerio de Agricultura. 


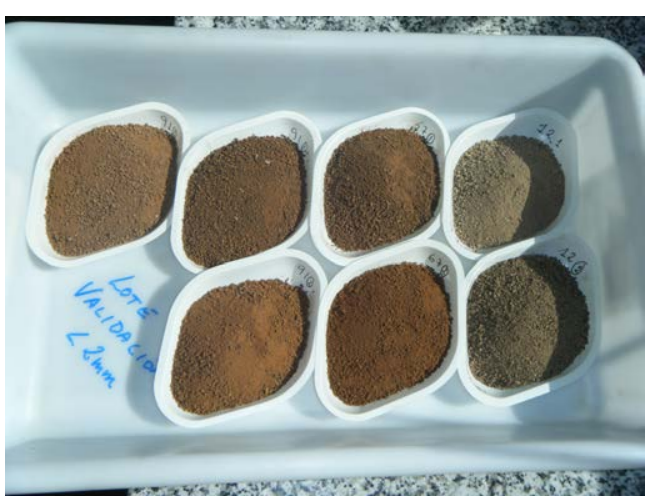

(a) Muestras secas

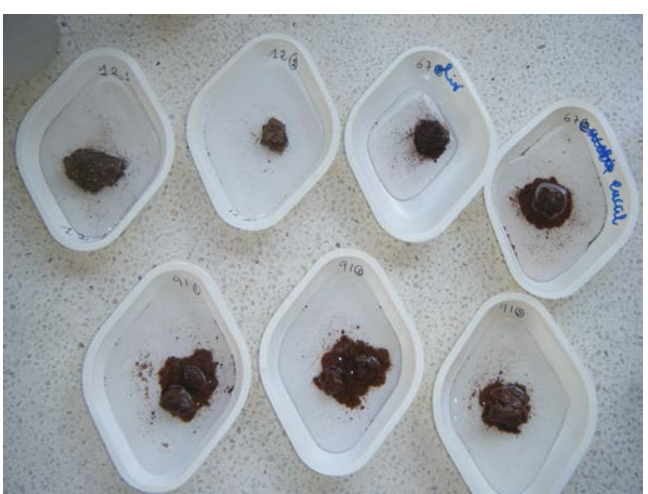

(c) Estructura

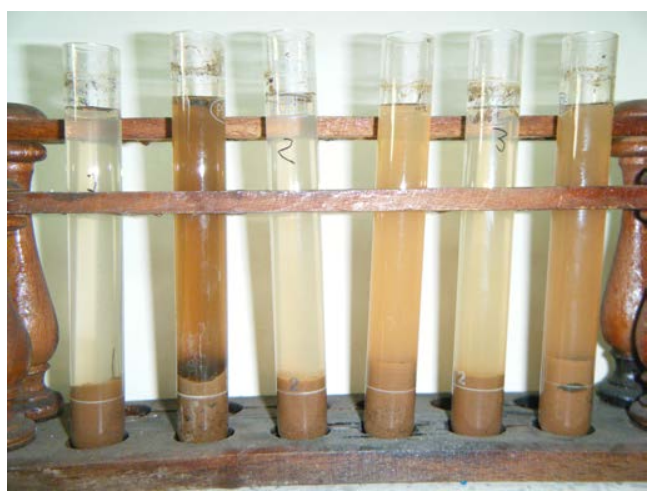

(e) Microestructura

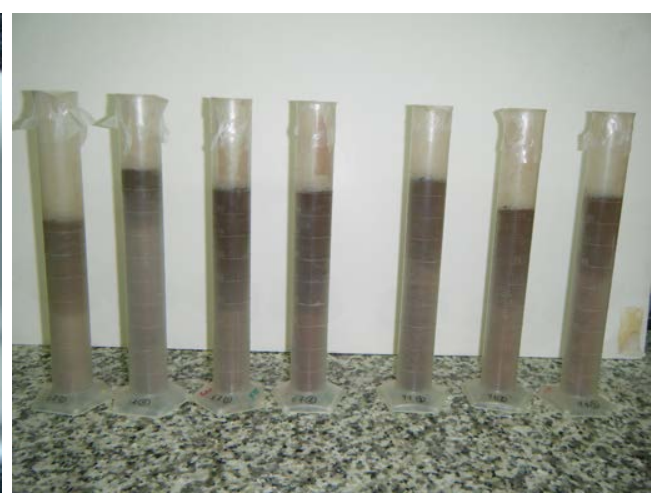

(b) Capacidad de Campo

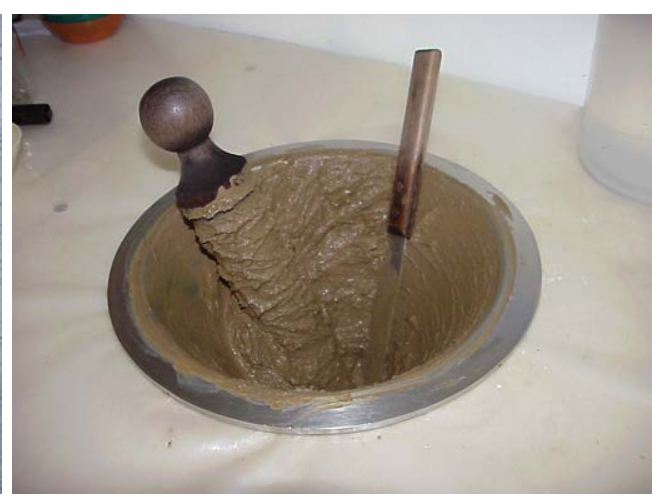

(d) Pasta Saturada. (www.drcalderonlabs.com)

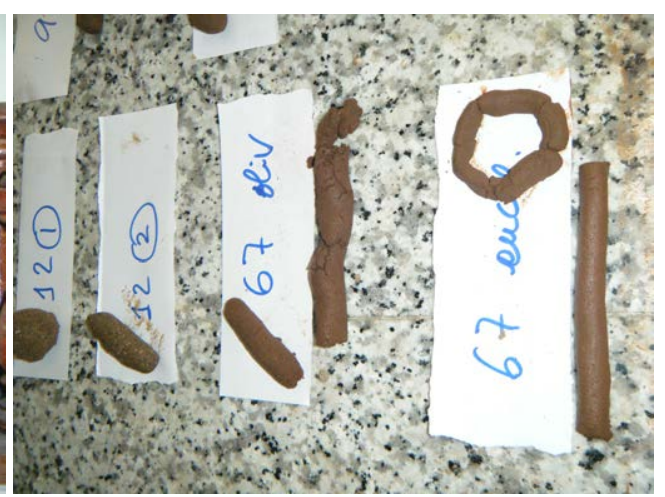

(f) Textura

Figura 30: Ensayos físicos sencillos

4. La Capacidad de Campo para 100 g será

$$
C C(\%)=\frac{H * 10}{H-h}
$$

\subsubsection{Densidad aparente}

Este parámetro se ha estimado con los datos del ensayo de capacidad de campo. La densidad aparente para $100 \mathrm{~g}$ de muestra será 


$$
D A=\frac{100}{H}
$$

La densidad aparente nos da una indicación del esponjamiento del suelo. Cuanto más alto es el resultado, mayor es la compactación del suelo.

\subsubsection{Estabilidad del suelo. Slake test}

Para ver la estabilidad del suelo, se puede usar un ensayo muy sencillo, que consiste en separar un elemento de estructura, o terrón de suelo y ver su comportamiento al cubrirlo o sumergirlo en agua. $\mathrm{Su}$ valor es cualitativo y lo hemos usado para comparar pares de muestras.

1. Se usa una muestra de tierra secada al aire.

2. Cuando esté seca se elige un grumo de tierra, o elemento de estructura, y se pone en una cápsula u otro recipiente. Se rellena con agua hasta la mitad de la altura del grumo o un poco más. El agua se añade vertiéndola sobre el recipiente y no directamente sobre el grumo.

3. Se observa que en algunas tierras el grumo cuando absorbe el

Soil stability serves as a qualitative indicator of soil biological activity, energy flow, and nutrient cycling. Binding of soil particles must constantly be renewed by biological processes (USDA, 2001) agua se rompe enseguida, otros tardan un poco en romperse, segundos o minutos, y otros no se rompen.

Si recogemos muestras de suelo de varias parcelas podemos comparar el tiempo que tardan en romperse cada una de ellas. Esta gradación en el tiempo nos habla de la capacidad que cada tierra tiene de mantener su estructura tras una lluvia o un riego. Las tierras en las que los grumos se rompen enseguida formarán una costra superficial que impedirá la entrada de aire y de agua desde la superficie del suelo y presentarán dificultades en la nascencia de las semillas, procesos de escorrentía superficial del agua de lluvia, erosión, etc. Sin embargo, las tierras en las que los grumos no se deshacen tras absorber agua van a comportarse como una esponja frente a una lluvia o el riego y van a facilitar la aireación de las zonas interiores del suelo, facilitando de esta forma los procesos de la vida. Las condiciones naturales de las tierras pueden favorecer o no la formación de una bioestructura estable al agua, pero con nuestro trabajo podemos facilitar su desarrollo o por el contrario destruirla en muy poco tiempo. (Garrido Valero, 2011C) 


\subsubsection{Estabilidad de la micro-bioestructura del suelo}

Este ensayo se hace con la fracción seca inferior a $2 \mathrm{~mm}$. Se han utilizado 2 tubos de ensayo con marcas a $2 \mathrm{~cm}^{3}$ y $12 \mathrm{~cm}^{3}$. Se necesita además calgón, fosfato sódico.

1. Se pone la misma cantidad de tierra seca en cada uno de los dos tubos

2. Se añade agua hasta una señal que hayamos hecho en la parte superior del tubo (alrededor de 1 parte de tierra y 6 partes de agua).

3. Se agitan los dos tubos a la vez durante el mismo tiempo, hasta que la tierra quede separada del fondo del tubo

4. En uno de los dos tubos se añade una pizca de fosfato sódico o de jabón de lavavajillas del tipo Calgón (nombre que se dio en el siglo XVIII al fosfato sódico), un jabón que tenga fosfato sódico y no tenga espumante. El sodio desplazará el calcio que unía los microgrumos de la tierra y entonces las arcillas y la materia orgánica descompuesta, ya separadas unas de otras, se dispersarán y enturbiarán el agua.

5. Dejamos reposar los dos tubos durante 2 ó 3 horas. Las arenas, los limos y los microgrumos de bioestructura caerán al fondo porque pesan. Las arcillas que están sueltas (dispersas) pues no forman parte de los microgranos, se dispersarán en el agua y la enturbiarán.

6. Si observamos el tubo al que solo pusimos tierra y agua, aquello que haya quedado enturbiando el agua es la arcilla que no estaba unida a otras arcillas. Si el suelo estaba mal estructurado estas arcillas enturbiarán el agua, más aún si hay mucha arcilla. Si el suelo estaba bien estructurado, el agua se verá muy limpia pues no hay arcillas sueltas sino que está formando grumitos. Si en esa tierra no hubiera nada de arcilla el agua se verá muy clara.

7. Observamos el tubo al que le hemos añadido el fosfato sódico. En el agua se habrán disuelto todas las arcillas y los compuestos húmicos solubles, está turbia. Aquí podemos ver si en nuestra tierra hay muchas o pocas arcillas, según el agua quede más o menos turbia.

8. Comparamos los dos tubos. Si hay mucha diferencia de turbidez, es que las arcillas están bien estructuradas. Si los dos tubos están igual de turbios es que no había grumitos de microestructura. 
Este método está recogido en Garrido Valero (2011b)

Changes in aggregate stability may serve as early indicators of recovery or degradation of soils. Aggregate stability is an indicator of organic matter content, biological activity, and nutrient cycling in soil. Generally the particles in small aggregates $(<0.25 \mathrm{~mm})$ are bound by older and more stable forms of organic matter. Microbial decomposition of fresh organic matter releases products (that are less stable) that bind small aggregates into large aggregates $(>2-5 \mathrm{~mm})$. These large aggregates are more sensitive to management effects on organic matter, serving as a better indicator of changes in soil quality. Greater amounts of stable aggregates suggest better soil quality. When the proportion of large to small aggregates increases, soil quality generally increases. Stable aggregates can also provide a large range in pore space, including small pores within and large pores between aggregates. Pore space is essential for air and water entry into soil, and for air, water, nutrient, and biota movement within soil. Large pores associated with large, stable aggregates favor high infiltration rates and appropriate aeration for plant growth. Pore space also provides zones of weakness for root growth and penetration. USDA (2008)

\subsubsection{Humedad de Saturación}

1. En un recipiente cóncavo de vidrio o de porcelana, se introducen $100 \mathrm{~g}$ de suelo seco cribado a $2 \mathrm{~mm}$

2. En una probeta graduada se introducen $100 \mathrm{~cm}^{3}$ de agua destilada.

3. Se añade, con cautela y revolviendo sin cesar con una espátula de plástico o metal, el agua necesaria para alcanzar el estado de pasta saturada.

4. Se mide la cantidad de agua sobrante que queda en la probeta. Esta cantidad se sustrae de la inicial, $100 \mathrm{~cm}^{3}$, para obtener el valor de la humedad de saturación en tanto por ciento.

La determinación correcta del punto de saturación de la pasta requiere cierta práctica. Cuando se alcanza la saturación, la pasta se cierra tras pasar transversalmente una espátula de unos $2 \mathrm{~cm}$ de ancho, y comienza a rezumar. $\mathrm{Al}$ acercarse a este punto hay que ir añadiendo casi gota a gota. 


\subsubsection{Textura}

1. Poner una cuchara de la fracción fina de suelo seco en la palma de la mano.

2. Verter agua despacio sobre el suelo hasta que empieza a pegarse a la mano.

3. Formar una bola de unos $2,5 \mathrm{~cm}$ de diámetro.

4. La posibilidad de modelar el suelo Está en relación con su textura, como se indica y se ilustra en la figura 31. (Tomado de UC DAVIS College of Agricultural and Environmental Sciences $(30 / 11 / 2012))$

\subsubsection{Coeficiente de Extensión Lineal, COLE}

Usamos la fracción de suelo seca, $<2 \mathrm{~mm}$.

1. Se amasa con agua una porción de tierra tamizada de cada una de las muestras recogidas hasta hacer un cilindro de $10 \mathrm{~cm}$ de largo y de $1 \mathrm{~cm}$ de ancho. Se hace el cilindro un poco más largo de $10 \mathrm{~cm}$, se pone una regla a lo largo y se corta con un cuchillo exactamente a una longitud de $10 \mathrm{~cm}$. Si la tierra no tiene arcilla o tiene más del $85 \%$ de arena no va a ser posible hacerlo pues se rompe.

2. Se coloca el cilindro sobre una mesa que tenga una superficie no absorbente, como es mármol, granito o formica, nunca sobre madera o papel. Y se deja ahí hasta que esté seco, normalmente hasta el día siguiente.

3. Al día siguiente cuando se ha secado se mide con una regla. Todas las tierras que tienen arcilla se encogen algo al secarse, al menos un $2 \%$ ( $2 \mathrm{~mm}$ ). Si el cilindro se encoge $7 \mathrm{~mm}$ o más, entonces sabemos que todas las arcillas que hay en ese suelo son expansivas, esto es arcillas de tipo 2:1 con elevada Capacidad de Intercambio Catiónico.

Estas indicaciones proceden de Garrido Valero (2011a, pp. 11-14).

\subsubsection{Notas sobre las arcillas}

Las arcillas son minerales secundarios complejos que determinan en gran medida las propiedades del suelo. En el anexo $C$ se expresan de forma muy sencilla algunas de sus características más importantes. 

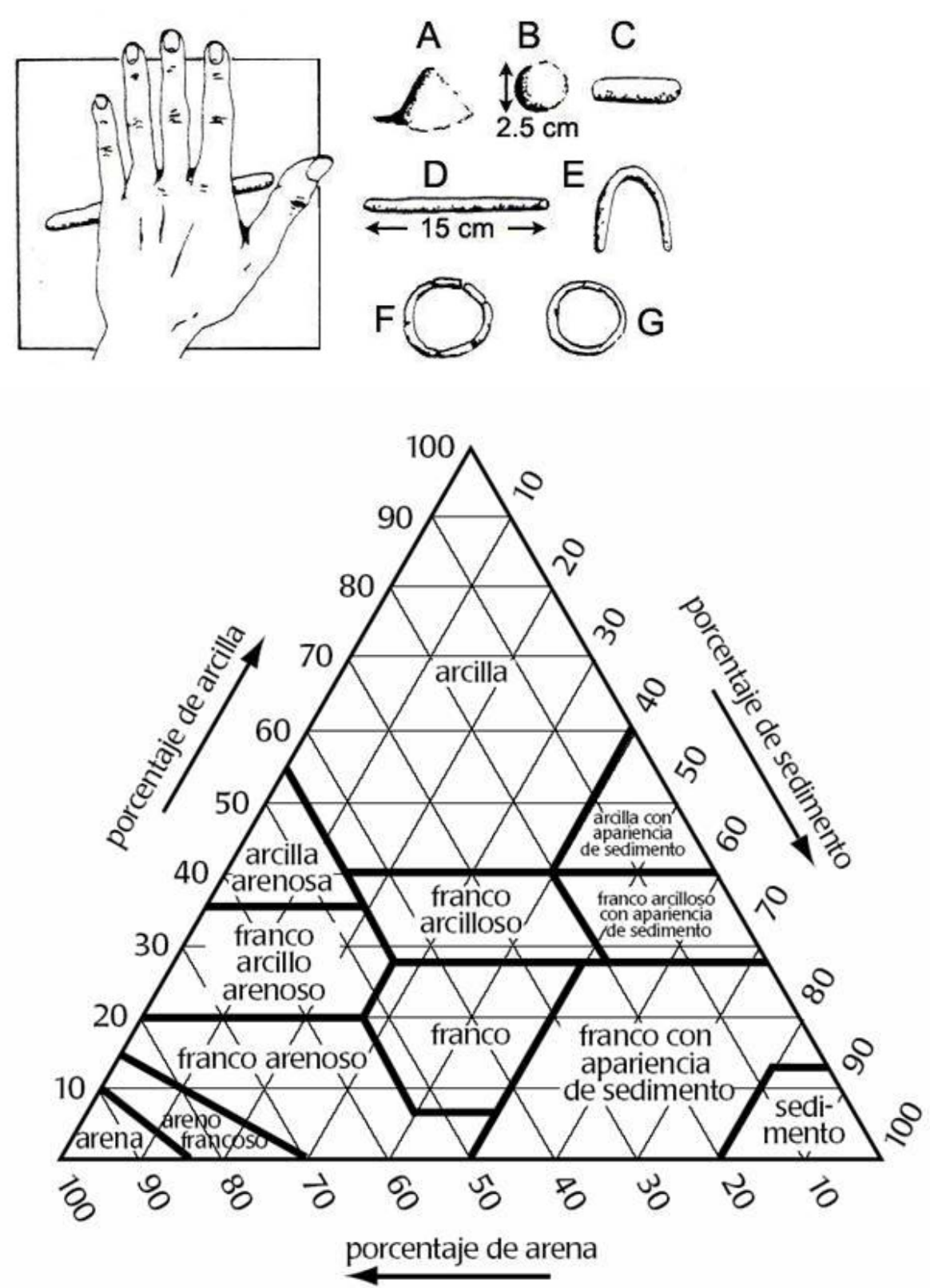

Figura 31: Estimación cualitativa de la Textura (De UC DAVIS College of Agricultural and Environmental Sciences (30/11/2012))

A Arena - El suelo queda suelto y granulado. Sólo se puede apilar en forma de pirámide cónica.

B Arenoso franco - El suelo contiene suficiente limo y arcilla para cohesionarse un poco. Se puede formar una bola muy frágil.

C Franco con apariencia de sedimento o Franco limoso- Como el anterior, pero permite formar un pequeño cilindro grueso.

D Franco - Aproximadamente el mismo contenido de arena y de limo, con arcilla. Se puede formar un cilindro de unos $15 \mathrm{~cm}$ de largo, que se rompe al doblarlo

E Franco arcilloso - Como el franco, aunque se llega a doblar en forma de $\mathrm{U}$ sin romperse.

F Arcilla ligera -El suelo se puede cerrar en un anillo que muestra grietas.

G Arcilla pesada - El suelo se cierra en un anillo sin agrietarse. 



\section{Parte IV}

\section{RESULTADOS}

Se sintetizan y se presentan agrupados los resultados relevantes de la parte experimental de la investigación en forma progresiva, conforme a los objetivos establecidos y siguiendo en lo posible el orden cronológico en que fue desarrollándose.

En el capítulo 9 se recoge la contribución realizada al desarrollo del Método Horizontal de Dinamolisis Capilar partiendo de la configuración del Chroma-Test.

En el capítulo 1o se muestra la evolución de la investigación y el potencial del método Horizontal de Dinamolisis Capilar para caracterizar los suelos contaminados.

En el capítulo II se comprueba por medio de ensayos ciegos que el método Horizontal de Dinamolisis Capilar es validable.

En el capítulo 12 se valora la investigación realizada en relación con las hipótesis y objetivos propuestos. Se presentan posibles aplicaciones de los resultados obtenidos y se indican posibles líneas de investigación para el futuro. 



\section{INTRODUCCIÓN}

Desde los primeros ensayos realizados en 2011 se fueron poniendo de manifiesto las dificultades para reproducir los resultados obtenidos mediante la configuración más popular del Método Horizontal de Dinamolisis Capilar, el denominado Chroma-Test de Pfeiffer (descrito en la sección 4.I en la página 34). Se experimentaron dificultades incluso con las réplicas simultáneas de los ensayos, lo cual ponía en entredicho cualquier posible valoración de los mismos. Como hemos visto en la sección $4 \cdot 3$, las investigaciones precedentes ya indican que las instrucciones de Pfeiffer son insuficientes o necesitan ser precisadas. En esa sección se recogen las principales contribuciones anteriores a este trabajo. Muestra que los principales investigadores han adoptado diversas modificaciones, pero en muchos casos no están suficientemente documentadas o no se justifica su utilidad, al menos para los fines que aquí perseguimos. Por ello ha sido necesario un laborioso y metódico trabajo previo para poder llegar a resultados reproducibles con un mínimo de modificaciones del Chroma-Test, y manteniendo en lo posible la simplicidad.

Este capítulo recoge la contribución propia al desarrollo del Método Horizontal de Dinamolisis Capilar, a partir del Chroma-Test, para hacer posible su estandarización. Se consideran los siguientes objetivos:

- Estandarizar el Método Horizontal de Dinamolisis Capilar en base a los planteamientos de L. Kolisko (1939) y partiendo del método denominado Chroma-Test de Pfeiffer (1959). Con este fin se han abordado los siguientes aspectos:

- Método de ensayo. Establecer modos de controlar el experimento y de evaluar la calidad de los resultados obtenidos. Sección 9.1.

- Estudio de los parámetros del experimento. Sección 9.2.

- Determinar las modificaciones necesarias del método del Chroma-Test para su estandarización. (Se presentan en la sección 8.3 del capítulo 8.)

En la sección 9.1 se resume la metodología usada para controlar la calidad de los reactivos y de los ensayos (subsección 9.1.1) y se resumen las conclusiones obtenidas de los ensayos preliminares (subsección 9.1.2). 
En la sección 9.2 recogemos los resultados de la investigación de los parámetros del experimento de Dinamolisis Capilar en la configuración horizontal. En la subsección 9.2.I se mencionan las limitaciones del desmuestre puntual. En la subsección 9.2.2 se investigan varias sales metálicas con distintas concentraciones. La subsección 9.2.3 muestra los resultados para dos fabricante de filtros y la variación debida a la posición de las marcas sobre los filtros que se usan para controlar la cantidad de disolución de nitrato de plata y de extracto.

En la sección 9.3 se resumen las causas de variabilidad imputables al procedimiento original del Chroma-Test.

\subsection{PUESTA A PUNTO DEL MÉtodo DE ENSAyo}

Al utilizar el Chroma-Test de Pfeiffer se pudo constatar la dificultad para repetir los resultados, incluso en los ensayos paralelos realizados por el mismo operador. Por ello se adoptaron referencias fijas para poder investigar las causas ambientales y operativas de la variabilidad y se establecieron ensayos de control de las disoluciones de $\mathrm{NaOH}$ y de $\mathrm{AgNO}_{3}$ que permitieron investigar sistemáticamente los factores de influencia. Esto permitió identificar las principales causas de variabilidad y fuentes de error.

\subsubsection{Ensayos de control}

La usual realización de ensayos paralelos de cada muestra, contemplada en el método de Pfeiffer, es una exigencia mínima, pero no permite detectar ningún tipo de error sistemático en los procesos de extracción y de sensibilización. Para ello es necesario realizar controles adicionales de las disoluciones de $\mathrm{NaOH}$ y de $\mathrm{AgNO}_{3}$. Los medios de control utilizados en todos los ensayos son los siguientes:

1. Realizar al menos dos ensayos paralelos de cada muestra.

2. Realizar dos ensayos blancos con la solución de $\mathrm{NaOH}$ al $1 \%$ utilizada en la extracción de las muestras de suelo.

3. Realizar dos controles de la disolución de la sal metálica, guardando el primer y el último filtro sensibilizados y manteniéndolos siempre en la oscuridad.

4. Como referencia se utilizó principalmente la muestra Cam. huerto, que junto con los ensayos en blanco, muestran la polaridad entre un buen suelo y la naturaleza exclusivamente mineral del $\mathrm{NaOH}$.

Estas medidas han resultado muy valiosas para detectar errores en la preparación de los reactivos y la sensibilización de los filtros. Las imágenes de los ensayos de control de los apartados 2. y 3. han de ser siempre iguales. 


\subsubsection{Ensayos preliminares}

Durante la etapa de aprendizaje del Chroma-Test se pusieron de manifiesto dificultades de repetibilidad incluso en los ensayos paralelos. Se apreciaba de forma bastante regular una diferencia entre el primer y el segundo dinamograma obtenidos a partir del mismo extracto, realizando los ensayos de forma simultánea. Se pensó que podría ser debido a la diferencia de temperatura entre la cámara climatizada y el laboratorio, ya que normalmente la temperatura en la cámara es más alta que en el laboratorio. Otras posibles causas que entraron en consideración fueron la alteración, por la luz o por contaminación, de la disolución de $\mathrm{AgNO}_{3}$, la alteración del extracto, y también se investigó el efecto de la iluminación durante las distintas etapas del experimento. Se realizaron ensayos para ver el efecto de estos factores, y se concluyó que los problemas de repetibilidad durante la etapa de aprendizaje del método de Pfeiffer son achacables en gran medida a un deficiente control de la cantidad de $\mathrm{AgNO}_{3}$ y de extracto.

En el laboratorio de la ETSIME se realizaron numerosos experimentos preliminares para estudiar además los aspectos más generales: influencia de la preparación de las muestras (secado, criba, molienda), de los parámetros ambientales (temperatura, humedad relativa, iluminación) y la estabilidad de los reactivos y extractos. Todos los ensayos preliminares se realizaron con los controles indicados en la sección 9.1. Estos experimentos fueron determinantes para comprobar la escasa influencia de los mencionados factores en el marco del ensayo, y atribuir la variabilidad indeseada a los parámetros del propio método del Chroma-Test. En este capítulo analizamos los principales factores de influencia.

\subsection{PARÁMETROS DE INFLUENCIA SOBRE EL EXPERIMENTO}

En esta sección resumimos la investigación de algunos aspectos relevantes que han recibido poca atención o están poco documentados, como son el método de desmuestre, los patrones de distintas sales y su variación en función de la concentración utilizada, la posibilidad de usar filtros de otros fabricantes, y por último la influencia del método de medida del volumen de sal y de extracto en el ensayo.

\subsubsection{Limitaciones del desmuestre puntual}

Los suelos expuestos a los mismos procesos geológicos, edáficos y antrópicos, deben mostrar la misma signatura con el método de Dinamolisis Capilar. Estos factores condicionan la representatividad de las muestras y hacen necesario utilizar métodos de desmuestre adecuados si se quieren extrapolar los resultados. En todos los casos se
Los experimentos preliminares fueron determinantes para comprobar la escasa o nula influencia del cribado y molienda para la preparación de la muestra y de los factores ambientales de humedad y temperatura en el ensayo. 
tomaron muestras selectivas puntuales sin análisis previo de la variabilidad, por lo que los análisis no son extrapolables. Para investigar la variabilidad de las muestras puntuales se repitió la toma de seis muestras en la $3^{\mathrm{a}}$ campaña de desmuestre, un año después de la $2^{\mathrm{a}}$. En las cuadrículas 93 y 91, se tomaron tres muestras cercanas para apreciar la variabilidad dentro de una misma parcela en el primer caso y entre parcelas contiguas en el segundo.

\subsubsection{Variabilidad espacial}

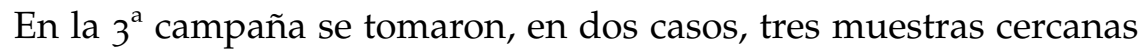
para apreciar la variabilidad del desmuestre puntual.

CUADRÍCULA 93 Las tres muestras, 93.1, 93.2 y 93.3 de la figura 49 en la página 159, muestran resultados algo diferenciados. Se tomaron en un prado urbano buscando la máxima variabilidad de las características observables sobre el terreno, como la proximidad a un afloramiento de la roca subyacente, la diferencia de coloración y la proximidad a la carretera.

CUADRícula 91 Todas las muestras de la cuadrícula 91 se tomaron en olivar. Los correspondientes dinamogramas de la figura 49 en la página 159 muestran diferencias. Las muestras proceden de olivares contiguos que pueden estar sujetos a prácticas agrícolas diferentes, lo que podría ser la causa de las diferencias observables.

\subsubsection{Reproducción del desmuestre en días diferentes}

La tabla 20 recoge las referencias de los pares de muestras tomadas con un año de diferencia.

Tabla 20: Repetición del desmuestre. Pares de muestras tomadas con un año de diferencia

\begin{tabular}{|c|c|c|c|c|c|c|}
\hline $1^{\text {a }}$ CAMPAÑA 4/5/2011 & 12 & 67 & 61 & 69 & 91 & 93 \\
\hline $2^{\mathrm{a}}$ CAMPAÑA 7/5/2012 & 12.1 & 67.1 & 61.1 & 69.1 & 91.3 & 93.1 \\
\hline
\end{tabular}

En la figura 49 en la página 159 se pueden comparar los resultados. A excepción de las muestra 69 y 69.1, los dinamogramas de las muestras repetidas de la tercera campaña son muy similares a las correspondientes de la segunda campaña de desmuestre. Las muestras de la cuadrícula 69 se tomaron en una zona con gran movimiento de tierras, que han podido traer a la superficie los niveles subyacentes pobres o carentes de materia orgánica, que observamos en la muestra 69. 
9.2.2 Influencia de la sal metálica y de su concentración

La influencia de la concentración de nitrato de plata se presenta en la figura 32 en la página siguiente. En ella se pone de manifiesto en forma resumida cómo cambia la morfología del patrón de la muestra Cam. huerto con varias concentraciones de nitrato de plata, según qué fabricante de papel de filtro se elija y dónde se sitúen las marcas de control. (Para la descripción del método original de Pfeiffer ver 4.I en la página 34.) En esta figura se puede ver el influjo de cada uno de estos factores sobre los resultados del experimento. 
Concentración de la sal de Ag:
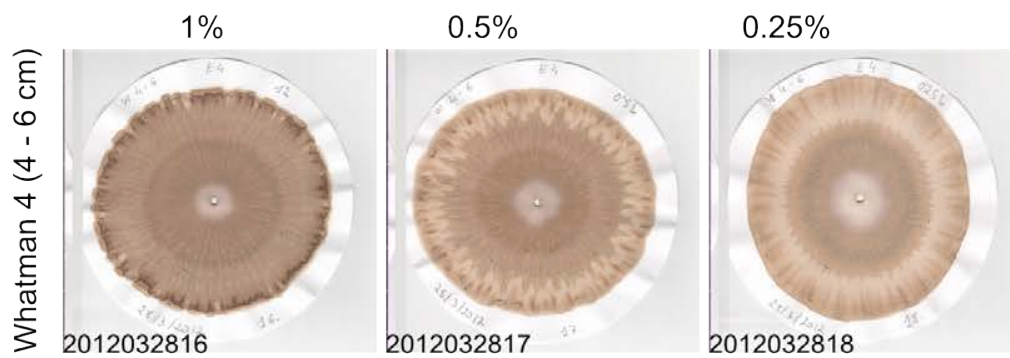

$0.125 \%$
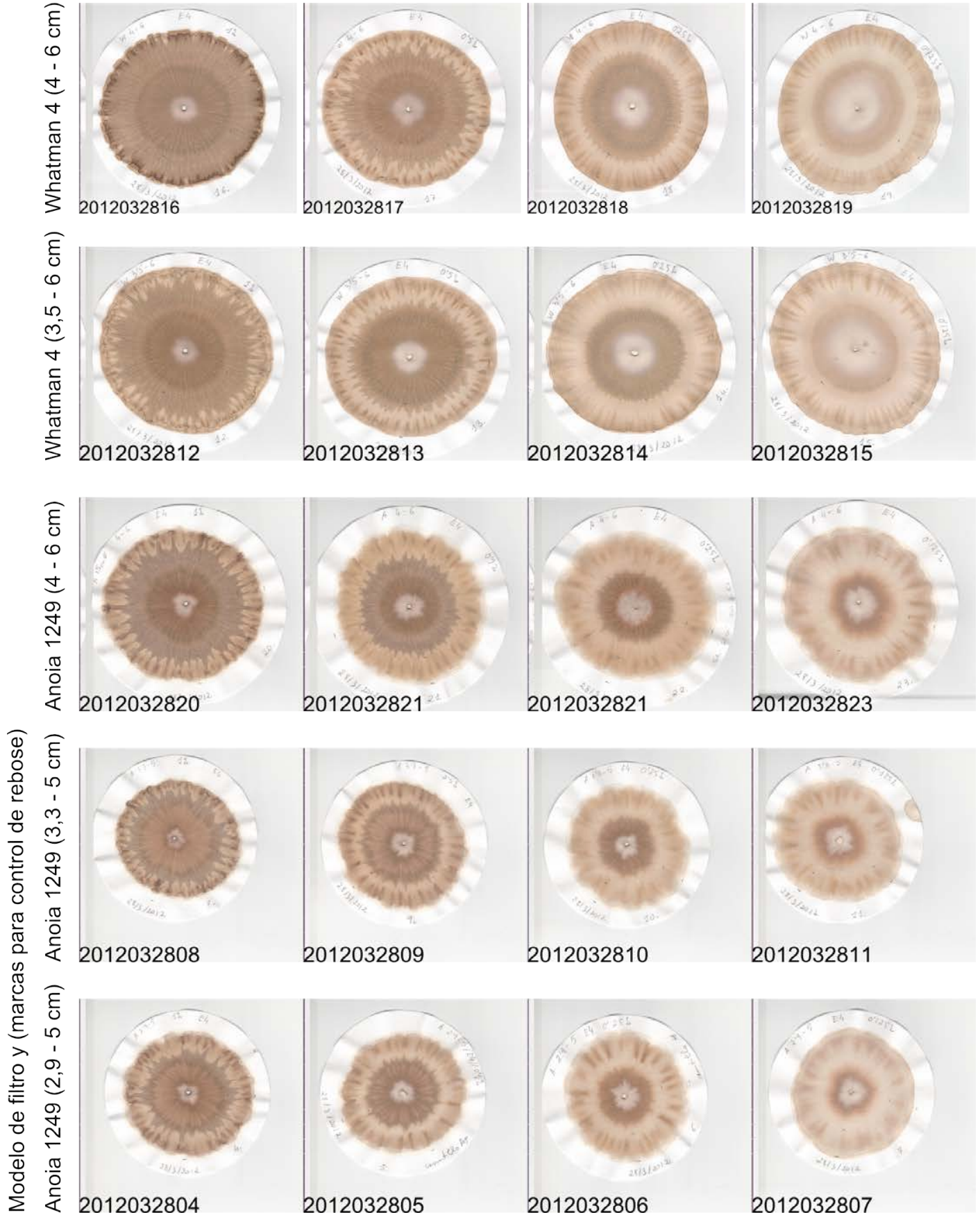

Figura 32: Efecto, sobre la muestra "Cam. huerto", de las concentraciones variables de nitrato de plata usando filtros Whatman 4 y Anoia 1249 con dos posiciones distintas de las marcas sobre los filtros. Dos primeras filas: filtro Whatman 4 de $15 \mathrm{~cm}$ de diámetro Tercera fila: filtro Anoia 1249 de $15 \mathrm{~cm}$ de diámetro Dos últimas filas: filtro Anoia 1249 de 12,5 cm de diámetro, con marcas reducidas proporcionalmente al tamaño del diámetro.

En esta figura se puede ver, a modo de resumen, para los filtros Whatman y Anoia y con marcas a distancias diferentes del centro del filtro, cómo varían los patrones con distintas concentraciones de $\mathrm{AgNO}_{3}$. 
Al querer generalizar la configuración original descrita por Pfeiffer, recogida en la sección 4.1, para poder utilizarla con otras sales metálicas, ha sido necesario estudiar la influencia de la concentración de las distintas sales metálicas sobre el resultado del experimento. En la figura 33 se muestra el abanico de resultados de suelos de diferentes calidades, usando varias concentraciones de la sal de oro (que se muestran en las cuatro columnas de la izquierda), y de la sal de plomo (recogidas en las tres columnas de la derecha). En esta figura se reproducen los dinamogramas del suelo de cultivo biodinámico Cam. huerto, de dos muestras de Linares y de los ensayos en blanco. Destaca el valor discriminatorio de las sales de $\mathrm{Au}$ y $\mathrm{Ag}$ frente a la de $\mathrm{Pb}, \mathrm{y}$ como veremos a continuación en la figura 34, también frente a todas las demás sales en las concentraciones ensayadas.

En la figura 34 se muestran los dinamogramas de la muestra de suelo biodinámico Cam. huerto obtenidos con 6 sales metálicas, cada una en 4 concentraciones diferentes. 


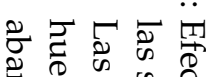

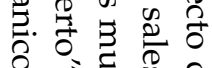

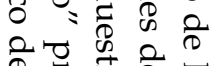

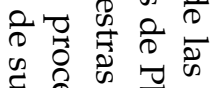

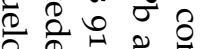

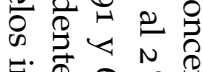

F.

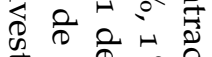

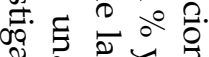

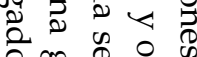

잉

蛋. $\frac{2}{2} \overbrace{0}^{\circ}$

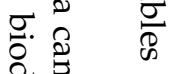

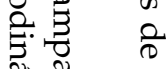

约羟

के क

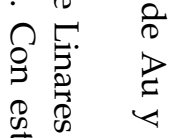

$\begin{array}{ccc}0 & 0 \\ 0 & 0 & 0 \\ 0 & 0 & 0 \\ 0 & 0 & 0 \\ 0 & 0 & 0 \\ 0 & 0 & 0\end{array}$

空

is

כ)

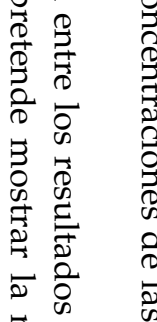

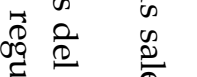

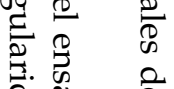

Identificación de la muestra:
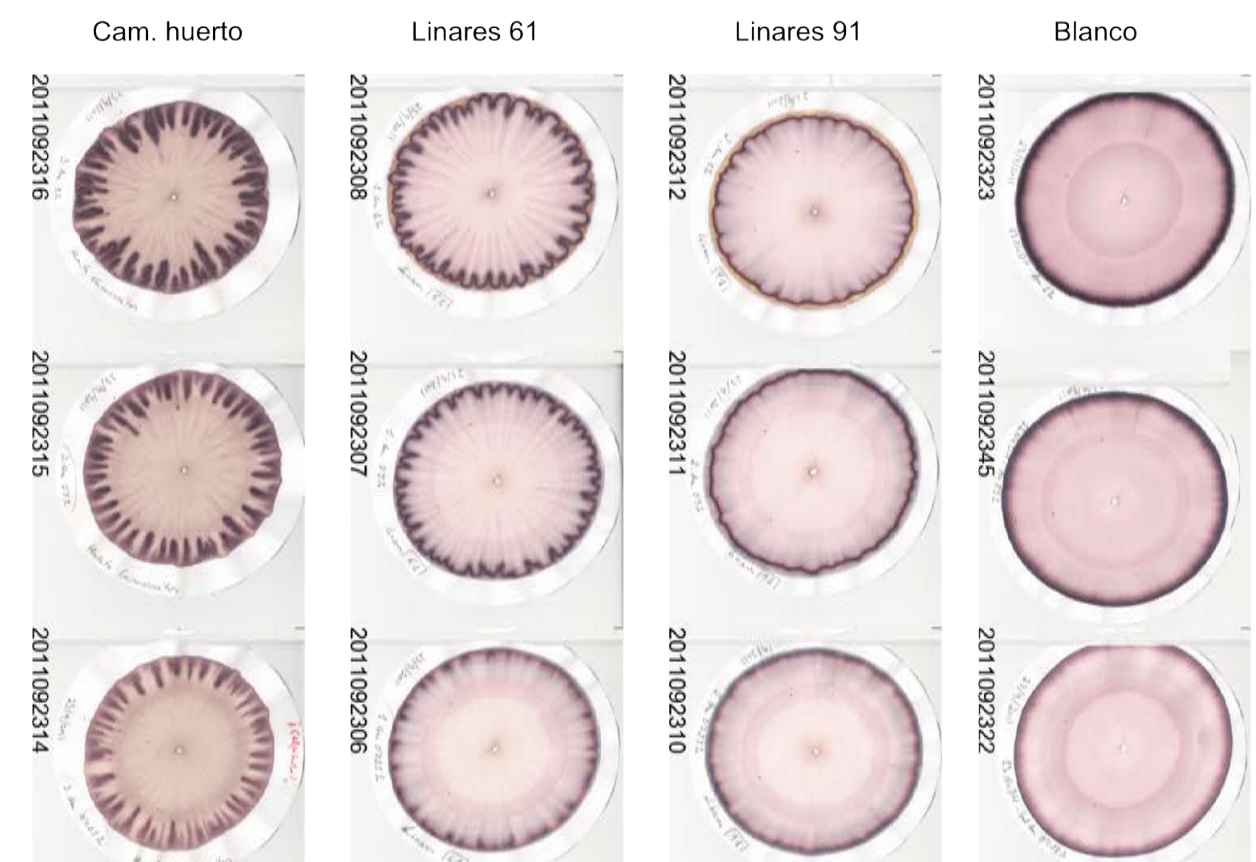

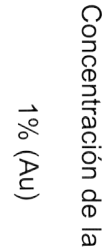
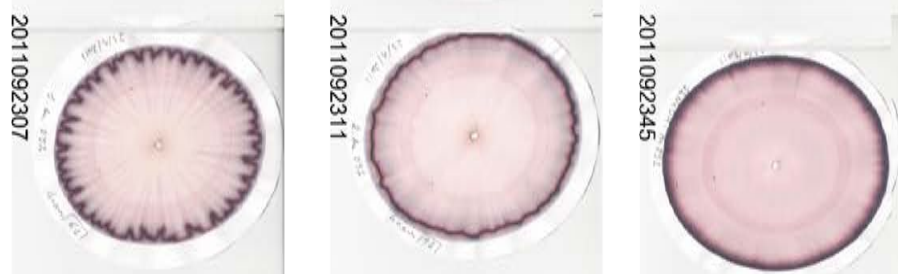

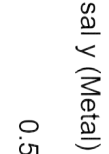
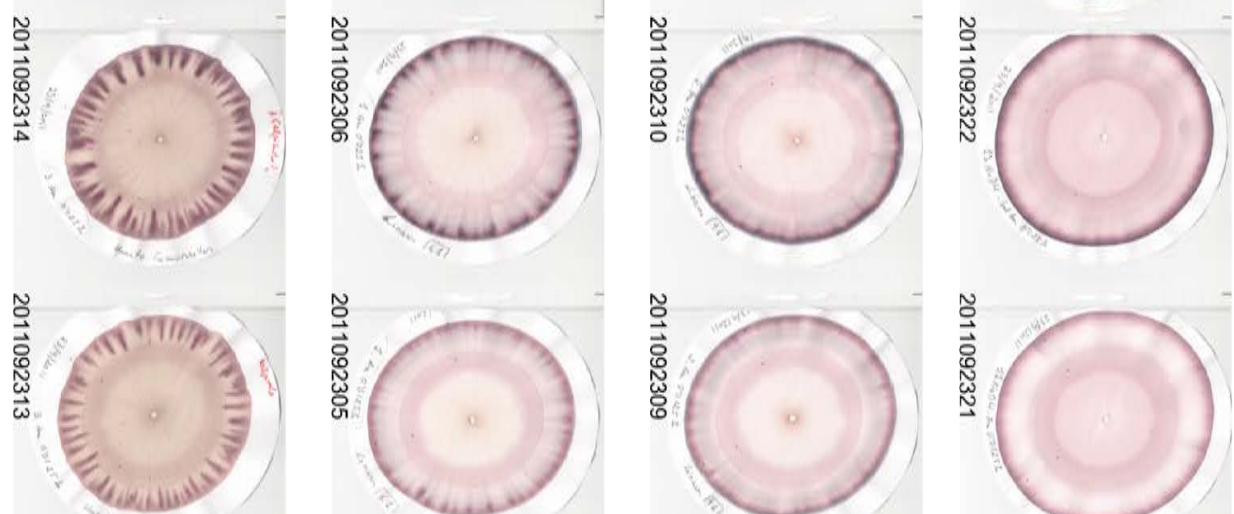

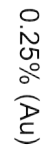
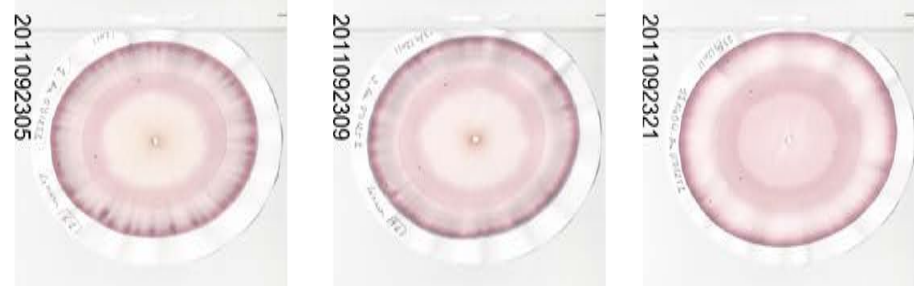

$\stackrel{\circ}{\vec{N}}$
O
$\stackrel{\circ}{D}$
D
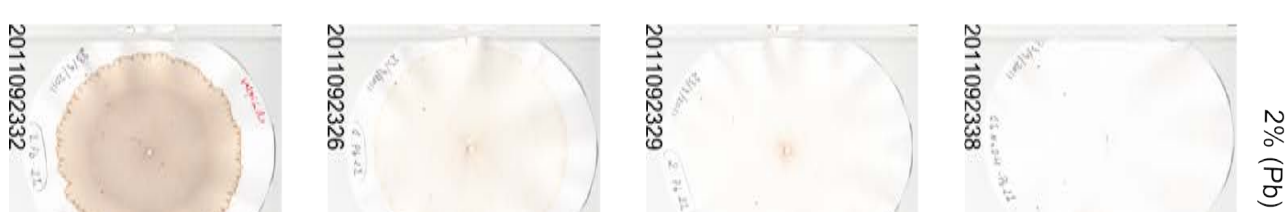

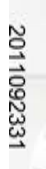
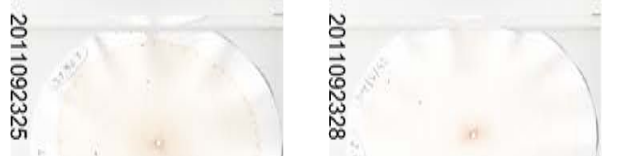

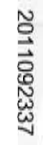

$\frac{\sqrt{0}}{\stackrel{0}{\circ}}$

है 己

89

จ

: 40

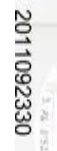

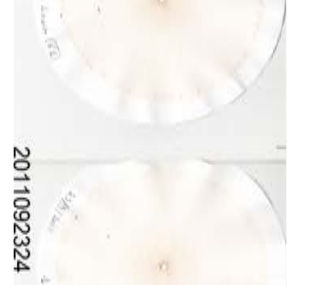

戠

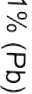

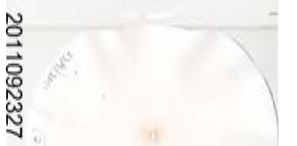

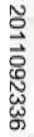

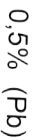

०ै ०

유 웅

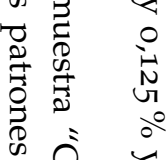

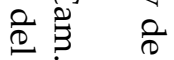




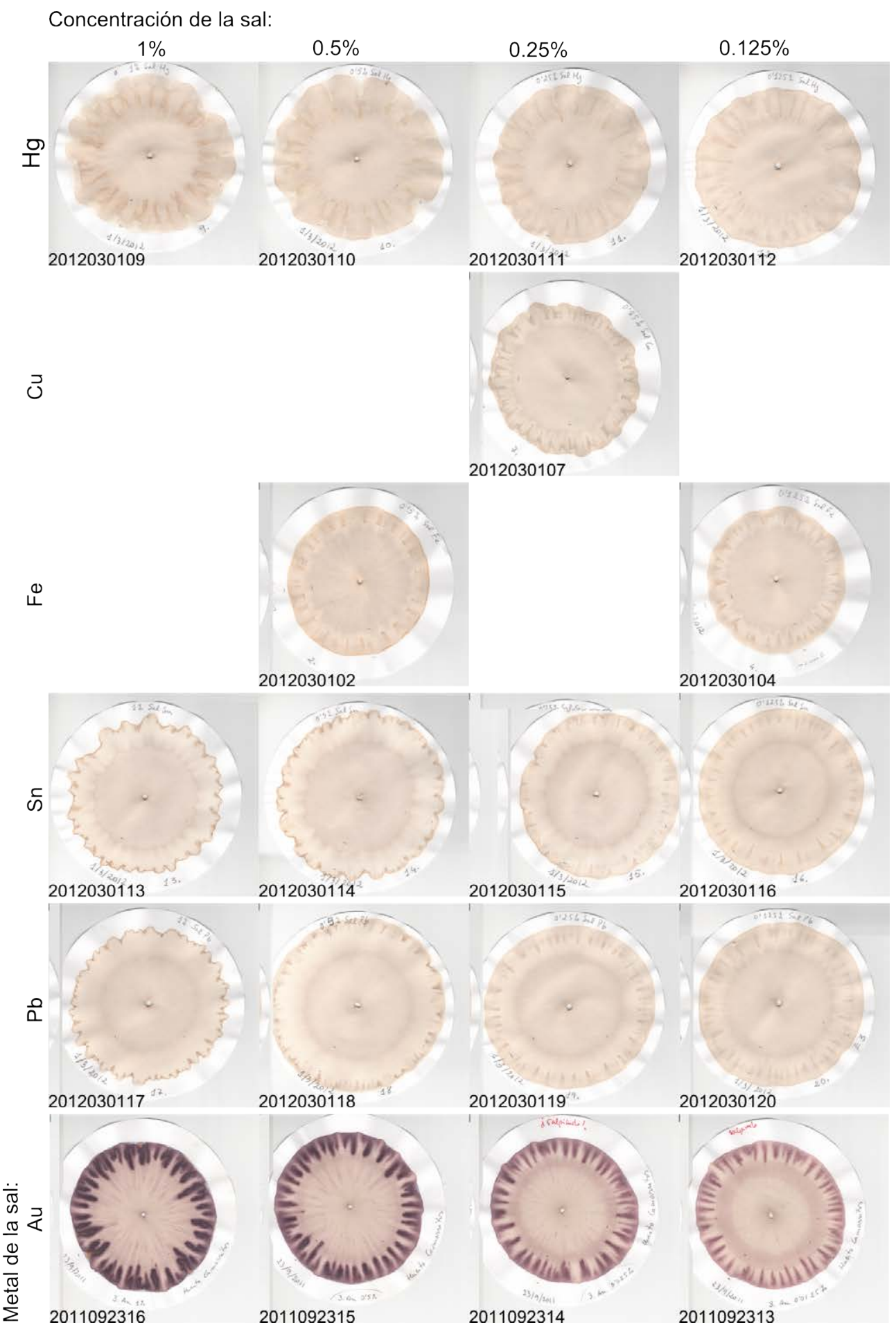

Figura 34: Efecto, para la muestra de suelo "Cam. huerto", de la variación de concentración sobre los patrones de las sales metálicas de $\mathrm{Hg}$, $\mathrm{Cu}, \mathrm{Fe}, \mathrm{Sn}, \mathrm{Pb}$ y $\mathrm{Au}$.

Esta figura muestra la regularidad de variación de los patrones con la concentración de la sal metálica. 


\subsubsection{Fabricante y marcaje de los filtros}

En la figura 32 en la página 116 podemos ver cómo cambia la morfología del patrón de la muestra Cam. huerto con dos fabricantes de papel de filtro y diferentes posiciones de las marcas sobre el filtro (ver descripción del Chroma-Test en la sección 4.I). A continuación presentamos estos factores con más detalle.

\subsubsection{Filtros Whatman 4 y Anoia 1249}

En la figura 35 se puede ver otro ejemplo de cómo varían los patrones al usar filtros de fabricantes diferentes.

Las características de los filtros Anoia 1249 y Whatman 4 se encuentran en el anexo A.

\subsubsection{Marcaje de los filtros y pipeteo}

En el método de Pfeiffer, la cantidad de sal está controlado por las marcas inscritas sobre el papel de filtro. La publicación original de Pfeiffer es americana, y las medidas de referencia aparecen en pulgadas. Indica, para sensibilizar el filtro con nitrato de plata, $1^{1 / 2}$ pulgadas, que corresponde a unos $3,8 \mathrm{~cm}$. Esto ha dado lugar a variaciones importantes del método ya que algunos autores como Voitl and Guggenberger (1986) establecen $4 \mathrm{~cm}$ y otros, como Kanzler (1991); Blank (1991); Hassold-Piezunka (2003), han adoptado 3,5 cm. La influencia de la posición de las marcas se muestra en esta sección.

En la figura 35 se puede apreciar cómo se modifican los patrones al variar la posición de las marcas de control sobre el filtro. Cada ensayo se ha repetido 5 veces.

Los ensayos reproducidos en la figura 35 se han hecho con filtros de $15 \mathrm{~cm}$ de diámetro (Whatman 4) y con filtros de $12,5 \mathrm{~cm}$ de diámetro (Anoia 1249). Para los filtros de tamaño menor, las distancias de las marcas al centro se han reducido proporcionalmente.

En la figura 36 se muestran los resultados obtenidos con filtros de $12,5 \mathrm{~cm}$ de diámetro (Anoia 1249) con marcas a 3,3 cm, 3,1 cm, 2,9 cm y $2,7 \mathrm{~cm}$. Cada ensayo se ha repetido 5 veces. Los elementos morfológicos varían entre cada serie de manera notable.

Las figuras 35 y 36 corresponden a la muestra Cam. huerto, cultivado con el método ecológico biodinámico. En la figura 37 se presentan los resultados de los mismos ensayos en blanco.

Los resultados anteriores muestran la gran importancia de la situación de las marcas para la morfología de los dinamogramas resultantes. Además, simplemente con las marcas no es posible controlar con suficiente precisión las cantidades de reactivo y de extracto utilizadas. Con el pipeteo de volúmenes fijos, además de las marcas sobre los filtros, se puede mejorar notablemente la repetibilidad como se verificará en los ensayos ciegos recogidos en la sección 11.1.1. 
Distancia de las marcas de rebose al centro del filtro:
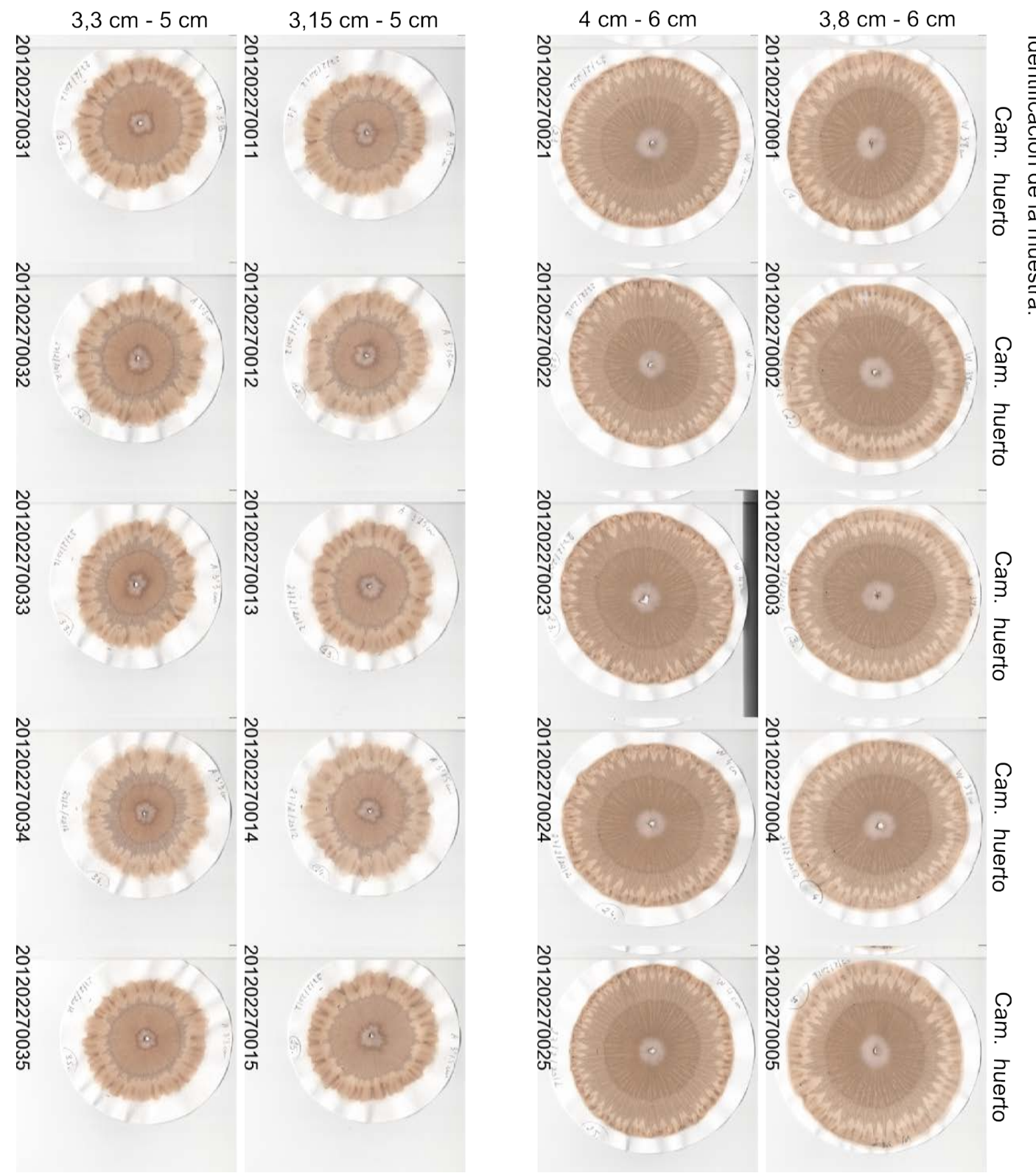

Figura 35: Posición de las marcas sobre los filtros y repetibilidad de los patrones con filtros Whatman 4 de $15 \mathrm{~cm}$ de diámetro y con filtros Anoia 1249 de $12,5 \mathrm{~cm}$ de diámetro.

Obsérvese que la primera marca determina el tamaño de la zona interior y que este tamaño debería ser mayor con las marcas a $3,3 \mathrm{~cm}$ del centro, frente a $3,15 \mathrm{~cm}$, para los filtros ANOIA de $12,5 \mathrm{~cm}$ de diámetro, y con las situadas a $4 \mathrm{~cm}$ frente a las situadas a $3,8 \mathrm{~cm}$ en los filtros Whatman de $15 \mathrm{~cm}$ ). La relación de tamaños esperable no siempre se mantiene. En las figuras que siguen se muestran más repeticiones. 
Distancia de las marcas de control de rebose al centro del filtro

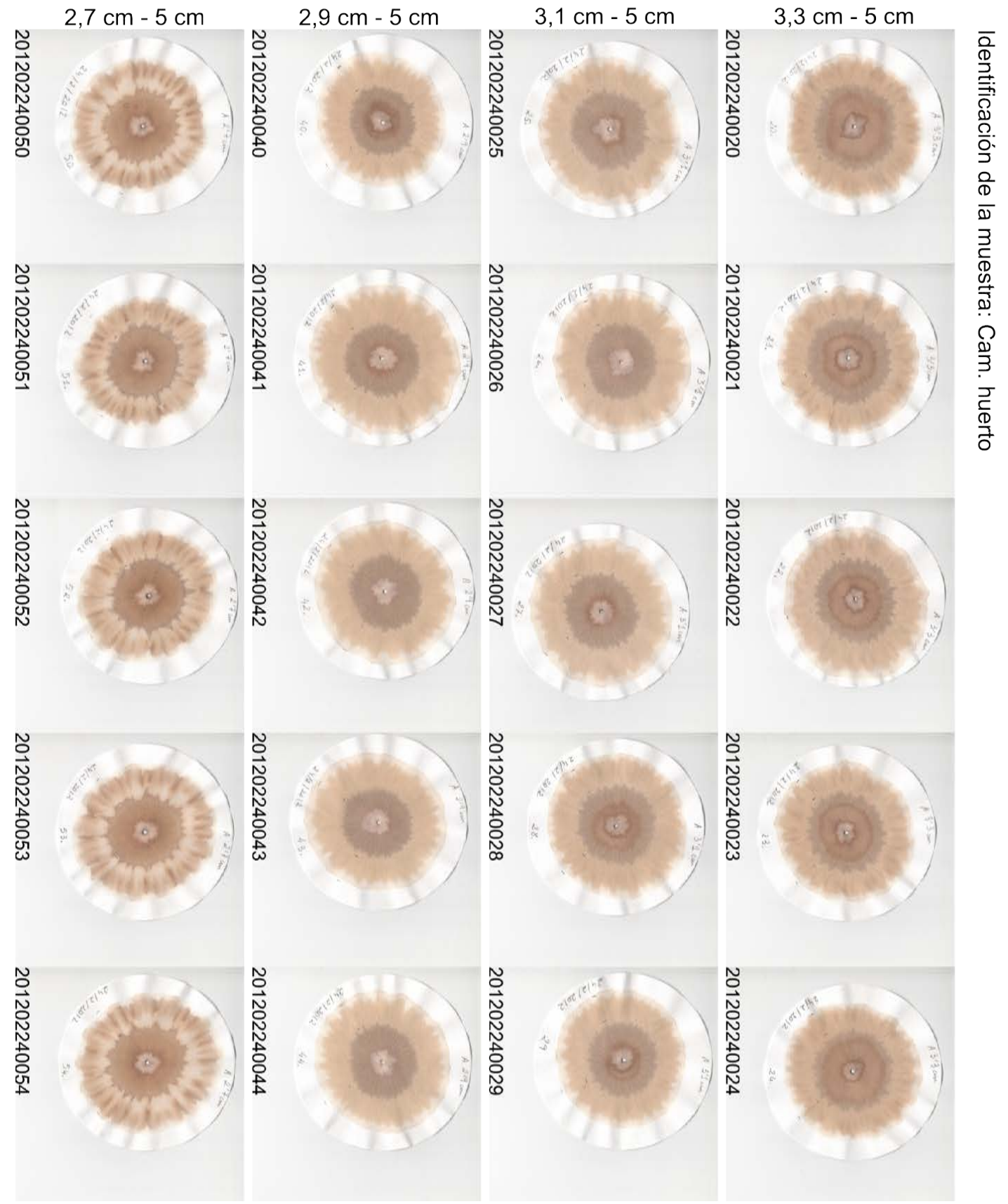

Figura 36: Influencia de la posición de las marcas sobre los filtros para la muestra "Cam. huerto". Se han usado filtros Anoia 1249 de 125 mm de diámetro.

Obsérvese que los rasgos morfológicos de los patrones varían notablemente al modificarse la posición de las marcas sobre el filtro. 
Distancia de las marcas de control de rebose al centro del filtro

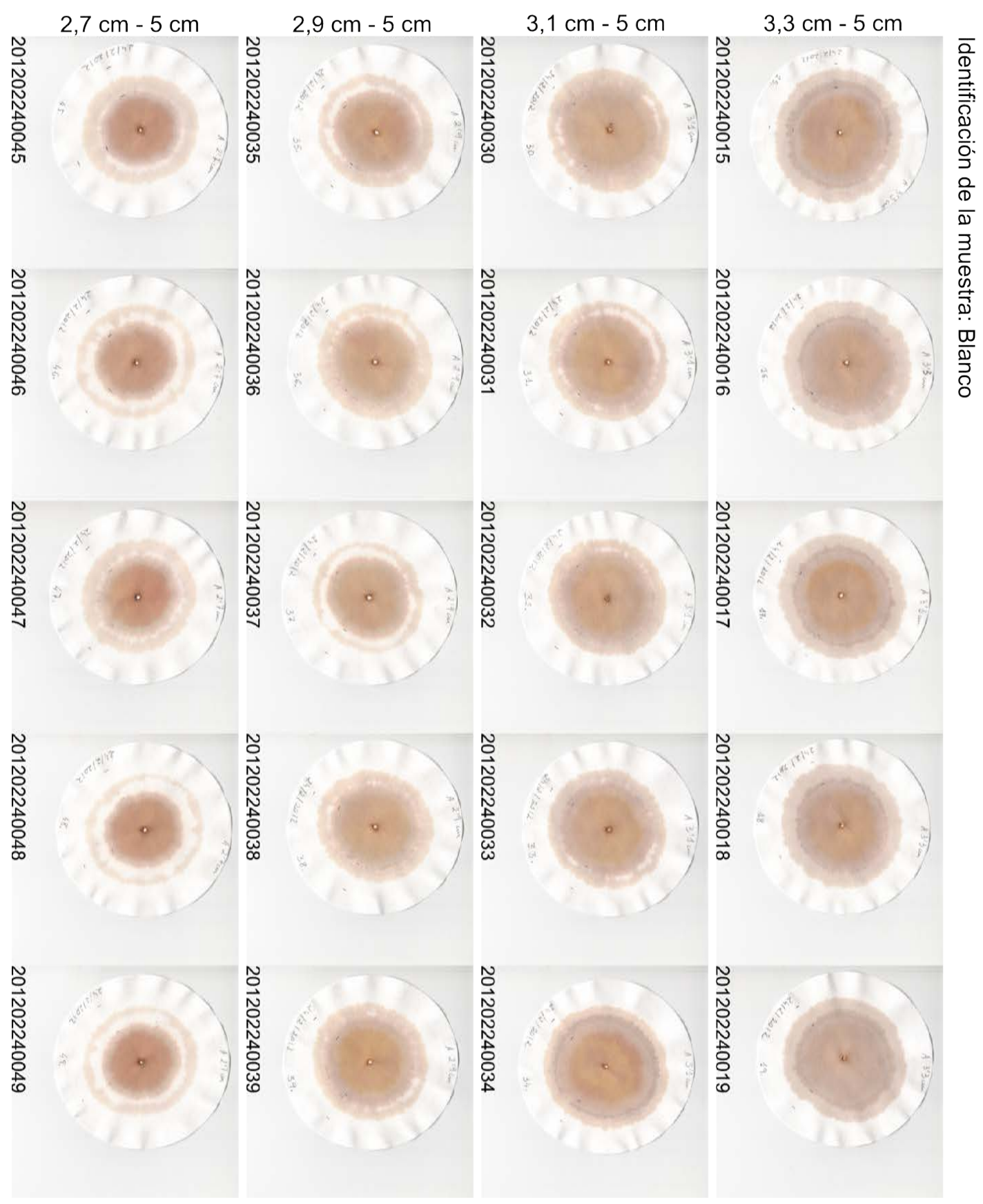

Figura 37: Influencia de la posición de las marcas sobre los filtros para el Blanco. Como en la figura precedente, se han usado filtros Anoia 1249 de $125 \mathrm{~mm}$ de diámetro. 



\subsubsection{Ampliación de la zona exterior}

Como indicamos en la sección 8.4, la interpretación de las imágenes se basa en el tipo de rasgos morfológicos identificables en las distintas zonas de los dinamogramas. La zona exterior es muy importante al proceder a valorar las imágenes. Es fácil constatar que, con los volúmenes y parámetros geométricos descritos en la sección 8.3 y utilizados para los ensayos ciegos, resulta muy reducida, dificultando la interpretación. Por ello se han realizado tres series de ensayos adicionales en condiciones idénticas, operador MTM, modificando el volumen pipeteado y la correspondiente posición de las marcas. Los resultados de estos ensayos adicionales se muestran en la figura 38 . Obsérvese que en la serie central, con volúmenes de $0,4 \mathrm{ml}$ de disolución de $\mathrm{AgNO}_{3}$ y de $1,3 \mathrm{ml}$ de extracto del suelo, se produce la aparición de un anillo blanquecino muy grueso entre la zona media y la zona interior. En la figura 39 se ha sustituido la serie central, poniendo en su lugar una de las series de los ensayos ciegos, para los que se usaron unos volúmenes de $0,5 \mathrm{ml}$ y 1,2 $\mathrm{ml}$. En la serie con $0,4 \mathrm{ml}$ y $1,2 \mathrm{ml}$ se ha ampliado la zona exterior a costa de reducir la zona interior. En la serie $0,5 \mathrm{ml}$ y $1,3 \mathrm{ml}$ se amplia la zona exterior sin reducir el tamaño de la zona interior. En esta última encontramos la mejor expresión de los rasgos morfológicos, coincidiendo con la elección de Balzer (ver sección 4.3.1).

Los mejores resultados se han obtenido con $0,5 \mathrm{ml}$ de disolución de nitrato de plata $y$ $1,3 \mathrm{ml}$ de extracto de suelo. 
Volumen de $\mathrm{AgNO}_{3}$ - Volumen de extracto:
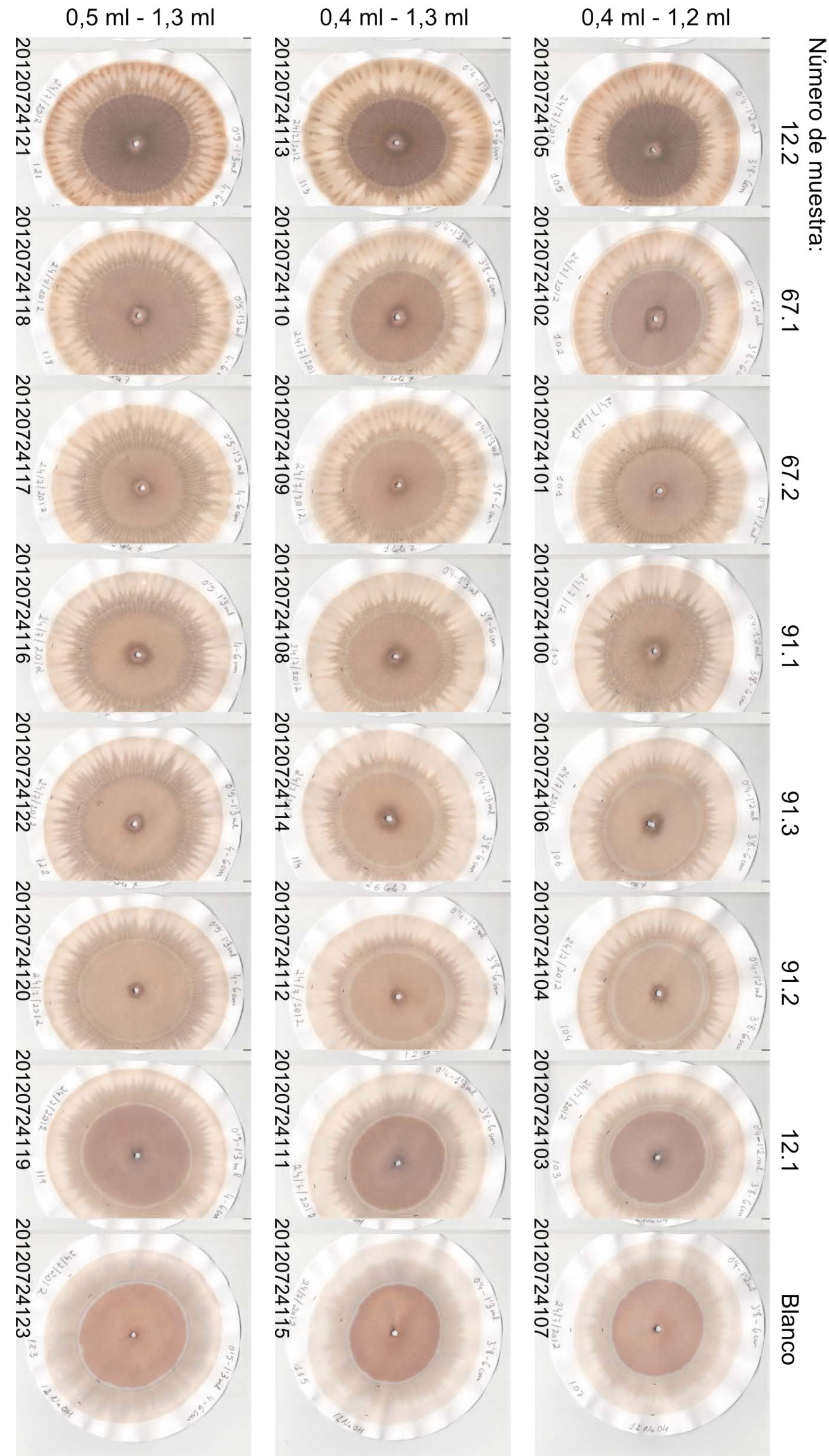

Figura 38: Ampliación de la zona exterior modificando el volumen de $\mathrm{AgNO}_{3}$ / / o del extracto utilizado 
Volumen de $\mathrm{AgNO}_{3}$ - Volumen de extracto

(Distancia de las marcas al centro)

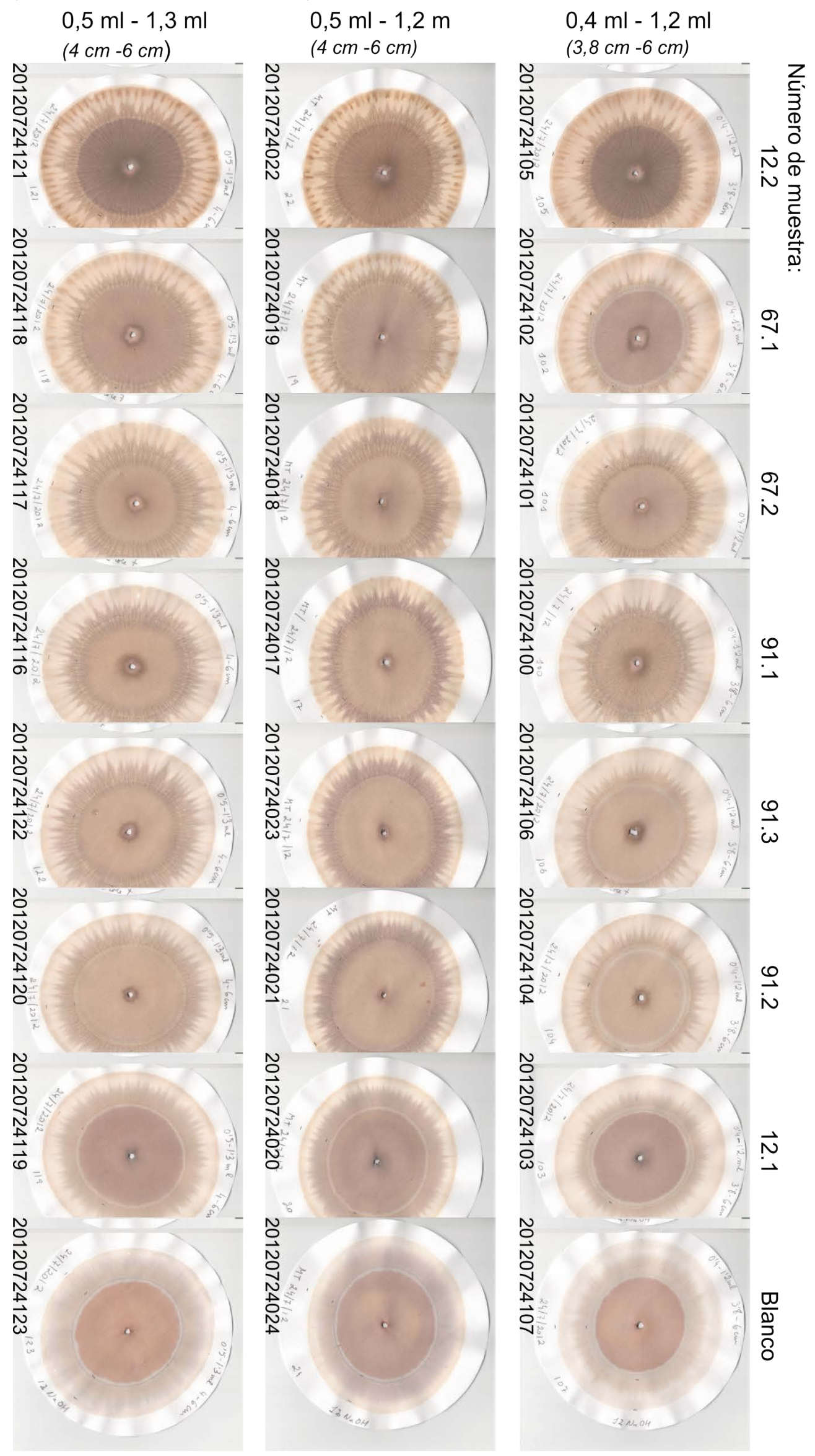

Figura 39: Posibilidades de ampliar la zona exterior 



\subsection{RESUMEN Y DISCUSIÓN DE LOS RESULTADOS}

El estudio de la influencia del marcaje de los filtros, recogido en la sección 9.2.3, pone de manifiesto que la carencia fundamental en el método original del Chroma-Test de Pfeiffer es la imprecisión en cuanto a los volúmenes utilizados en el ensayo. Los ensayos muestran que el pipeteo de volúmenes exactos es imprescindible para asegurar la repetibilidad de los resultados.

Las modificaciones necesarias para poder validar el método se recogen en la sección 8.3. Su validez es objeto de estudio en el capítulo II.

A continuación se enumeran los factores críticos y las fuentes de error más frecuentes que se han podido identificar en las investigaciones llevadas a cabo anteriormente por diferentes investigadores.

\subsubsection{Control del experimento}

La metodología establecida para realizar los ensayos, descrita en la sección 9.1, ha permitido comparar los efectos de las diferentes condiciones experimentales. Así ha sido posible identificar los factores insuficientemente definidos en el método original de Pfeiffer (recogido en la sección 4.1). La realización de los ensayos de control se ha mostrado muy útil para detectar errores en la operación con los reactivos y contaminaciones de los mismos, por lo que se ha incorporado al método utilizado en los ensayos ciegos del capítulo i1 (ver la sección 8.3 en la página 93).

Es muy aconsejable utilizar una muestra de referencia en todos los ensayos, para controlar el experimento, y se ha de incluir al planificar los ensayos. En esta investigación se han usado durante meses las muestras de Camorritos con resultados satisfactorios.

\subsubsection{Factores críticos}

9.3.2.1 Variabilidad imputable al método original de Pfeiffer y a carencias técnicas

Mediante los ensayos realizados en esta investigación se identificaron como causas fundamentales de variabilidad de los resultados obtenidos por el método de Pfeiffer (descrito en la sección 4.I), las siguientes:

- Imprecisión en cuanto a las cantidades de disolución de nitrato de plata y de extracto.

Pfeiffer no mide los volúmenes utilizados en ninguna de las fases de difusión. Se limita a poner marcas en los filtros para controlar este factor, lo que puede dar lugar a importantes variaciones en el volumen utilizado. Ver los apartados c), f) y 2. de 
la sección 4.1. Esta parece ser la causa principal de variabilidad del procedimiento establecido por Pfeiffer. La modificación de Balzer, relativa al pipeteo de volúmenes exactos, es fundamental para poder controlar el experimento de manera adecuada y poder garantizar la repetibilidad de los resultados. La influencia de este factor crítico se estudia en detalle en la sección 9.2.3. Es difícil, sirviéndose tan solo de marcas sobre el filtro, controlar la cantidad de fluido que absorbe el papel de filtro por las siguientes razones:

- La dificultad de controlar visualmente el límite de difusión de los fluidos cuando se realizan varios ensayos a la vez.

- La difusión se detiene sin rebasar las marcas cuando se frena el avance por falta de fluido en el recipiente. Pero si queda fluido abundante, continuará el avance tras retirar la mecha y se rebasarán las marcas de forma incontrolada.

Algunas de las diferencias observables en la figura 8a en la página 49 pueden ser atribuidas a este defecto en la operación y no al uso de cámara o campana al que alude Bangert.

- Uso de filtros sensibilizados alterados

El proceso descrito en el apartado g) de la sección 4.I en la página 34 permite que los filtros recién sensibilizados se sequen expuestos a la luz. Esto puede dar origen a variaciones de coloración en la zona interior en forma de coronas circulares. En la figura $8 \mathrm{~b}$ en la página 49 se puede observar este defecto en las imágenes de la fila inferior, lo que puede modificar la interpretación de Bangert en la tabla 5 en la página 48 y en la figura 8a en la página 49. La sensibilización se puede realizar con iluminación atenuada, pero suficiente para llevarla a cabo con comodidad. Los filtros sensibilizados se deben guardar a oscuras hasta su uso, que normalmente se produce entre dos y cinco horas tras la sensibilización.

- Variación de las condiciones de iluminación

Pfeiffer no especifica suficientemente las condiciones de iluminación durante el ensayo y la fase de revelado hasta el momento de la interpretación, como se puede ver en los apartados 2. Procedimiento de ensayo y 3. Revelado, de la sección 4.I. Los ensayos realizados confirman la necesidad de fijar las condiciones de iluminación en las distintas etapas desde la sensibilización de los filtros hasta el archivo de los resultados.

- Escaneo de los dinamogramas

El problema técnico más difícil de solucionar desde el punto de vista de la interpretación y valoración de los patrones es el hecho de que las imágenes se vayan alterando con el tiempo debido a la foto sensibilidad de las sales de plata. Esto actualmente 
se puede solucionar gracias a las tecnologías de digitalización de imágenes y la adopción de normas internacionales para calibrar los escáneres y demás dispositivos de salida gráfica. En la sección 7.2 se detalla la metodología que hemos empleado en el escaneo de los dinamogramas.

\subsubsection{Causas de variabilidad imputables al operador}

El método del Chroma-Test de Pfeiffer es muy simple y puede ser implementado fácilmente. Hay que tener en cuenta la posibilidad de cometer errores en las operaciones que no son achacables al método en sí, y que pueden dar lugar a

- Contaminación de la disolución de nitrato de plata.

Los ensayos de control indicados en los apartados 2 y 3 de la sección 9.1.1 ayudan a controlar este factor.

- Errores de identificación de las muestras y/o de los ensayos.

\subsubsection{Estandarización del Método Horizontal de Dinamolisis Capilar}

Las dificultades indicadas en la literatura para la valoración e interpretación de los dinamogramas parecen radicar en el problema de repetibilidad del Chroma-Test original. De hecho los investigadores que han mostrado más confianza en el método y fiabilidad en sus valoraciones han trabajado con modificaciones del método. Desgraciadamente estas modificaciones no han sido suficientemente documentadas ni investigadas de forma sistemática, y se han acompañado de otras muchas, como hemos visto en le capítulo 4 en la página 33, que complican el procedimiento sin conseguir mejora alguna que justifique su adopción.

A partir de los resultados indicados en este capítulo se establecieron las modificaciones del método del Chroma-Test que se utilizaron posteriormente para la validación del método mediante los ensayos ciegos que se presentan en la sección 8.3 en la página 93 del capítulo 8. Constituyen un conjunto mínimo de especificaciones que permiten asegurar la reproducción de los ensayos y su valoración en base a los rasgos morfológicos de los patrones. En la sección 12.3 en la página 187 del capítulo 12 de conclusiones finales se indican sugerencias para optimizar algunos aspectos del procedimiento de cara a una posible estandarización. 



\section{INTRODUCCIÓN}

En la actualidad encontramos en uso dos configuraciones del método de Dinamolisis Capilar, el Chroma-Test de Pfeiffer y el método Wala. Ambos métodos usan la sal de plata como reactivo y el de Wala se sirve adicionalmente de una sal de hierro. La configuración de Pfeiffer fue diseñada específicamente para valorar composts y suelos, está documentada, hay antecedentes bibliográficos y es muy sencilla de implementar, por lo que la hemos tomado como punto de partida para investigar el potencial del método de Dinamolisis Capilar como criterio para calificar los suelos contaminados (en el sentido del RD 9/2005).

Originalmente el método de Dinamolisis Capilar descrito por L. Kolisko menciona la posibilidad de usar otras sales metálicas para caracterizar las sustancias. En particular, para evaluar suelos y composts, indicó su preferencia por la sal de oro. Por ello, también se han hecho ensayos para poder valorar esta aserción.

Se han ensayado, con la configuración del Chroma-Test, muestras de suelos de la zona de Linares afectados por la minería del plomo y muestras de suelos de agricultura Biodinámica no afectados por actividades potencialmente contaminantes. La descripción de las muestras se encuentra en el capítulo 6.

Las muestras de suelos del antiguo distrito minero de Linares fueron seleccionadas en base a los resultados de la investigación geoquímica realizada en la tesis doctoral de J. Martínez López (2007; 2008).

En este capítulo se han considerado los aspectos siguientes:

- Investigar el potencial del Método Horizontal de Dinamolisis Capilar para caracterizar la calidad de los suelos

- Potencial del Chroma-Test para caracterizar distintos tipos de suelos con las siete sales metálicas utilizadas originalmente por L Kolisko. Ensayos preliminares. Sección 10.1

- Valoración de la calidad de los suelos mediante sus dinamogramas. Sección 10.2.

- Caso práctico: aplicación a suelos del antiguo distrito minero de Linares. Secciones 10.3 y 10.4 .

En la sección 10.5 se resume el capítulo. 
1O.I ENSAYOS PRELIMINARES DE SUELOS DE DISTINTAS CALIDADES USANDO DIFERENTES SALES METÁLICAS

Los primeros pasos de la investigación se encaminaron a investigar la capacidad de discriminación del método y su sensibilidad de forma general. Tras el estudio de los antecedentes bibliográficos y unos primeros ensayos con suelos, plantas y composts, que permitieron familiarizarse con sus características y posibilidades en un marco más amplio, se decidió abordar la investigación del potencial del método para caracterizar los suelos contaminados mediante un caso práctico. Se eligieron los suelos de Linares, por contar con el trabajo previo de investigación de J. Martínez López, cuya tesis doctoral fue dirigida también por el Profesor Juan Llamas Borrajo.

Los ensayos se han realizado con la configuración de Pfeiffer original, conocida como Chroma-Test (descrita en la sección 4.I en la página 34), extendiéndola a todas las sales utilizadas por L. Kolisko, indicadas en la tabla 8 en la página 66. Para la interpretación de las imágenes se han utilizado los criterios expuestos en la sección 8.4.1 en la página 95.

En esta sección se muestran agrupados los ensayos de suelos de forma que se pueda apreciar el contraste entre los dinamogramas de suelos con distinta calidad. Se ha partido de un abanico de situaciones, desde los suelos muy afectados por la actividad minera, hasta los favorecidos por la agricultura ecológica Biodinámica.

ZONA MUY AFECTAdA POR LA MINERÍA: $1^{a}$ CAMPAÑa En la figura 40 se pueden observar los dinamogramas correspondientes a los suelos de la zona de Linares más afectada por la actividad minerometalúrgica ligada a sus yacimientos de plomo. Además de los ensayos con nitrato de plata al o, $\%$, se presentan los realizados con sales de oro y de plomo en la misma concentración del o,5\%. Estas muestras se obtuvieron en la primera campaña de Linares, realizada el 30 de marzo del 2011. Todas ellas fueron tomadas en olivares.

La característica común de estos dinamogramas es la escasez de rasgos radiales y su similitud con el blanco. 
Sal metálica al 0,5\% (Metal)

$(\mathrm{Ag})$
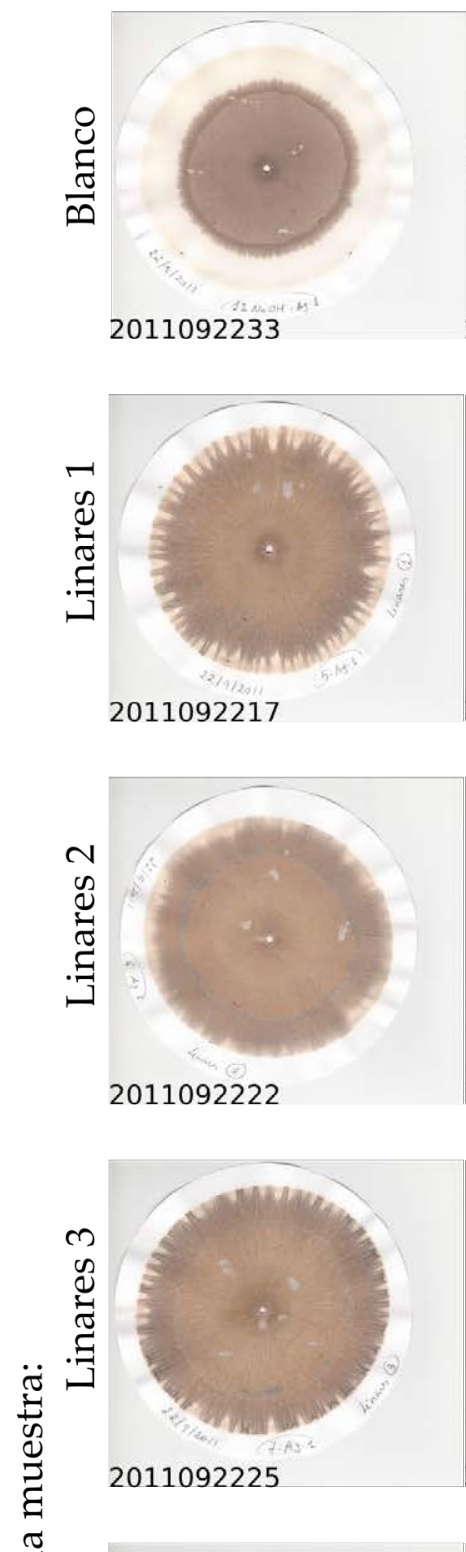

$(\mathrm{Au})$

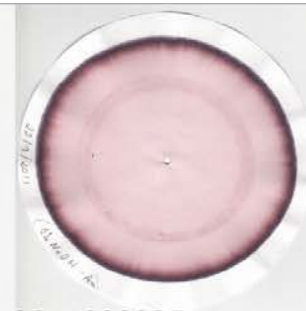

2011092235

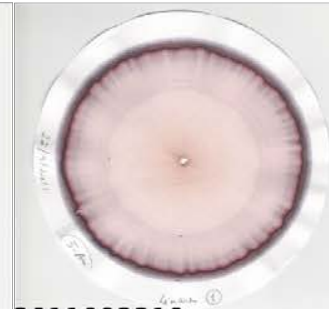

2011092219

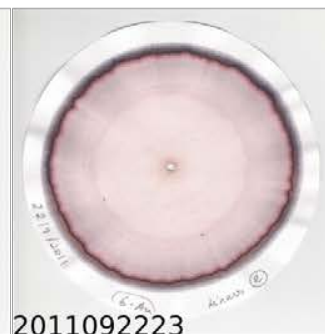

2011092223

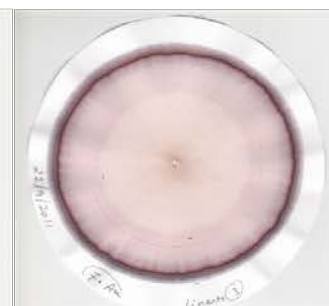

2011092227

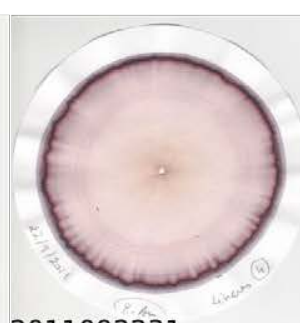

2011092231
$(\mathrm{Pb})$
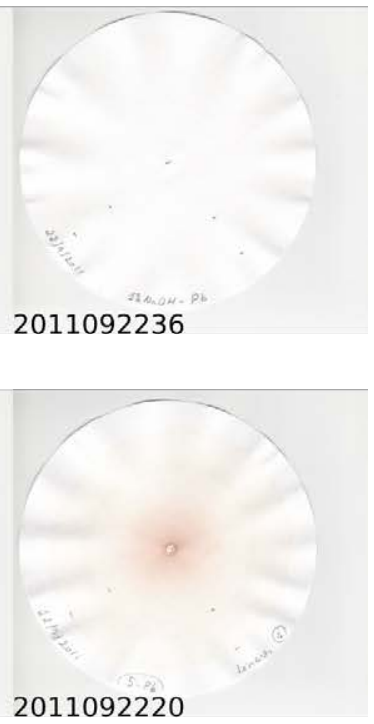

2011092220

2011092224
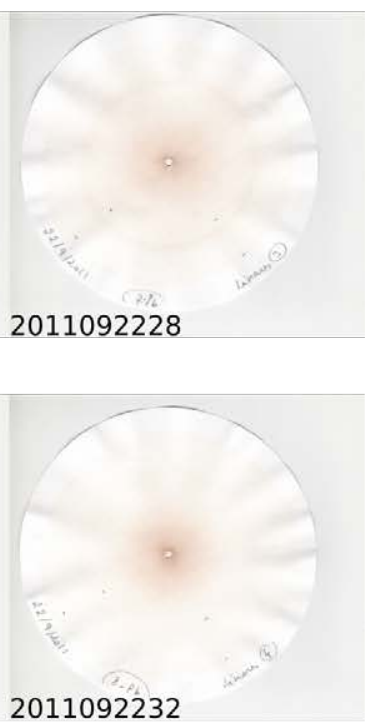

Figura 40: Dinamogramas de las muestras de la primera campaña de Linares con sales al $0,5 \%$ de $\mathrm{Ag}$, $\mathrm{Au} \mathrm{y} \mathrm{Pb}$. Las muestras han sido tomadas en olivares situados en la zona más afectada por la actividad minero metalúrgica vinculada al plomo. 

DIFERENTES GRADOS DE AFECCIÓN POR LA MINERÍA: $2^{a}$ CAMPANA En las figuras 41 y 42 se reproducen los resultados de ensayos análogos a los anteriores, realizados con las muestras de la segunda campaña de Linares tomadas el 4 de mayo del 2011. La mayoría fueron tomadas también en olivares, pero hay además muestras de monte bajo, prados y dehesas. Las muestras de esta segunda campaña fueron elegidas en base a los datos geoquímicos disponibles (ver sección 10.3.2) de modo que fueran representativas de los distintos niveles de afección identificados previamente en la zona por Martínez López et al. (2008). Los dinamogramas se presentan ordenados por los ensayos de la sal de Ag, como se indica a continuación en la sección 10.2.

En conjunto estas dos figuras de las muestras de la $2^{\text {a }}$ campaña presentan, como era de esperar, una mayor variedad de resultados que la figura 40, que recordemos corresponde a la zona más afectada por la actividad minera. 
Sal metálica al 0,5\% (Metal)

$(\mathrm{Ag})$
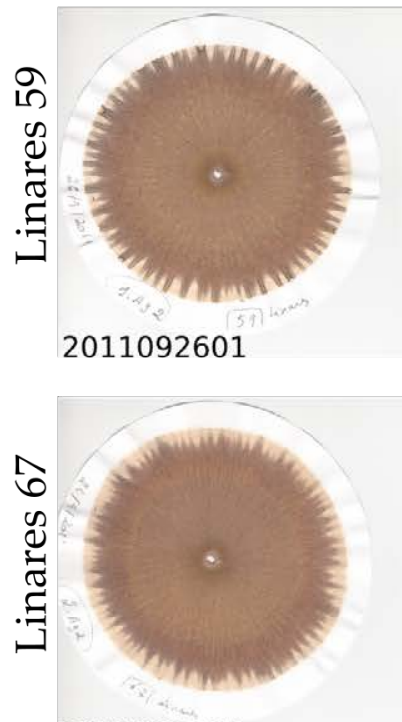

2011092603
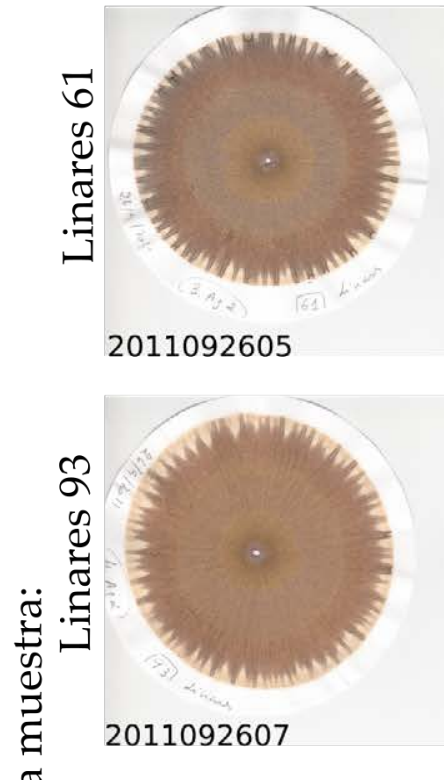

$\frac{\pi}{0}$

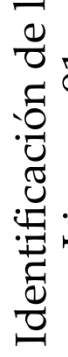

$(\mathrm{Au})$
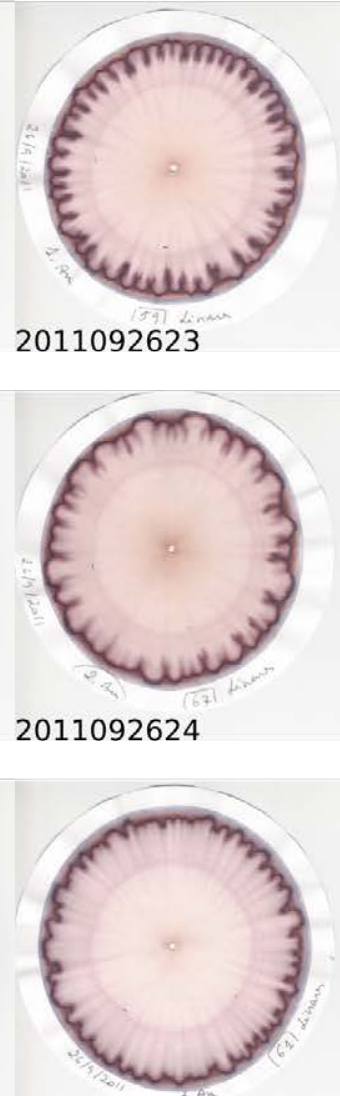

2011092625

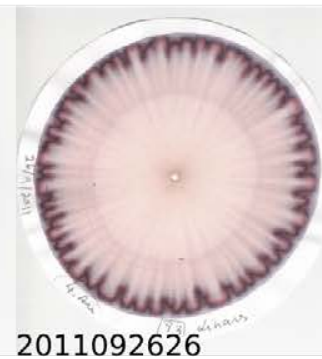

2011092626

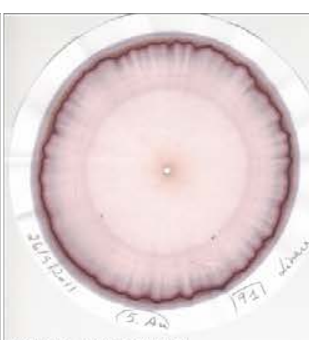

2011092652
$(\mathrm{Pb})$

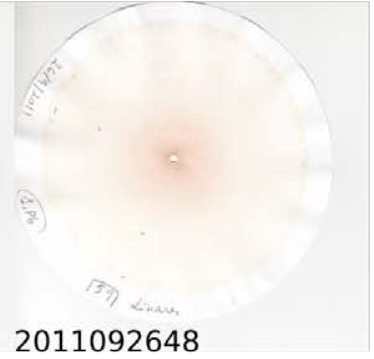

2011092649

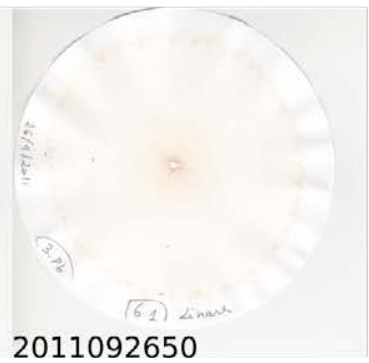

2011092651

2011092627

Figura 41: Dinamogramas de las muestras 59, 67, 61, 93 y 91 de la segunda campaña de Linares con sales al 0,5\% de Ag, $\mathrm{Au} \mathrm{y} \mathrm{Pb}$. Las nueve muestras de la segunda campaña, recogidas en esta figura y en la siguiente, están ordenadas atendiendo a la presencia de rasgos circulares (ver la sección 8.4.1 sobre morfología). 
Sal metálica al 0,5\% (Metal)
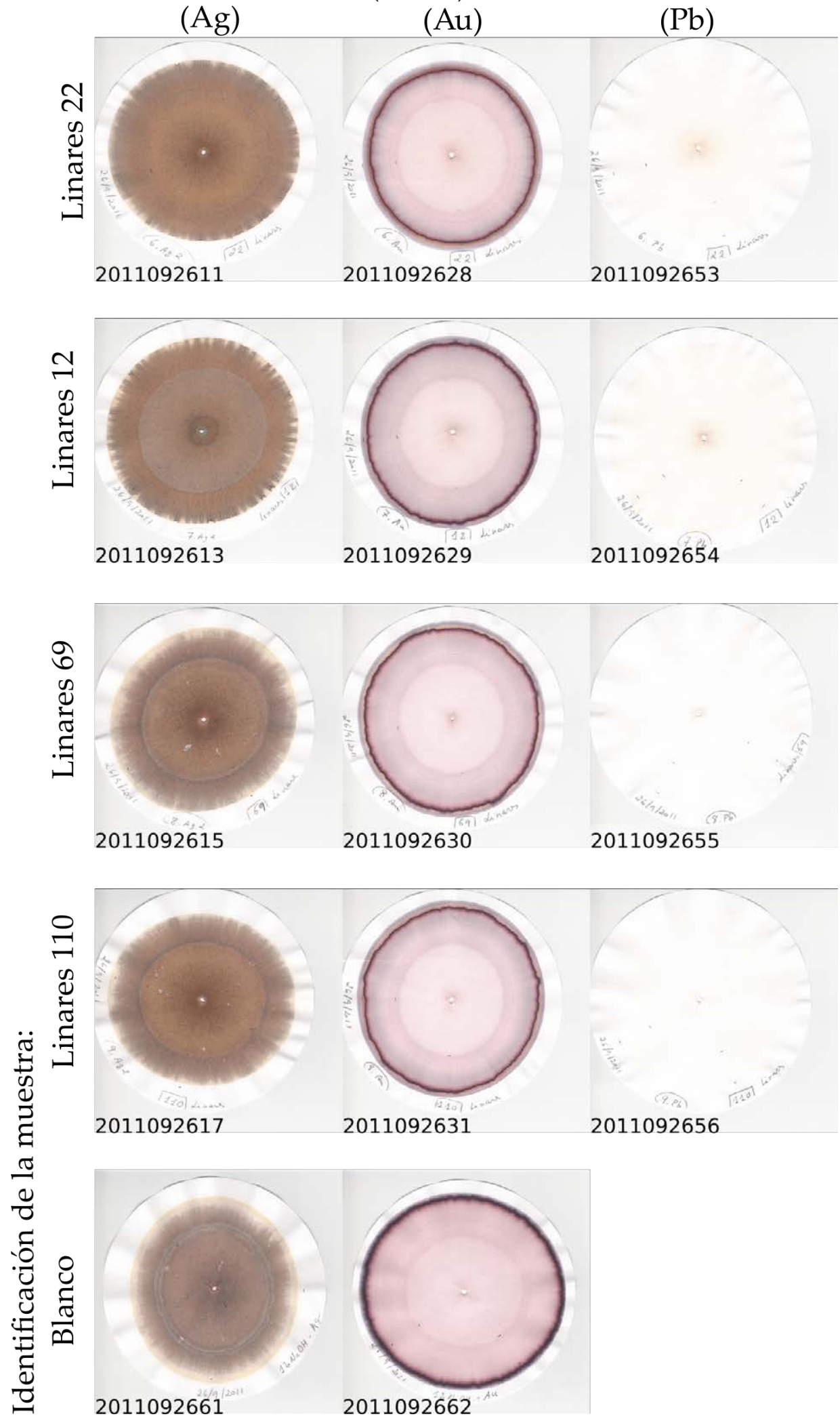

Figura 42: Dinamogramas de las muestras 22, 12, 69, 110 y Blanco de la segunda campaña de Linares con sales al o,5\% de Ag, $\mathrm{Au} \mathrm{y} \mathrm{Pb.} \mathrm{Las}$ nueve muestras de la segunda campaña, recogidas en esta figura y en la anterior, son representativas de las zonas con diferentes categorías de impacto de la actividad minera, establecidas en base a los estudios geoquímicos disponibles de Martínez López et al. (2008). 
Suelos de Agricultura biodinámica En la figura 43 se recogen los resultados correspondientes a las muestras de suelos y de compost de estiércol de vaca, procedentes de dos granjas que aplican el método de agricultura Biodinámica y no están sujetas a fuentes de contaminación.

En esta figura, como también era de esperar, la presencia de rasgos radiales es mucho más notoria. 
Sal metálica al 0,5\% (Metal)
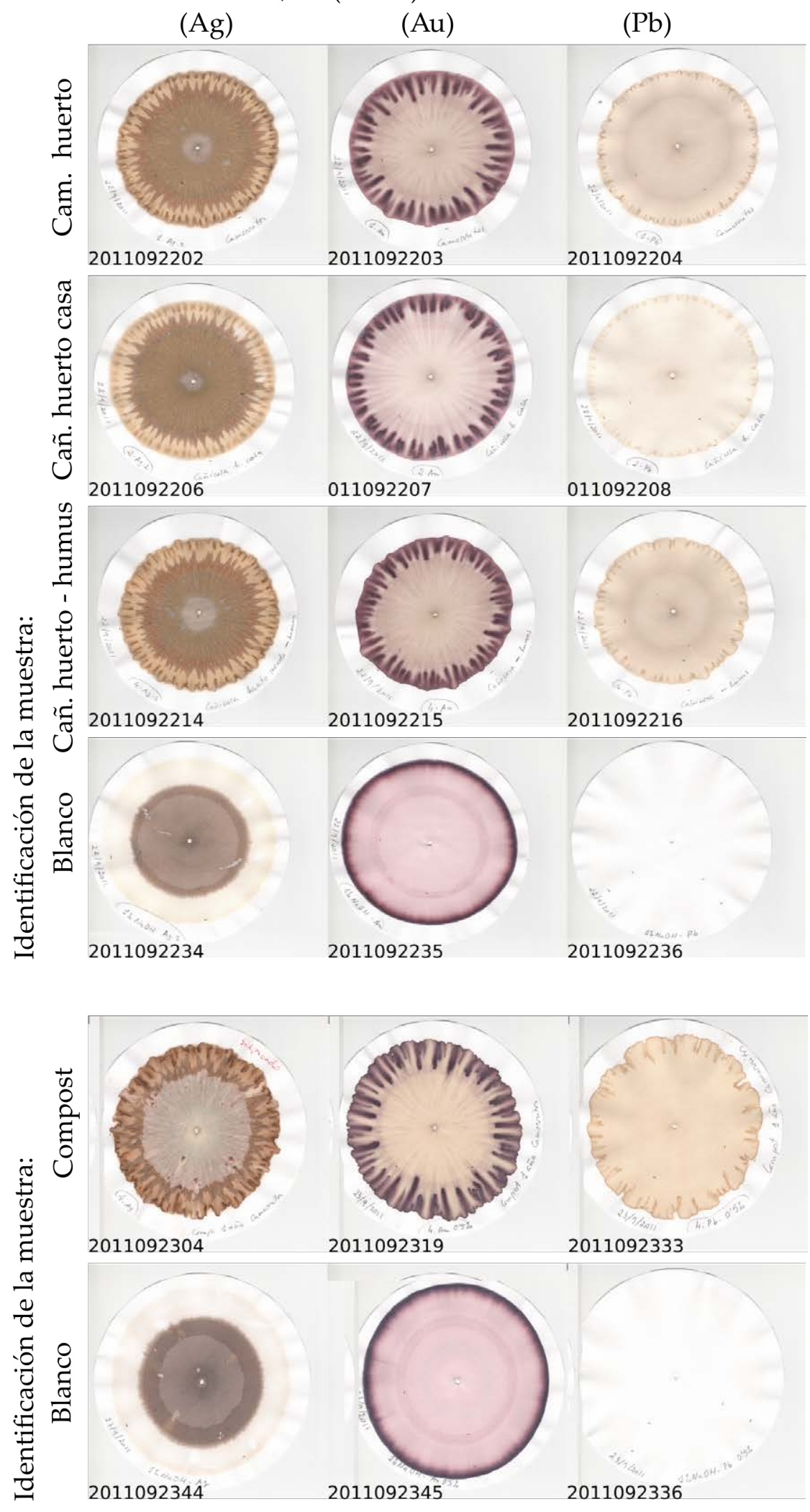

Figura 43: Dinamogramas de muestras procedentes de granjas que aplican el método de cultivo biodinámico, ensayadas con sales de Ag, Au y $\mathrm{Pb}$ al o,5 \%. Suelos Cam. huerto, Cañ. huerto casa, Cañ. huerto -humus y una muestra de compost. Se trata de suelos no expuestos a fuentes de contaminación conocidas y que se han mejorado por el método de cultivo Biodinámico. Obsérvese la gran riqueza de rasgos radiales, que están ausentes en los blancos y presentes en muy menor medida en algunas de las muestras de Linares. 
RESUMEN DE ENSAYOS CON SUELOS Y COMPOSTS En la figura 44 se presentan a modo de resumen los patrones representativos del abanico de suelos y composts investigados. En la fila inferior se puede observar el blanco, en el que solamente hay rasgos circulares. En los demás patrones se puede observar la creciente presencia de rasgos radiales, que alcanzan el máximo en el compost de la fila superior. La figura ilustra la relación entre los rasgos radiales y la vitalidad del suelo o su calidad.

El Nitrato de Plata y el Cloruro de Oro muestran los mejores resultados. Se opta por continuar la investigación con la sal de plata. 
Sal metálica al 0,5\% (Metal)
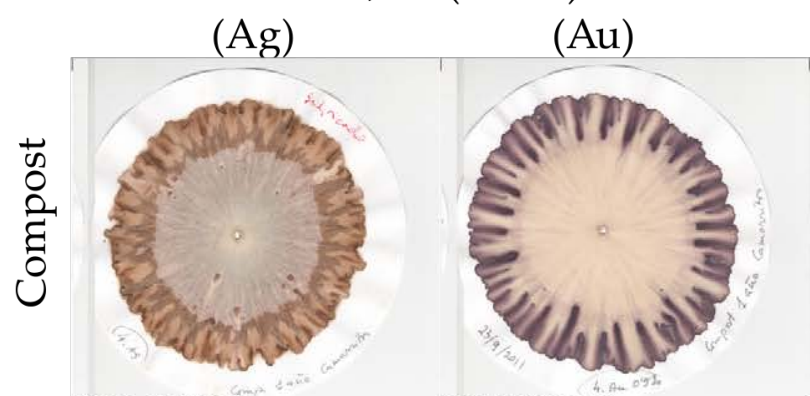

$(\mathrm{Pb})$

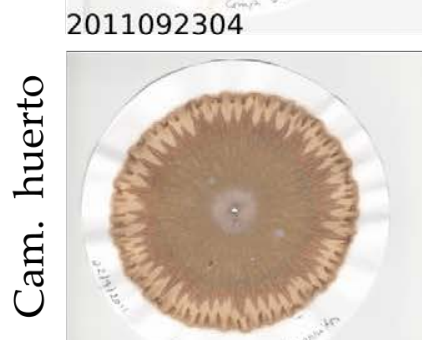

2011092319

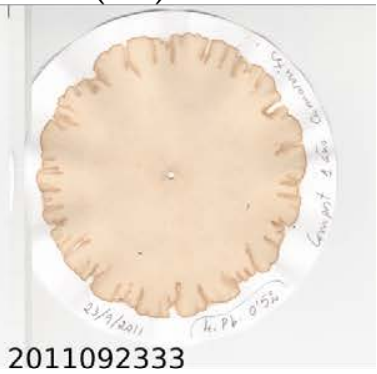

2011092202
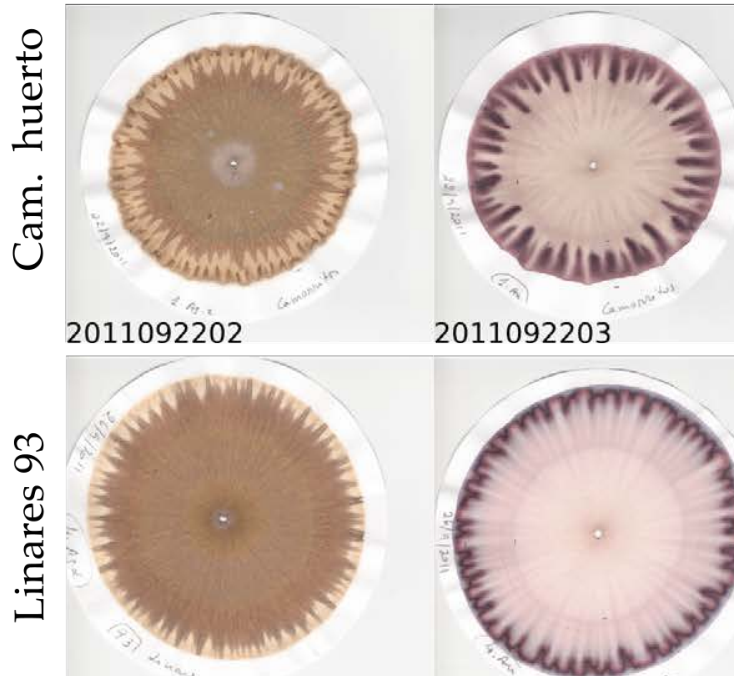

2011092203
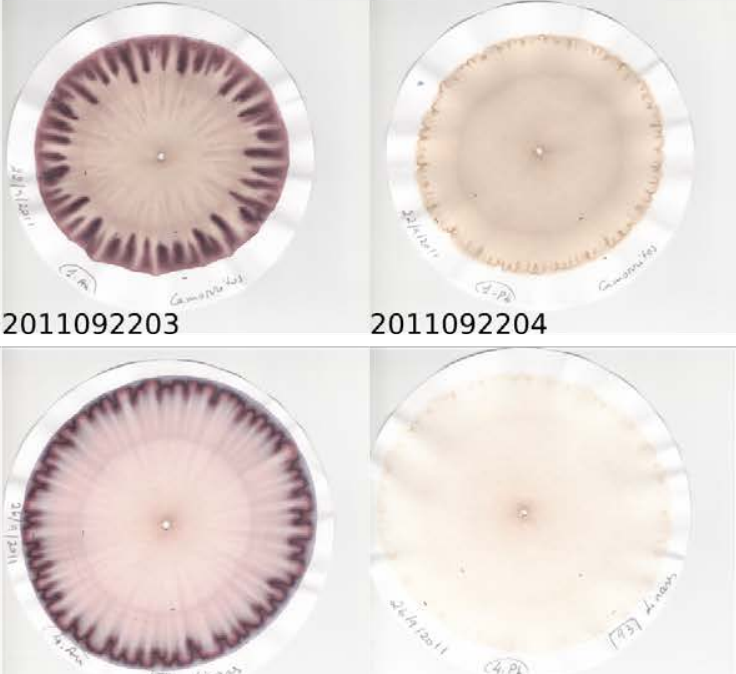

2011092626

2011092204

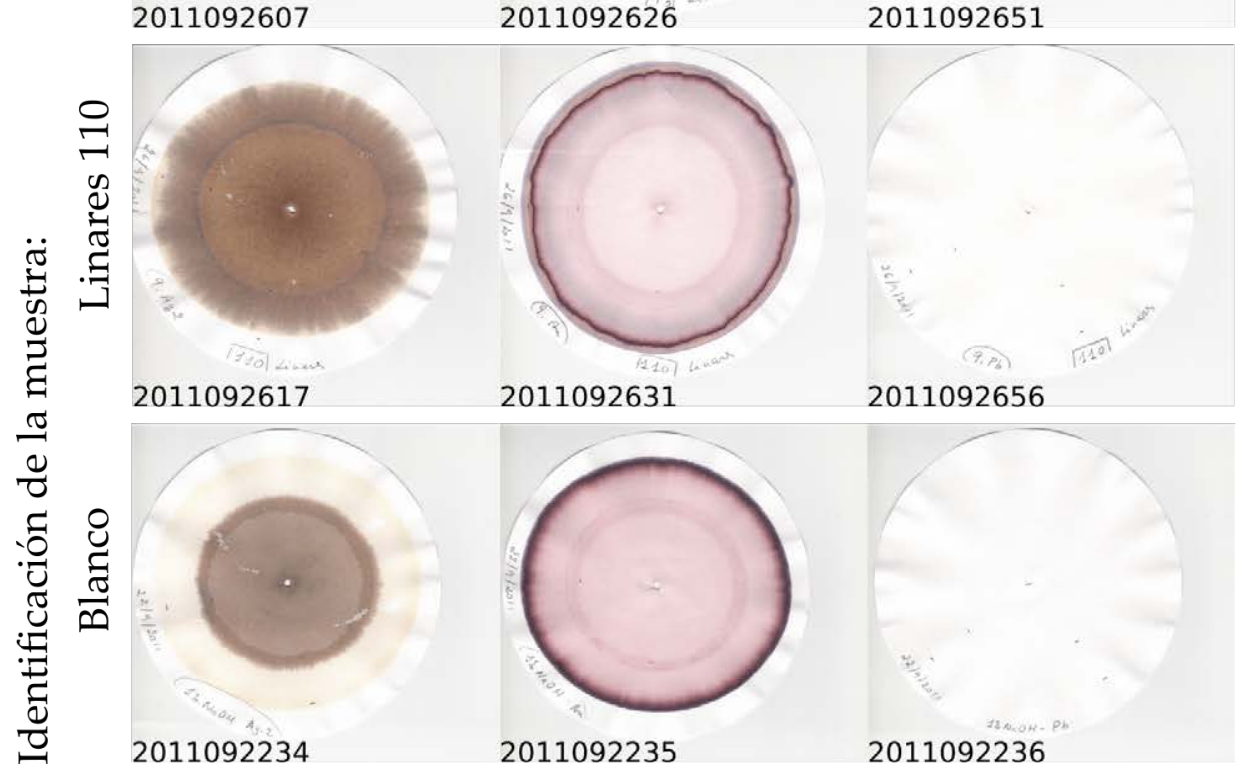

Figura 44: Resumen del potencial del Chroma-Test para diferenciar suelos y compost de diferentes calidades. 

10.2 VALORACIÓN DE LA CALIDAD DE LOS SUELOS POR MEDIO DE SUS DINAMOGRAMAS

En la sección 8.4 en la página 95 se indican las bases morfológicas que hacen posible una primera aproximación a la interpretación y evaluación de los dinamogramas que se muestran en los resultados. En la misma sección se define la nomenclatura utilizada. Recordemos que:

Los dinamogramas de los blancos sirven como referencia de la conducta mineral inorgánica. Se obtienen con la disolución de $\mathrm{NaOH}$ utilizada para extraer las muestras. No presentan ningún rasgo radial. Se pueden comparar los distintos resultados tomando como referencia los ensayos en blanco de cada serie.

LOS RASGOS RADIALES están relacionados con la vitalidad del suelo y su tendencia a comportarse de forma más orgánica. Ponen de manifiesto las fuerzas formativas del suelo. Los rasgos radiales que presenten los dinamogramas de los suelos hay que atribuirlos a las fuerzas presentes en las sustancias del propio suelo, ya que los blancos sólo presentan rasgos circulares. Su variedad y riqueza se relaciona con la vitalidad del suelo.

LOS RASGOS CIRCULARES están relacionados con la mineralización del suelo y con su tendencia a comportarse de modo más inorgánico. Ponen de manifiesto las fuerzas físicas minerales del suelo. Los blancos solo presentan rasgos circulares.

Tabla 21: Calidad de los suelos en base a los rasgos radiales presentes en las zonas exterior e interior del dinamograma (Basado en Voitl and Guggenberger (1986))

\begin{tabular}{cccc}
\hline CRITERIO UTILIZADO & Z. EXTERIOR & Z. INTERIOR & CALIDAD \\
\hline \hline \multirow{2}{*}{ Presencia de rasgos radiales } & si & si & I \\
\cline { 2 - 4 } & si & no & 2 \\
\cline { 2 - 4 } & no & no & 3 \\
\hline
\end{tabular}

I Suelo con actividad enzimática y posible formación de humus estable

2 Suelo con alguna actividad enzimática pero sin formación de humus estable

3 Suelo sin actividad, inerte

Los resultados anteriormente descritos en la sección 10.1 permitieron ordenar los dinamogramas en base a los rasgos radiales. A la vista de los mismos y como primera aproximación para establecer una escala de calidades en base a la presencia o ausencia de los rasgos morfológicos básicos, se propuso una clasificación con los criterios recogidos en la tabla 21 y se aplicó a los suelos de Linares investigados, como veremos en la siguiente sección. 
En esta sección se muestran los resultados obtenidos con la configuración original de Pfeiffer $y$ con las modificaciones que se fueron introduciendo, hasta llegar a la configuración validable que se describe en la sección 8.3. Se puede seguir la progresiva mejora del método de ensayo

\subsection{INVESTIGACiÓN DE SUELOS DEL ANTIGUO DISTRITO MINE- RO DE PLOMO DE LINARES}

A continuación mostramos el desarrollo de caso práctico, consistente en la caracterización de suelos del antiguo distrito minero de plomo de Linares, en la provincia de Jaén, utilizando el Chroma-Test como configuración de partida.

Se realizaron tres campañas de muestreo. La primera de ellas vinculada a los primeros ensayos para apreciar el potencial del método de Dinamolisis Capilar para caracterizar distintos tipos de suelos; la segunda para conocer la sensibilidad del método en el caso de suelos contaminados, en base al conocimiento previo de la geoquímica de la zona; y la tercera para tratar de diferenciar la posible afección por las prácticas agrícolas de la afección minera previamente identificada por geoquímica.

\subsubsection{Zona muy afectada por la minería: $1^{a}$ campaña}

En la figura 45 se presentan los resultados de cuatro muestras tomadas en olivares sobre el itinerario que, partiendo de la antigua Fundición La Cruz, discurre por el camino transversal al filón de Arrayanes, como se ve en la foto de satélite en la figura 17 en la página $77 . \mathrm{La}$ muestra $3 \mathrm{~b}$ fue tomada sobre la antigua balsa de lodos. Se presentan también los resultados del blanco, que proceden de la disolución de $\mathrm{NaOH}$ al $1 \%$ utilizada para extraer las muestras.

Solamente las muestras 1, 3 y 4 presentan débiles rasgos radiales en la zona exterior, confirmando el mal estado de estos suelos.

La muestra 3 b es muy similar al blanco, resultado que concuerda con el hecho de haber sido tomada en una antigua balsa de lodos. 
Pfeiffer original Modificación del revelado
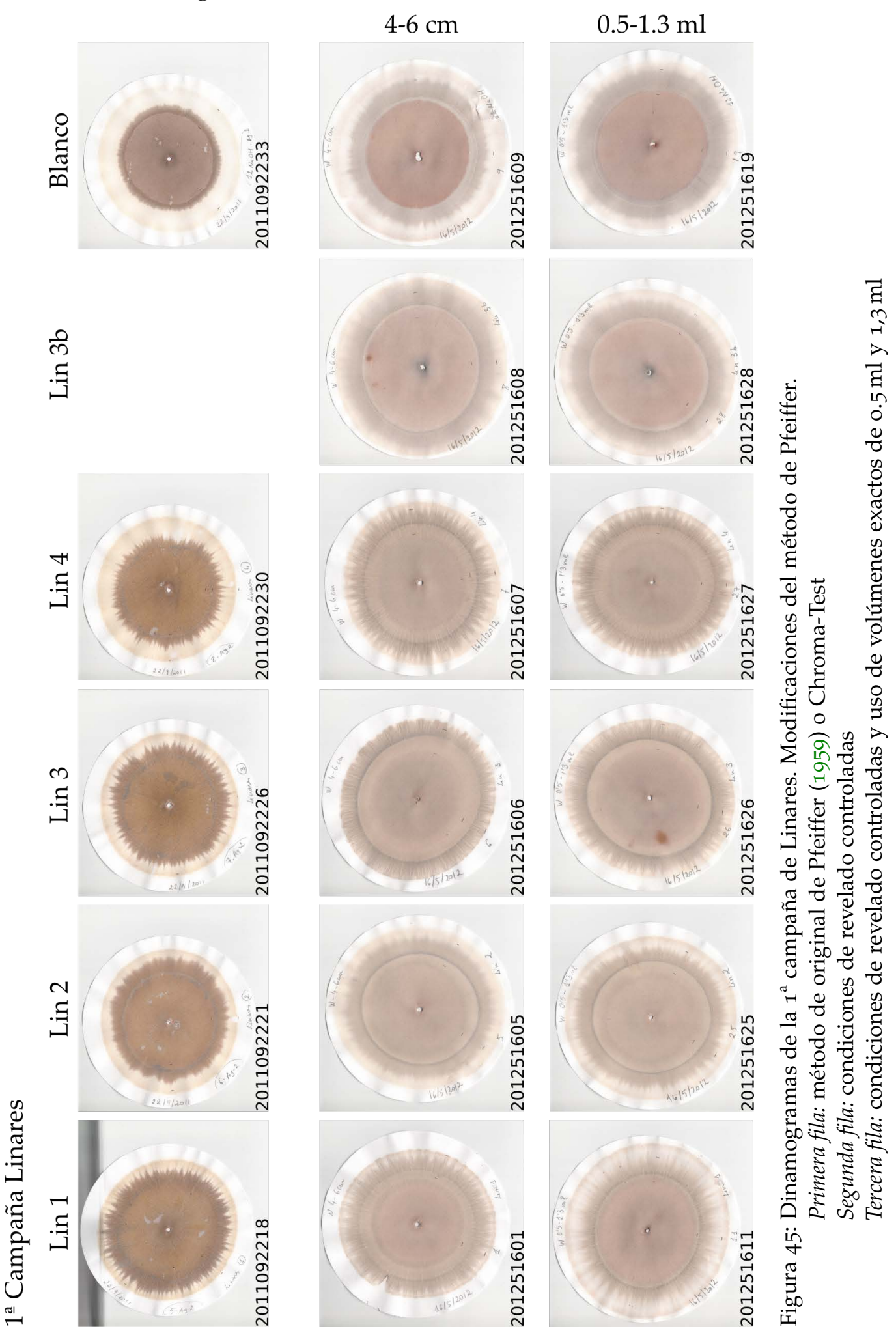
10.3.2 Diferentes grados de afección por la minería: $2^{a}$ Campaña

Las muestras de la segunda campaña fueron seleccionadas en base a los resultados de investigaciones geoquímicas previas. El análisis de clusters realizado sobre los resultados geoquímicos permitió a Martínez López et al. (2008) diferenciar 3 grupos. Los dos primeros corresponden a terrenos contaminados, el primero por la mineralurgia, el segundo por la actividad minera extractiva o por influencia urbana, y el tercero no habría sido afectado. Se eligieron muestras de cada grupo de los distintos grados de contaminación para ver la respuesta del método de Dinamolisis Capilar en cada uno de ellos. Los clusters diferenciados están reflejados en la figura 46.

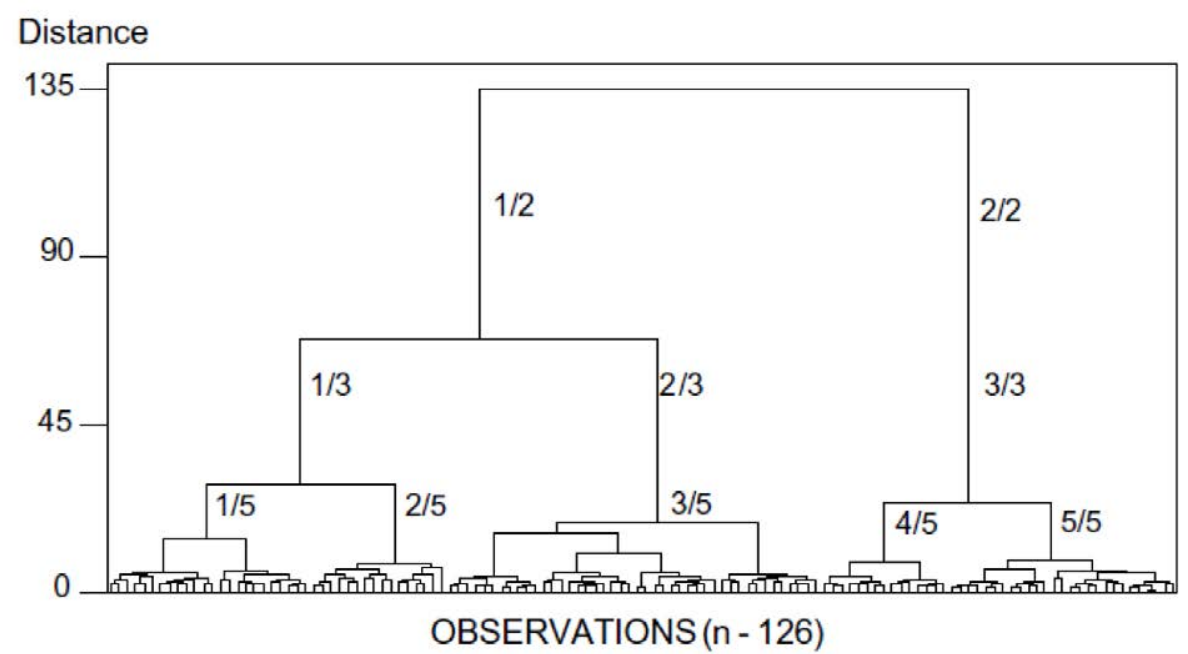

\begin{tabular}{|c|c|c|c|c|c|c|}
\hline $\begin{array}{l}\text { Cluster } \\
2\end{array}$ & $\begin{array}{l}\text { Cluster } \\
5\end{array}$ & $\begin{array}{l}\text { Land use - } \\
\text { activities }\end{array}$ & $\begin{array}{l}\text { Cluster } \\
9\end{array}$ & $\begin{array}{l}\text { Geological } \\
\text { time }\end{array}$ & Lithology & Squares \\
\hline \multirow[t]{7}{*}{$1 / 2$} & $1 / 5$ & Mining & $1 / 9$ & $\begin{array}{l}\text { Quaternary } \\
\text { and Palaeozoic }\end{array}$ & $\begin{array}{l}\text { Granitic- } \\
\text { colluvium and } \\
\text { granite }\end{array}$ & $6.7,27,12,26,20,8,32,34,54,19,21,46$ \\
\hline & & & $2 / 9$ & Triassic & Lutites & $49,106,36,24,39,64,31,65,52,104,105$ \\
\hline & $2 / 5$ & $\begin{array}{l}\text { Mineral } \\
\text { processing } \\
\text { Metallurgy }\end{array}$ & $3 / 9$ & $\begin{array}{l}\text { Palaeozoic and } \\
\text { Triassic }\end{array}$ & $\begin{array}{l}\text { Granite and } \\
\text { lutites }\end{array}$ & $\begin{array}{l}9,22,23,10,40,41,11,37,33,35 \\
25.51 .53,63.91 .38\end{array}$ \\
\hline & $3 / 5$ & Dehesa & $4 / 9$ & Palaeozoic & Granite & $5,55,60,13,14,28,18,61,42,62,75$ \\
\hline & & Pasture (Mining) & $5 / 9$ & $\begin{array}{l}\text { Triassic and } \\
\text { Palaeozoic }\end{array}$ & Lutites Granite & $45,87,74,4,56,59,88,73,67,68,82$ \\
\hline & & $\begin{array}{l}\text { Mining (spoil } \\
\text { tips) }\end{array}$ & $6 / 9$ & Triassic & Lutites & $50,77,76,90,47,48,78,79,89,92$ \\
\hline & & Mining -Urban & $7 / 9$ & Triassic & Lutites & $44,66,80,81,93,103,86,121,94,95,107,108$ \\
\hline \multirow[t]{2}{*}{$2 / 2$} & $4 / 5$ & Olive groves & $8 / 9$ & $\begin{array}{l}\text { Triassic- } \\
\text { Miocene } \\
\text { contact }\end{array}$ & Lutites Marls & $1,3,100,69,120,70,85,119,2,30,17,72,101,102,116$ \\
\hline & $5 / 5$ & $\begin{array}{l}\text { Cultivation } \\
\text { Urban }\end{array}$ & $9 / 9$ & Miocene & Marls & $\begin{array}{l}15,43,115,16,57,113,71,98,126,112,114,111,58,110, \\
83,96,117,118,29,99,109,84,97,124,125,122,123\end{array}$ \\
\hline
\end{tabular}

Figura 46: Desmuestre en base a geoquímica. La tabla muestra los clusters identificados por Martínez López et al. (2008) con indicación del uso del suelo, de la edad geológica y litología. En amarillo se han resaltado las cuadrículas seleccionadas en la $2^{\mathrm{a}}$ campaña. (Para más información sobre las muestras y la cuadrícula, ver la sección 6.2.3 en la página 72). 
Las muestras elegidas están en las cuadrículas 12, 22, 91, 61, 59, $67,93,69$, y 110. (Ver mapas de situación de las cuadrículas y de las muestras en las figuras de la figura $15 \mathrm{~b}$ en la página 75 ).

En la figura 47 se presentan los dinamogramas obtenidos con la configuración de Pfeiffer original (ver sección 4.I) y por el método modificado (ver sección 8.3), de modo que se pueden comparar y apreciar la mejora aportada por las modificaciones adoptadas. Esta mejora se pone de manifiesto en la mayor definición de las imágenes y la mayor diferenciación entre ellas.

Si separamos los dinamogramas, como en el análisis de clusters, también en tres grupos de calidades y según los criterios de la tabla 21 en la página 145 , vemos su correspondencia con la presencia de rasgos radiales en las zonas exterior e interior ilustrada en la tabla 22 bajo los encabezados CLUSTER Y CALIDAD.

Como era de esperar los dinamogramas indican que los suelos más afectados son los vinculados a la mineralurgia, que muestran menor calidad que los vinculados a la minería extractiva. Sin embargo el grupo de peor calidad (calidad 3) según el ensayo de Dinamolisis Capilar corresponde al que, según la geoquímica, no estaría afectado por la contaminación (Cluster 3/3). Este resultado contradictorio y las observaciones realizadas sobre el terreno, hicieron sospechar una degradación de origen agrícola vinculada al cultivo del olivar. Para verificar los grupos de la geoquímica se realizaron nuevos análisis químicos de algunas muestras de la $2^{\text {a }}$ campaña. 


\section{$2^{a}$ Campaña Linares}

Método:

Pfeiffer original:

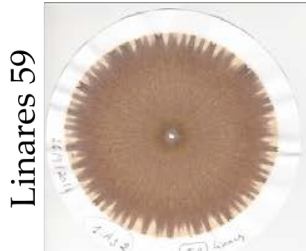

2011092601

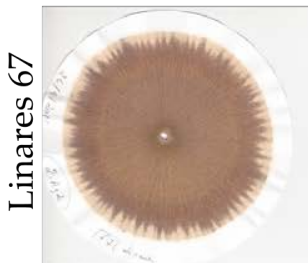

2011092603

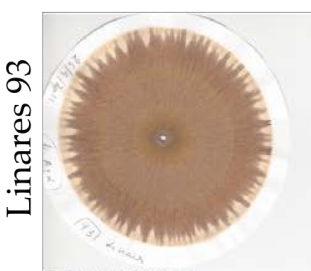

2011092607
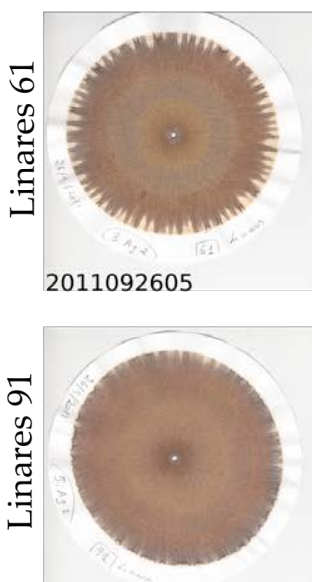

2011092609
Pfeiffer modificado:
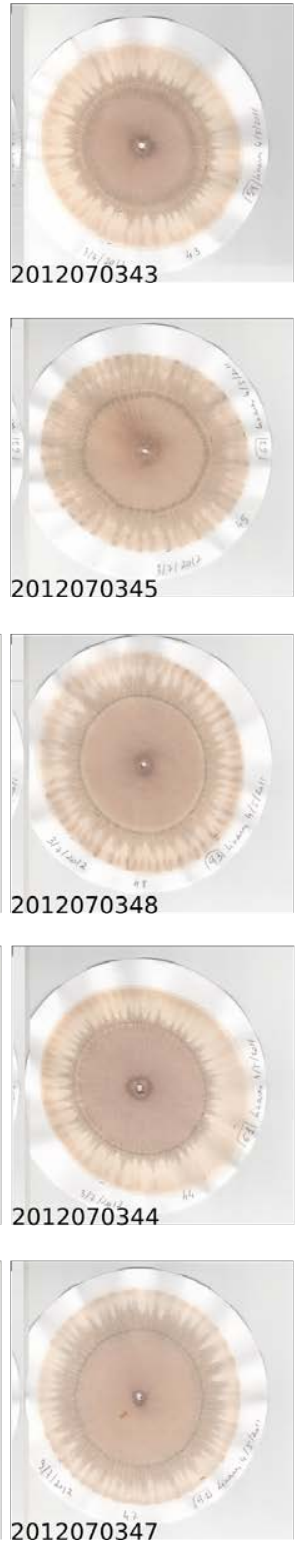

Método:

Pfeiffer original: Pfeiffer modificado:
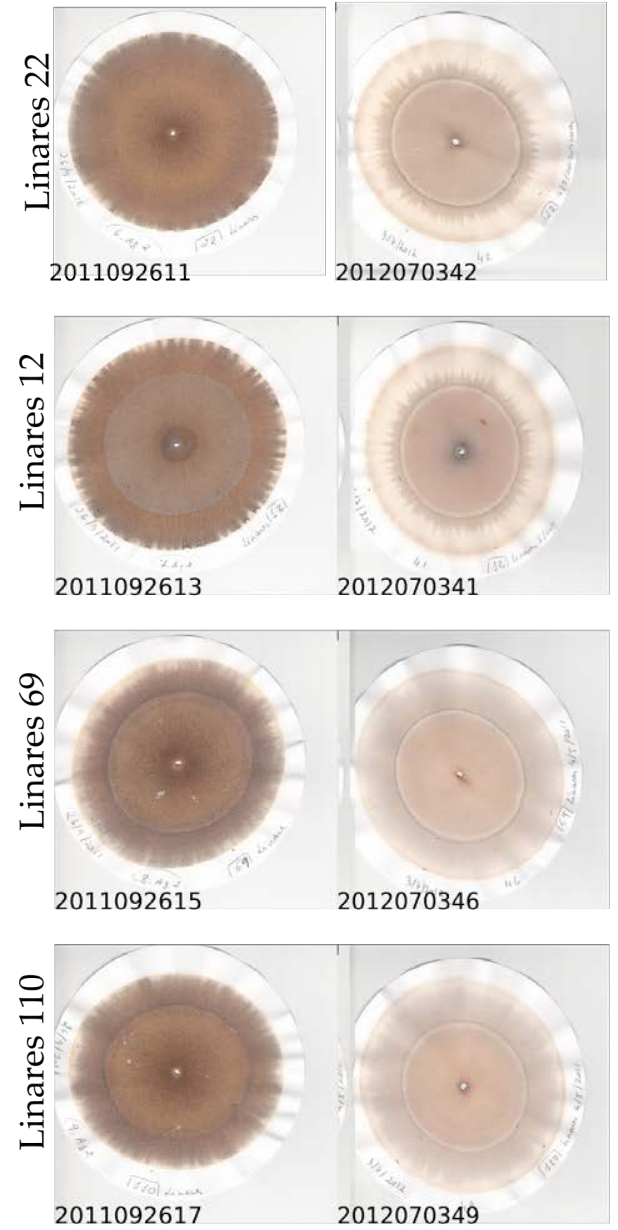

2011092617

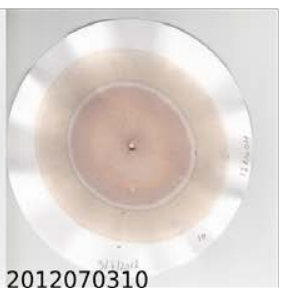

Figura 47: $2^{\mathrm{a}}$ campaña de Linares. Método de Pfeiffer original y modificado. Para cada muestra se presentan, a la izquierda los resultados por el método original, y a la derecha los obtenidos con el método modificado. Obsérvese la mejor definición y riqueza de los rasgos en los dinamogramas del método modificado, y la consiguiente mejora en la diferenciación de las muestras. 
10.3 INVESTIGACIÓN DE SUELOS DE LINARES 151

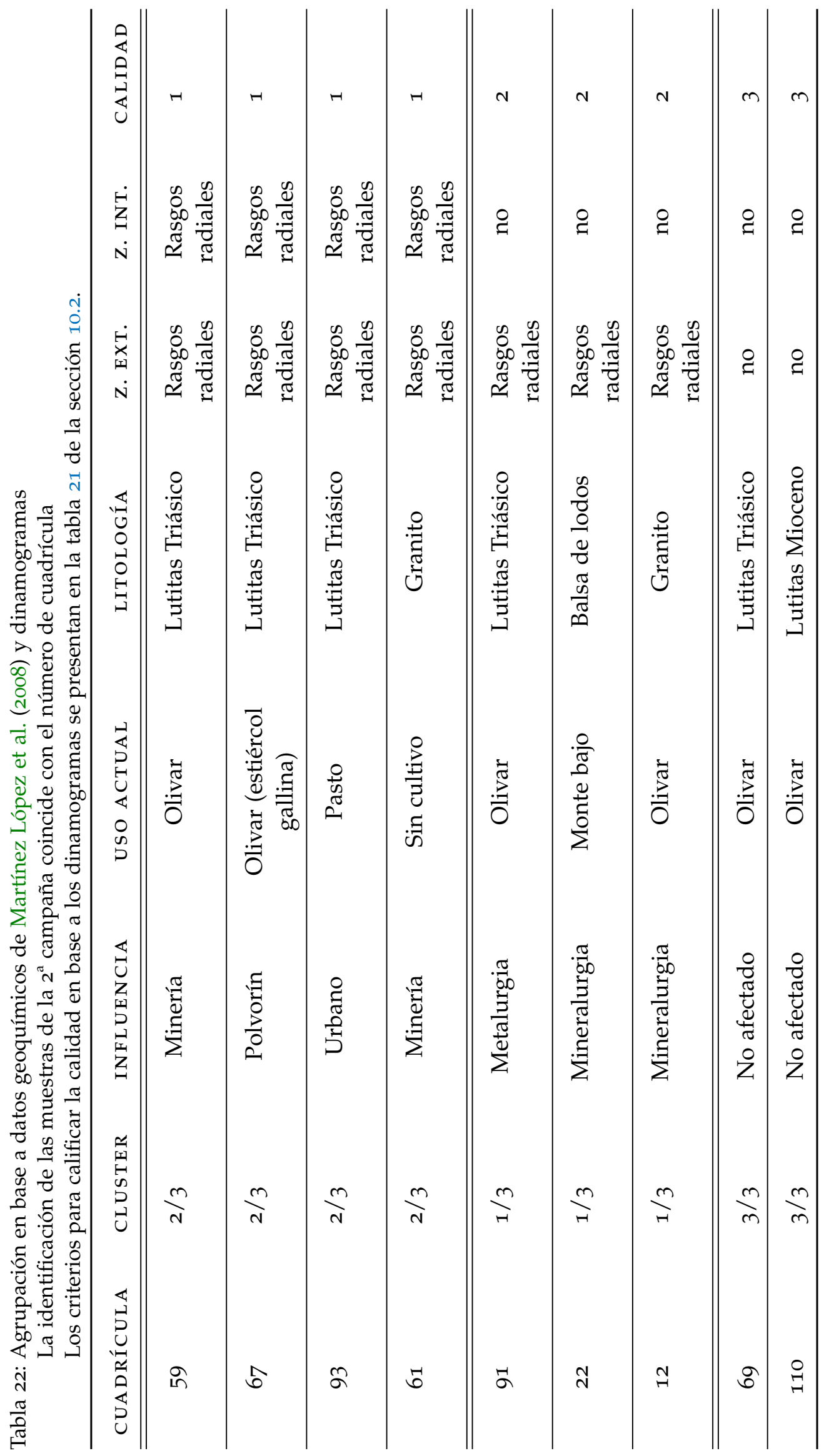


En la tabla 23, se muestran los resultados de los nuevos análisis químicos realizados sobre seis muestras de la segunda campaña y sobre la muestra de Camorritos. 


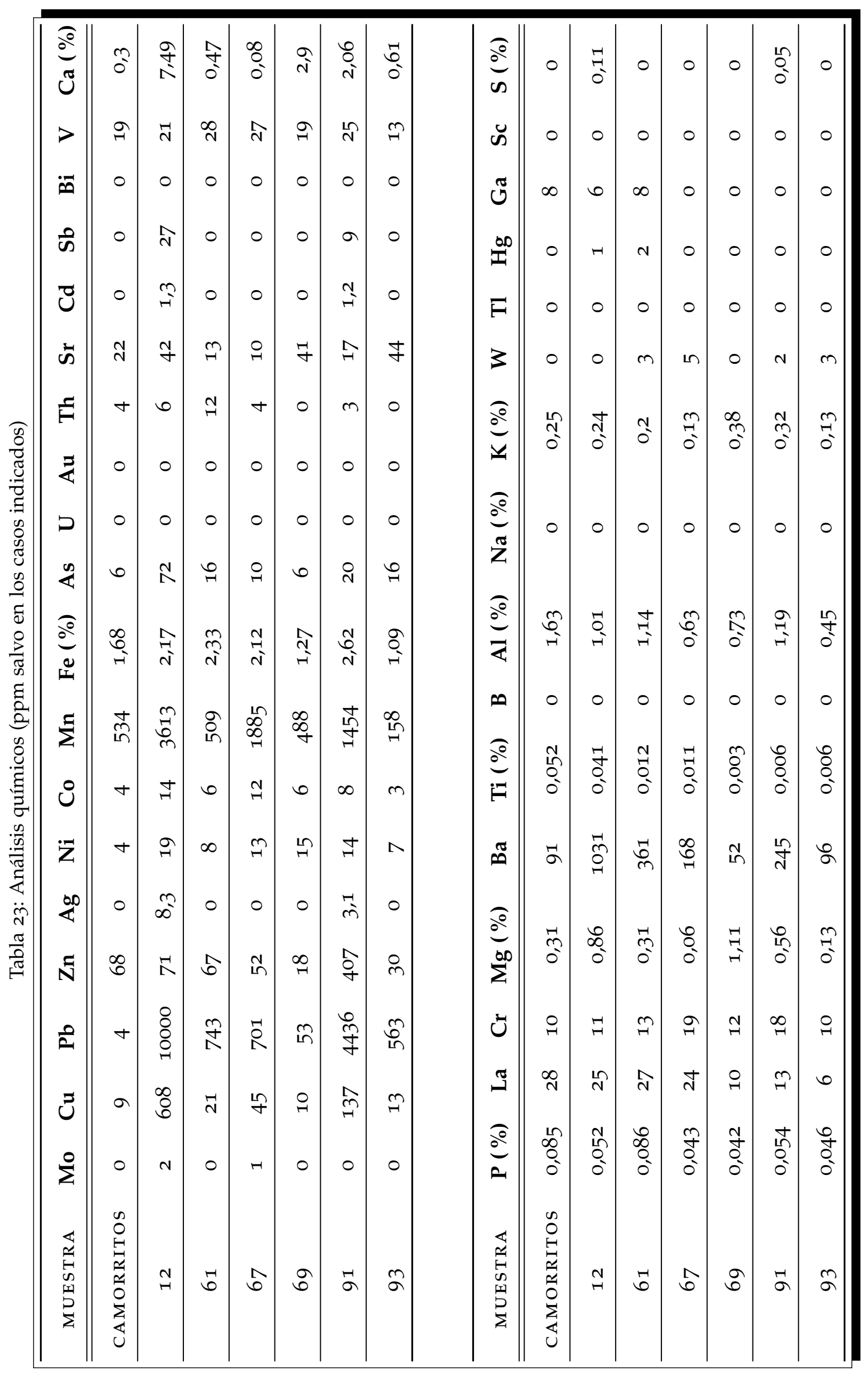


En la figura 48 se muestran los valores más significativos de los análisis químicos, junto con los dinamogramas correspondientes. Los nuevos análisis confirmaron los resultados geoquímicos previos. Como cabía esperar los contenidos más altos de cationes relacionados con la actividad minera, y en especial el plomo, se encuentran en las muestras de las cuadrículas 12 (La Garza) y 91 (La Tortilla), del grupo vinculado a la mineralurgia y/o metalurgia. El grupo de muestras vinculadas a la actividad minera meramente extractiva muestra valores intermedios de metales pesados y los más bajos corresponden a las muestras de los suelos no afectados.

En los dinamogramas vemos la misma relación que en los análisis químicos entre los suelos afectados por la mineralurgia o por la minería, mostrando menor calidad los primeros que los segundos. No ocurre lo mismo con los suelos no afectados, que pese a los bajos contenidos en metales pesados, carecen de rasgos radiales en sus dinamogramas (ver figura 48), lo que indica su peor calidad. Al quedar excluida la afección minera en estos suelos, es evidente que tiene que haber otra fuente de contaminación. Por haberse tomado la mayoría de las muestras en olivares se atribuyó esta contaminación al manejo del olivar, y para tratar de diferenciar la afección agrícola de la minera, se realizó un tercer desmuestre cuyos resultados se describen en la siguiente sección. 


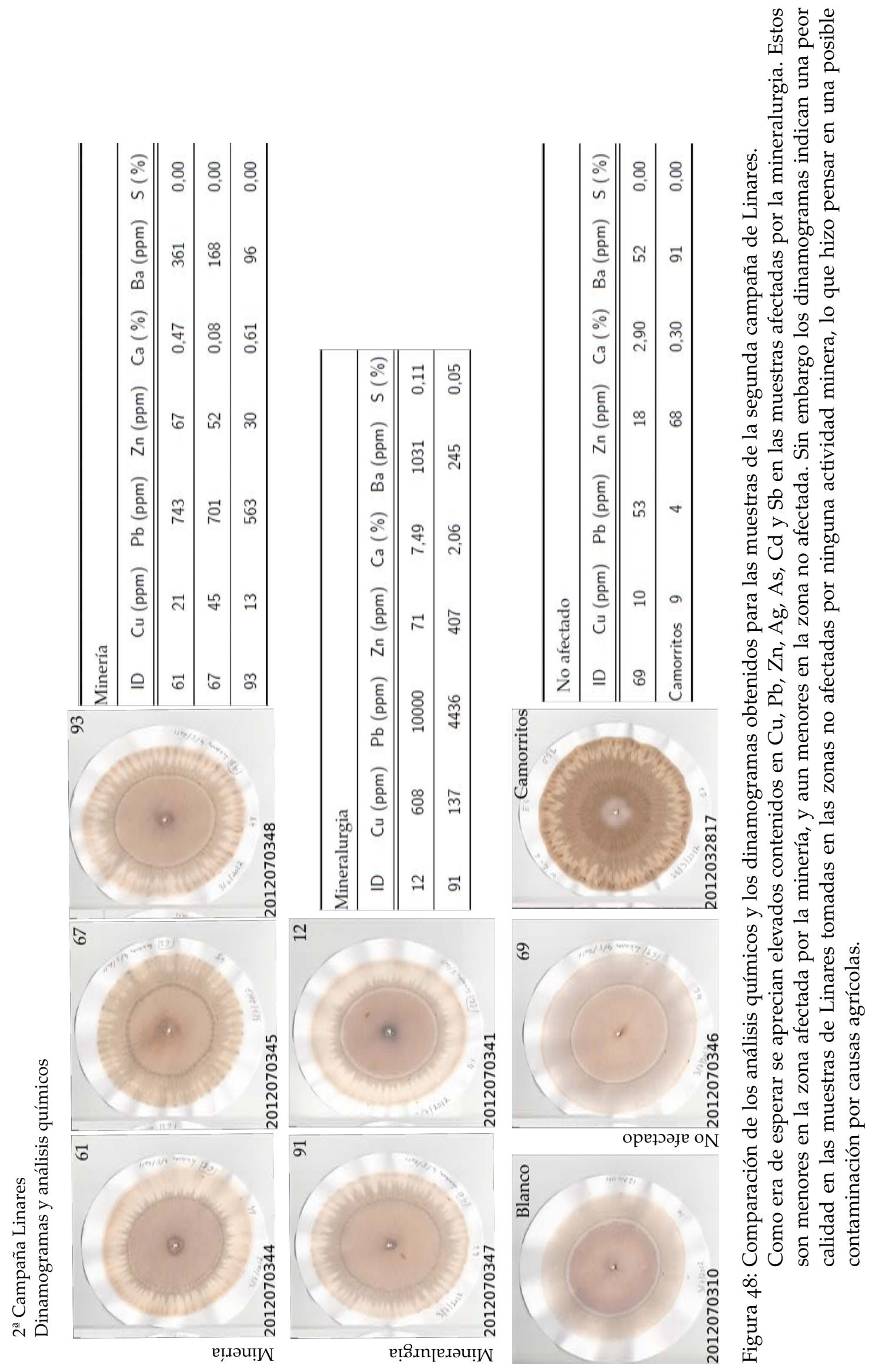


10.4 POSible CONTAMINACiÓN AgRícola: $3^{\text {a CAMPAÑA }}$

A la vista de los resultados de la segunda campaña y de la discordancia en la afección atribuible a la minería (ver la figura 48), se consideró la posibilidad de que la mala calidad de los suelos indicada por los dinamogramas correspondientes a las muestras $110 \mathrm{y}$ 69, situadas fuera del ámbito de influencia de la actividad minera, fuera debida a las prácticas agrícolas. Como vimos en la sección precedente, los nuevos análisis químicos de muestras de la $2^{\mathrm{a}}$ campaña confirmaron los resultados geoquímicos previos.

En esta sección se describe la $3^{\text {a }}$ campaña de muestreo, que tuvo por objeto repetir algunos desmuestres en los mismos lugares que en la $2^{\mathrm{a}}$ campaña para comparar las muestras en olivar con muestras en zonas próximas no cultivadas y poder diferenciar la contaminación agrícola de la minera.

\subsubsection{Objetivos y descripción de las muestras de la $3^{a}$ campaña}

En la tabla 24 se resumen los usos de los suelos investigados en la tercera campaña y los objetivos de la investigación asociados a esta tercera toma de muestras. Se pueden ver las figuras de localización de las muestras en la sección 6.4 en la página 75.

Para la $3^{\text {a }}$ campaña de desmuestre, con el objetivo principal de diferenciar la afección agrícola de la minera, se tomaron muestras cercanas, dentro y fuera del olivar, en las cuadrículas 12, 67 y 69 .

La muestra 61 fue tomada al borde de la carretera, en zona afectada por la actividad extractiva. El interés en hacer un segundo desmuestre se debió principalmente al hecho de encontrarse en zona de granito, al igual que la muestra de referencia de Camorritos, y poder por ello comparar los patrones de los dinamogramas. Tanto la muestra 61 como la 61.1 fueron tomadas al borde de la carretera, por no poder acceder al interior de la finca. La 61.2 fue tomada al otro lado de la carretera y a distancia de la misma.

En esta tercera campaña se tomaron también algunas muestras adicionales para ver la variabilidad de la toma de muestras puntual, que se considera en la sección 9.2.1 en la página 113. 
Tabla 24: Planificación de la tercera campaña de desmuestre.

\begin{tabular}{|c|c|c|c|}
\hline MUESTRA & USO ACTUAL & AFECCIÓN & OBJETIVOS \\
\hline 12.1 & Olivar & \multirow{2}{*}{ Mineralurgia } & \multirow{6}{*}{$\begin{array}{l}\text { Diferenciar } \\
\text { influjo } \\
\text { minero de } \\
\text { influjo } \\
\text { agrícola }\end{array}$} \\
\hline 12.2 & $\begin{array}{c}\text { Sin influencia } \\
\text { agrícola }\end{array}$ & & \\
\hline 67.1 & $\begin{array}{c}\text { Olivar sin abono } \\
\text { químico }\end{array}$ & \multirow[t]{2}{*}{ Polvorín } & \\
\hline 67.2 & Eucaliptos & & \\
\hline 69.1 & Olivar & \multirow{2}{*}{$\begin{array}{l}\text { No } \\
\text { afectado }\end{array}$} & \\
\hline 69.2 & $\begin{array}{l}\text { Monte bajo de } \\
\text { retama }\end{array}$ & & \\
\hline 61.1 & \multirow{2}{*}{ Prado } & \multirow{2}{*}{$\begin{array}{l}\text { Minería } \\
\text { extractiva }\end{array}$} & \multirow{2}{*}{$\begin{array}{l}\text { Comparar } \\
\text { suelos } \\
\text { graníticos }\end{array}$} \\
\hline 61.2 & & & \\
\hline 91.1 & \multirow{3}{*}{$\begin{array}{l}\text { Olivares } \\
\text { contiguos }\end{array}$} & \multirow{3}{*}{ Mineralurgia } & \multirow{6}{*}{$\begin{array}{l}\text { Evaluar la } \\
\text { toma de } \\
\text { muestras } \\
\text { puntual }^{*}\end{array}$} \\
\hline 91.2 & & & \\
\hline $91 \cdot 3$ & & & \\
\hline 93.1 & \multirow{3}{*}{ Prado } & \multirow{3}{*}{ Urbano } & \\
\hline 93.2 & & & \\
\hline $93 \cdot 3$ & & & \\
\hline
\end{tabular}


10.4.2 Resultados de la $2^{a}$ y $3^{a}$ campañas

En la figura 49 se recogen los resultados de la $3^{\mathrm{a}}$ campaña. Se muestran junto con los correspondientes de la $2^{\mathrm{a}}$ campaña. El tipo de uso actual del suelo se indica en cada caso sobre las imágenes de los dinamogramas. En las muestras de las cuadrículas 12, 67 y 69 se tomaron de nuevo muestras puntuales sobre el olivar próximas a las tomadas en la $2^{\mathrm{a}}$ campaña, y adicionalmente se tomaron muestras fuera del olivar en zonas incultas inmediatamente contiguas. 
$2^{\text {a }}$ Campaña
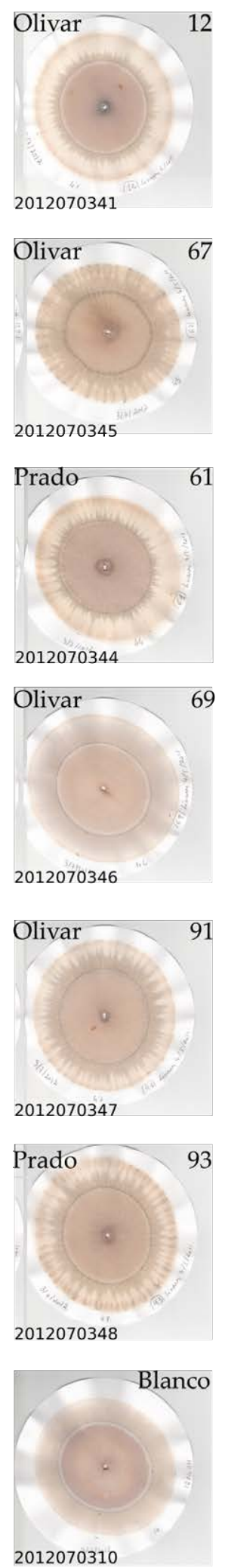

3 ${ }^{\text {a }}$ Campaña Linares
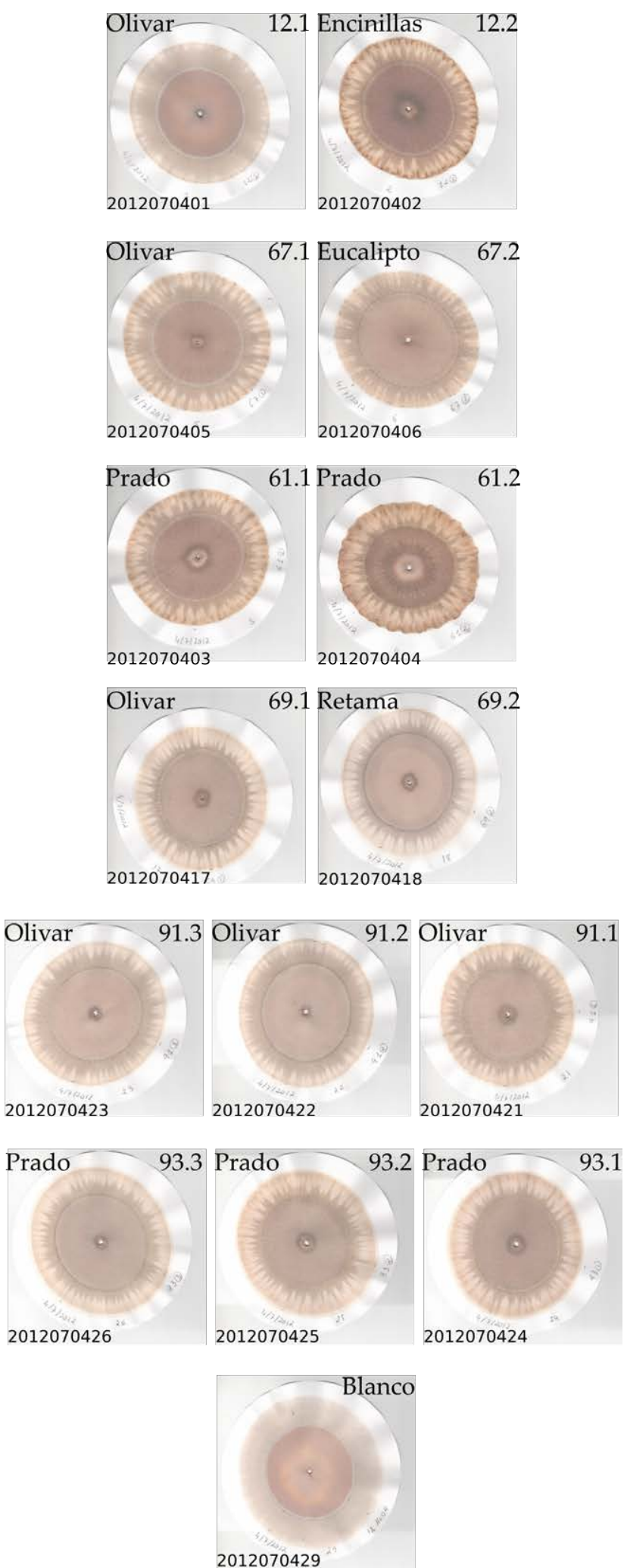

Figura 49: Dinamogramas de la $3^{\text {a }}$ campaña de Linares, con indicación del uso actual del suelo.

A la izquierda se presentan los dinamogramas de la $2^{\mathrm{a}}$ campaña para facilitar la comparación 


\subsubsection{Contaminación por mineralurgia}

CUADRÍCUla 12 Los resultados de la Dinamolisis Capilar ilustran grandes diferencias entre las muestras, que no son atribuibles a la minería por estar muy próximas entre sí, al pie del antiguo lavadero de mineral. La muestra 12 y la 12.1 se tomaron en olivar y los patrones son muy similares al del Blanco. En cambio la muestra 12.2, tomada fuera del olivar, pero más próxima al antiguo lavadero de mineral, presenta un dinamograma con rasgos radiales en la zona exterior e interior, que indican la superior calidad del suelo. Esto permite identificar la afección por el manejo agrícola, que se pone de manifiesto en los dinamogramas de las muestras 12 y 12.1 tomadas dentro del olivar. La afección atribuible sólo a la mineralurgia está indicada por la muestra 12.2 y es evidente que es mucho menor que la producida adicionalmente por el manejo agrícola indicada por la 12 y la 12.1.

\begin{tabular}{|c|c|c|c|c|c|c|}
\hline \multicolumn{7}{|c|}{ Mineralurgia } \\
\hline ID & $\mathrm{Cu}(\mathrm{ppm})$ & $\mathrm{Pb}(\mathrm{ppm})$ & $\mathrm{Zn}(\mathrm{ppm})$ & $\mathrm{Ca}(\%)$ & $\mathrm{Ba}(\mathrm{ppm})$ & $S(\%)$ \\
\hline 12 & 608 & 10000 & 71 & 7,49 & 1031 & 0,11 \\
\hline 91 & 137 & 4436 & 407 & 2,06 & 245 & 0,05 \\
\hline
\end{tabular}
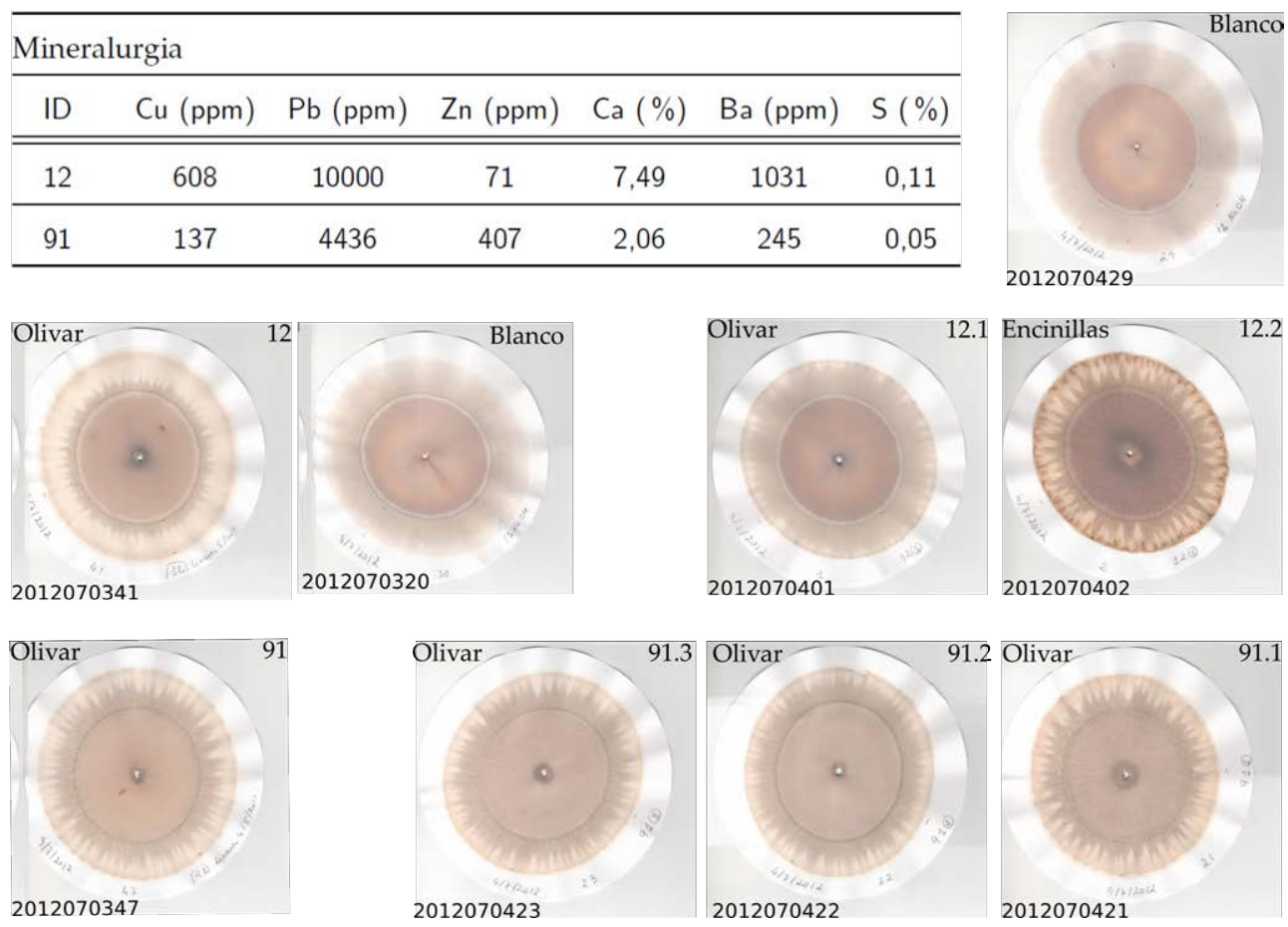

Figura 50: Mineralurgia. Análisis y dinamogramas. Obsérvese que el dinamograma de la muestra 12.2, próxima a la 12 y también bajo el antiguo lavadero de mineral, pero fuera del olivar, presenta rasgos radiales tanto en la zona interior como en la exterior.

Los análisis químicos de la muestra 12 muestran altos contenidos en $\mathrm{Cu}, \mathrm{Pb}, \mathrm{As}$, Ca y Ba que corresponden con la paragénesis de los minerales beneficiados, y es de suponer que se encuentren presentes también en las muestras 12.1 y 12.2 por su situación también bajo el lavadero de mineral. Sin embargo la buena calidad indicada por los dinamogramas de la muestra 12.2, pone de manifiesto que la contaminación minera se puede encontrar atenuada por el propio suelo debido a 
la función de buffer que pueden realizar los suelos y que la contaminación agrícola inhibe esta función del suelo.

CUADRÍCULA 91 Situada en una zona afectada por la mineralurgia. La muestra 91 presenta altos contenidos en $\mathrm{Cu}, \mathrm{Pb}$ y $\mathrm{Zn}$, que son atribuibles a la actividad minera. No obstante la presencia de rasgos radiales en la zona interior del dinamograma de la muestra 91.1 haría de nuevo sospechar que el empeoramiento de calidad mostrado en las muestras 91, 91.2 y 91.3 respecto a la 91.1 podría ser debido a las prácticas agrícolas.

CUADRÍCULA 22 Y MUESTRA 3 B La muestra tomada en la cuadrícula 22 se sitúa sobre la antigua balsa de lodos del Pozo Chaves, lo que justifica la peor calidad indicada por el dinamograma, similar al de la muestra 3 b de la primera campaña, tomada también en una balsa de lodos. En ambos casos los patrones son muy cercanos a los del Blanco.
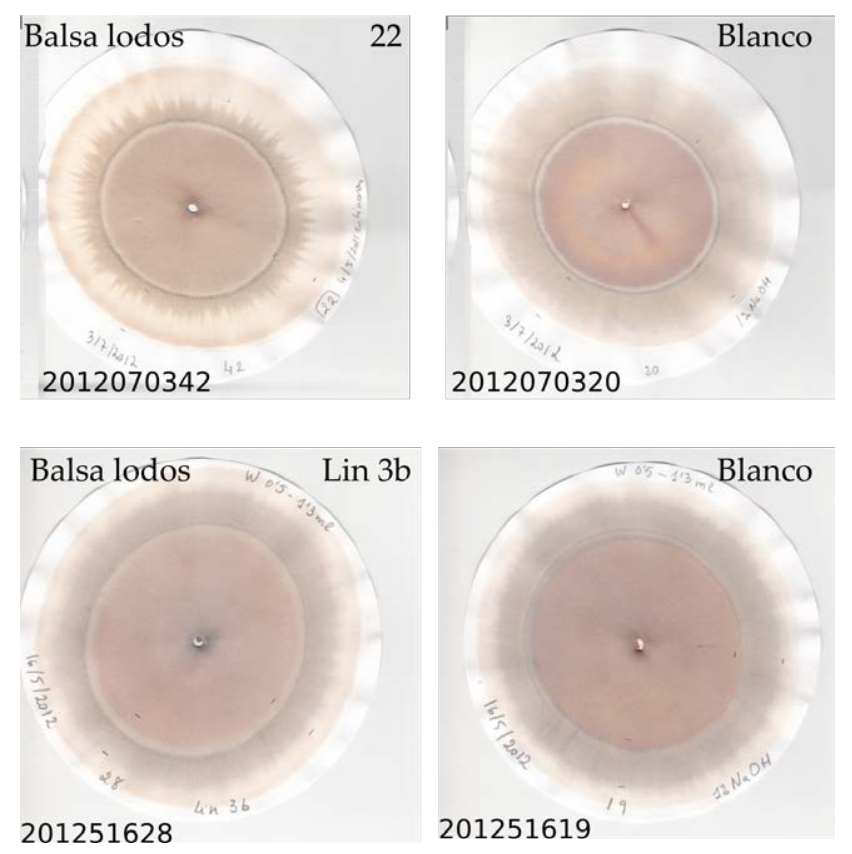

Figura 51: Balsas de lodos. Los dinamogramas no muestran rasgos radiales.

MUestras 1, 2, 3 Y 4 DE LA PRIMERA CAmpaña Al haber sido tomadas en olivares, no es posible saber si la mala calidad actual del suelo indicada por los dinamogramas (ver la figura 40 en la página 135) se debe a la actividad vinculada a la minería o a la agrícola. Por haberse producido muchos movimientos de tierra, con aportes de otras zonas, no se han hecho más desmuestres. 
10.4.2.2 Contaminación por minería

Los dinamogramas muestran en general rasgos radiales tanto en la zona exterior como en la interior, indicando que en este grupo se encuentran los suelos con más vitalidad.

muestra 59 Tomada en zona de dehesa con algún olivo viejo, pese a su proximidad a la mina esmeralda, su dinamograma muestra rasgos radiales en la zona exterior y en la interior que indican buena calidad del suelo. La estructura grumosa, observada al tomar la muestra, corrobora este resultado.

CUADRÍCULA 61 La muestra 61 fue tomada al borde de la carretera, en zona afectada por actividad minera extractiva. El interés en hacer una segundo desmuestre se debió principalmente al hecho de encontrarse en zona de granito, al igual que la muestra de referencia de Camorritos, lo que permite comparar los dinamogramas de suelos con el mismo tipo de roca madre.

El dinamograma de la muestra 61 presenta comparativamente poca riqueza morfológica. En principio se atribuyó a la influencia de la actividad vinculada al cercano pozo San José dentro del paraje de Cañada Incosa. Inesperadamente los resultados de las muestras 61.1 y 61.2 de la tercera campaña (figura 49) indican una calidad del suelo mejor que la mostrada por la primera muestra 61. Por consiguiente la menor calidad de la muestra 61 se podría atribuir a la excesiva cercanía a la carretera.

Los dinamogramas de las muestras 61.1 y 61.2 presentan también rasgos radiales en la zona exterior e interior, indicio de buena vitalidad del suelo.

CUADRÍCULA 67 Estas muestras se sitúan sobre la zona que estuvo afectada por el polvorín. El olivar donde se tomaron las muestras $67 \mathrm{y}$ 67.1 se abona sólo con estiércol de gallina y no recibe fertilizantes químicos ni fitosanitarios. En la parcela de la muestra 67.2 actualmente hay eucaliptos. Las tres muestran tienen un patrón similar que indica mejor calidad que el resto de muestras tomadas en olivares. Esto corrobora también que el impacto de la minería en la actualidad es menor que la posible afección por las malas prácticas agrícolas indicada en el resto de olivares investigados.

CUADRÍCULA 93 Esta zona de prado urbano presenta según la investigación geoquímica de Martínez López et al. (2008) una contaminación de tipo urbano, similar a la atribuida a la minería. Los dinamogramas de las cuatro muestras ensayadas muestran patrones similares, pero con diferencias debidas a la intencionalidad del desmuestre buscando la máxima variabilidad. 


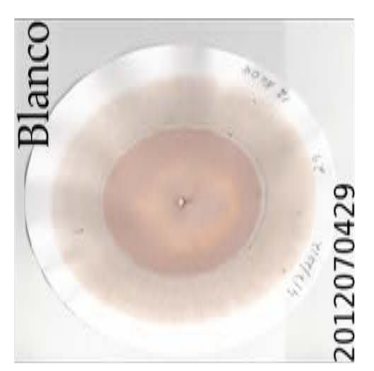

พิ

通

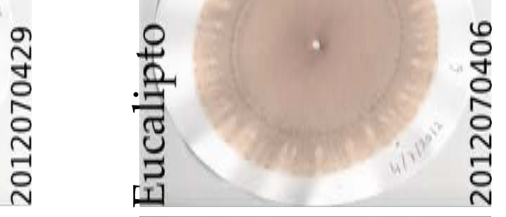

๕్రి
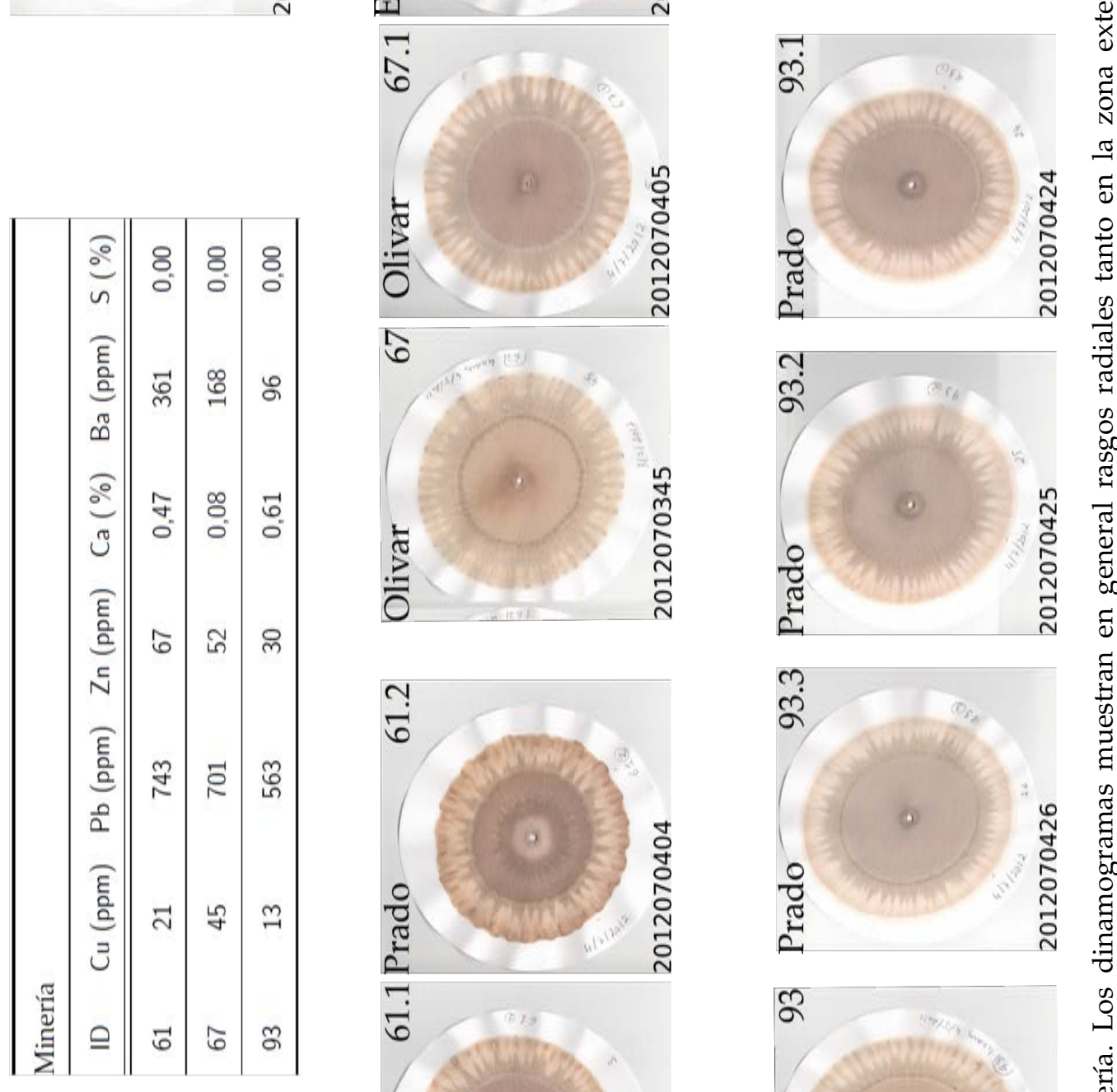

0
0
0
0
0
0
0

흔

กำ

ฮี

节

$\frac{0}{0}$

商
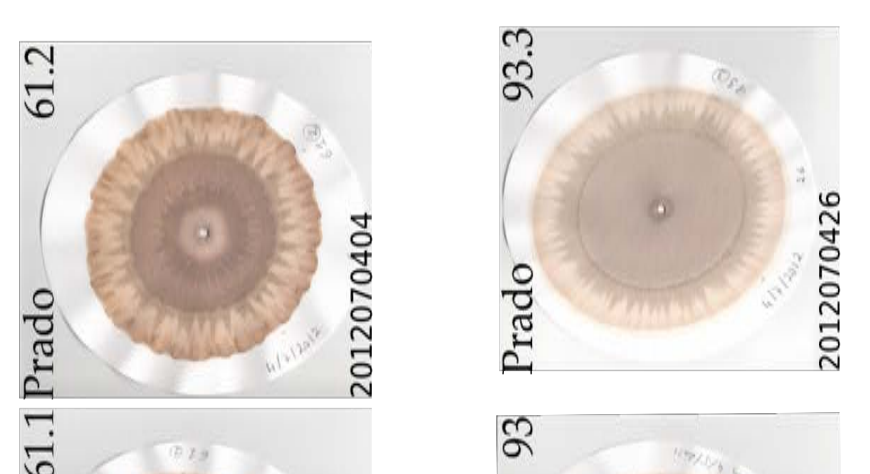

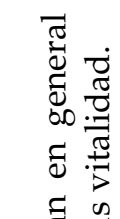

ह્ત્心

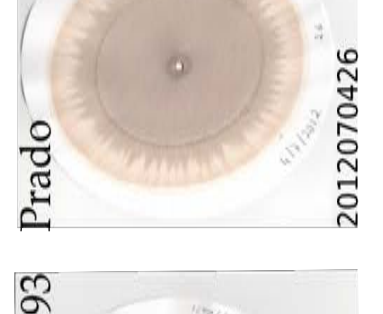

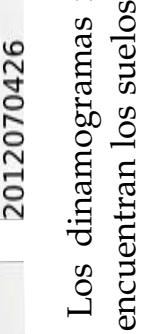

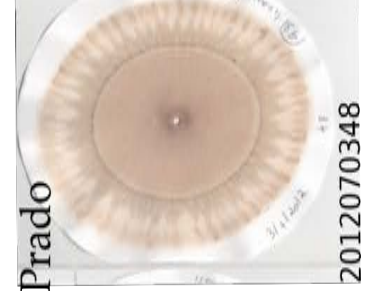

ฮี่ क

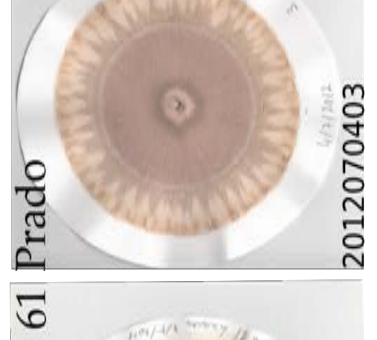

离 苛

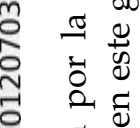

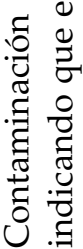
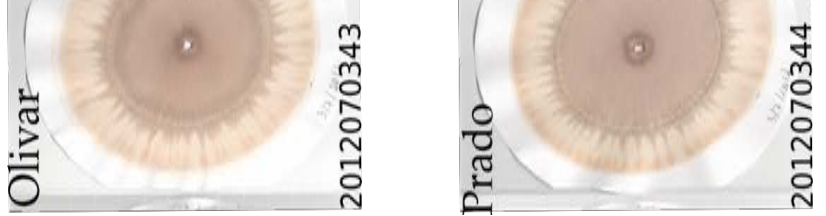
ỉ

ํㅠㄹ 
10.4.2.3 No afectado por la actividad minera

Los dinamogramas de las muestras de suelos de Linares no afectados por actividades mineras, figura 53, no muestran rasgos radiales, indicando la peor calidad de todos los suelos investigados.

CUADRÍCULA 69 Se sitúa en una zona no afectada por la actividad minera. Atribuimos la variabilidad de los dinamogramas 69.1 y 69.2 visible en la figura 49, al manejo agrícola, y en este caso, sobre todo a la construcción reciente de terrazas, lo que implica un gran movimiento de tierras que también hace que el desmuestre puntual no sea en absoluto representativo y que los resultados no se pueden valorar.

MUESTRA 11o Por su situación fuera de la zona de actividad minera hemos de sospechar que el manejo del olivar es la causa de la mala calidad, indicada tanto por los dinamogramas, como por el estado empastado en que se encontraba el suelo el día de la toma de muestras. Se trata de un suelo formado sobre lutitas del Mioceno, que son generalmente preferidos para usos agrícolas frente a los suelos sobre las lutitas del Triásico.

CAMORRITOS Para evidenciar el contraste se presenta también una muestras de Camorritos con marcados rasgos radiales. 


\begin{tabular}{|c|c|c|c|c|c|c|}
\hline \multicolumn{7}{|c|}{ No afectado } \\
\hline ID & $\mathrm{u}(\mathrm{ppm})$ & $\mathrm{Pb}(\mathrm{ppm})$ & $\mathrm{Zn}(\mathrm{ppm}$ & $\mathrm{Ca}(\%)$ & $\mathrm{Ba}(\mathrm{ppm})$ & $S(\%)$ \\
\hline 69 & 10 & 53 & 18 & 2,90 & 52 & 0,00 \\
\hline Camorritos & 9 & 4 & 68 & 0,30 & 91 & 0,00 \\
\hline 1 & & & 69 & & & 110 \\
\hline & c. & & & & 9 & \\
\hline 201207034 & $46^{2 / 2}$ & & 201 & 70349 & 49 & \\
\hline
\end{tabular}
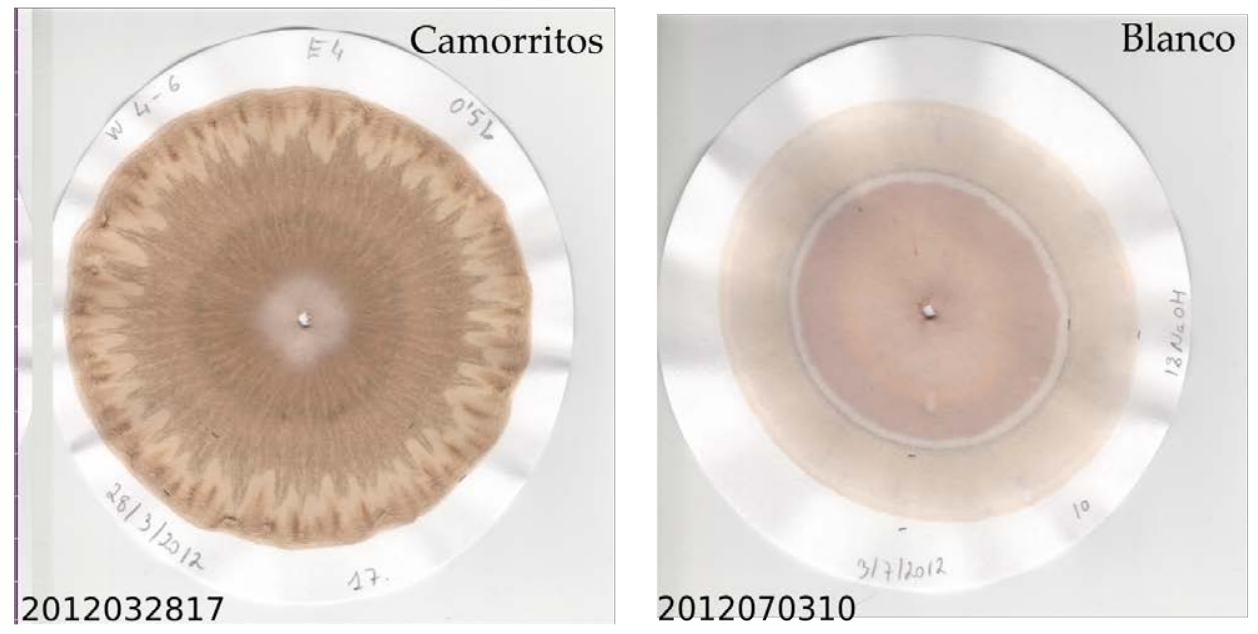

Figura 53: Suelos no afectados por la minería. Pese a no estar influidos por la minería, los dinamogramas correspondientes a las muestras de los suelos 69 y 110 no presentan ningún rasgo radial, como el blanco. Para evidenciar el contraste se presenta también una muestras de Camorritos con marcados rasgos radiales. 
Con objeto de estimar el potencial del método Horizontal de Dinamolisis Capilar como indicador de la contaminación de los suelos, se investigó la expresión de sus patrones en los dinamogramas ensayando un espectro amplio de suelos contaminados y de suelos y composts procedentes de la agricultura Biodinámica.

Se realizaron en primer lugar ensayos con siete sales metálicas. La figura 44 en la página 143 resume los resultados más representativos con las sales de plata, de oro y de plomo, mostrando el espectro de variación de los patrones de las muestras de suelos y de compost investigadas. Las sales que mostraron mayor potencial de discriminación son el Nitrato de Plata y el Cloruro de Oro. La investigación posterior se restringió al Nitrato de Plata.

Tras esta primera etapa se realizó, tomando como base la investigación geoquímica previa de Martínez López et al. (2008), un segundo desmuestre en Linares para investigar el potencial del Chroma-Test para caracterizar los suelos contaminados de esta antigua zona minera. Tomando como referencia la muestra de mejor calidad (Cam. huerto) en un extremo y los ensayos en blanco en el otro extremo, fue posible comparar y ordenar los dinamogramas de las muestras obtenidos con la sal de plata ${ }^{1}$, como se muestra en las figuras 41 en la página 138 y 42 en la página 139 .

Tras esta primera ordenación en base a los rasgos morfológicos de los dinamogramas se propuso la clasificación de la tabla 21 para caracterizar las diferencias de calidad en tres niveles atendiendo a la presencia/ausencia de rasgos morfológicos radiales. Esta clasificación se usó para caracterizar los suelos de la $2^{\mathrm{a}}$ campaña de Linares, resultando las calidades indicadas en la última columna de la tabla 22 en la página 151. Al compararla con los grupos obtenidos en base a los datos geoquímicos de Martínez López et al. (2008) (columnas CALIDAD y CLUSTER en la tabla 22), a partir de los cuales se había diseñado el muestreo, se constataron discrepancias con los resultados esperados para las muestras no afectadas por ninguna actividad minera. Según los dinamogramas, las muestras 110 y 69 corresponden a suelos muy degradados, mientras que los resultados de la geoquímica y su situación, alejada de las instalaciones mineras, excluyen que esa afección tenga origen minero. Ello hizo sospechar una afección de origen agrícola. Para verificar la validez de la agrupación por la geoquímica se procedió a realizar análisis químicos de una selección de seis muestras de la segunda campaña. Los nuevos análisis confirmaron las conclusiones de los resultados geoquímicos previos. En la figura 48 se muestran los dinamogramas y los análisis de los

1 Para las otras sales el resultado de la ordenación podría ser diferente, ya que es de esperar que cada metal se relaciona con la naturaleza y funciones de los suelos de forma diferente. 
tres grupos de muestras de la segunda campaña. Se puede visualizar claramente una mayor afección vinculada a la mineralurgia que a la simple minería extractiva, y que la mala calidad de las muestras no afectadas por la minería no es atribuible a la presencia de metales pesados.

Para diferenciar la posible afección agrícola de la minera se realizó un tercer desmuestre que permitió relacionar la peor calidad del suelo con las prácticas agrícolas más que con la contaminación por la minería. Si además tenemos en cuenta los contenidos de metales pesados identificados en la muestras 12, podemos inferir también una función atenuadora (buffer) en algunos suelos con más vitalidad, indicada de forma más clara por los dinamogramas de la muestra 12.2, fuera del olivar y en menor medida por los suelos correspondientes a las muestras $67,67.1$ y 67.2 que no están expuestos a las prácticas convencionales de cultivo del olivar. 

VALIDACIÓN DEL MÉTODO HORIZONTAL DE DINAMOLISIS CAPILAR

\section{INTRODUCCIÓN}

En el capítulo 9 se resumen los resultados de la investigación de los factores de influencia y de los parámetros del Chroma-Test que han permitido identificar los factores críticos e introducir las modificaciones necesarias para obtener resultados reproducibles. En este capítulo se resumen los resultados obtenidos en ensayos ciegos colaborativos por el método Horizontal de Dinamolisis Capilar, desarrollado a partir del Chroma-Test de Pfeiffer (1959) y modificado como se indica en la sección 8.3. Se trata de verificar que operadores diferentes pueden reproducir los ensayos, con los procedimientos estándar adoptados, en días diferentes y en laboratorios diferentes. En el laboratorio de Madrid se han realizado además una serie de ensayos físicos sencillos adicionales para poder comparar sus resultados con los del método de Dinamolisis Capilar investigado.

- El objetivo de este capítulo es verificar que el Método Horizontal de Dinamolisis Capilar es validable modificando la configuración original del Chroma-Test de Pfeiffer (1959).

- Los ensayos son repetibles: ensayos paralelos realizados por un operador. Sección 11.1.1.

- Los ensayos son reproducibles por operadores diferentes. Sección 11.1.1.

- Los ensayos son reproducibles en días diferentes. Sección 11.1.2.

- Los ensayos son reproducibles en distintos laboratorios. Sección 11.1.3.

- Comparación de los resultados con otros tipos de ensayos. Sección 8.5. 


\subsection{ENSAYOS CIEGOS COLABORATIVOS}

11.1.1 Repetibilidad de cada ensayo y reproducción por operadores diferentes

Se trata de verificar en primer lugar que los ensayos son repetibles por el mismo operador si no se modifica ninguna condición. Para ello se realizan 3 ensayos paralelos de cada muestra. En segundo lugar se quiere verificar que operadores diferentes pueden reproducir los ensayos. Para ello tres operadores realizan los ensayos ciegos el mismo día.

Los ensayos realizados en los laboratorios de la ETSIME en Madrid se realizaron en el mismo día, con los mismos materiales y con la misma disolución de nitrato de Plata, que se preparó también el mismo día de los ensayos. Cada operador realizó la extracción de las muestras del lote que le fue asignado, preparando de forma independiente la disolución de $\mathrm{NaOH}$. Se hicieron tres ensayos por muestra y tres ensayos en blanco.

En las figuras 54 a 56 se muestran los resultados de cada operador. Se puede apreciar que la repetibilidad es buena en todos los casos. 

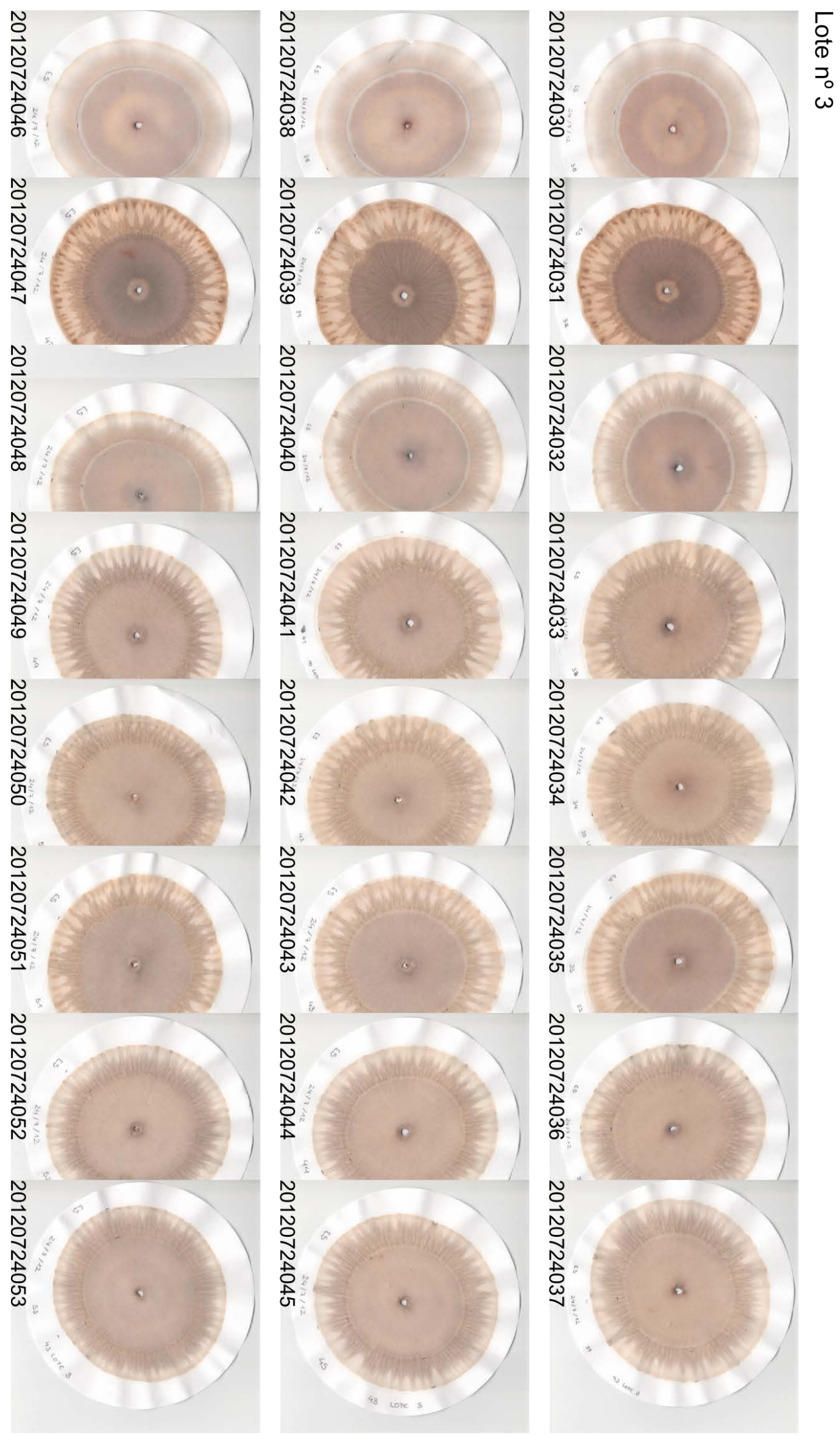

Figura 54: Repetibilidad. Lote $\mathrm{n}^{\circ} 3$ ETSIME/ES 
O
N
0
N
今
0

N
N
N
जे
ป
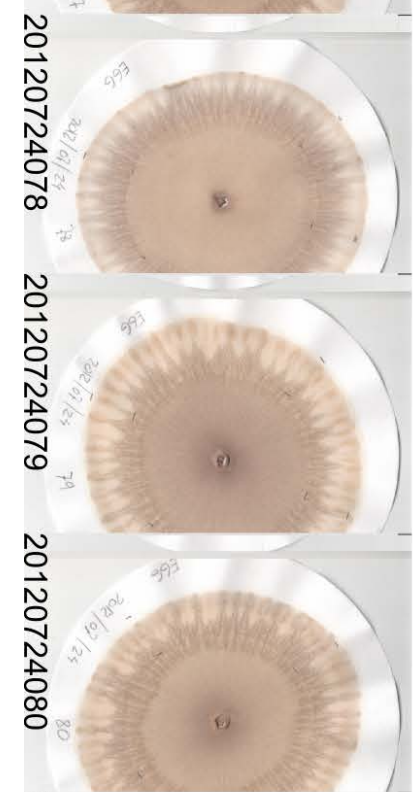

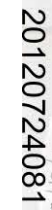
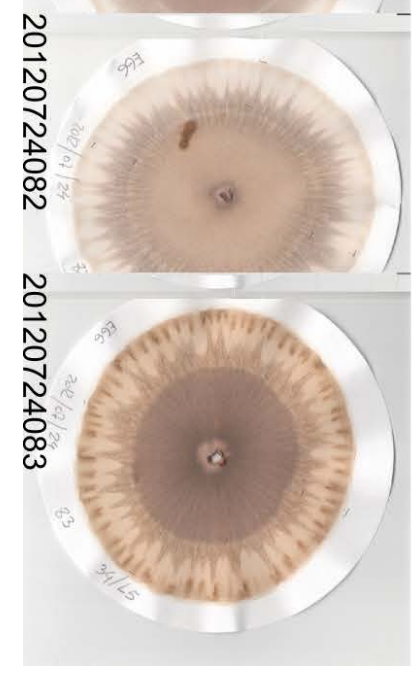
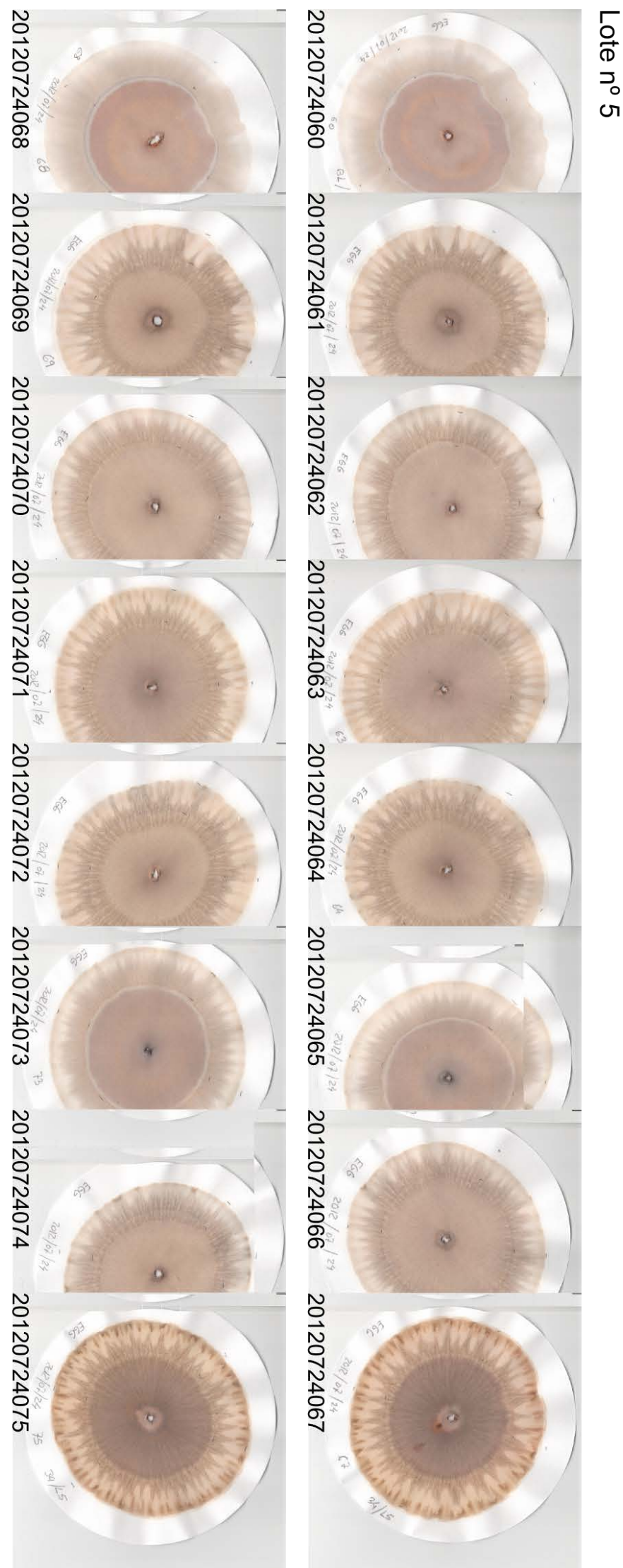

Figura 55: Repetibilidad. Lote $n^{\circ} 5$ ETSIME/EGG 

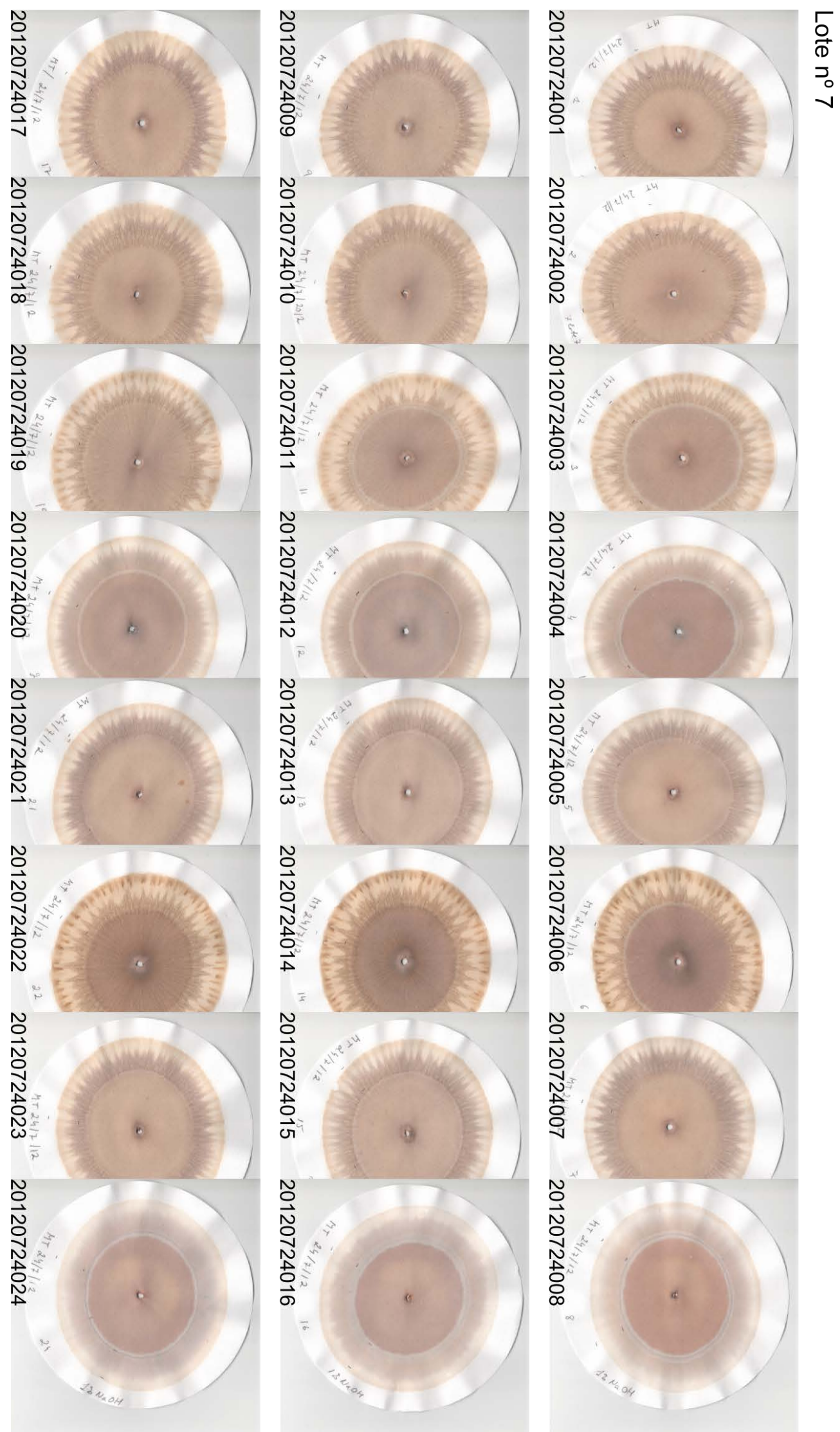

Figura 56: Repetibilidad. Lote $\mathrm{n}^{\circ} 7$ ETSIME/MTM 
En la figura 57 se muestra una serie de ensayos de cada operador, con indicación de la muestra a la que corresponden. En esta figura se puede observar la buena reproducción de los ensayos por diferentes operadores. Se puede concluir, por tanto, que el operador no influye en las operaciones de extracción, sensibilización, ensayo y revelado. 

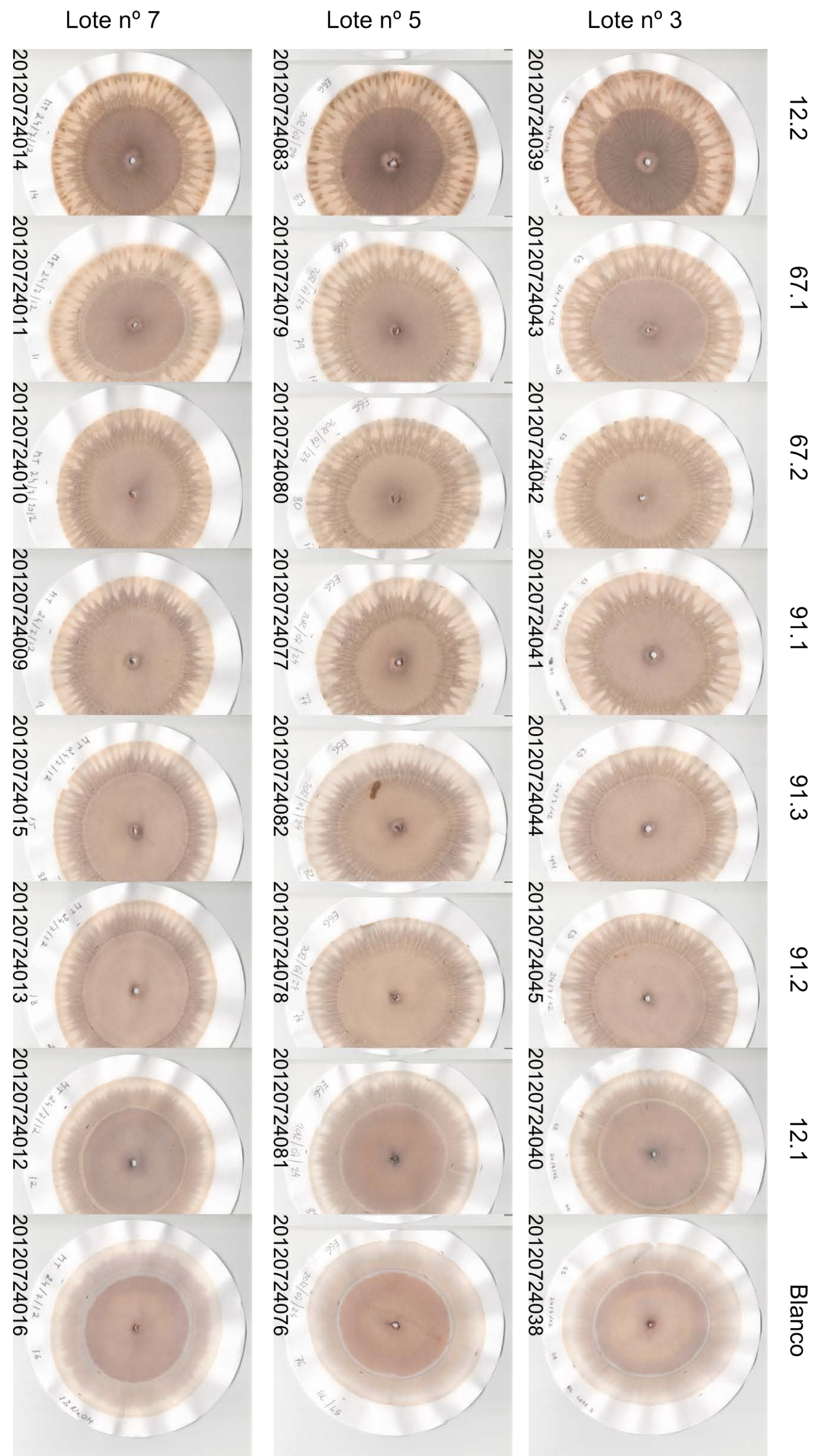

Figura 57: Reproducción de los ensayos por tres operadores diferentes en los laboratorios de la ETSIME. 
11.1.2 Reproducción en días diferentes

El lote $n^{\circ} 7$ ha sido ensayado en días diferentes. En la figura 58 se muestran los resultados. Podemos ver que no influye el día. 


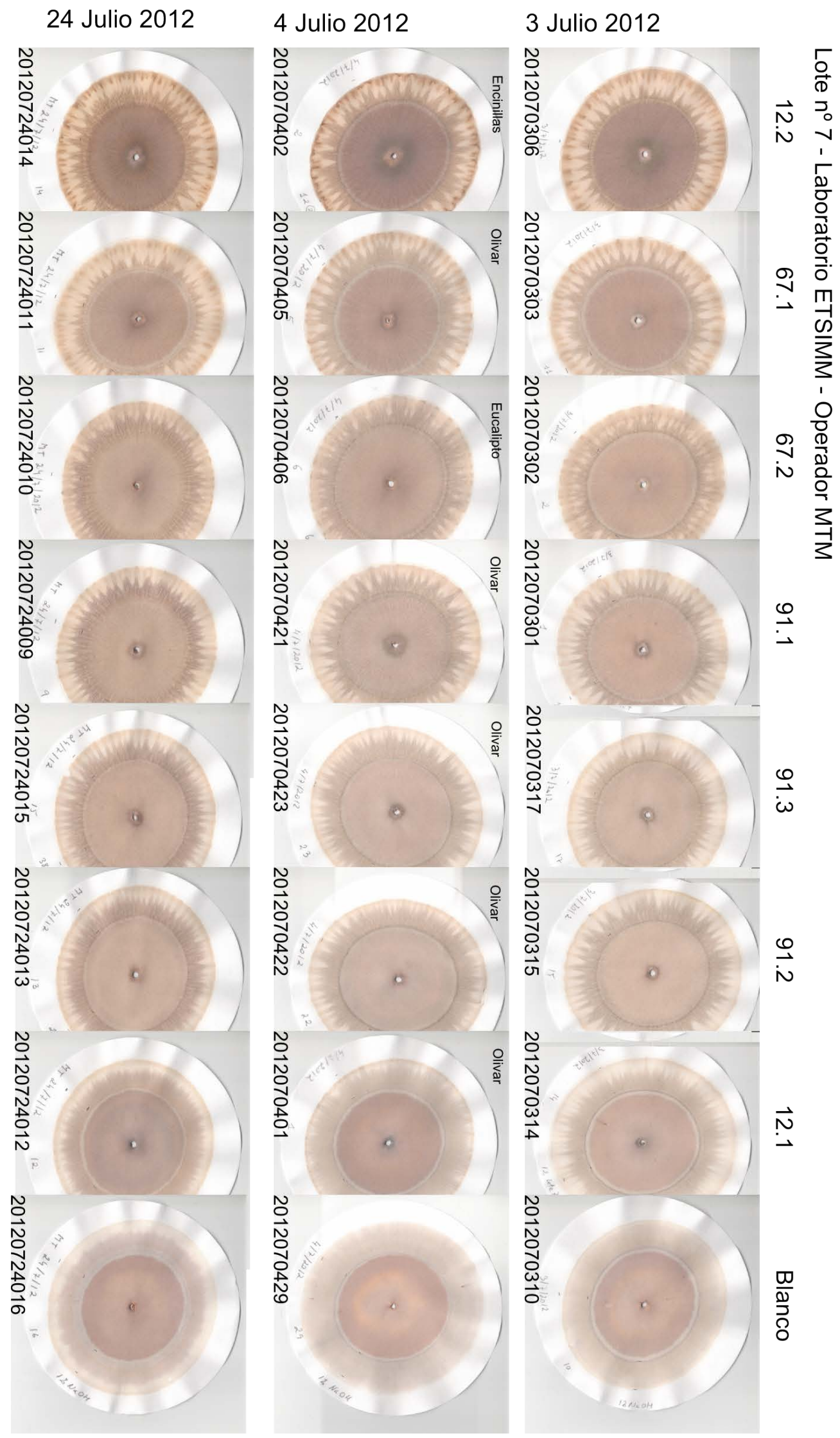

Figura 58: Reproducción de los ensayos por el mismo operador en tres días diferentes. 


\subsubsection{Reproducción en laboratorios diferentes}

Para estos ensayos se ha contado con la colaboración del laboratorio de la granja Andreashof, en Ueberlingen, Alemania. En el laboratorio de esta granja se ha seguido el procedimiento original de Pfeiffer (descrito en la sección 4.1). La comparación de sus resultados con los de los otros dos laboratorios permite comprobar las ventajas que reporta la modificación descrita en cuanto a la mayor nitidez y diferenciación de los patrones de las muestras analizadas.

Además ha colaborado el laboratorio farmacéutico de la Ita Wegman Klinik, en Arlesheim, Suiza. El procedimiento seguido por este laboratorio es el mismo que el utilizado en los laboratorios de la ETSIME, que se describe en la sección 8.3.

El escaneado de los dinamogramas obtenidos en la ETSIME se realizó tan sólo tres días después del experimento, mientras que los dinamogramas de la granja Andreashof, realizados el 24 de julio de 2012, no se escanearon hasta el 28 de agosto, y los del laboratorio de la IWK, realizados el 16 de agosto, se escanearon también el 28, a los 12 días de su obtención. Esto justifica que los dinamogramas del laboratorio de la ETSIME sean más pálidos que los de los otros dos laboratorios.

En la figura 59 se recoge una de las series de ensayos de cada uno de los laboratorios para facilitar la comparación de los mismos. Se aprecia que los resultados obtenidos en $\mathrm{AH}$ usando el método original de Pfeiffer muestran una menor diferenciación de los rasgos, y por tanto una menor eficiencia en la diferenciación de las muestras. Se puede constatar el efecto del pipeteo de cantidades exactas (ver sección 4.2) en los ensayos de ETSIME y de IWK, que al medir exactamente los volúmenes de reactivos y de muestras, limita la difusión y permite una precisión que no es alcanzable si se utilizan únicamente las marcas sobre el filtro. 


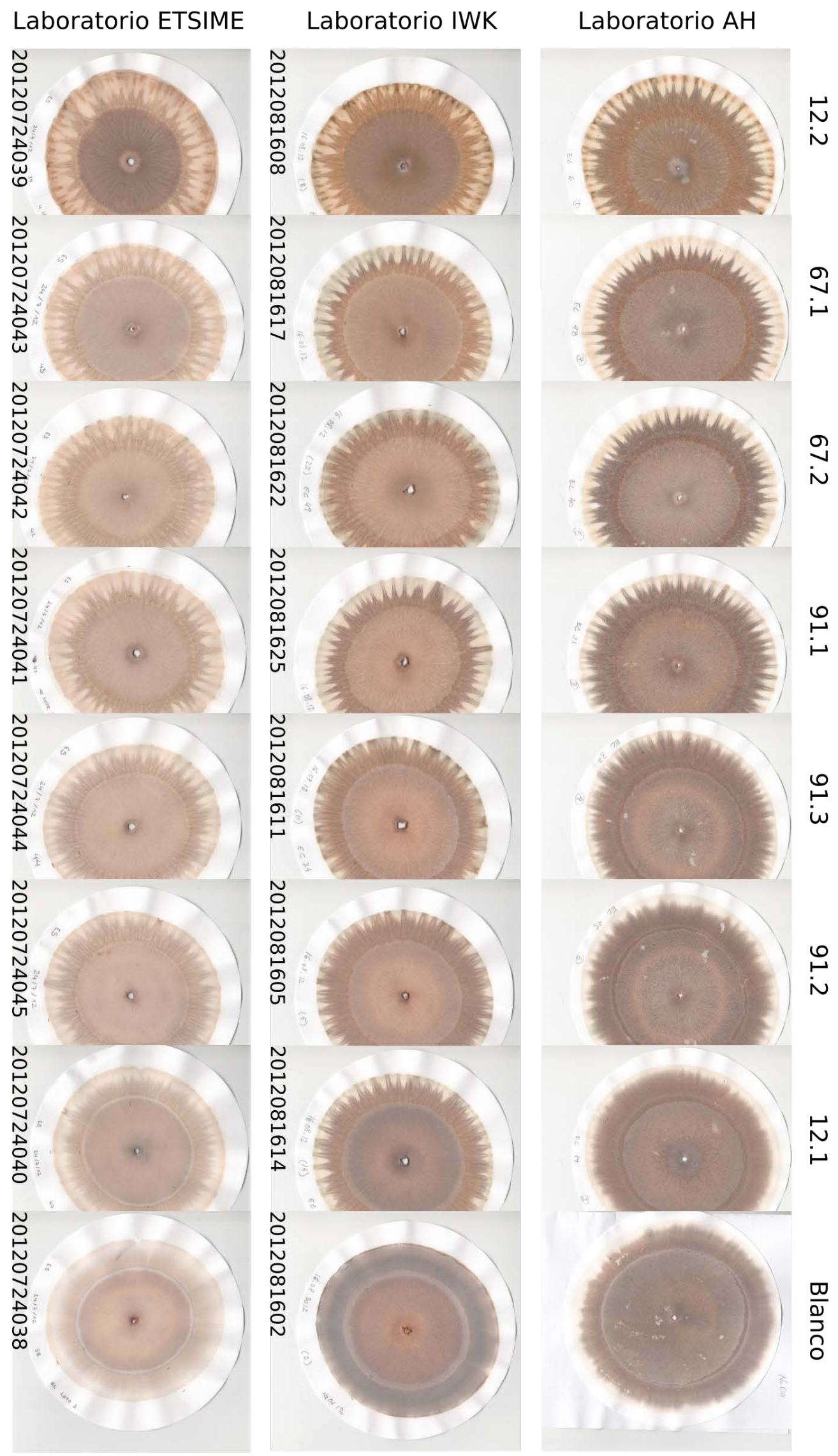

Figura 59: Reproducción de los ensayos en tres laboratorios diferentes. Las condiciones no han sido homogéneas. En el laboratorio de la ETSIME el tiempo de revelado fue muy inferior, por lo que los dinamogramas de la ETSIME son más pálidos. Además el operador de Andreashof usó el método del Chroma-Test original (sección 4.1), mientras el resto de operadores aplicaron las modificaciones que están descritas en la sección 8.3 en la página 93. 


\subsection{ENSAYOS FÍSICOS SENCILLOS}

Se ha realizado una batería de ensayos físicos cualitativos muy sencillos, como se describe en la sección 8.5, para poder contrastarlos con los resultados de la Dinamolisis Capilar. Las muestras ensayadas son las seleccionadas para los ensayos ciegos 12.1, 12.2, 67.1, 67.2, 91.1, 91.2 y 91.3. Los resultados se resumen en la tabla 25 .

Estos resultados concuerdan en general con los obtenidos por el método de Dinamolisis Capilar.

\subsubsection{Cuadrícula 12}

La muestra 12.1 presenta cualidades muy inferiores a la muestra 12.2. La 12.1 fue tomada en olivar, mientras que la 12.2 se tomó en una zona inculta. Este resultado refuerza los argumentos expuestos en la subsección 10.4.2.1 en la página 160.

\subsubsection{Cuadrícula 67}

La muestra 67.1, de olivar con abono natural de estiércol de gallina, muestra resultados algo mejores que la 67.2, tomada en zona inculta, afectada por el polvorín. En este caso se puede atribuir un efecto positivo a la práctica agrícola.

\subsubsection{Cuadrícula 91}

Las muestras de la cuadrícula 91 muestran resultados algo diferenciados, que no podemos valorar por desconocer si las condiciones de cultivo son homogéneas, ya que aunque todas fueron tomadas en olivares, corresponden a tres parcelas diferentes. 
Tabla 25: Resultados de los ensayos físicos

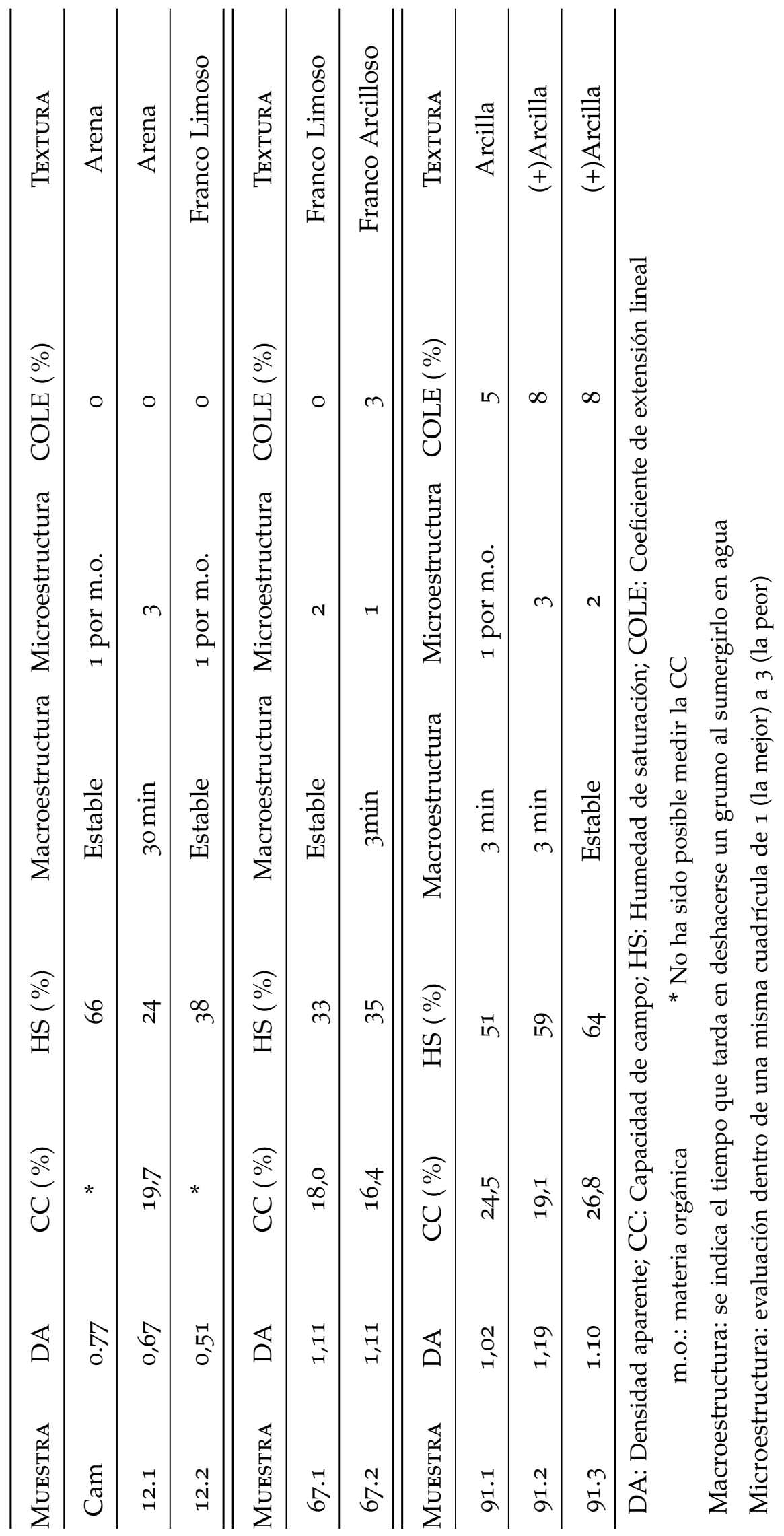

$\begin{array}{lll}\text { (a) Cuadrícula } 12 & \text { (b) Cuadrícula } 67 & \text { (c) Cuadrícula } 91\end{array}$ 



\subsection{RESUMEN Y DISCUSIÓN DE LOS RESULTADOS}

La sociedad demanda soluciones a la ciencia y la ciencia es consciente de que el recurso suelo debe ser reconocido como un sistema dinámico vivo que emerge mediante un especial equilibrio e interacción de sus componentes biológicos, químicos y físicos (Karlen et al., 1997). Las percepciones de la calidad del suelo son muy variadas, y la introducción de nuevas ideas y métodos experimentales es importante porque, pese a los esfuerzos realizados, al contrario que con el aire y el agua, no se han podido generalizar estándares legales de calidad de suelo.

Se ha comprobado mediante ensayos ciegos que los ensayos son repetibles por un mismo operador y que son reproducibles tanto por diferentes operadores como en días diferentes. Los resultados de los ensayos realizados en laboratorios diferentes aconsejan verificar la repetibilidad de los ensayos en caso de utilizar nitrato de plata procedente de distintos fabricantes.

Los ensayos de este capítulo indican que el método Horizontal de Dinamolisis Capilar puede ser estandarizado y validado a partir de la configuración del Chroma-Test de Pfeiffer (1959) adoptando las modificaciones recogidas en la sección 8.3 y justificadas en el capítulo 9. Estas modificaciones, además de asegurar la repetibilidad, mejoran la definición y diferenciación de los dinamogramas, como se puede ver, por ejemplo, en la figura 59 en la página 179 comparando los resultados del laboratorio de la ETSIME con los del laboratorio AH. 

1. El método Horizontal de Dinamolisis Capilar puede servir como indicador de calidad medioambiental del suelo.

2. El método Horizontal de Dinamolisis Capilar es estandarizable y validable modificando la configuración original del ChromaTest de Pfeiffer (1959).

3. El método Horizontal de Dinamolisis Capilar da una imagen de la vitalidad del suelo, y pone de manifiesto los efectos perniciosos de la contaminación difusa vinculada a la agricultura ${ }^{1}$.

\subsection{RESUMEN}

Este trabajo ha sido realizado desde la idea de que la contaminación química o de cualquier otro tipo afecta negativamente a la vitalidad del suelo. Hemos asumido que la calidad del suelo y su capacidad para proporcionar servicios ecosistémicos medioambientales está determinada por la vitalidad del mismo y que ésta última se puede caracterizar por medio de sus fuerzas formativas. Hemos investigado las fuerzas formativas de los suelos seleccionados, partiendo del Chroma-Test de Pfeiffer (1959), una configuración particular del Método Horizontal de Dinamolisis Capilar de Kolisko and Kolisko (1939).

En el capítulo 9, dedicado al desarrollo y caracterización del método Horizontal de Dinamolisis Capilar, identificamos las carencias metodológicas del Chroma-Test original de Pfeiffer (1959), que han obstaculizado hasta ahora el desarrollo y la difusión del método. La principal carencia es la imprecisión de los volúmenes utilizados cuando se controla la difusión sólo por medio de marcas sobre los filtros. Otras carencias notables son la ausencia de metodología de control del experimento y la falta de definición de las condiciones de iluminación en las diferentes etapas del mismo. El escaneo de los dinamogramas y la mayor precisión en las condiciones y duración de la fase de revelado, previa al escaneo, hacen posible la protocolización de todo el proceso de ensayo. Este es un requisito imprescindible para

1 En Europa se usa normalmente el término contaminación para referirse únicamente a la contaminación química vinculada a la actividad industrial. En cambio en Canadá y especialmente en los Estados Unidos el término contaminación también se refiere a la contaminación química agrícola, que en Europa se considera aparte, como un tipo de contaminación difusa (sin un foco puntual). 
que la interpretación y valoración de los dinamogramas pueda ser validable ${ }^{2}$.

El capítulo 1o del presente trabajo indica que el Método Horizontal de Dinamolisis Capilar puede servir para identificar los suelos contaminados de forma directa. El método ha permitido establecer una ordenación de los suelos investigados en base a los rasgos morfológicos, usando como referencia los ensayos en blanco. Este tipo de ordenación es el primer paso para poder proceder a una evaluación de los suelos según su degradación, confirmando su potencial como indicador de calidad medioambiental para poder ser utilizado en políticas de protección del suelo.

La investigación en los suelos de Linares, afectados por la actividad minera, indica que el manejo agrícola del olivar puede ser la causa principal del deterioro actual de los suelos investigados, que presentan peores resultados que los que han sido afectados únicamente por la actividad minero metalúrgica y que el método puede servir para evaluar de forma directa los suelos degradados o contaminados por cualquier tipo de afección, ya sea por contaminación local con un foco puntual (industrial) o de contaminación difusa vinculada principalmente a la agricultura (sección 10.4).

El capítulo II muestra que el Método Horizontal de Dinamolisis Capilar es validable. Los ensayos ciegos realizados muestran que la modificación adoptada proporciona resultados repetibles y reproducibles. La ampliación del marco conceptual, asociando el potencial del suelo para funcionar a su vitalidad, permite explicar racionalmente las funciones naturales del suelo y comprender mejor el alcance de otros tipos de experimentos, y en particular, el valor de los ensayos físicos sencillos elegidos en el contexto de la validación del método.

Según Hassold-Piezunka (2003) los dinamogramas reflejan el contenido de compuestos húmicos solubles en medio alcalino. El ensayo de Dinamolisis Capilar diferencia suelos con diferente grado de capacidad de retención de agua y por tanto de diferente porosidad y estructura. La porosidad y la estructura del suelo se relacionan con la actividad biológica de este, y por tanto con su contenido en materia orgánica.

Por todo ello podemos afirmar que los resultados obtenidos confirman el potencial del método Horizontal de Dinamolisis Capilar para caracterizar la aptitud de los suelos para prestar servicios ecosistémicos medioambientales, como reserva de carbono, filtro, almacén y regulador de sustancias, biodiversidad y actividad biológica.

No se ha podido avanzar en la caracterización del suelo por medio de la "signatura" constituida por los patrones de las siete sales metálicas investigadas, por la imposibilidad de abarcar este aspecto tan

2 El escaneo estandarizado es posible a partir de la publicación en 1997 de la norma ISO 12641 sobre tecnologías gráficas, que establece estándares para calibrar escáneres, impresoras y demás dispositivos de salida de gráficos y asegurar la misma visualización de las imágenes en cualquier dispositivo. 
amplio en el necesariamente limitado marco de este trabajo y por la carencia de investigación previa en este sentido.

\subsection{POSIBLES USOS}

La sencillez del Método Horizontal de Dinamolisis Capilar hace posible que los ensayos se realicen en cualquier laboratorio mínimamente dotado, o incluso instalar fácilmente un laboratorio allí donde se requiera investigar el suelo. Además de la ventaja de la simplicidad técnica, el método ofrece un modo directo de valorar la calidad del suelo y conceptualmente sencillo para comprender e interpretar los resultados.

El primer uso podría ser para evaluar el estado de los suelos contaminados, a escala local y de un modo estandarizado, incluyendo la posibilidad de detectar de forma directa los efectos de la contaminación difusa por causa de las prácticas agrarias. El Método de Dinamolisis Capilar, en comparación con los métodos basados en análisis químicos, no precisa que las sustancias contaminantes sean conocidas a priori, ni que sus efectos sobre el ser humano o sobre los ecosistemas hayan sido investigados previamente, ya que proporciona patrones en forma de imágenes directamente relacionadas con la vitalidad del suelo, que ilustran los efectos de los contaminantes sobre el propio suelo. En general los contaminantes de origen agrícola exigen métodos de análisis complejos, caros y que a veces precisan un tiempo largo de ejecución. Debido a la gran complejidad de la dinámica del suelo, la gran variedad de sustancias que presentan los contaminantes químicos orgánicos y al elevado coste de los análisis de este tipo de sustancias, su análisis no está al alcance de todos los laboratorios (Locutura Rupérez et al. (2012)) ni posibilita una evaluación rápida y directa del estado del suelo. El método de Dinamolisis Capilar podría ser de gran utilidad al proporcionar una indicación del estado del suelo con un reducido coste y en un breve plazo de pocos días.

Un segundo uso podría ser la monitorización de la evolución o de la recuperación de suelos contaminados y de las labores de remediación realizadas con este fin.

\subsection{RECOMENDACIONES PARA FUTURAS INVESTIGACIONES}

El futuro desarrollo del método Horizontal de Dinamolisis Capilar podría orientarse a

- aplicar métodos numéricos de análisis de imágenes para interpretar y valorar los resultados, usando como parámetros los rasgos morfológicos característicos. En este sentido se están realizado avances significativos para otros Métodos de Formación de Imágenes: para el método de Cristalizaciones Sensibles, por Andersen et al. (1999), Szulc et al. (2010), Kokornaczyk et al. (2012), 
Unluturk et al. (2013) y Doesburg et al. (2015), y para el método Wala de Dinamolisis Capilar por Unluturk et al. (2011).

- validarlo como criterio para la declaración de suelos contaminados, lo que dotaría a las administraciones de un instrumento eficaz para la calificación legal del suelo. Los dinamogramas de suelos de calidad conocida, se pueden establecer como referencias, atendiendo a las diferentes litologías y pedogénesis. En base a los rasgos morfológicos de los dinamogramas sería posible definir distintos "estándares" de calidad o de protección, de modo análogo a como se realiza con los datos procedentes del análisis químico en base al RD 9/2005 (España. Ministerio de la Presidencia, 2005).

- investigar el potencial del método de Dinamolisis Capilar para evaluar la condición de los ecosistemas terrestres (estructura, composición y funciones) y los servicios que proporcionan, en cumplimiento del Objetivo 2, Acción 5 de la Estrategia de la Unión Europea sobre la Biodiversidad hasta 2020 (Comisión Europea (2011), Brouwer et al. (2013) y MAES).

Se han detectado las siguientes necesidades de investigación

- Muchos suelos de España tienen de forma natural un contenido muy bajo de materia orgánica. En caso de suelos pobres puede ser conveniente aumentar (al menos al doble o el triple) la cantidad de suelo utilizada en el experimento para obtener rasgos morfológicos más intensos y permitir una mejor diferenciación de las calidades.

- El revelado de las imágenes obtenidas con $\mathrm{AgNO}_{3}$ depende de la iluminación, por lo que es necesario usar siempre condiciones similares de iluminación y plazos de tiempo homogéneos hasta el escaneado. Para los ensayos descritos en el capítulo II hemos realizado el secado a oscuras (con exposición posterior de 6 horas) y esta opción hace que los colores sean pálidos y los rasgos débiles, por lo que parece aconsejable realizar el secado con iluminación, manteniendo los dinamogramas expuestos a la iluminación del laboratorio hasta el día siguiente y después guardarlos a oscuras hasta el momento del escaneado.

- El papel de filtro Whatman 4 se usa por ser una marca tradicional ampliamente implantada, que ofrece una calidad mantenida y unas características muy estables, necesarias para poder comparar los resultados. Otros fabricantes de papel e incluso otros soportes podrían contribuir a la mejora de las imágenes. Los ensayos realizados con los filtros ANOIA 1249 han dado buenos resultados, proporcionan imágenes más nítidas y con mejor definición de las formas, por lo que es recomendable su uso en el 
futuro. En caso de gran sequedad ambiental, como en Madrid en verano, es recomendable asegurar que los papeles de filtro no estén demasiado secos metiéndolos en la cámara climatizada antes de usarlos.

- Es necesario investigar los patrones de cada tipo de roca madre y su ámbito de validez geográfico. En la figura 60 se pueden apreciar los dinamogramas de diferentes suelos graníticos.
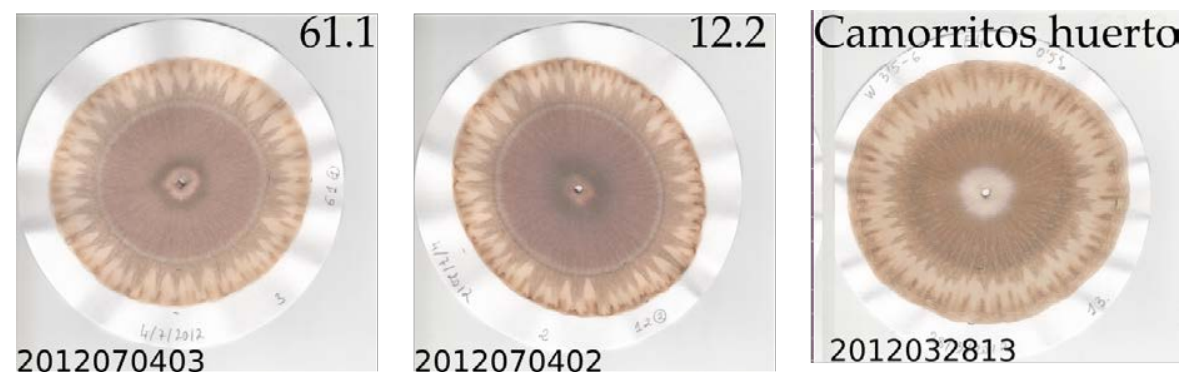

Figura 6o: Dinamogramas de diferentes suelos graníticos

- En base a las ideas de Rudolf Steiner, las sustancias se pueden caracterizar por su relación con los 7 "metales principales": Au, $\mathrm{Ag}, \mathrm{Hg}, \mathrm{Cu}, \mathrm{Fe}, \mathrm{Sn}, \mathrm{Pb}$. El procedimiento de ensayo utilizado posibilita un conocimiento de estas relaciones y abre una vía a la investigación apenas explorada. Es de esperar que puedan ser de utilidad a la hora de caracterizar el tipo de contaminación. Los ensayos realizados son muy pocos, muestran la regularidad del fenómeno, pero no son suficientes para poder valorarlos en el sentido indicado. 

Parte V

APÉNDICES 



\section{BIBLIOGRAFÍA}

AEMA. El medio ambiente en Europa: Estado y perspectivas 2015 - Informe de sintesis. Agencia Europea de Medio Ambiente, Copenhague, 2015. (Cited on page 4.)

Andersen, J.-O., Henriksen, C., Laursen, J., and Nielsen, A. A. Computerised image analysis of biocrystallograms originating from agricultural products. Computers and Electronics in Agriculture. Elsevier, 22(1):51-69, 1999. (Cited on pages 26 y 187.)

Balzer, F. M. and Balzer-Graf, U. R. Rundfilterchromatogramm nach Pfeiffer-eine ganzheitliche Untersuchungsmethode. Labor für Bodenuntersuchungen und Spurenmetall-Analytic Dr.Balzer, Amönau, 1989. (Cited on page 26.)

Balzer, U. Vitalaktivität von Nahrungsmitteln. Elemente der Naturwissenschaft, (46):69-92, 1987. (Cited on page 26.)

Balzer-Graf, U., Hoppe, H., and Straub, M. Äpfel - organisch und biologisch-dynamisch. Erntemenge und Vitalqualität im Vergleich. Lebendige Erde, 49(5):387-397, 1998. (Cited on page 26.)

Balzer-Graf, U. R. and Balzer, F. M. Steigbild und Kupferchloridkristallisation. Spiegel der Vitalaktivität von Lebensmittel. In MeierPloeger, A. and Vogtmann, H., editors, Lebensmittelqualität - Ganzheitliche Methoden und Konzepte, volume 66 of Alternative Konzepte, pages 163-210. Verlag C. F. Müller, Karlsruhe, 1991. ISBN 3-78809752-3. (Cited on page 26.)

Bangert, D. Zu den naturwissenschaftlichen Grundlagen des ChromaBoden-Tests als bildschaffender Methode - Empirische Untersuchungen und theoretische Deutungen: Diplomarbeit FB Landwirtschaftsentwickelung der TU Berlin, in ueberarbeiteter Form, volume 41. Verlag Edition Zukunft, Barsinghausen, cd edition, 1994. ISBN 3-89799-098-9. (Cited on pages XIV, 6, 41, 42, 45, 47, 48, 49, 50, 51 y 94.)

Barker, J. The Handbook of Rising Pictures. Anastasi, UK, 2009. ISBN 978-0-9553077-6-8. (Cited on pages 26 y 28.)

Baumgartner, S., Doesburg, P., Scherr, C., and Andersen, J.-O. Development of a Biocrystallisation Assay for Examining Effects of Homeopathic Preparations Using Cress Seedlings. Evidence-Based Complementary and Alternative Medicine, 2012(1-6):1-14, 2012. (Cited on page 26.)

Bechmann, A. Zwischenstation 1995. Edition Zukunft, Barsinghausen - Alemania, 2011. (Cited on page 42.) 
Beckman, J. Untersuchungen zum Chroma-Boden-Test nach Pfeiffer 1. Meßtheoretisch gestützte Überprüfung der Methode 2. Vorstellung von Konzepten zur Auswertung der Chromatogramme, volume 42 of Barsinghäuser Bericht. Edition Zukunft, Barsinghausen- Alemania, 1994. ISBN 3-89799-099-7. (Cited on pages 39, 41 y 42.)

Beckman, J. and Stölzer, S. Unterschidliche praxisübliche Kompostierungsverfahren im Spiegel chemischer und physikalischer Parameter sowie des Chroma-Boden-Tests. Barsinghäuser Bericht. Edition Zukunft, Barsinghausen, 1994. ISBN 3-89799-097-0. (Cited on page 42.)

Beckman, J., Römer, B., and Jacke, S. Die Abwandlung des ChromaBoden-tests nach Pfeiffer zu einer Untersuchungsmethode für die Bestimmung der Nahrungsmittelqualität, volume 33 of Barsinghäuser Bericht. Verlag Edition Zukunft, Barsinghausen- Alemania, 1993. ISBN 389799-106-3. (Cited on pages 39 y 42.)

Beneke, K. Friedrich (Fritz) Feigl (1891-1071) und die Geschichte der Chromatographie und der Tüpfelanalyse. In Beneke, K., editor, Biographien und wissenschaftliche Lebensläufe von Kolloidwissenschaftlern, deren Lebensdaten mit 1996 in Verbindung stehen. Mitteilungen der Kolloid-Gesellschaft, volume VII of Beiträge zur Geschichte der Kolloidwissenschaften, pages 216-244. Verlag Reinhard Knof, Nehmten, 1999. ISBN 3-934413-01-3. (Cited on pages 21 y 24.)

Blank, S. Untersuchungen zur Bildentstehung der Pfeifferschen Rundfilterchromatographie und Beurteilung von Chromas verschiedener Bodentzpen (Anmooriger, Gley, Moor, Marsch, Ranker, Rendzina) und unterschiedlicher Komposte in Zusammenhang mit ihren analytishen Kenndaten, 1991. (Cited on pages 6, 43, 52 y 120.)

Brinton, W. F. J. A qualitative method for assessing humus condition. In Knorr, D., editor, Sustainable food systems, pages 382-393. AVI Inc, Westport, Connecticut, USA, 1983. (Cited on page 43.)

Brouwer, R., Brander, L., Kuik, O., Papyrakis, E., and Bateman, I. A synthesis of approaches to assess and value ecosystem services in the EU in the context of TEEB. 2013. (Cited on page 188.)

Bühler, W. Das Pentagram und der Goldene Schnit als Schöpfungsprinzip. Verlag Freies Geistesleben, Stuttgart, 1996. ISBN 3-7725-1457-X. (Cited on page 98.)

Bussemas, H. H. and Ettre, L. S. Forerunners of Chromatography: Runge s Self-Grown pictures: Milestones in Chromatography. LCGC North America, 22(3):262-270, 2004. (Cited on pages 21 y 23.)

Chapin III, F. S., Matson, P. A., and Mooney, H. A. Principles of Terrestrial Ecosystem Ecology. Springer, New York, 2002. ISBN 0-38795439-2. (Cited on page 10.) 
Cloos, W. Lebensstufen der Erde: Beitraege zu einer organischen Gesteins und Mineralkunde: reprint in limitierter Auflage. Info3-Verlag, Kirchgartenstr. 1 and 60439 Frankfurt and Alemania, reprint, 2. ed. 1970 edition, 2003. ISBN 377250485 X. (Cited on page 11.)

Comisión Europea. Hacia una estrategia temática para la protección del suelo. Comunicación de la Comisión al Consejo, el Parlamento Europeo, el Comité Económico y Social y el Comité de las Regiones: $\operatorname{COM}(2002) 179$ final, 2002. (Cited on page 7.)

Comisión Europea. Estrategia de la UE sobre la biodiversidad hasta 2020. EUR-OP, Luxemburgo, 2011. ISBN 978-92-79-20763-1. (Cited on page 188.$)$

Custodio, E., Garrido, A., and Coleto, C. S. G. The challenges of agricultural diffuse pollution. In Martinez-Santos, P., Aldaya, M. M., and Llamas, M. R., editors, Integrated Water Resources Management in the 21st Century: Revisiting the Paradigm, pages 153-163. CRC Press, Balkema, 2014. ISBN 978-1-138-00143-5. (Cited on page 4.)

Doesburg, P., Huber, M., Andersen, J.-O., Athmann, M., Bie, G. v. d., Fritz, J., Geier, U., Hoekman, J., Kahl, J., Mergardt, G., and Busscher, N. Standardization and performance of a visual Gestalt evaluation of biocrystallization patterns reflecting ripening and decomposition processes in food samples. Biological Agriculture $\mathcal{E}$ Horticulture, 31(2):128-145, 2015. URL http://dx.doi.org/10.1080/01448765. 2014.993705. (Cited on pages 26 y 188.)

España. Ministerio de la Presidencia. REAL DECRETO 9/2005, de 14 de enero, por el que se establece la relación de actividades potencialmente contaminantes del suelo y los criterios y estándares para la declaración de suelos contaminados. RD 9/2005, 2005. (Cited on pages 4 y 188.)

Ettre, L. S. Evolution of Liquid Chromatography: A Historical Overview. In Horvâth, C., editor, High-Performance Liquid Chromatography, volume 1, pages 2-75. Academic Press, London, 1980. ISBN 0-12-312201-5. (Cited on page 21.)

Fritz, J., Athmann, M., Kautz, T., and Köpke, U. Grouping and classification of wheat from organic and conventional production systems by combining three image forming methods. Biological Agriculture $\mathcal{E}$ Horticulture, 27(3-4):320-336, 2011. (Cited on pages 26 y 34.)

Fritz, J., Athmann, M., and Köpke, U. Untersuchungen von Weizen (Triticum aestivum L.) mit den drei Bildschaffenden Methoden Kupferchloridkristallisation, Steigbildmethode und Rundfilterchromatographie. In Neuhoff, D., Stumm, C., Ziegler, S., Rahmann, G., 
Hamm, U., and Köpke, U., editors, Beiträge zur 12. Wissenschaftstagung Ökologischer Landbau, pages 358-361. Dr. Köster, 2013. (Cited on page 26.)

García Olmedo, F. El Ingenio y el hambre: De la revolución agrícola a la transgénica. Crítica, Barcelona, 2009. ISBN 978-84-7423-884-6. (Cited on page 11.$)$

Garrido Valero, M. Interpretación de Análisis de Suelos: Guía práctica para muestrear los suelos e interpretar sus análisis. Hojas Divulgadoras. Ministerio de Agricultura Pesca y Alimentación. Instituto Nacional de Reforma y Desarrollo Agrario, 1993. ISBN 84-341-0810-o. (Cited on page 101.)

Garrido Valero, M. Las arcillas del suelo, esos minerales tan especiales. La Fertilidad de la Tierra, (46):11-14, 2011a. (Cited on pages 106 y 225.)

Garrido Valero, M. La bioestructura de las tierras. La Fertilidad de la Tierra, (47):60-63, 2011b. (Cited on page 105.)

Garrido Valero, M. A qué llamamos fertilidad de la tierra. La Fertilidad de la Tierra, (45):18-21, 2011c. (Cited on page 103.)

Ghilarov, A. Lamarck and the prehistory of ecology. Internatl Microbiol. Springer-Verlag Ibérica, (1):161-164, 1998. URL http://Www.im. microbios. org/02june98/12\%20Ghilarov\%20 (P) . pdf. (Cited on pages 8 y 9.)

Haßold, N. Zu Kenntnisstand und Methodenentwickelungen des ChromaBoden-Tests. Edition Zukunft, Barsinghausen, 1994. ISBN 3-89799100-4. (Cited on pages 43, 44, 53, 54, 56 y 57.)

Hassold-Piezunka, N. Eignung des Chroma-Boden-Test zur Bestimmung von Kompostqualitaet und Rottegrad. PhD thesis, Universität Oldenburg, Alemania, 2003. (Cited on pages 6, 41, 43, 52, 54, 56, 57, 120 y 186.)

Hertelendy, K. Paper chromatography, a quick method to determine the degree of humification of refuse compost. IRCWD News, (7), 1974. (Cited on page 43.)

Huber, M., Andersen, J.-O., Kahl, J., Busscher, N., Doesburg, P., Mergardt, G., Kreschner, S., Zalecka, A., Meelursam, A., Ploeger, A., Nierop, D., van de Vijver, L., and Baars, E. Standardization and Validation of the Visual Evaluation of Biocrystallizations. Biological Agriculture and Horticulture, 27:25-40, 2010. (Cited on page 26.)

Inoko, A. A rapid test for the check of maturity of city refuse compost using a paper chromatographic method. Soil Science and plant Nutrition, (25):279-280, 1979. (Cited on page 43.) 
Jiménez, E. I. and García, V. P. Evaluation of city refuse compost maturity: a review. Biological wastes: agricultural, industrial and organic wastes and their development. Elsevier Appl. Sc. Publ., (27): 115-142, 1989. (Cited on page 43.)

Jones, A., Panagos, P., Erhard, M., Tóth, G., Barcelo, S., Bouraoui, F., Bosco, C., Dewitte, O., Gardi, C., Hervás, J., Hiederer, R., Jeffery, S., Penizek, V., Strassburger, T., Lükewille, A., Marmo, L., Montanarella, L., Olazábal, C., Petersen, J.-E., van Den Eeckhaut, M., van Liedekerke, M., Verheijen, F., Viestova, E., and Yigini, Y. The State of Soil in Europe: A contribution of the JRC to the European Environment Agency's environment state and outlook report - SOER 2010, volume 25186 of EUR, Scientific and technical research series. Publications Office of the European Union, Luxembourg, 2012. ISBN 978-92-7922806-3. (Cited on page 4.)

Kahl, J. and Zalecka, A., editors. Standardisierung der Steigbildmethode für die Unterscheidung von Proben aus verschiedener Herkunft: In 10. Wissenschaftstagung Ökologischer Landbau, ETH Zürich, volume 2, Berlin, 2009. Verlag Dr. Köster. (Cited on pages 26, 34 y 58.)

Kahl, J., Busscher, N., Doesburg, P., Mergardt, G., Huber, M., and Ploeger, A. First tests of standardized biocrystallization on milk and milk products. Eur Food Res Technol Springer-Verlag, (229):175178, 2009. (Cited on pages 26 y 34.)

Kanzler, C. Untersuchungen zur Bildentstehung der Pfeifferschen Rundfilterchromatographie und Beurteilung von Chromas verschiedener Bodentzpen (Braunerde, Parabraunerde, Plaggenesch, Podsol) und unterschiedlicher komposte in Zusammenhang mit ihren analytishen Kenndaten. Master's thesis, Universität Oldenburg, Alemania, 1991. (Cited on pages 6, 43, 52 y 120.)

Karlen, D. L., Mausbach, M. J., Doran, J. W., Cline, R. G., Harris, R. F., and Schuman, G. E. Soil Quality: A Concept, Definition, and Framework for Evaluation (A Guest Editorial). Soil Science Society of America Journal, pages 4-10, 1997. URL http://dx.doi.org/10.2136/ sssaj 1997.03615995006100010001x. (Cited on page 183.)

Koepf, H. H. Soil tests and chromatograms. Bio-Dynamics, (69), 1964. (Cited on page 41.)

Kokornaczyk, M. O., Dinelli, G., and Betti, L. Approximate bilateral symmetry in evaporation-induced polycrystalline structures from droplets of wheat grain leakages and fluctuating asymmetry as quality indicator. Springer. Naturwissenschaften, 2012. (Cited on pages 26 y 187.) 
Kolisko, E. and Kolisko, L. Agriculture of Tomorrow. original publication. Kolisko Archive, England, 1939. (Cited on pages 3, 13, 26, 27, 28, III y 185.)

Kränzlein, G. Zum 100 jährigen Gedächtnis der Arbeiten von F. F. Runge. Angewandte Chemie, 48(1):1-3, 1935. (Cited on page 21.)

Krätz, O. Goethe und die Naturwissenschaften: 2. Korrigierte Aufl., Sonderausg. Callwey, München, 1998 edition, 1992. ISBN 3-7667-1335-3. (Cited on pages 23 y 24.)

Krynine, P. D. Die Kupferchlorid Kristallisation; by A. and O. Selawry. The American journal of science. Yale University. Dept. of Geology and Geophysics, 255(8):596-599, 1957. (Cited on page 26.)

Liedekerke, M. v., Prokop, G., Rabl-Berger, S., Kibblewhite, M., and Louwagie, G. Progress in the management of contaminated sites in Europe: JRC REFERENCE REPORT S, volume 26376 of EUR, Scientific and technical research series. Publications Office of the European Union, Luxembourg:, 2014. ISBN 978-92-79-34846-4. (Cited on page 4.)

Livio, M. La proporción áurea: La historia de phi, el número más enigmático del mundo. Ariel, Barcelona, 1 edition, 2006. ISBN 843444495X. (Cited on page 98.)

Locutura Rupérez, J., Bel-Lan, A., García Cortés, A., and Martínez, S. Atlas Geoquímico de España. Instituto Geológico y Minero de España, Madrid, 2012. ISBN 978-84-7840-875-7. (Cited on page 187.)

Mäder, P., Hahn, D., Dubois, D., Gunst, L., Alföldi, T., Bergmann, H., Oehme, M., Amadò, R., Schneider, H., and Graf, U. Wheat quality in organic and conventional farming: results of a 21 year field experiment. Journal of the Science of Food and Agriculture, 87(10):18261835, 2007. (Cited on page 26.)

Martínez, J., Llamas, J., Miguel, E. d., Rey, J., and Hidalgo, M. Determination of the geochemical background in a metal mining site: example of the mining district of Linares (South Spain). Journal of Geochemical Exploration. Elsevier, 94:19-29, 2007. (Cited on pages 13, 72 y 133.$)$

Martínez López, J., LLamas Borrajo, J., Miguel García, E. d., Rey Arrans, J., Hidalgo Estévez, M. C., Sáez Castillo, A. J., Hidalgo Estévez, M. C., and Sáez Castillo, A. J. Multivariate analysis of contamination in the mining district of Linares (Jaén, Spain). Applied Geochemestry. Elsevier, 23(8):2324-2336, 2008. (Cited on pages 13, 75, 133, 137, 139, 148, 151, 162 y 166.)

Ministerio de Agricultura. Orden del 5 de diciembre de 1975 por la que se aprueban como oficiales los métodos de análisis de suelos y aguas, 1976. (Cited on pages 69 y 93.) 
Mittelman, N. Cromatografía de adsorción y partición. Chemia, XV (103):73-92, 1941. (Cited on page 20.)

Niederlechner, M. Der Boden-Chroma-Test, seine Grundlagen und seine Aussagen im Vergleich zur chemisch-physikalischen Bodenuntersuchung. Master's thesis, FHS Weihenstephan, Alemania, 1987. (Cited on page 42.)

Panagos, P., van Liedekerke, M., Yigini, Y., and Montanarella, L. Contaminated Sites in Europe: Review of the current Situation Based on Data Collected through a European Network: Review Article. Journal of Environmental and Public Health, 2013(Article ID 158764): 11 pages, 2013. (Cited on page 4.)

Pelikan, W. Sieben Metalle: Vom Wirken des Metalwesens in Kosmos, Erde und Mensch: 1. Aufgabe 1952 als Band II der Beitraege zur Substanz Forschung. Hybernia Verlag Dornach / Stuttgart. Verlag am Goetheanum, 1996. ISBN 3-735-0955-X. (Cited on page 14.)

Pfeiffer, E. Studium von Formkraften an Kristallizationen. Naturwissenschaftliche Sektion am Goetheanum, Dornach and Schweiz, 1931. (Cited on page 26.)

Pfeiffer, E., editor. Chromatography applied to quality testing: revised by Erica Sabarth. Bio-Dynamics Literature, USA, 1984 edition, 1959. ISBN 0-938250-21-3. (Cited on pages XIV, 3, 6, 13, 26, 27, 33, 34, 35, $39,40,66,67,68,91,93,95,98,99$, I11, 147, 169, 183 y 185.)

Piqueras, M. Meeting the Biospheres: on the translations of Vernadsky's work. Internatl Microbiol. Springer-Verlag Ibérica, (1):165170, 1998. (Cited on page 8.)

Richards, R. J. Kant and Blumenbach on the Bildungstrieb: A Historical Misunderstanding: Studies in History and Philosophy of Biological and Biomedical Sciences. Elsevier Science: Stud. Hist. Phil. Biol. $\mathcal{E}$ Biomed. Sci., (31):11-32, 2000. (Cited on page 23.)

Runge, F. F. Musterbilder für Freunde des Schönen und zum Gebrauch für Zeichner, Maler, Verzier und Zeugdrucker: [Química de los colores. Ilustraciones de patrones para amigos de lo bello y para uso de dibujantes, pintores, decoradores e impresores]. Farben - Chemie. E.S.Mittler \& Sohn, Berlin, 1850. (Cited on page 24.)

Runge, F. F. Bildungstrieb der Stoffe. Veranschaulicht in selbständig gewachsenen Bildern [La fuerza formativa de las sustancias, hecha visible en imágenes creadas por si mismas]: (Fortsetzung der Musterbilder). Musterbilder. Selbstverlag, Oranienburg and Alemania, 1855. URL http://publikationen.ub.uni-frankfurt.de/ frontdoor/index/index/docId/16047. (Cited on page 22.) 
Runge, F. F. Der Bildungstrieb der Stoffe, volume 12 of Naturkunden. Matthes \& Seitz Berlin, Berlin, 1 edition, 2014. ISBN 9783882219364. (Cited on page 21.)

Saalfeld. Methodische Untersuchungen zur Pfeifferischen Rundfilterchromatographie an Boden und Substraten. Master's thesis, FHS Osnabrück, 1989. (Cited on page 42.)

Sabarth, E. Chromatograms of soils: B.D. preparations end their source materials. Bio-Dynamics, (62), 1962. (Cited on page 41.)

Sabarth, E. Plant relationships made visible by chromatography: An interin report from the Biochemical Research Laboratory. BioDynamics, (85), 1968. (Cited on page 41.)

Schultz, J. Der Goldene Schnitt im Aufbau des Sonnensystemes. In Heinze, H., editor, Pflanzen, Planeten, Goldener Schnitt, pages 2328. Forschungsring fuer biologisch-dynamische Wirtschaftsweise, Darmstadt, 1968. (Cited on page 98.)

Schwenk, E. F. Friedlieb Runge and his capillary designs. Bull. Hist. Chem., 30(1):30-34, 2005. (Cited on pages 21 y 24.)

Selawry, A., editor. Die Kupferchlorid-Kristallisation: in Naturwissenschaft und Medizin: Mit einer Einfuerung in die kristallographischen Grundlagen von Professor Dr. A. Newhaus. Gustav Fischer, Stuttgart, 1957. (Cited on page 26.)

Selawry, A. Ehrenfried Pfeiffer: Pioneer of spiritual Research and Practice. Mercury Press, Spring Valley and N.Y., 1992. ISBN 0-929979-23-0. (Cited on page 26.)

Steiner, R. Verdad y Ciencia, volume 3 of GA. Editorial Rudolf Steiner, Madrid, 2011 edition, 1892. ISBN 978-84-89197-24-4. (Cited on page 23.)

Steiner, R. Curso de Agricultura Biodinámica, volume 327 of GA. Editorial Rudolf Steiner, España, 2009 edition, 1924. ISBN 978-84-8537047-4. (Cited on page 3.)

Steiner, R. and Wegman, I. Grundlegendes für eine Erweiterung der Heilkunst nach geistes-wissenschaftliches Erkenntnissen, volume 27 of GA. Philosophisch-Anthroposophischer Verlag am Goetheanum, Dornach and Schweiz, 1925. (Cited on page 14.)

Stolbovoy, V., Montanarella, L., Filippi, N., Jones, A., Gallego, J., and Grassi G. Soil sampling protocol to certify the changes of organic carbon stock in mineral soil of the European Union. Version 2. EUR 21576 $E N / 2$. Office for Official Publications of the European Communities, Luxembourg, 2007. ISBN 978-92-79-05379-5. (Cited on page 5.) 
Szulc, M., Kahl, J., Busscher, N., Mergardt, G., Doesburg, P., and Ploeger, A. Discrimination between organically and conventionally grown winter wheat farm pair samples using the copper chloride crystallisation method in combination with computerised image analysis. Computers and Electronics in Agriculture, 74(2):218222, 2010. URL http://www. sciencedirect. com/science/article/ pii/S0168169910001456. (Cited on pages 26 y 187.)

Tesson, M.-F. and Fernandez-Bravo, M.-A. Cristaux sensibles: Contribution théorique et pratique à une science du vivant. Ed. du Fraysse, Monclar de Quercy, 2000. ISBN 2-87909-007-5. (Cited on page 26.)

Tondl, M. Zur Methodik und Interpretationsmöglichkeit des BodenChroma-Testes nach Pfeiffer. Master's thesis, Universität Wien, Austria, 1989. (Cited on page 42.)

UC DAVIS College of Agricultural and Environmental Sciences. Soil Texture by Feel, 30/11/2012. URL http://afghanag. ucdavis . edu/natural - resource-management/ soil - topics/soil - fact-sheets/FS_Soil_Texture_Feel . pdf.

(Cited on pages 106 y 107.)

Unluturk, M. S., Unluturk, S., Pazir, F., and Abdollahi, F. Capillary Dynamolysis Image Discrimination Using Neural Networks. Information Technology \& Software Engineering, 2011. (Cited on pages 26 y 188.)

Unluturk, S., Unluturk, M. S., Pazir, F., and Kuscu, A. Discrimination of bio-crystallogram images using neural networks. Neural Computing and Applications, 2013. (Cited on pages 26 y 188.)

USDA. Soil Quality Test Kit Guide, 2001. URL http: //afghanag.ucdavis .edu/other-topic/soil-topics/Man_Soil_ test_kit_USDA.pdf. (Cited on pages 103 y 105.)

USDA. Aggregate Stability. Soil Quality Indicators., 2008. (Cited on page 105.$)$

Vernadsky, V. I. The Biosphere and the Noösphere: Excerpt. EIR, February 18, 2005. URL http://www. larouchepub.com/eiw/public/ 2005/2005_1-9/2005-7/pdf/30-33_7_featnoosphere.pdf. (Cited on page 9.)

Voitl, H. and Guggenberger, E. Der Chroma-Boden-Test: Die Bodenqualität bestimmen, bewerten und verbessern : ein unentbehrlicher Ratgeber für Landwirte, Berufs- und Hobbygärtner. Verl. Orac, Wien, 1986. ISBN 3-7015-0036-3. (Cited on pages 26, 39, 41, 42, 69, 96, 120 y 145.)

Wachsmuth, G. Rudolf Steiners Erdenleben und Wirken: Von der Jahrhundertwende bis zum Tode - Die Geburt der Geisteswissenschaft - Eine 
Biographie. Philosophisch-Anthroposophischer Verlag am Goetheanum, Dornach, 1964 edition, 1951. (Cited on page 24.)

Williams, K. R. Colored Bands: History of Chromatography. Journal of Chemical Education, 79(8):922, 2002. (Cited on page 20.)

Williams, T. I. and Weil, H. Definition of Chromatography. Nature, 170(4325):503, 1952. URL http://dx.doi.org/10.1038/170503b0. (Cited on page 20.)

Zalecka, A. Entwicklung und Validierung der Steigbildmethode zur Differenzierung von ausgewählten Lebensmitteln aus verschiedenen Anbausystemen und Verarbeitungsprozessen. PhD thesis, Universität Kassel, Witzenhausen, DE, 2006. (Cited on pages 58 y 87.)

Zalecka, A., Kahl, J., Doesburg, P., Pyskow, B., Huber, M., Skjerbaek, K., and Ploeger, A. Standardization of the Steigbild Method. Biological Agriculture \& Horticulture, 27(1):41-57, 2010. (Cited on page 58.) 
En las páginas que siguen se reproducen las fichas suministradas por los fabricantes de los filtros seleccionados. 

31/5/2015
83 gelifesciences.com

Typical Properties of Filter Papers and Glass Fiber Filters

http://www.gelifesciences.com/webapp/wcs/stores/servlet/catalog/en/GELifeSciences-es/applications/typical-properties-of-filter-papers-andglass-fiber-filters

\section{Typical Properties of Filter Papers and Glass Fiber Filters}

Flow rate, particle retention, and thickness are some of the aspects you need to consider when choosing the most suitable filter paper for your application. The selection tree and tables on this page help you identify the appropriate product.

1. Use the decision tree below to identify the filter paper that meets your needs.

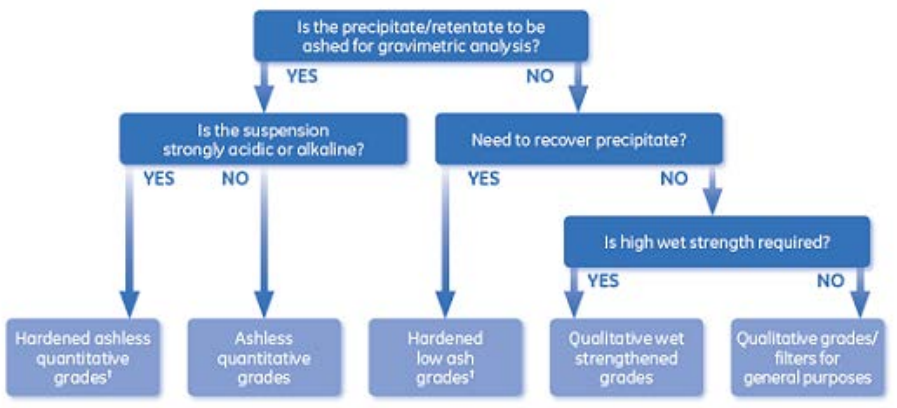

2. Use the tables in the tabs below to choose the most suitable product for your filtration needs. The tables provide overviews of typical properties of different types of filter papers and glass fiber filters.

Standard qualitative filter papers

\begin{tabular}{|c|c|c|c|c|c|}
\hline Grade & $\begin{array}{c}\text { Typical } \\
\text { Thickness }(\mu \mathrm{m})\end{array}$ & $\begin{array}{l}\text { Basis Weight } \\
\qquad\left(\mathrm{g} / \mathrm{m}^{2}\right)\end{array}$ & $\begin{array}{c}\text { Flow Rate / } \\
\text { Aspect }\end{array}$ & 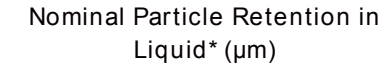 & $\begin{array}{l}\text { Prepleated } \\
\text { grade }\end{array}$ \\
\hline 1 & 180 & 88 & Medium flow & 11 & \\
\hline 2 & 190 & 103 & Medium flow & 8 & Grade 2V \\
\hline 3 & 390 & 187 & $\begin{array}{l}\text { Medium flow, } \\
\text { thick }\end{array}$ & 6 & \\
\hline 4 & 205 & 96 & Very fast & 25 & \\
\hline 5 & 200 & 98 & Slow & 2.5 & Grade 5V \\
\hline
\end{tabular}

${ }^{*}$ Particle retention rating at $98 \%$ efficiency.

Please note that this data may be based on historic performance, which was established before Whatman was acquired by GE Healthcare.

http://mww.gelifesciences.com/webapp/wcs/stores/servet/catalog/en/GELifeSciences-es/applications/typical-properties-of-filter-papers-and-glass-fiber-filters $\quad 1 / 1$

Figura 61: Guía para selección y características típicas de los filtros Whatman Grado 4. 


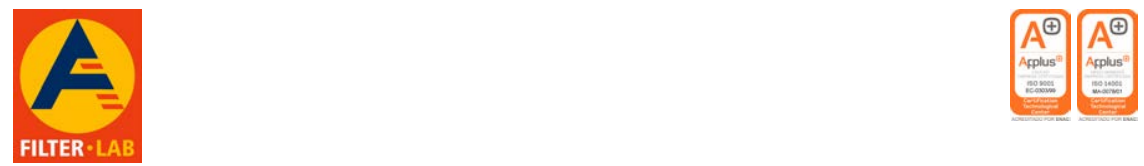

filtros anoia, S.a. Sant Pere de Riudebitlles (Barcelona) SPAIN tel.+34938995036 fax.+34938997172,fanoia@fanoia.com www.fanoia.com

\section{FICHA TECNICA}

PRODUCTO: Papel filtro análisis cualitativo, bajo en cenizas ref. 1249

FECHA DE CREACIÓN: Enero 2003

DENOMINACIÓN: Papel filtro análisis cualitativo, bajo en cenizas.

REF.:

1249

PRESENTACIÓN: Cajas de 100 unidades

FORMATOS: $\quad$ - Círculos: $42,5,47,50,55,70,90,100,110,125,130,150,185,200,240$, $250,270,320,350,400,450,500,650 \mathrm{~mm}$. $\varnothing$ formato plano y plegado

- Hojas: $460 \times 570 \mathrm{~mm}$.

TRAZABILIDAD: - Denominación: 5 cifras

- Localización: En la misma etiqueta de descripción del artículo

\section{ESPECIFICACIONES TÉCNICAS:}

Gramaje (ISO 536): $80 \mathrm{gr} . / \mathrm{m} 2$.

Espesor: 0,180 mm.

Velocidad de filtración (DIN 53137): 16-24 s

Filtración: Rápida

Retención: 20 - $25 \mu \mathrm{m}$

Resistencia al reventamiento en húmedo (ISO 2758): >20 kPa

Contenido en cenizas (DIN 54370): $<0,06 \%$

Propiedades: Papel filtro análisis cualitativo, bajo en cenizas, de filtración rápida.

martamento Técnico

FILTROS ANOIA, S.A.

Figura 62: Ficha técnica del filtro ANOIA 1249 

En las páginas que siguen se reproducen las fichas suministradas por los fabricantes de los reactivos utilizados. 

PanReac CODIGO PRODUCTO: 131687

Sodio Hidróxido lentejas para análisis, ACS, ISO

$\mathrm{NaOH}$ SINONIMOS: Sosa Cáustica

$M .=40,00 \quad$ CAS [1310-73-2] EINECS 215-185-5 TARIC

2815110000

DATOS FISICOS: Sólido blanco en forma de lentejas o escamas , translúcido, cáustico, delicuescente, absorbe $\mathrm{CO} 2 \mathrm{del}$ aire, Soluble en agua $1.090 \mathrm{~g} / \mathrm{l}$ a $20^{\circ} \mathrm{C}$ D 2,13 P P.F.: 318 ${ }^{\circ} \mathrm{C} \cdot$ P.E.: $1.390{ }^{\circ} \mathrm{C} \cdot \mathrm{pH}(50 \mathrm{~g} / \mathrm{l}) 14$ •

BIBLIOGRAFIA: Merck Index 13, 8.701 Sax SHS000 • Safety 2 , 3144 A • Römp 8 , 2738 • Kühn-Birett N 12 • Fieser 561573368460 • ACS X617IX5924 (30-10-2003) • ISO 6353/21983 R - 34 , 48 • BP. 2014 • USP -NF 33 • Ph. Eur. 7.0 (2013) 8.0 (2014) • F.C.C 89 • BOE 243(8-10-2009) • Reglamento (UE) n²31/2012JP XV

ESPECIFICACIONES:

\begin{tabular}{|lr|}
\hline Riqueza mínima (Acidim.) & $98,0 \%$ \\
Límite máximo de impurezas & \\
Insoluble en $\mathrm{H} 2 \mathrm{O}$ & $0,005 \%$ \\
Cloruro (Cl) & $0,001 \%$ \\
Compuestos de $\mathrm{N}(\mathrm{en} \mathrm{N})$ & $0,0005 \%$ \\
Fosfato (PO4) & $0,0005 \%$ \\
Sulfato (SO4) & $0,002 \%$ \\
Silicato SiO2 & $0,001 \%$ \\
Carbonato (en Na2CO3) & $1,0 \%$ \\
\hline
\end{tabular}

\begin{tabular}{|cr|}
\hline $\begin{array}{l}\text { Metales pesados } \\
\text { (en } \mathrm{Pb})\end{array}$ & $0,0005 \%$ \\
$\mathrm{Al}$ & $0,0005 \%$ \\
$\mathrm{As}$ & $0,00004 \%$ \\
$\mathrm{Ca}$ & $0,0005 \%$ \\
$\mathrm{Cd}$ & $0,0005 \%$ \\
$\mathrm{Co}$ & $0,0005 \%$ \\
$\mathrm{Cu}$ & $0,0005 \%$ \\
$\mathrm{Fe}$ & $0,0005 \%$ \\
$\mathrm{Hg}$ & $0,00001 \%$ \\
$\mathrm{~K}$ & $0,02 \%$ \\
$\mathrm{Mg}$ & $0,0005 \%$ \\
$\mathrm{Mn}$ & $0,0005 \%$ \\
$\mathrm{Ni}$ & $0,0005 \%$ \\
$\mathrm{~Pb}$ & $0,0005 \%$ \\
$\mathrm{Zn}$ & $0,001 \%$ \\
\hline
\end{tabular}

Figura 63: Especificaciones del hidróxido sódico utilizado 

3050 Spruce Street, Saint Louis, MO 63103, USA

Website: www.sigmaaldrich.com

Email USA: techserv@sial.com

Outside USA: eurtechserv@sial.com

\section{Product Specification}

Product Name:

Silver nitrate - ACS reagent, $\geq 99.0 \%$

Product Number:

CAS Number:

MDL:

Formula:

Formula Weight:
209139

7761-88-8

MFCD00003414

AgNO3

$169.87 \mathrm{~g} / \mathrm{mol}$
$\mathrm{AgNO}_{3}$

\section{TEST}

Appearance (Color)

Appearance (Form)

$X$-Ray Diffraction

Titration by KSCN (\% Purity)

Appearance (Clarity)

Chloride (CL)

Copper $(\mathrm{Cu})$

Iron $(\mathrm{Fe})$

Lead $(\mathrm{Pb})$

Sulfate

Free Acid

Substances not ppt. by $\mathrm{HCl}$

Recommended Retest Period

$$
2 \text { Years }
$$

Meets ACS Requirements

10th Edition

Specification: PRD.0.ZQ5.10000024086

\section{Specification}

White

Crystals

Conforms to Structure

$\geq 99.0 \%$

Pass

$\leq 5 \mathrm{ppm}$

$\leq 2 \mathrm{ppm}$

$\leq 2 \mathrm{ppm}$

$\leq 0.001 \%$

$\leq 0.002 \%$

Pass

$<0.01 \%$

Current ACS Specification

Sigma-Aldrich warrants, that at the time of the quality release or subsequent retest date this product conformed to the information contained in this publication. The current Specification sheet may be available at Sigma-Aldrich.com. For further inquiries, please contact Technical Service. Purchaser must determine the suitability of the product for its particular use. See reverse side of invoice or packing slip for additional terms and conditions of sale.

1 of 1

Figura 64: Especificaciones de la sal de plata utilizada 

3050 Spruce Street, Saint Louis, MO 63103, USA

Website: www.sigmaaldrich.com

Email USA: techserv@sial.com

Outside USA: eurtechserv@sial.com

Product Specification

Product Name:
Gold(III) chloride trihydrate $-\geq 99.9 \%$ trace metals bas is

Product Number:

CAS Number:

MDL:

Formula:

Formula Weight:
520918

16961-25-4

MFCD00149904

$\mathrm{HAuCl} 4 \cdot 3 \mathrm{H} 2 \mathrm{O}$

$393.83 \mathrm{~g} / \mathrm{mol}$

\section{$\mathrm{HAuCl}_{4} \cdot 3 \mathrm{H}_{2} \mathrm{O}$}

\section{TEST}

Appearance (Color)

Appearance (Form)

Insoluble matter

Gold $(\mathrm{Au})$

ICP Major Analysis

Confirms Gold Component

Trace Metal Analysis

Purity

$>=99.9 \%$ Based On Trace Metals Analysis

Specification: PRD.2.ZQ5.10000003877

\section{Specification}

\author{
Crystals or Crystals with Chunks \\ $\leq 0.1 \%$ \\ $48.50-50.25 \%$ \\ Confirmed \\ $<1000.0 \mathrm{ppm}$ \\ Meets Requirements
}

Sigma-Aldrich warrants, that at the time of the quality release or subsequent retest date this product conformed to the information contained in this publication. The current Specification sheet may be available at Sigma-Aldrich.com. For further inquiries, please contact Technical Service. Purchaser must determine the suitability of the product for its particular use. See reverse side of invoice or packing slip for additional terms and conditions of sale.

$$
1 \text { of } 1
$$

Figura 65: Especificaciones de la sal de oro utilizada 



\section{Specification}

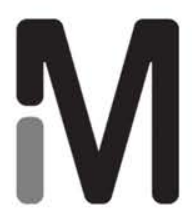

1.02790.0250 Copper(II) sulfate pentahydrate for analysis EMSURE® ACS,ISO,Reag. Ph Eur

Spec. Values

$\begin{array}{lll}\text { Assay (iodometric) } & 99.0-100.5 & \% \\ \text { Insoluble matter } & \leq 0.005 & \% \\ \text { Chloride }(\mathrm{Cl}) & \leq 0.0005 & \% \\ \text { Total nitrogen (N) } & \leq 0.001 & \% \\ \mathrm{Ca} \text { (Calcium) } & \leq 0.005 & \% \\ \mathrm{Fe} \text { (Iron) } & \leq 0.003 & \% \\ \mathrm{~K} \text { (Potassium) } & \leq 0.001 & \% \\ \mathrm{Na} \text { (Sodium) } & \leq 0.005 & \% \\ \mathrm{Ni} \text { (Nickel) } & \leq 0.005 & \% \\ \mathrm{~Pb} \text { (Lead) } & \leq 0.005 & \% \\ \mathrm{Zn} \text { (Zinc) } & \leq 0.03 & \%\end{array}$

Corresponds to ACS,ISO,Reag. Ph Eur

Dr.Matthias Ohm

This document has been produced electronically and is valid without a signature.

Merck KGaA, Frankfurter Straße 250, 64293 Darmstadt (Germany): +49 6151 72-0 EMD Millipore Corporation - A division of Merck KGaA, Darmstadt, Germany

Figura 66: Especificaciones de la sal de cobre utilizada 



\section{Specification}

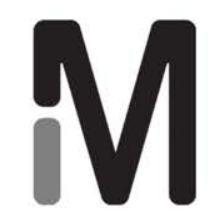

1.04419.0050 Mercury(II) chloride for analysis EMSURE® Reag. Ph Eur,ACS

Specification

Assay (complexometric)

Assay (complexometric; calculated on dried

substance)

Identity

Appearance of solution

Solution in Ether

Acidity or alkalinity

Mercury(l)-chloride

$\mathrm{Fe}$ (Iron)

Residue after reduction

Loss on drying ( $24 \mathrm{~h}$ im Vakuum)

Correspons to Reag. Ph Eur,ACS $\geq 99.5$

$99.5-100.5$

passes test

passes test

passes test

passes test

passes test

$\leq 0.002$

$\leq 0.02$

$\leq 1.0$
$\%$

$\%$

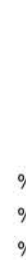

$\%$

This document has been produced electronically and is valid without a signature.

Merck KGaA, Frankfurter Straße 250, 64293 Darmstadt (Germany): +49 6151 72-0 EMD Millipore Corporation - A division of Merck KGaA, Darmstadt, Germany

Figura 67: Especificaciones de la sal de mercurio utilizada 



\section{Specification}

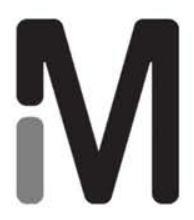

1.07815.0100 Tin(II) chloride dihydrate for analysis EMSURE® ACS,ISO,Reag. Ph Eur

Specification

Assay (iodometric, $\mathrm{SnCl}_{2} \cdot 2 \mathrm{H}_{2} \mathrm{O}$ )

Identity

Appearance of solution in hydrochloric acid

Sulphate $\left(\mathrm{SO}_{4}\right)$

Heavy metals (as $\mathrm{Pb}$ )

As (Arsenic)

Ca (Calcium)

$\mathrm{Cu}$ (Copper)

$\mathrm{Fe}$ (Iron)

K (Potassium)

$\mathrm{Na}$ (Sodium)

$\mathrm{NH}_{4}$ (Ammonium)

$\mathrm{Pb}$ (Lead)

Substances not precipitated with $\mathrm{H}_{2} \mathrm{~S}$ (as

sulphates)

$\begin{array}{ll}\begin{array}{l}9.0-103.0 \\ \text { passes test }\end{array} & \% \\ \text { passes test } & \\ \leq 0.002 & \% \\ \leq 0.005 & \% \\ \leq 0.0001 & \% \\ \leq 0.005 & \% \\ \leq 0.001 & \% \\ \leq 0.002 & \% \\ \leq 0.005 & \% \\ \leq 0.01 & \% \\ \leq 0.002 & \% \\ \leq 0.005 & \% \\ \leq 0.05 & \%\end{array}$

Dr. Andreas Lang

Responsible laboratory manager quality control

This document has been produced electronically and is valid without a signature.

Merck KGaA, Frankfurter Straße 250, 64293 Darmstadt (Germany): +49 6151 72-0 EMD Millipore Corporation - A division of Merck KGaA, Darmstadt, Germany

Page 1 of 1

290 Concord Road, Billerica, MA 01821, USA, Phone: (978) 715-4321

SAlSA $000000000000 / / \mathrm{V}$. 45466 Date: 26.03 .2013

Figura 68: Especificaciones de la sal de estaño utilizada 



\section{Specification}

1.07398.0100 Lead(II) nitrate for analysis EMSURE® ACS,Reag. Ph Eur

Spec. Values

Assay (complexometric)

Insoluble matter

Chloride (Cl)

Ca (Calcium)

$\mathrm{Cu}$ (Copper)

Fe (Iron)

K (Potassium)

$\mathrm{Na}$ (Sodium)

corresponds to ACS, Reag. Ph Eur

corresponds to ACS, Reag. Ph Eur $\geq 99.5$

$\leq 0.005$

$\leq 0.0005$

$\leq 0.005$

$\leq 0.0005$

$\leq 0.0005$

$\leq 0.005$

$\leq 0.02$

This document has been produced electronically and is valid without a signature.

Merck KGaA, Frankfurter Straße 250, 64293 Darmstadt (Germany): +49 6151 72-0 EMD Millipore Corporation - A division of Merck KGaA, Darmstadt, Germany

Figura 69: Especificaciones de la sal de plomo utilizada 



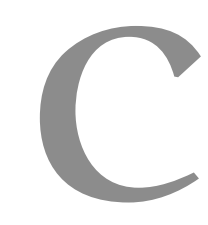

El texto que sigue procede de la publicación divulgativa Garrido Valero (2011a) y se reproduce con ligeras modificaciones tras ser revisado por su autora.

Las arcillas están formadas por láminas constituidas por unidades de silicatos y de aluminatos. Las arcillas más simples son las que denominamos de tipo 1:1 que idealmente están constituidas por una capa de silicatos y otra capa de aluminatos, las llamamos caolinitas y son las arcillas que se están formando actualmente en ambientes tropicales y subtropicales. Otras más complejas son las de tipo 2:1, que están constituidas por dos capas de silicatos que tienen en medio una capa de aluminatos, éstas pueden ser de diversos tipos según su organización en láminas onduladas donde algunas tienen aspecto parecido al de las esponjas naturales cuando las miramos a través de un microscopio electrónico. Entre ellas se encuentran las illitas que son muy ricas en potasio, montmorillonitas, esmectitas, vermiculitas, sepiolitas o paligorskitas. En la Península Ibérica aparecen sobre todo arcillas de tipo 2:1, aunque en algunos lugares se encuentran suelos con arcillas 1:1 pues son suelos que se formaron en épocas que hubo clima tropical.

La diferencia entre las arcillas de tipo 1:1 y las de tipo 2:1 es que aquellas absorben menos agua que éstas y dan lugar a suelos de menor fertilidad. Esta diferencia tiene que ver con la propiedad más interesante de las arcillas que es que están cargadas eléctricamente con carga neta negativa, esto es que tienen muchos lugares en su estructura donde les sobran electrones, con lo que son lugares de carga negativa, y otros pocos lugares donde les faltan electrones y por lo tanto tienen ahí cargas positivas. Esta propiedad es la que ha hecho que las arcillas se hayan utilizado a lo largo de la historia de la Humanidad de diferentes formas para fines terapéuticos. En los lugares de carga negativa se adsorben sustancias con carga positiva, tales como los cationes que predominan en los suelos y que son muy importantes para la nutrición vegetal, calcio, magnesio, sodio, potasio y otros cationes como el hierro, aluminio, boro, cobre, etc., incluido el hidrógeno. En los lugares con carga positiva, que son pocos, se adsorben aniones, tales como sulfatos, carbonatos, nitratos, cloruros, etc. También los microorganismos del suelo con carga eléctrica, tales como algunas bacterias y amebas, pueden unirse en estos lugares utilizando eventualmente la carga eléctrica disponible. Tanto en unos lugares como en otros desgraciadamente también se pueden unir sustancias contaminantes que han llegado al suelo de diferentes fuentes, tales 
como herbicidas (por ej. el herbicida paraquat, hoy ya prohibido su uso, que tiene carga positiva o el glifosato con carga negativa), plaguicidas, metales pesados, etc. Cuando estas sustancias se unen a las arcillas ocupando estos lugares con carga eléctrica, por un lado impiden que otras sustancias que son interesantes para las plantas se puedan unir a ellas de forma que el suelo va perdiendo poco a poco fertilidad pues los nutrientes se quedan en el agua del suelo disueltos pudiéndose lavar con el agua de lluvia o de riego y salir del suelo por escorrentía o percolación. Por otro lado, algunos contaminantes pueden estar adsorbidos a las arcillas durante un tiempo y en un momento dado desprenderse y pasar al agua del suelo afectando a los organismos del suelo y a las propias plantas.

Las capas de arcillas se van uniendo mediante fuerzas electrostáticas débiles a otras capas constituyendo algo parecido a un "hojaldre", de forma que entre una capa y otra se introducen moléculas de agua, cationes y cualquier producto catiónico. Por ello cuando las arcillas se humedecen se hinchan y cuando se secan se contraen, cuestión que podemos percibir cuando vemos las grietas que se forman en la superficie de un suelo arcilloso. La anchura de la grieta que se forma depende de la cantidad de arcilla que tenga el suelo y del tipo de arcilla. La unión entre las capas de las arcillas de tipo 2:1 es mucho más flexible lo que permite que se puedan introducir más moléculas de agua que en el caso de las arcillas de tipo 1:1, y en algunas de las arcillas de tipo 2:1 pueden caber todavía más moléculas de agua observándose que cuando el suelo se seca las grietas que se forman son extraordinariamente anchas, $25-40 \mathrm{~cm}$, y profundas, de hasta 1,5-2 $m$ de profundidad en casos extraordinarios. La unión entre las capas de las arcillas tipo 1:1 es menos flexible y por tanto la cantidad de agua que cabe entre ellas es mucho menor que en el caso de las arcillas 2:1. Por ello los suelos que tienen arcillas de tipo 1:1 se encharcan enseguida en los periodos de lluvias y como dicen los agricultores de las zonas donde hay estas arcillas que prefieren los años de inviernos secos y sin embargo los años malos son cuando hay mayores lluvias invernales, pues encharcan las tierras y los cereales mueren. Estas arcillas se encuentran en nuestro país en las zonas que se llaman Rañas que se formaron al final del Plioceno y principio del Cuaternario en un clima tropical.

... Las arcillas dan y reciben cationes continuamente en lo que se ha llamado proceso de "intercambio catiónico" o cuando lo analizamos en el laboratorio "capacidad de intercambio catiónico (CIC)". Las arcillas expansivas tienen mayor CIC que algunas arcillas de tipo 2:1 como las illitas, y las de tipo 1:1, las caolinitas, tienen valores bajísimos de CIC por lo que los suelos que las contienen son muy poco fértiles. Sin embargo, las arcillas que se forman en suelos sobre rocas volcánicas, que se llaman de forma general alófanas, pueden tener valores de CIC más elevados que las arcillas expansivas y casi tan 
elevados, como vamos a ver ahora, como la materia orgánica, por lo que pueden dar lugar a suelos muy fértiles.

Curiosamente la materia orgánica muy descompuesta que hay en el suelo, que llamamos en general compuestos húmicos, siendo una sustancia de origen completamente diferente al de las arcillas, tiene la misma propiedad que éstas de tener cargas eléctricas negativas y algunas positivas, esto es de tener lugares de intercambio catiónico. A igualdad de peso, la materia orgánica tiene mayor cantidad de cargas eléctricas que las arcillas, por lo que al añadir un poco de materia orgánica observamos que las plantas se desarrollan mucho mejor, siendo ésta una de las funciones importantes de la materia orgánica. 



\section{DECLARACIÓN}

Declaro que esta tesis doctoral ha sido realizada por mí de manera independiente y que no me he servido de ayuda alguna que no haya sido autorizada ni de ningún medio que no esté expresamente recogido en este documento. Todas las nociones que, literal o contestualmente proceden de publicaciones o comunicaciones de otro tipo, han sido citadas como tales. Ninguna parte de esta tesis ha sido utilizada en otra tesis doctoral.

Madrid, 19 de Enero de 2016

Montserrat Trio Maseda 